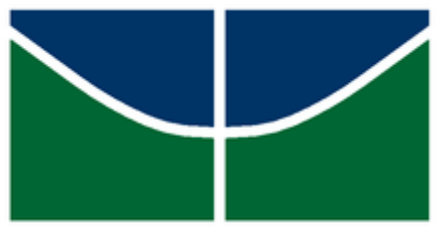

UNIVERSIDADE DE BRASÍLIA PÓS-GRADUAÇÃO EM GEOGRAFIA

REGIÃO, PLANEJAMENTO E GEOGRAFIA MODELO-TEÓRICA: CONTRIBUIÇÕES BASILARES À INTERVENÇÃO GOVERNAMENTAL INTERFEDERATIVA 


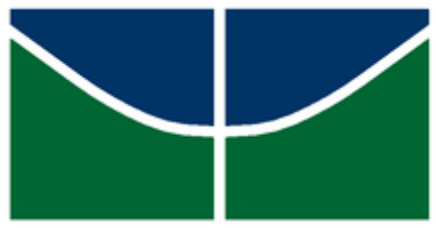

UNIVERSIDADE DE BRASÍLIA PÓS-GRADUAÇÃO EM GEOGRAFIA

\title{
REGIÃO, PLANEJAMENTO E GEOGRAFIA MODELO-TEÓRICA: CONTRIBUIÇÕES BASILARES À INTERVENÇÃO GOVERNAMENTAL INTERFEDERATIVA
}

\author{
Francisco Carneiro Portela
}

Orientador:

Prof. Dr. Dante Flávio da Costa Reis Júnior

Dissertação de Mestrado 


\title{
UNIVERSIDADE DE BRASÍLIA \\ PÓS-GRADUAÇÃO EM GEOGRAFIA
}

\section{REGIÃO, PLANEJAMENTO E GEOGRAFIA MODELO-TEÓRICA: CONTRIBUIÇÕES BASILARES À INTERVENÇÃO GOVERNAMENTAL INTERFEDERATIVA}

\author{
Francisco Carneiro Portela
}

Dissertação de Mestrado submetida ao Departamento de Geografia da Universidade de Brasília como parte dos requisitos necessários à obtenção do Grau de Mestre em Geografia, Área de Concentração de Gestão Ambiental e Territorial, opção Acadêmica.

Aprovada Por:

Prof. Dr. Dante Flávio da Costa Reis Júnior - UnB

Orientador

Prof. Dr. Fernando Luiz Araújo Sobrinho - UnB

Examinador Interno

Dr. Rodrigo Herles dos Santos - IBAMA

Examinador Externo

Prof. Dr. Valdir Adilson Steinke - UnB

Suplente

Brasília-DF, 04 de fevereiro de 2016 


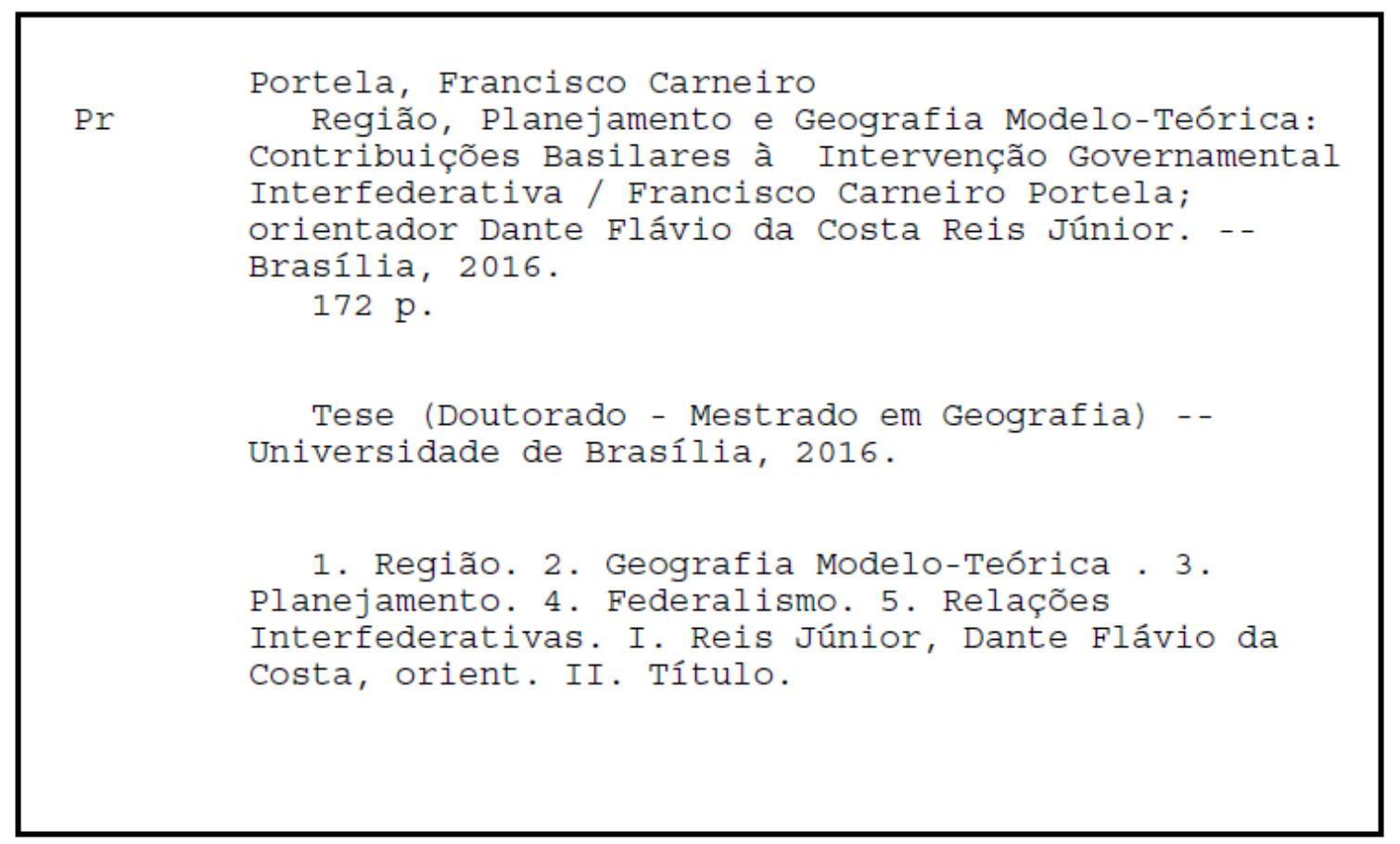

É concedida à Universidade de Brasília permissão para reproduzir cópias desta dissertação e emprestar ou vender tais cópias somente para propósitos acadêmicos e científicos. O autor reserva outros direitos de publicação e nenhuma parte desta dissertação de mestrado pode ser reproduzida sem a autorização por escrito do autor.

Francisco Carneiro Portela 
À Marina e Miguel, fontes de inspiração.

A todos os contribuintes brasileiros que, com os seus árduos trabalhos, mantêm o funcionamento dos serviços públicos no Brasil. 


\section{AGRADECIMENTOS}

- Pessoais: Prof. Dr. Dante Flávio, Prof. MSc Osmundo Cavalcante, Prof. Dr. Everaldo Batista, Adélia Sousa, Pablo Castro Neres, Arturo Toscanini, Vitor Pedroza, Cláudia Barros, Maria dos Reis, Michelle Milhomem, Prof. Dr. Leonardo Monastério, Prof. Dr. Fernando Sobrinho, Profa. Emérita Ignez Costa Barboza Ferreira, Antonia Carneiro, Venceslau Portela, Prof. Dr. Sebastião Portela, Geógrafo Wagner Salles Tramm (in memorian) e tantos outros.

- Institucionais: Instituto Brasileiro de Meio Ambiente e dos Recursos Naturais Renováveis (IBAMA), Universidade de Brasília (UnB), e Western Idiomas. 
The crystallization of mass around a nucleus is, in inorganic as well as organic nature, an elementary form of order of things which belong togheter - a centralistic order.

Walter Christaller

Finding the right location is essential to successful life, but it is essential also to a successful enterpise, to the establischment of the lasting settlement - in short, to group survival.

August Lösch 


\section{RESUMO}

A presente Dissertação tem por objetivo abordar o conceito de região como fundamento modelo aplicável ao planejamento governamental territorializado, sob a ótica das contribuições teóricas da Filosofia da Ciência, da corrente de pensamento denominada Geografia Modelo-Teórica e da Economia Regional. Para tanto, os postulados da Teoria dos Lugares Centrais e dos Modelos de Interação Gravitacional, Potencial e Espacial, bem como a forma federalista de Estado, foram estudados em prol da análise das dimensões espaciais da lógica da distribuição das atividades humanas e econômicas. Os imperativos e possibilidades institucionais para execução de políticas públicas por meio de cooperação interfederativa reforçam a abordagem teórica desenvolvida. Como exemplificação concreta dos conceitos e fundamentos desenvolvidos neste trabalho foi realizada uma análise dos conflitos interfederativos originados na implantação das faixas de servidão de Linhas de Transmissão de Energia Elétrica, e elaborado um estudo da distribuição espacial modelar das unidades de saúde geridas pelo Sistema Único de Saúde no âmbito do Entorno Sul do Distrito Federal.

Palavras-chave: Região. Geografia Modelo-Teórica. Planejamento. Federalismo. Relações Interfederativas. 


\begin{abstract}
This dissertation discusses the concept of region as a useful framework for regionalized government planning from the perspective of the theoretical contributions of the Philosophy of Science, of the school of thought known as Model-Theoretical Geography, and of Regional Economics. To do so, the tenets of the Central Place Theory and of the Models of Gravitational, Potential and Spatial Interaction as well as the federalist form of state were studied in order to address the spatial dimensions of the logic of distribution of human and economic activities. The imperatives and institutional possibilities of the execution of public policy through interfederative cooperation reinforce the theoretical approach used in this study. An analysis of the interfederative conflicts created by the establishment of transmission line easements was performed as a concrete example of the ideas presented in this dissertation. An additional example was a study of the spatial model distribution of the health units managed by the Unified Health System within the southern border of the Federal District.
\end{abstract}

Keywords: Region. Model-Theoretical Geography. Planning. Federalism. Interfederativas Relations. 


\section{SUMÁRIO}

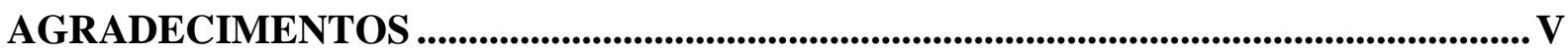

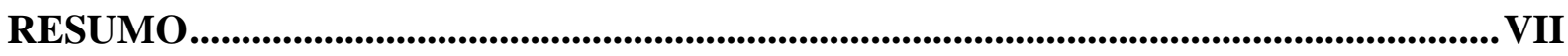

ABSTRACT ...........................................................................Erro! Indicador não definido.

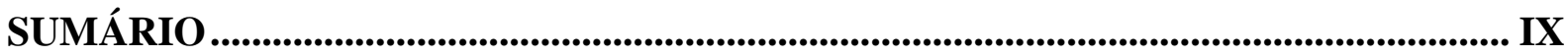

LISTA DE FIGURAS..............................................................................................

LISTA DE QUADROS....................................................................................................... XV

LISTA DE TABELAS .......................................................................................................XVI

LISTA DE ABREVIATURAS E SIGLAS .............................................................XVII

1 INTRODUÇÃ O ............................................................................................................................1

1 A FILOSOFIA DA CIÊNCIA E A CIÊNCIA GEOGRÁFICA.........................................5

1.1 O CONHECIMENTO CIENTÍFICO E OS ESTUDOS DE FILOSOFIA DA

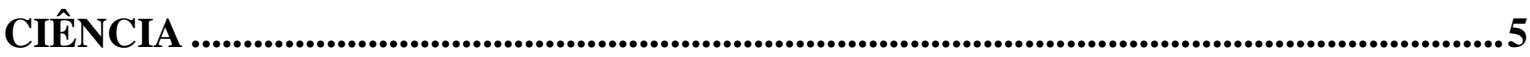

1.2 A CONTRIBUIÇÃO DA FILOSOFIA DA CIÊNCIA AOS MODELOS

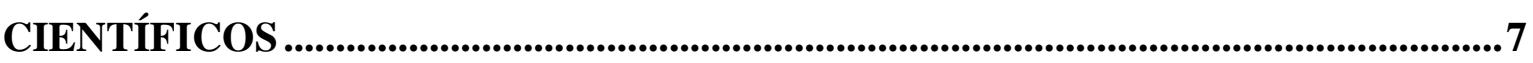

1.3 REPRESENTAÇÃO E MODELOS NAS CIÊNCIAS ...............................................10

1.4 MODELOS, MÉTODO CIENTÍFICO E INTERVENÇÃO NA REALIDADE ...13

1.5 REGIÃO: MODELO GEOGRÁFICO ORIGINÁRIO ...............................................16

2 A NOVA GEOGRAFIA: GEOGRAFIA APLICADA E O PLANEJAMENTO ...........26

2.1 A CONJUNTURA DO SURGIMENTO DA NOVA GEOGRAFIA..........................26

2.2 CARACTERÍSTICAS ELEMENTARES DA "NOVA GEOGRAFIA"

(GEOGRAFIA TEORÉTICA E QUANTITATIVA OU GEOGRAFIA "MODELO-

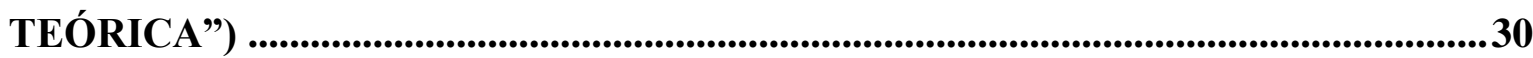

2.3 PERSPECTIVA IDIOGRÁFICA E A PERSPECTIVA NOMOTÉTICA ..............32

2.4 ALGUNS EXEMPLOS DE TRABALHOS REALIZADOS SOB A

PERSPECTIVA DA NOVA GEOGRAFIA ......................................................................35

2.4.1 $\mathrm{O}$ trabalho de William Warntz ................................................................................35

2.4.2 O trabalho de Michael F. Dacey .................................................................................37

2.5 A GEOGRAFIA APLICADA E O PLANEJAMENTO ............................................39

2.6 A GEOGRAFIA APLICADA E A REGULAMENTAÇÃO DA PROFISSÃo dO

GEÓGOLO NO BRASIL .........................................................................................................47 
3 TEORIAS CLÁSSICAS DA LOCALIZAÇÃO E DAS CENTRALIDADES PREMISSAS TEÓRICO-FILOSÓFICAS DO PLANEJAMENTO TERRITORIAL ....50

3.1 A EVOLUÇÃO DO PENSAMENTO ECONÔMICO-ESPACIAL...........................50

3.1.1 Outros estudos locacionais: os trabalhos de Von Thunen e Weber...................53

3.2 A TEORIA DOS LUGARES CENTRAIS................................................................55

3.2.1 Os lugares centrais de Christaller .............................................................................57

3.2.2 Regiões econômicas: os cones espaciais de Losch .................................................63

3.2.3 A Geometria Hexagonal ............................................................................................68

3.3 MODELOS DE INTERAÇÃO GRAVITACIONAL, POTENCIAL OU

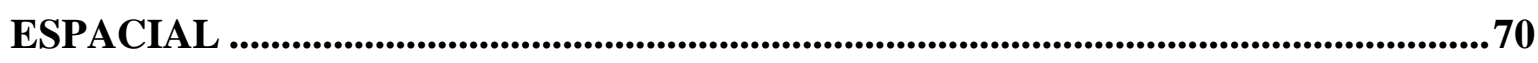

3.4 TEORIAS CLÁSSICAS DA LOCALIZAÇÃO E DAS CENTRALIDADES APLICADAS AO PLANEJAMENTO DE UNIDADES ADMINISTRATIVAS..........74 3.5 A NATUREZA DEDUTIVO-PROBABILÍSTICA DOS MODELOS E AS TEORIAS LOCACIONAIS: A ANALOGIA COMO PROCEDIMENTO TÉCNICOCIENTÍFICO. .79

4 O FEDERALISMO COMO PREMISSA INSTITUCIONAL PARA REGIONALIZAÇÕES NO PLANEJAMENTO..................................................................84

4.1 ASPECTOS TEÓRICOS DO FEDERALISMO .84

4.2 O FEDERALISMO BRASILEIRO: ASPECTOS HISTÓRICOS E JURÍDICOS

4.3 NOVAS TERRITORIALIDADES EM ARANJOS INTERFEDERATIVOS: CONSORCIAMENTOS E ECONOMIA DE ESCALA ...................................................91

4.3.1 As políticas públicas e o federalismo fiscal ..............................................................95

4.3.2 As relações intergovernamentais consorciativas e o Teorema da

Descentralização .99

4.4 A POLÍTICA NACIONAL DE DESENVOLVIMENTO REGIONAL:

ENTENDIMENTOS PARA TEMÁTICA FEDERATIVA 100

5 REGIÃO, UNIDADE INTERFEDERATIVA APLICADA À GESTÃO AMBIENTAL DE PROJETOS DE INFRAESTRUTURA E AO PLANEJAMENTO DE SERVIÇOS PÚBLICOS CONSORCIADOS. .103

5.1 UMA ABORDAGEM CONCEITUAL DOS IMPACTOS DE PROJETOS DE INFRAESTRUTURA: REPARAÇÕES E AS INSTITUIÇÕES FEDERATIVAS...103 


\subsection{FEDERALISMO COOPERATIVO, ATUAÇÕES SUPLETIVAS OU}

SUBSIDIÁRIAS DE ENTES FEDERATIVOS NA POLÍTICA AMBIENTAL ........109

5.3 EMPREENDIMENTOS LINEARES: O IMPACTO TRANSVERSAL DA FAIXA DE SERVIDÃO E A POSSIBILIDADE DE AÇÕES INTERFEDERATIVAS .........113

5.3.1 O vazio institucional interfederativo em empreendimentos pontuais e os impactos socioambientais

5.4 OS SERVIÇOS PÚBLICOS DE SAÚDE: POSSIBILIDADES DE CONSORCIAMENTO INTERFEDERATIVO 123

CONSIDERAÇÕES FINAIS. 139

REFERÊNCIAS 


\section{LISTA DE FIGURAS}

Figura 1.1 - Interação princípios-hipóteses-conceitos-modelos............................. 30

Figura 1.2 - Representação científica e intencionalidade de propósitos................. 32

Figura 2.1 - Esquema da inter-relação teoria dedutivo-indutiva, variância, escala e replicação de casos

Figura 2.2 - Níveis de renda per capita nos Estados Unidos da América e a densidade populacional.

Figura 2.3 - Diagrama de ilustração de Dispersão Espacial (da esquerda para direita): concentração ou clusters, aleatória ou random, e regularidade.

Figura 2.4 - $\quad$ Padrão, Densidade e Dispersão de Fenômenos................................... $\quad 59$

Figura 3.1 - Teorias clássicas da localização e das centralidades........................... 71

Figura 3.2 - Estrutura conceitual de abordagem das teorias clássicas da localização e das centralidades e das teorias do desenvolvimento regional.

Figura 3.3 - Relação entre a renda e a distância para produtos agrícolas: Modelo dos Anéis de Von Thünen.

Figura 3.4 - Comportamento anelar da relação renda-distância de atividades econômicas em ambiente urbano.

Figura 3.5 - Triângulo locacional de Weber: escolhas a partir do mínimo custo de transporte.

Figura 3.6 - Variações de comportamento de demandas de um bem.

Figura 3.7 - Relação entre o núcleo e o alcance dos lugares centrais, segundo o Modelo de Christaller.

Figura 3.8 - Esquema hexagonal do Princípio de Mercado.

Figura 3.9 - Esquema hexagonal do Princípio de Transporte..

Figura 3.10 - Esquema hexagonal do Princípio Administrativo.

Figura 3.11 - Variações preço-distância e preço-quantidade de um bem ou serviço.

Figura 3.12 - Cone de demanda espacial de Lösch.

Figura 3.13 - Desenvolvimento de redes de mercado: da circunferência ao hexágono ( $\operatorname{situação~(A)~para~a~situação~(D))....~}$ 
Figura 3.14 - Zona onde a escolha dos consumidores é indiferente entre (A) e (B). $\quad 88$

Figura 3.15 - Eficácia de distintos tipos de polígonos regulares em relação à distância do centro e ao cumprimento do perímetro

Figura 3.16 - Probabilidade para consumo em 03 (três) centros comerciais distintos (A, B e C)

Figura 3.17 - Curva de Custo Médio de Longo Prazo em processos industriais....... 95

Figura 3.18 - Relação entre o custo e a dimensão da área administrativa................ 96

Figura 3.19 - Relação entre participação comunitária e distância............................ 97

Figura 3.20 - Relação entre custo do serviço, participação comunitária e dimensão da área administrativa.

Figura 3.21 - Representação esquemática de menor custo de transporte 102

Figura 3.22 - Rotas hipotéticas de deslocamentos e análises da curva de esforço.... 103

Figura 4.1 - Relação entre a força centrífuga e a força centrípeta e o formato do Estado.

Figura 4.2 - Esquema gráfico do Teorema da Descentralização de Wallace Oates

Figura 5.1 - Compensações ambientais e financeiras pelo uso de recursos naturais

Figura 5.2 - Esquema das forças contrárias na análise de intervenções ambientais.

Figura 5.3 - Cooperação federativa vertical, horizontal e interfederativa.

Figura 5.4 - Impacto da restrição ao uso e ocupação do solo e as implicações urbanísticas e as barreiras conceituais no processo de licenciamento ambiental.

Figura 5.5 - Visada frontal do perímetro urbano do município de Águas Lindas de Goiás (Entorno do Distrito Federal) com situações de vazio urbano criado pelas faixas de servidão das Linhas de Transmissão 500 kV Norte-Sul, Circuitos 1, 2 e 3

Figura 5.6 - Visada diagonal do perímetro urbano do município de Águas Lindas de Goiás (Entorno do Distrito Federal) com situações de vazio urbano criado pelas faixas de servidão das Linhas de Transmissão 500 kV Norte-Sul, Circuitos 1, 2 e 3. 
Figura 5.7 - Vazio urbano em Taguatinga Sul (Distrito Federal) - Vista da direita para esquerda: faixas de servidão das Linhas de Transmissão 230 kV Brasília Sul-Brasília Geral, circuitos 1 e 2, e da faixa de servidão da Linha de Transmissão 138 kV Brasília Sul-Brasília Norte

Figura 5.8 - Situação de sinergia entre faixa de domínio da Rodovia BR - 060 e a faixa de servidão da Linha de Transmissão 138 kV SamambaiaMonjolo (sentido Brasília-Goiânia)

Figura 5.9 - Extinção de um vazio urbano com a construção de um parque urbano e vivencial - Vista da Linha de Transmissão $138 \mathrm{kV}$ Taguatinga-Ceilândia e da Linha de Transmissão 138 kV Taguatinga-Taguatinga Norte, parque urbano Taguaparque, Taguatinga, Distrito Federal

Figura 5.10 - Extinção de um vazio urbano com a construção de um parque urbano com ciclovia - Vista da Linha de Transmissão $138 \mathrm{kV}$ Taguatinga-Taguatinga Norte e da Linha de Transmissão 138 kV Taguatinga-Ceilândia, parque urbano Taguaparque, Taguatinga, Distrito Federal.

Figura 5.11 - Trajetória do número de municípios com consórcios intermunicipais - anos 1999, 2005 e 2009.

Figura 5.12 - Disposição geográfica dos municípios do Entorno Sul do Distrito Federal.

Figura 5.13 - Esquema teórico clássico da Teoria dos Lugares Centrais aplicados ao setor de saúde no Entorno Sul do Distrito Federal

Figura 5.14 - Relação entre a complexidade dos serviços de saúde, fator distância e hierarquia urbana.

Figura 5.15 - Relação entre custo de serviço, participação comunitária e dimensão da área administrativa. 


\section{LISTA DE QUADROS}

Quadro 2.1 - Perspectiva idiográfica e nomotética da pesquisa geográfica.............

Quadro 5.1 - Abordagens múltiplas do dano, da externalidade e do impacto

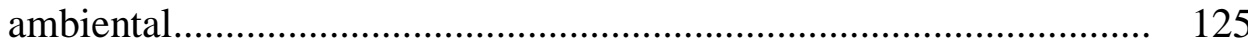




\section{LISTA DE TABELAS}

Tabela 5.1 - Distribuição de recursos do Fundo Nacional de Saúde por rubrica e Municípios do Entorno Sul do Distrito Federal - 2014...

Tabela 5.2 - Leitos de internação do Sistema Único de Saúde no Entorno Sul e os repasses para custeio de média e alta complexidade..................... 


\section{LISTA DE ABREVIATURAS E SIGLAS}
AAR
- Área de Abrangência Regional
ABNT - Associação Brasileira de Normas Técnicas
ADA - Área Diretamente Afetada
AI
- Ato Institucional
AID
- Área de Influência Direta
AII
- Área de Influencia Indireta
ANEEL - Agência Nacional de Energia Elétrica
ARENA - Aliança Renovadora Nacional
Art.
- Artigo
CEB
Companhia Energética de Brasília
$\mathrm{Cf}$
- Conferir
$\mathrm{CF}$
- Constituição Federal
CFEM - Compensação Financeira pela Exploração de Recursos Minerais
CFURH - Compensação Financeira pela Utilização de Recursos Hídricos para Fins de Geração de Energia Elétrica
CMeLP - Custo Médio de Longo Prazo
$\mathrm{CN} \quad-$ Congresso Nacional
CONFEA - Conselho Federal de Engenharia e Agronomia
CREA - Conselho Regional de Engenharia e Agronomia
C(q) - Custo
DNOCS - Departamento Nacional de Obras Contra a Seca
EC - Emenda Constitucional
EIA - Estudo de Impacto Ambiental
EUA - Estados Unidos da América
FAO - Food and Agriculture Organization
FC - Filosofia da Ciência
FNS $\quad$ - Fundo Nacional de Saúde
FUNAI - Fundação Nacional do Índio
GMT - Geografia Modelo-Teórica
GNCs - Governos Não Centrais
GTQ - Geografia Teorético-Quantitativa 


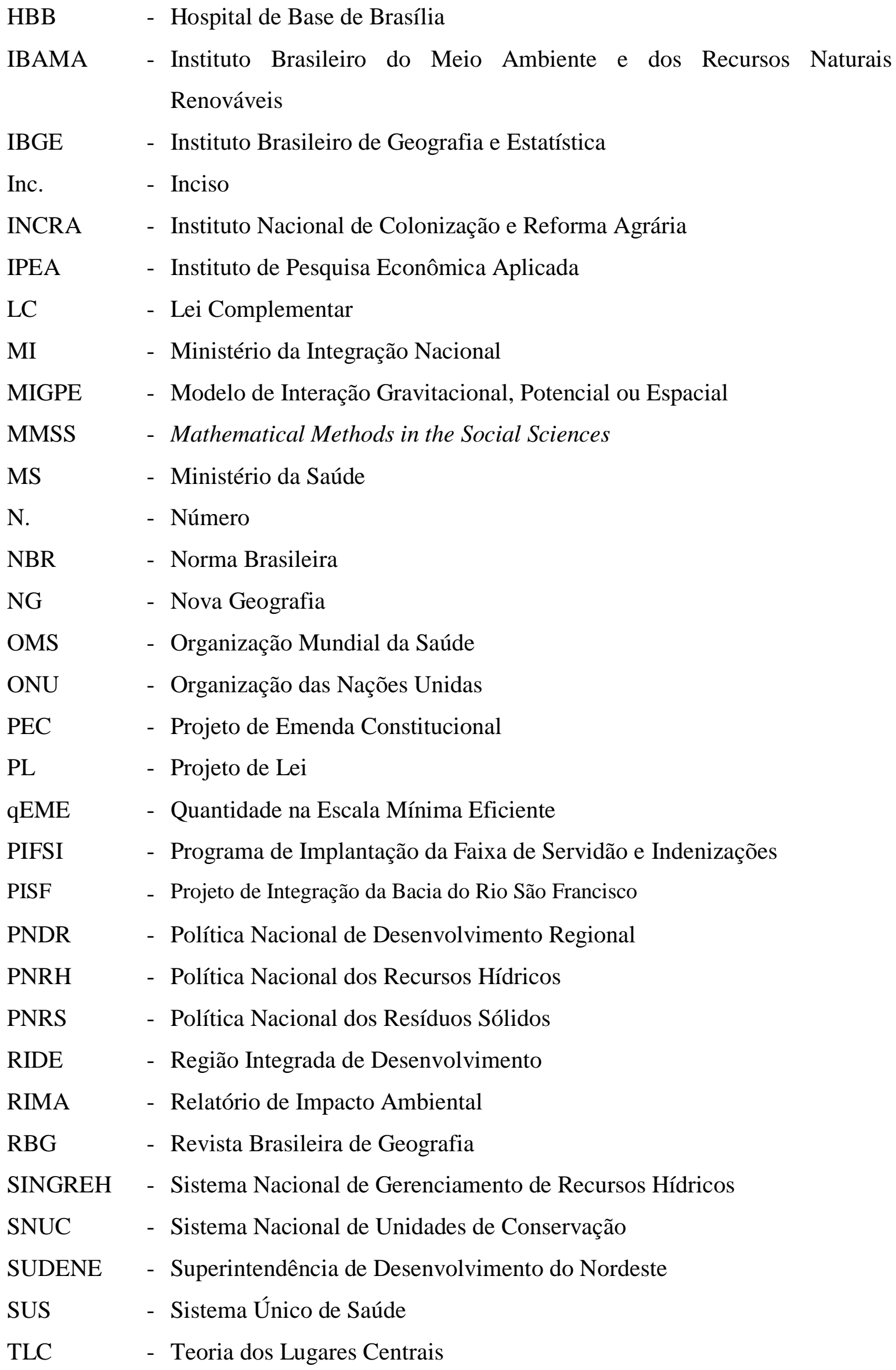


TVA

- Tennessee Valley Authority

UE

- União Europeia

UNESCO

- United Nation Educational, Scientific and Cultural Organization

UNESP - Universidade Estadual Paulista "Julio de Mesquita Filho"

UTI

- Unidade de Terapia Intensiva 


\section{INTRODUÇÃO}

O presente estudo, intitulado "Região, Planejamento e Geografia Modelo-Teórica: Contribuições basilares à intervenção governamental interfederativa", representa um esforço teórico na busca da sistematização de conhecimentos de natureza filosófico-científicos com vistas a fornecer referenciais para o resgate do planejamento territorial enquanto atividade de geográfica de Estado.

Para tanto, o conceito de região trazido por este trabalho representa o núcleo analítico e, por conseguinte, um insumo basilar do planejamento sob o viés de uma abordagem da intervenção governamental que agrega os quatro entes da federação, a saber: 1) o Município; 2) o Estado; 3) a União; e o 4) o Distrito Federal.

A fim de abordar o conceito de região enquanto paradigma geográfico originário, foi necessário resgatar a história, o contexto e as características da Nova Geografia (NG) que também foi designada como Geografia Teorético-Quantitativa (GTQ), Geografia Pragmática, Geografia Aplicada ou, como preferimos (à luz da moderna Filosofia da Ciência-FC) "Geografia Modelo-Teórica" (GMT). Esta corrente de pensamento foi de fundamental importância para o processo de planejamento pelo intrínseco viés instrumental dos estudos que foram produzidos.

Deste modo, os fundamentos geográficos da Teoria dos Lugares Centrais (TLC) e dos Modelos de Interação Gravitacional Potencial e Espacial (MIGPEs) auxiliaram tecnicamente na fundamentação da construção das abordagens conceituais, juntamente com conceitos oriundos da ciência política e da filosofia das ciências.

Como premissa institucional do planejamento regionalizado foi necessária a compreensão da complexidade federativa brasileira que representa, a um só tempo, um desafio para gestão territorial e dos serviços públicos, e um dado real a ser considerado nas análises.

Com efeito, este trabalho apresenta um viés para a ciência geográfica que transpõe a perspectiva analítica, ao adentrar em questões de cunho instrumental voltadas ao planejamento regionalizado sob a perspectiva da formação de um arranjo envolvendo os três entes federados, por isso, a escala interfederativa para as intervenções.

Em relação à problematização da pesquisa objeto desta Dissertação, as ausências de ações de planejamento governamental na gestão de políticas públicas de escala interfederativa são entendidas como o entrave teórico a ser solucionado. A falta de abordagem de políticas 
públicas em escala interfederativa é uma das causas de diversos problemas sociais e econômicos no Brasil.

Como objetivo geral este trabalho buscou propor o conceito de região como modelo e parâmetro basilar ao planejamento governamental interfederativo, a partir dos fundamentos modelares da FC e da NG.

E como objetivos específicos, buscou-se: $1^{\circ}$ ) a análise da contribuição da FC na formulação de modelos a serem aplicados e utilizados pelo método científico na ciência geográfica; $2^{\circ}$ ) a avaliação das contribuições da GMT ao planejamento, contextualizando sua contribuição tecno-científica; $3^{\circ}$ ) a avaliação das complexidades que envolvem o Estado de padrão federativo e os respectivos desafios ao planejamento governamental; e $4^{\circ}$ ) a reflexão sobre a aplicação concreta do conceito de região em serviços públicos essenciais de escala interfederativa, aplicando-se o conceito econômico de Economia de Escala (soluções territoriais consorciadas).

Em relação às hipóteses norteadoras iniciais de pesquisa tentou-se confirmar: $1^{\circ}$ ) os modelos podem nortear teórico-filosoficamente a elaboração dos fundamentos e dos limites do conceito de região; $2^{\circ}$ ) o planejamento governamental e não-governamental tem na região um suporte modelar da dimensão de atuação; e $3^{\circ}$ ) a execução de políticas públicas podem ser mais eficientes a partir da criação de uma unidade de planejamento e de gestão baseada no conceito da região interfederativa.

No que se refere ao material de pesquisa optou-se preponderantemente pela revisão bibliográfica disponível em língua portuguesa, inglesa e espanhola, seguida de pesquisas em conteúdos de sites governamentais. Pesquisas junto a alguns processos administrativos de licenciamento ambiental sob encargo do Instituto Brasileiro do Meio Ambiente e dos Recursos Naturais Renováveis (IBAMA) e um breve trabalho de campo para levantamento de informações e obtenção de fotografias a título de exemplificações de situações abordadas no Capítulo 5 também se encontram como material informativo da pesquisa.

Do ponto de vista do desenvolvimento do corpo teórico, a abordagem desta Dissertação possui 05 (cinco) Capítulos, a saber:

1) A FC e a Ciência Geográfica;

2) A NG: Geografia Aplicada e o Planejamento;

3) Teorias clássicas da localização e das centralidades: premissas teórico-filosóficas do planejamento territorial;

4) $\mathrm{O}$ federalismo como premissa institucional para regionalizações no planejamento; e 
5) Região, unidade interfederativa aplicada à gestão ambiental de projetos de infraestrutura e ao planejamento de serviços públicos consorciados.

Capítulo 1 aborda a interação entre a FC e a ciência geográfica por meio da análise da relação entre o conhecimento, a filosofia e os modelos científicos, e por meio da análise entre a representação, os modelos nas ciências e a intervenção na realidade. A região como modelo geográfico originário fecha a abordagem introdutória.

O Capítulo 2 trata das inter-relações entre a NG e o planejamento. Para tanto, realiza uma resgate histórico da conjuntura mundial que contextualiza a efervescência técnicocientífica do período do surgimento da NG, juntamente com as suas características mais determinantes. Este ainda aponta exemplos de trabalhos realizados sob o paradigma metodológico da NG como forma de demonstrar o caráter instrumental dos conhecimentos produzidos por esta corrente de pensamento, e encerra com uma breve análise da regulamentação da profissão do geógrafo no Brasil.

O Capítulo 3 realiza uma robusta revisão nas teorias clássicas da localização e das centralidades para enfatizar os fundamentos conceituais e técnicos da TLC e dos MIGPEs aplicados no planejamento. O caráter dedutivo-probabilístico das teorias clássicas da localização e das centralidades é outro aspecto abordado neste Capítulo como forma de demonstrar a complexidade e a diversidade dos padrões humanos de ocupação do território.

Por sua vez, o Capítulo 4 apresenta uma revisão teórica do federalismo como premissa institucional para as regionalizações no processo de planejamento por meio da análise das particularidades históricas e jurídicas do federalismo brasileiro, e por meio da análise dos novos arranjos de cooperação interfederativa. O Teorema da Descentralização de Oates e o cotejamento da Política Nacional de Desenvolvimento Regional (PNDR) diante da temática federativa também são abordados.

Por fim, o Capítulo 5 aplica o conceito de região à gestão ambiental de projetos de infraestrutura e ao planejamento de serviços consorciados. Para tanto, realiza uma abordagem conceitual do significado social, econômico e jurídico da terminologia impacto ambiental e termos conexos, ao tempo que analisa as ações supletivas e subsidiárias dos entes federativos determinados pela Lei Complementar (LC) n. 140/2011.

A situação de conflito de uso e ocupação do solo entre entes federativos distintos surgida com implantação de faixas de servidão de linhas de transmissão é analisada como forma exemplificativa das teorias e conceitos abordados nos capítulos anteriores. Outro 
exemplo prático trazido neste último Capítulo refere-se à possibilidade de consorciamento interfederativo de serviços públicos de saúde no Entorno Sul do Distrito Federal, a partir da aplicação de conceitos da TLC e dos MIGPEs. 


\section{A FILOSOFIA DA CIÊNCIA E A CIÊNCIA GEOGRÁFICA}

\subsection{O CONHECIMENTO CIENTÍFICO E OS ESTUdOS DE FILOSOFIA DA CIÊNCIA}

O conhecimento científico, por se caracterizar como uma atividade humana de grande complexidade, se constitui em um tipo de saber obtido a partir da evolução dos conhecimentos que a humanidade construiu, conquistou e refutou.

Contemporaneamente, o conhecimento científico tem se constituído em um fenômeno cultural em expressiva evolução, que passou a ser objeto de estudo por variadas matizes do pensamento acadêmico e filosófico.

A evolução do conhecimento científico vem ocorrendo de forma difusa, a partir da contribuição de vários ramos de conhecimento especializado. É interessante ressaltar a inexistência de ramo de conhecimento uno que seja capaz de abordar as complexas teias de relações subjacentes à produção do conhecimento científico.

Com efeito, as abordagens acerca do desenvolvimento do conhecimento científico possuem um viés multidisciplinar, uma vez que variados ramos do conhecimento se dedicam a colaborar com os entendimentos e a construção do saber científico. A distinção entre o conhecimento científico e os conhecimentos referentes à ciência em si dá-se nos limites definidos pelo objeto de análise, objeto de abordagem, método analítico e o foco das teorizações.

No objeto de análise e de abordagem, no método analítico e no foco das teorizações concentram, então, a clivagem epistemológica da identificação de ramos disciplinares ou dos saberes. A identificação do objeto determina o rumo que seguirá a construção do conhecimento e, por conseguinte, baliza as fronteiras disciplinares de abordagem da ciência, da filosofia e dos saberes em geral. É sempre muito importante ter clareza sobre o ponto de origem e o ponto de destino de uma abordagem teórica, bem como seus limites de abrangência metodológica.

A construção de conhecimentos referentes às ciências ou às "abordagens científicas" tem merecido destaque, pois, da análise do método, das linguagens e das abstrações científicas surgiram outras ciências (chamadas "metaciências"), outros saberes ou aperfeiçoamentos dos já existentes. A ciência, de construção humana e técnica social de investigação da natureza, passou a ser o "objeto" de abordagens teóricas de cunho filosófico. 
O conhecimento, então, pode ser analisado a partir de outros conhecimentos, em uma perspectiva metacientífica. As abordagens acerca do conhecimento científico podem ser entendidas como metacientíficas, pois tal denominação, segundo o filósofo Pablo Lorenzano (2011), englobaria teorizações de segunda ordem. Para este autor, “los llamados estudios metacientíficos o estudios sobre la ciencia, están conformados precisamente por estas diversas teorizaciones de segundo orden sobre las teorizaciones (científicas) de primer orden" (LORENZANO, 2011, p. 134).

A classificação de qualquer ramo de conhecimento ou do saber como de primeira ou de segunda ordem deriva da relação direta existente entre o pesquisador e o objeto pesquisado. A ausência de meios intermediários entre o pesquisador e o objeto pesquisado, impõe uma classificação ao conhecimento produzido como sendo de primeira ordem. De igual modo, as abordagens teóricas de segunda ordem assim se classificam por tratarem não do objeto de estudo da ciência, e sim da estrutura e da dinâmica da produção do conhecimento obtido a partir da análise científica (portanto, de "primeira ordem”) em relação ao objeto.

A denominação dos conhecimentos de segunda ordem como metacientíficos (LORENZANO, 2011) indica que as referidas teorizações transpõem o conhecimento científico em si, ao abranger os fundamentos linguísticos, psicológicos, filosóficos e ontológicos que lhes dão sustentação. Os conhecimentos metacientíficos constituiriam uma espécie de ciência das ciências.

Acerca da multiplicidade de abordagens sobre o conhecimento científico e metacientífico, Lorenzano (2011, p. 134) afirma ainda que

Sin embargo, y debido a su gran complejidad, la ciencia no es susceptible de ser abordada desde un único punto de vista: cada uno de los aspectos de la actividad científica abre una perpectiva desde la que se puede estudiar dicha actividad. Sin ánimos de exhaustividad, mencionaremos al menos siete aspectos diferentes de la actividad científica objeto de reflexión metateórica: el psicológico, el sociológico, el antropológico, el político, el económico, el histórico y el filosófico.

Com efeito, os aspectos de reflexão da abordagem científica mencionados por Lorenzano (2011) determinam as matrizes de conhecimento de segunda ordem denominadas de Psicologia da Ciência, Sociologia da Ciência, Antropologia da Ciência, Política da Ciência, Economia da Ciência, História da Ciência e, notadamente, Filosofia da Ciência (FC).

Neste cenário, a perspectiva da abordagem filosófica da ciência, isto é, da FC, passa a ter grande destaque devido à amplitude de sua abordagem, sobretudo no estágio mais 
contemporâneo de seu desenvolvimento. A FC como uma derivação do conhecimento filosófico tem um compromisso original com a racionalidade lógica e com a "verdade" enquanto valores fundamentais.

A FC não é um campo teórico contemporâneo. Possui origens na filosofia clássica grega. Porém, a institucionalização dos conhecimentos da FC em cátedras universitárias surgiu, mesmo que de forma incipiente, no final do século XIX, nas Universidades de Zurique e Viena, por meio de estudos de filosofia indutivista. Posteriormente, a contribuição daquelas iniciativas institucionais consubstanciou-se no que ficou conhecido como Círculo de Viena. Houve, a partir daí, uma profissionalização e a consolidação de debates que viriam a constituir a disciplina FC no período conhecido como "entre guerras".

Após o período de consolidação da FC como campo de conhecimento academicamente reconhecido, Lorenzano (2011) aponta para a existência de 03 (três) momentos estruturantes deste ramo do conhecimento, quais sejam:

1) a fase "clássica", que abarcaria desde os fins dos anos 1920 até o final dos anos 1960;

2) a fase "historicista", iniciada nos anos 1960, fortemente atuante nos anos 1970 e abrangendo o início dos anos 1980; e

3) a fase "contemporânea", que se inicia no começo dos anos 1970 e se estende até os dias atuais.

\subsection{A CONTRIBUiÇÃo DA FILOSOFIA DA CIÊNCIA AOS MODELOS CIENTÍFICOS}

A FC, como um campo metacientífico, contribui nas explicações e elucidações dos aspectos conceituais da atividade científica ao buscar explicação racional para, por exemplo, a compreensão dos fundamentos do método científico.

A natureza do método científico, isto é, os meios para determinar a validade de informações de um dado objeto real e os tipos de argumentos utilizados para se chegar às conclusões, são nuances percorridos pela FC. Aspectos linguístico-conceituais tornam-se importantes no processo investigativo.

Para o filósofo Pablo Lorenzano (2011, p. 136, grifo nosso) - representante de uma das vertentes mais recentes da FC (intitulada "estruturalismo metateórico") -, este campo do conhecimento estuda "los conceptos fundamentales de la actividad científica, tales como concepto (científico), hipótesis, ley o teoría, y reordena conceptualmente o reconstruye los 
sistemas de concetos (o teorías) produzidos por la ciencia".

Desta forma, entende-se que a FC estuda a produção e a atividade científica, a partir da análise de seus fundamentos estruturantes. A FC realiza, então, um exame pormenorizado dos elementos materiais, procedimentais e conceituais do método científico.

A FC, de fato, é considerada um conhecimento de segunda ordem, pois não lida diretamente com os objetos das ciências particulares. Estuda sim, o modo como elas produzem e o que produzem. Este ramo do conhecimento filosófico busca compreender a "natureza da ciência"; o modo como esta funciona. Ademais, cabe salientar que a Filosofia é uma fonte de conhecimento legítima, racional, bem como a ciência também o é.

Para Lorenzano (2011, p. 135), a FC pode ser entendida como um ramo do conhecimento que cuida da "elaboración de esquemas conceptuales interpretativos de carácter filosófico" ou como uma "teorización filosófica - con la finalidad de entender a la ciencia. La filosofía de la ciencia es así, no sólo una parte de la metaciencia, sino también una parte de la filosofía, aquella que precisamente se encarga de analizar a la ciencia".

A FC apresenta ramificações de abordagens teóricas, destacando-se, contemporaneamente, segundo Lorenzano (2011, p.147), as linhas denominadas de “concepção semântica” (ou "família semanticista”), FC “modelo-teórica” (ou "modelista”), e “concepção estruturalista".

Do ponto de vista da perspectiva temporal, a contribuição da FC na produção de estruturas conceituais que fomentaram a produção e interpretação dos fazeres científicos tornou-se fenômeno salutar ao longo do século XX. Entre as estruturas conceituais aperfeiçoadas a partir da colaboração da FC, teve enorme destaque o conceito de "modelo", entendido tanto como formatação teórica (onde o cientista enquadra os fenômenos que investiga), quanto artefato de representação (onde o filósofo da ciência avalia o exercício de mediação que o cientista executa, a fim de representar o mundo real).

Tanto para a concepção de FC estruturalista, quanto para a semanticista, teorias trazem contribuições de análise representadas por "famílias de modelos". Segundo Frederick Suppe (2000), existe uma relação entre teorias e modelos na definição da natureza das estruturas das teorias, uma vez que as teorias poderiam ser consideradas coleções ou classes de modelos.

Os "modelos" ou "modelos teóricos" possuem a capacidade de sintetizar esquematicamente o layout e o esboço conceitual de teorias em desenvolvimento. Os modelos conceituais, produzidos na interface filosofia-ciência, constituem um núcleo sintetizador de teorias, ou seja, os modelos, quando devidamente aceitos, delimitam um cerne conceitual 
estruturante.

Embora os modelos conceituais tenham emergido da evolução das teorizações e descobertas das ciências da natureza, este formato de estruturação do pensamento tem sido, com sucesso, recepcionado pelas ciências humanas - notadamente na Economia e na Psicologia. Os modelos facilitam, nas ciências humanas, a abordagem teórica ao permitirem o isolamento, mesmo que em situação hipotética, de variáveis interferentes no objeto de estudo.

Para o filósofo Frederick Suppe (2000, p. 110), "models are the heart of scientific experimentation, observation, instrumentation, and experimental design. Data typically are insufficient or of the wrong sort, and modeling is required to interpret them in scientifically meaningful ways".

Suppe (2000, p. 109) acrescenta ainda que "today, models are the main vehicle of scientific knowledge". Inclusive, situa-se nos modelos conceituais, ou simplesmente nos modelos, uma das distinções essenciais entre os filósofos da ciência contemporâneos (sejam eles estruturalistas ou semânticos) e os filósofos da ciência do período clássico (sejam eles os do Círculo de Viena ou seus herdeiros em solo anglofônico). Estes últimos, por primarem pela construção sintática dos enunciados, não admitiam a possibilidade de representações alternativas para os axiomas.

Para os filósofos positivistas, as teorias de per si somente funcionariam já como veículos de retransmissão dos enunciados científicos sobre o mundo. Enquanto que para Suppe (2000, p. 109) (a exemplo de Lorenzano, também um nobre representante da vertente contemporânea de FC), "if theories are vehicles of scientific knowledge, then so too must models be".

Patrick Suppes (1961, p. 165 apud SUPPE, 2000, p. 111) sentencia que "the meaning of the concept of model is the same in mathematics and the empirical sciences. The difference to be found in these disciplines is to be found in their use of the concept".

Logo, conforme preconiza P. Suppes (1961), está no uso e na operacionalização dos modelos, sob a perspectiva instrumental, uma das diferenciações entre os ramos do conhecimento científico, e entre as correntes filosóficas que abordam os saberes referentes à produção científica. Os modelos constituiriam tão somente uma ferramenta conceitual descritiva. Teria, portanto, uma função essencialmente instrumental e pragmática.

Em relação à linguagem descritiva subjacente aos modelos, verifica-se o uso da linguagem matemática por meio de teoremas lógicos. Os modelos devem ser devidamente estruturados para que sejam sustentadas sua contundência e validade argumentativa. Ou seja, 
a aceitação de um modelo é proporcional à sua fundamentação lógica e argumentativa e à capacidade de se manter em pé frente às tentativas de refutações.

A teorização filosófica sobre a ciência, também conhecida como FC, é útil como abordagem teórico-conceitual para fundamentar a proposição do conceito de região - o qual será aqui apresentado enquanto "estrutura modelar" dirigida a uma intervenção via planejamento.

\subsection{REPRESENTAÇÃO E MODELOS NAS CIÊNCIAS}

A construção de arranjos teóricos nas ciências, em geral, é precedida pelo estabelecimento de conceitos que definem o significado ontológico do objeto de abordagem. A FC oferta contribuições à interpretação sobre como o cientista concebe e emprega seus artefatos abstratos (conceitos e modelos).

A perspectiva conceitual do pensamento é consequência da identificação e da coisificação dos objetos. Quando a abordagem se refere aos aspectos antropológicos ou sociológicos, tal denominação é consequência da individualização dos seres ou de grupos de indivíduos. Quaisquer que sejam as abordagens teórico-analíticas, elas possuirão um viés seletivo.

A identificação e a individualização conceitual possibilitam uma similaridade entre o "conceito" e sua denominação por uma simples relação biunívoca entre significante e significado linguístico, ou seja, existe um "vínculo de associação" (SAUSSURE, 1967, p. 80) arbitrado. Cabe à semiologia linguística o aprofundamento dos conceitos "significante", "significado" e "signo", linguístico.

A estruturação e sistematização de conceitos, por conseguinte, culmina na elaboração de esquemas cujos fundamentos contribuem para desenvolver modelos descritivos. As ciências possuem a necessidade da representação clara do seu objeto de estudo e de seu procedimento de investigação.

Os modelos estruturantes trazem consigo a possibilidade (a partir, é claro, de verificada a eficácia e veracidade lógica da situação particular) da aplicação em formato ampliado dos postulados intrínsecos ao modelo ou à representação parcial do mundo.

As generalizações, como procedimento metodológico, constituem a extensão de princípios que, isoladamente, podem ver-se manifestos em uma dada unidade particularizada de análise (modelo). Do ponto de vista da FC, entende-se por modelo uma estrutura teórica 
que pode veicular princípios gerais até certa escala do real. O modelo seria, então, a unidade padronizada que configura um esquema de sustentação teórico-conceitual acerca de um objeto determinado (porção da realidade), definido segundo os propósitos de um agente - o modelizador.

A construção de um modelo nada mais é do que a representação de um sistema de objetos, ou de parte da realidade, por meio de um esquema conceitual. Um modelo não é a realidade em si; é tão somente uma representação aproximada dela, ou seja, um design da porção do mundo real que o cientista desejou especialmente simplificar e representar.

O filósofo Ronald Giere (2004, p. 744) apresenta esquematicamente como princípios, modelos, generalizações e hipóteses se encadeiam e se relacionam, conforme exposto na Figura 1.1.

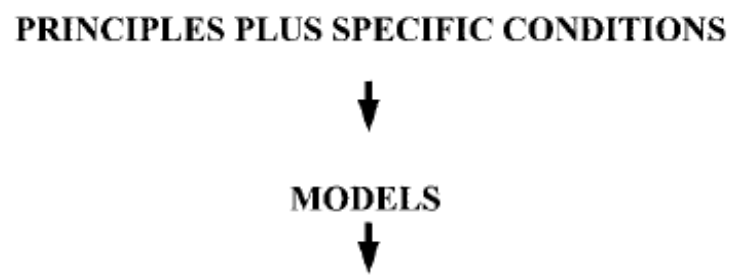

\section{HYPOTHESES AND GENERALIZATIONS

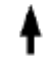

WORLD

Figura 1.1 - Interação princípios-hipóteses-conceitos-modelos.

Fonte: Giere (2004, p. 744).

O esquema de Giere demonstra que os modelos orientam a formulação de hipóteses, as quais, observadas as condições específicas que definem o modelo, terão de ser confrontadas com o mundo real e com as generalizações para classes designadas de objetos similares. Haverá a possibilidade de "confirmação" sob a perspectiva da similaridade "modelo-mundo", na medida em que a generalização constante das hipóteses corresponda minimamente à porção do mundo sob investigação.

Acerca das inter-relações contidas na construção de modelos, Giere (2004, p. 747, grifo nosso) afirma que "models in advanced sciences such as physics and biology should be abstract objects constructed in conformity with appropiate general principles and specific conditions".

Nesta linha de pensamento, os modelos são construídos adotando consigo os 
“princípios gerais" utilizados pelas ciências da natureza e podem servir de padrão explicativo para outras ciências. A observância das particularidades do objeto e o propósito a que se destina sua abordagem condicionam a aplicação e replicação de um arranjo modelar.

Assim, no âmbito do método científico, a necessidade de construção de representações por meio de modelos decorre da necessidade da identificação e seleção de variáveis para a análise. A partir de modelagens, a infinita complexidade do mundo torna-se manejável por meio do recorte de abordagem. O modelo torna reduzido, simples e limitado o objeto de estudo. Tal simplificação do real é um obstáculo a ser transposto pelo cientista, caso pretenda gerar protótipos teóricos úteis à intervenção.

Para Ian Hacking (1996), os modelos funcionam como uma conexão entre fenômenos reais e as estruturas matemáticas (descritivas e simplificadoras) subjacentes às teorias préestabelecidas. Para este autor, os modelos podem ter um viés descritivista, bem como podem ser úteis a uma aplicação prática. Assim, devem ser submetidos à comprovação empírica, questionamentos e contínuos aperfeiçoamentos.

A consolidação de um modelo dá-se na medida da aferição do nível de coerência e de adequação entre a representação (recursos analógicos, por exemplo) e o objeto representado (realidade). O modelo é, sobretudo, um sistema descritivo abstrato sujeito às refutações. Somente tem relevância "científica" aquilo que, em qualquer tempo, pode ser submetido vis à vis aos questionamentos oriundos das faculdades da razão.

Acerca da relação de adequação e reciprocidade entre os modelos e o objeto, Giere (2010, p. 274) afirma ainda que "models cannot exhibit a perfect fit to any real system, or cannot justifiably be claimed to do so, or are often explicitly known not to provide a perfect fit”. Deste modo, os modelos são construídos em um processo de aproximação e adequação aos objetos e sistemas que eles representam. Do contrário (havendo distanciamento), tornamse necessários aperfeiçoamentos entre o modelo e o objeto representado.

Assim, para Giere (2010, p. 274), os modelos representam a intenção de quem os constrói ou de quem os propõe - processo que denominou de "intentional conception of scientific representation".

Sob este aspecto, este o mesmo autor apresenta um desenho esquemático que demonstra em etapas a construção de modelos, observando-se a relação agenteintencionalidade-propósito/intenção, conforme expresso na Figura 1.2, a seguir. 


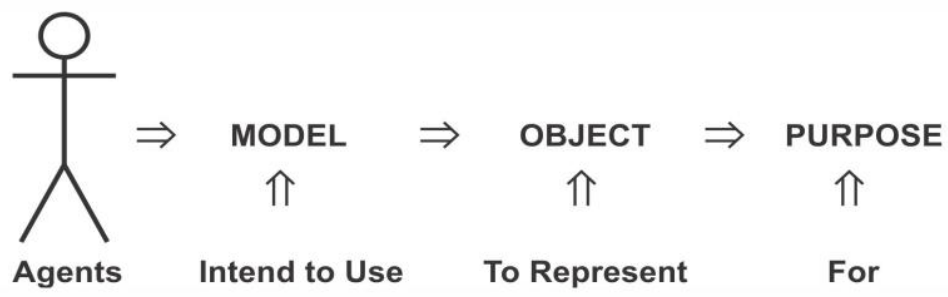

Figura 1.2 - Representação científica e intencionalidade de propósitos.

Fonte: Giere (2010, p. 275).

Para Giere (2010), os modelos são construídos conforme a finalidade a que se destinam e possuem sempre um viés de utilidade teórica explícita, de acordo com intencionalidades. Deste modo, o objetivo a ser perseguido é matéria subjacente às escolhas de um agente ou a uma "intenção conceitual" definida. Inexistem modelos teórico-científicos sem propósito pré-definidos. Centra-se no objeto um ponto de origem importante, pois as representações modelares são, sobretudo, seleções de informações e variáveis.

A identificação e a interpretação do objeto - condições necessárias à construção de modelos, é uma tarefa que requer o uso das faculdades sensoriais e cognitivas, sendo a capacidade perceptiva bastante requisitada neste processo. Ou seja, a percepção, bem como a capacidade de compreender a realidade de um dado modo, torna-se chave no processo de edificação dos modelos.

Sob este aspecto, embora a dimensão do visível (do paisagístico) seja a manifestação mais explícita do real, torna-se necessário transpô-la para agregar as demais percepções derivadas de outras capacidades sensoriais.

\subsection{MODELOS, MÉTODO CIENTÍFICO E INTERVENÇÃO NA REALIDADE}

A história do pensamento filosófico e científico possui uma intrínseca perspectiva evolucionista, materializada na transformação continuada dos conceitos e paradigmas que ajudaram nas tentativas de compreensão e explicação da realidade existente.

É sabido que a compreensão da realidade se dá por meio de representações abstratas do mundo real, e que destas aproximações teóricas derivam modelos mentais descritivos.

Para Hacking (1996, p. 246), os modelos são

[...] doblemente modelos. Son modelos de los fenómenos y son modelos de la teoría. Esto es, las teorías son siempre demasiado complejas para que 
podamos discernir sus consecuencias, y por lo tanto las simplificamos en modelos matemáticos manejables. Al miesmo tiempo, estos modelos son representaciones aproximadas de las representaciones del universo.

Do ponto de vista da corrente contemporânea da FC, considera-se a ciência como um instrumental de conhecimentos teórico-filosóficos produzidos a partir das necessidades de determinados setores da sociedade - o que possibilitou, ao longo da história, notáveis avanços tecnológicos. A perspectiva do "controle" de determinados processos dos ciclos naturais é a face mais visível dos avanços tecnológicos modernos. De fato, avanços tecnológicos comumente redundam em formas de controle e intervenção sobre a natureza e seus processos.

É sabido que as ciências físicas (naturais) possuem nos modelos os fundamentos explicativos dos fenômenos naturais que a representam, o que (provavelmente) possibilitou a concepção das denominadas "Leis Naturais".

Por sua vez, as ciências humanas também fazem uso de modelagens como forma de construir explicações plausíveis do mundo social, apesar das dificuldades da moldagem de um design padrão para a explanação de determinados aspectos de seus objetos (organizações espaciais, organizações sociais, padrões produtivos, regramentos sociais, comportamentos etc.).

Invariavelmente, a estatística, as compartimentações sociais, as categorizações, as periodizações, as tendências e os arranjos de gestão constituem modos de formatação e, por conseguinte, ferramentas potenciais para a descrição da realidade social. Contudo, as ciências humanas possuem objetos e abordagens interpretativas próprios, diferentes daqueles das ciências da natureza.

Entretanto, do ponto de vista do método científico, inexistem diferenças aplicadas às ciências da natureza ou às ciências humanas. O método científico, sendo passível de universalidade, ao representar uma forma de abordagem e de processamento tecnificado de informações, pode ser aplicado a quaisquer ciências.

Apesar da unicidade do método científico, existem inequívocas diferenças das abordagens das "humanidades" em relação às "ciências", no que se refere à replicação do conhecimento, à previsibilidade de fenômenos e à constituição de leis de regularidade. $\mathrm{O}$ fazer científico nas humanidades é dotado de especificidades que o difere das ciências da natureza.

A respeito de eventuais clivagens entre as ciências humanas e as ciências da natureza, Christofoletti (1982, p. 16, grifo nosso), adotando a Geografia como exemplo, afirma que 
das ciências. Há métodos científicos para pesquisa geográfica, mas não métodos geográficos de pesquisa. Em cada ciência, o que a diferencia das demais é o seu objeto. Cada ciência contribui para a compreensão da ordem da estrutura existente, e o setor da geografia é o das organizações espaciais.

Adentrando especificamente na interpretação da realidade social por meio de arranjos conceituais, entende-se que a referida realidade, que não é una, passa a ser entendida a partir de um formato, de um padrão conceitual delineado - que pode ser denominado "modelo" que se constitui tão somente em uma estrutura lógica simplificada e aproximada do real. $\mathrm{O}$ modelo é uma forma de entender o objeto, a realidade - o que não implica na exclusão de outros modos variantes ou até divergentes de entendimento do mesmo objeto.

A este respeito, Campos (2011, p. 455) afirma que "um modelo é um passo inicial do processo de investigação [...] o modelo não é uma teoria, embora sua construção dependa das concepções do seu autor; é somente um meio de simplificar a complexidade, de facilitar a compreensão".

A interação "modelos-ciências" aplica-se tanto para as ciências da natureza quanto para as ciências da sociedade. Muitas teorias, independentemente do ramo científico, carecem de instrumentais racionais e argumentativos que forneçam fundamentação lógica-positiva.

Particularmente, a ciência geográfica como uma ciência síntese ou de interface entre os elementos da natureza e da sociedade, possui nas representações e modelos especial sustentação de linguagem e de sua epistemologia.

Neste contexto, a "região" é um dos conceitos centrais para a ciência geográfica do ponto de vista da perspectiva "representação $\rightarrow$ modelos $\rightarrow$ intervenção", materializado na escolha de um determinado recorte espacial temático. Assim, toda região é um modelo um modelo espacial de abordagem.

Entender a realidade a partir de um recorte espacial - a região - possibilita a constituição de atos de regionalização, independentemente da variável utilizada para aferir o fenômeno espacializado. Deste modo, a região existe na medida em que é identificada e classificada; isto é, existe a partir do ato de sua qualificação. O termo "região" é uma construção abstrata, fruto de quem a fundamenta, a dissemina e a sustenta.

Por conseguinte, as intervenções no mundo real, a partir de um arcabouço teórico modelar, tornam-se possíveis a partir da constatação de que uma determinada situação foge do padrão definido como "ideal" ou "normal". As intervenções partem de uma perspectiva idealizada, que é confrontada com uma situação fática. Os modelos e, mais ainda, os modelos regionais, podem sim ser considerados a base para a intervenção estatal. 
Sob tal viés, a identificação do quanto uma situação foge ao modelo ideal pode ser aferida através de estudos estatísticos, notadamente aqueles definidos a partir da Curva de Gauss, cuja definição de uma curva "normal" revela o padrão descritivo comportamental de qualquer variável. Por conseguinte, o chamado "Desvio Padrão" constitui-se em uma robusta ferramenta que pode ser utilizada nas ciências sociais, pois demonstra o quanto (para mais ou para menos, a partir de uma mediana) uma determinada variável se distancia da distribuição "normal".

O uso da estatística adentra em questões relacionadas ao uso de análises quantitativas e qualitativas no âmbito das ciências. Para a Geografia, ambas as análises são fundamentais para definição dos modelos regionais, pela inequívoca função descritivo-interpretativa frente aos dados obtidos. Outras análises, como, por exemplo, a da "percepção", de caráter humanista, e a de linhagem crítico-marxista, podem, complementarmente, colaborar no entendimento de certos fenômenos regionalizados.

Com efeito, o conceito de território pode ser considerado como uma base de intervenção, e a região como um modelo geográfico estruturante para a ação de planificação, seja via instrumentos de Estado ou para atender interesses de agentes de mercado. A Geografia, mais que uma ciência analítica, é, notadamente, uma ciência de caráter e saber instrumental a serviço do planejamento. Não há planejamento sem a consideração do substrato territorial/locacional dos fatores de produção.

Ademais, vale reconhecer a relevância teórica da FC como aporte útil ao entendimento sobre o modo como o cientista formata suas estruturas analíticas - fato que aqui autoriza a formular corolários na construção de uma espécie de "pensamento científico orientador de projetos de intervenção". Por conseguinte, também nesta linha, é possível identificar a formatação de "unidades de gestão", com base em padrões regionais modelares estruturantes, visando a intervenção no mundo real.

\subsection{REGIÃO: MODELO GEOGRÁFICO ORIGINÁRIO}

É perceptivo que os modelos tornaram-se instrumentos técnico-científicos de representação de objetos de estudo, utilizados por vários ramos da ciência. Ciência e representação imbricam-se como linguagem, sendo a delimitação do objeto de estudo um imperativo para o conhecimento sistêmico daquilo cujo "mecanismo" se deseja estimar e predizer. 
A ligação entre teorias e modelos é de linguagem e correspondência do design da representação esquemática. A modelagem destaca-se como a estrutura operacional do método científico contemporâneo; logo, é válida para toda ciência que visa, entre outros aspectos, ressaltar a relevância de determinadas variáveis (frente a outras) e o tratamento de informações conforme a finalidade a que se destina.

Para George (1975, p. 20), "assim como no uso das analogias ou metáforas, os modelos também, para terem valor de previsão, devem possuir de algum modo semelhança com a estrutura ou com o processo que vão representar". Portanto, os modelos constituiriam, preponderantemente, uma forma de tratamento da informação selecionada.

De fato, os modelos representam uma ferramenta a serviço do método científico, que visa dar um tratamento sistemático às variáveis entendidas como circunstancialmente significantes. Para o geógrafo Antonio Christofoletti (1982, p. 91)

[...] o modelo é um instrumento que formaliza a hipótese para ser devidamente testada, implicando formulações quantitativas, verificáveis e universalmente aplicáveis. O modelo deve ser construído conforme as premissas das teorias geográficas, construindo aplicação das mesmas a determinado conjunto de fenômenos.

Este autor reforça o caráter instrumental do modelo ao expor que ele "é um meio para melhor se atingir a compreensão da realidade" (CHRISTOFOLETTI, 1982, p. 20). Acrescenta ainda, afirmando que tal formato conceitual é um caminho para "análise dos sistemas das organizações espaciais" (CHRISTOFOLETTI, 1982, p. 20). Ou seja, o modelo representa uma estrutura analítica para abordagem sistêmica de informações (do quadro físico e/ou socioeconômico) distribuídas espacialmente.

É de fundamental importância o tratamento das informações de natureza geográfica para que haja um melhor arranjo descritivo das "organizações espaciais" existentes. Em relação à relevância do tratamento de informações na busca da compreensão lógica de fenômenos espaciais, os geógrafos Richard J. Chorley e Peter Haggett (1975, p. 1, grifo nosso) afirmam que

[...] a informação em geografia é suscetível de tratamento em termos de teoria geral da informação. Nesse contexto, as informações factuais só têm relevância dentro de uma estrutura de referência mais geral e a operação básica para definir o que é de fato relevante só pode ser feita com base em estruturas teóricas. 
Acerca da definição e operacionalização de fatos relevantes, estruturados sistemicamente a partir de uma referência mais geral, Chorley e Haggett (1975, p. 3, grifo nosso) asseveram que o

[...] modelo é uma estruturação simplificada da realidade que supostamente apresenta, de forma generalizada, características ou relações importantes. Os modelos são aproximações altamente subjetivas, por não incluírem todas as observações ou medidas associadas, mas são valiosos por obscurecerem detalhes acidentais e por permitirem o aparecimento de aspectos fundamentais da realidade.

A imperiosa necessidade de selecionar informações, eliminando aspectos entendidos como não centrais, aponta que a medida do sucesso de um modelo "é a importância das propriedades que escolhemos para representar a realidade" (Grigg, 1973, p. 33). Ou seja, o operador do modelo teórico tem por dever de clareza teórico-metodológica "eliminar o ruído" (GRIGG, 1973, p. 46) do arranjo de representação.

Neste sentido, a abordagem científica por meio de modelos aplicados possibilita a constatação, com certo rigor, de resultados e aspectos relevantes, destacando-se nas ciências da natureza a perspectiva de leis e da previsibilidade; e nas ciências humanas, a perspectiva da identificação de funcionalidades, de temporalidades, de padrões e de tendências, entre outros aspectos.

Sobre tal questão, George (1975, p. 22) assevera que "o método científico, naturalmente, é vital a qualquer investigação científica do uso de modelos, já que [...] os modelos e as teorias científicas são ligados muito intimamente". Os resultados dos conhecimentos obtidos nas "ciências humanas" ou nas "ciências da natureza" é uma questão de aplicação de método, do método científico.

Vale reconhecer a ocorrência de certo pensamento comum na aplicação do método científico no âmbito das ciências sociais cuja "distinção geralmente é feita entre as humanidades, que se preocupam principalmente com o único e não periódico, e as ciências, que se procuram estabelecer generalizações para acontecimentos e processos repetitivos" (CHORLEY; HAGGETT, 1975, p. 1).

Sob este aspecto, Chorley e Haggett (1975, p. 1) afirmam que "se verificou ser intelectualmente mais vantajoso, satisfatório e produtivo considerar os fenômenos do mundo real em termos de suas características comuns, em vez de se concentrar nas diferenças individuais". Isto é, a perspectiva da captura do "todo idêntico" possibilita uma compreensão mais lúcida inclusive das diferenças e das particularidades. 
Em relação aos estudos de comportamentos comuns e a detecção de tendências e comportamentos prospectivos, o geógrafo francês Jean Bastié (1973, p. 52), discorrendo sobre as reflexões de pesquisas em Geografia Humana, afirma que

[...] o estudo geográfico é, por natureza, além das monografias, o estudo de fatos coletivos, isto é, de somas de fatos e comportamentos individuais. $\mathrm{O}$ ato individual é predeterminado, condicionado pelo contexto físico, econômico, social, jurídico ou político no qual o indivíduo se encontra situado? Em caso afirmativo ele é previsível e, por conseguinte, devem poder ser também as adições de atos individuais.

É certo que atos e comportamentos individuais possuem forte influência do meio social, do modo de vida e da conjuntura econômica aos quais estão inseridos ou dos quais são partícipes. Embora se reconheça a eficácia das tendências e prospecções nas ciências sociais, há de se demonstrar as precauções necessárias na adoção da chamada "Lei da Maioria" (BASTIÉ, 1973, p. 53). Existem situações diversas onde, embora os padrões gráficos de fenômenos sociais materializem-se em histogramas normais, detectam-se os chamados "pontos fora da curva" - situações minoritárias, porém, muito recorrentes e interessantes.

Para fundamentar as situações humanas fora do espectro da "Lei da Maioria", Bastié (1973) apresenta ressalvas em relação à questão da previsibilidade dos comportamentos humanos em função da constituição do rol de fatores determinantes nos processos de escolhas individuais. Sob este aspecto, este autor afirma que

[...] os homens não se decidem sempre segundo critérios de racionalidade ou rentabilidade? Vide os tabus religiosos! Em situações aparentemente semelhantes, o dinamismo desigual dos homens, a existência ou não de fortes personalidades não darão resultados diferentes dos quais alguns mesmo imprevisíveis [...] (BASTIÉ, 1973, p. 53).

Conforme o exposto, parece existir uma "força de inércia" comportamental de cunho coletivo. Igualmente, existem individualidades autênticas, que fundamentam, justificam e comportam as exceções aos padrões de escolha ou aos modos de vida dominantes. Bastié (1973, p. 53), arrematando o debate acerca de generalidade versus individualidade, sob o olhar da metodologia e da veracidade da abordagem científica em ciências humanas, afirma que "não existem dois indivíduos iguais e isto não impede a Anatomia, a Fisiologia, a Medicina e mesmo a Psicologia de progredirem”.

Uma acepção teórica contemporânea mais equilibrada buscaria saber até que ponto as inter-relações dos processos e fenômenos gerais produzem e alteram as individualidades 
sociais; ou até que ponto as individualidades sociais adensadas local ou regionalmente sobrevivem à hegemonia da maioria. Existem interdependências e respostas de aspectos gerais em relação aos específicos, e de específicos em relação aos gerais, pois, a racionalidade humana, suas crenças e sua força transformadora atuam de forma orgânica. Este é um dilema ainda a ser melhor esclarecido.

Atentando-se especificamente nas questões que fundamentam os modelos, é possível afirmar que eles emergem como instrumento do método científico aplicável a quaisquer ramos do conhecimento científico e, como tal, possuem natureza exploratória sujeita a comprovação empírica.

Acerca dos requisitos básicos que um modelo deve preencher, Minshull apud Christofolletti (1982, p. 70, grifo nosso) aponta que este deve ser em primeiro lugar "uma representação da estrutura, dos elementos do sistema; em segundo lugar ser uma descrição de como o sistema funciona, de como os elementos interagem, e em terceiro ser uma explicação suficiente e necessária do sistema e de seu funcionamento".

Apesar de existir várias acepções ao conceito de modelo, bem como diversos tipos de uso, Grigg (1973, p. 32) simplifica a questão ao afirmar que “o uso de modelos não é mais do que uma maneira de pensar" o mundo real. Para aquele autor, a realidade pode ser abstraída/concebida, identificada, controlada, analisada a partir da metodologia do "modelo regional". O modelo regional apresenta-se como um contundente instrumental teórico a serviço da ciência geográfica.

Para Grigg (1973), todas as regiões são modelos, pois se baseiam na seleção quanto à natureza e abrangência das coisas. Um sistema regional não se pode apoiar em todas as propriedades possíveis das coisas regionalizadas. Com efeito, este autor enumera os seguintes tipos de "modelo regional" ou de "modelo de região" identificados ou possíveis, quais sejam:

- "Regiões como abstrações da realidade" - isto é, manifestações espaciais de fenômenos cotidianos;

- "Regiões como sistemas isomórficos" - i.e., manifestações espaciais idealizadas dedutivamente;

- "Regiões como modelos controlados" - i.e., manifestações espaciais de variáveis manejáveis;

- "Regiões como base analítica" - i.e., manifestações espaciais identificadas a partir da escolha de características-chaves (GRIGG, 1973, p. 32).

Por sua vez, a natureza dos modelos, ou seja, as características intrínsecas que os fundamentam, pressupõe, segundo Chorley e Haggett (1975): 
1) a necessidade de idealização (sentido abstrato/idealizante);

2) o caráter seletivo das informações (escolha de dados);

3) a perspectiva sugestiva (possibilidade de generalizações); e

4) as faculdades de reaplicação (utilização em outra localidade ou em situação análoga).

O modelo, enquanto procedimento, é parte de uma metodologia científica aplicada. Acerca dos modelos regionais, interessante contribuição oferta Anuchin (1973, p. 57, grifo nosso) ao afirmar que

[...] regional modelling as a method of investigation is certainly not new, and has been applied in geography more and less from its inception, often by means of the mapping of information. But every regional modelling presupposes a preliminary qualitative study in order to select the most important data and to formalize them correctly.

Isto posto, a construção de modelos regionais é precedida pela escolha de certos tipos de dados para posteriores análises e interpretações. Para Anuchin (1973), a análise qualitativa precede a escolha dos dados quantitativos, que somente a reforça e dela é derivado. Da seleção de informações (dados) resultarão dados quantitativos que formatarão a modelagem espacial. $\mathrm{Na}$ verdade, inexiste antagonismo entre dados quantitativos e qualitativos. As complementaridades possuem maior campo de força do que as eventuais contradições.

A questão da modelagem enquanto ferramenta conceitual de entendimento da realidade possui severa importância, pois, em geral, "contemporary geographical problem is to a considerable degree based on the use of a whole system of models (graphical schemes, maps, geographical matrices etc.)" (ANUCHIN, 1973, p. 58). Anuchin (1973) destaca, ainda, o amplo uso de modelos sintéticos de sistemas de forças produtivas regionais como um exemplo prático da Geografia Regional.

Em termos de classificação, Grigg (1970) assevera que os modelos podem ser "descritivos ou normativos", "estáticos ou dinâmicos", "simbólicos/conceituais” ou "materiais/experimentais".

É preciso atentar-se que, embora muitos desconheçam o cerne - o espírito do conceito "modelo", ele é por demais utilizado em descrições e intervenções de políticas públicas de gestão territorial como forma de restrição do uso do solo ou para imposição de contingenciamento do usufruto de recursos naturais. São exemplos de modelos no Brasil diversos territórios ou espaços de usos espaciais ou sujeitos à legislação própria ou com 
manejo próprio, tais como: áreas militares, terras indígenas, terras quilombolas, unidades de conservação, polígonos de irrigação, regiões metropolitanas, zona de fronteira, zona econômica exclusiva marítima, zona franca, Regiões Integradas de Desenvolvimento (RIDEs), polígono de outorga minerária, faixas de domínio, faixas de servidão, dentre outros.

Para a Geografia, enquanto ciência de abordagem das implicâncias das técnicas e ações humanas sobre e a partir de um substrato territorial da natureza, os modelos tornam-se recortes necessários em função da necessidade da particularização e/ou da individualização dos objetos de estudos.

Para a corrente da Geografia denominada de Nova Geografia (NG), surgida após a $2^{\mathrm{a}}$ Grande Guerra, a modelagem constitui-se, ao lado de outros aspectos metodológicos, como uma das técnicas que fundamentam sua abordagem teórica. Uma extensa produção de artigos por parte de seguidores da NG veio a público, onde se ressaltou o papel dos modelos no âmbito da "revolução metodológica" ocorrida na ciência.

Neste sentido, destacam-se como emblemáticos os seguintes textos: New Geography as General Spatial Systems Theory: old social physics writ large?, de W. Warntz (1973); Regiões, Modelos e Classes, de D. Grigg (1973); Modelos de Desenvolvimento Econômico, de D. E. Keeble (1975); Modelos de Localização Industrial, de F. E. Ian Hamilton (1975); O Uso de Modelos em Ciências, de F. H. George (1975), entre outros. Estes são exemplos de como os modelos constituem robusta metodologia para a abordagem científica nas humanidades, quebrando a falsa dicotomia, já superada, da exclusividade do método científico pelas ciências da natureza.

Embora a ciência geográfica não apresente um consenso sobre seu objeto de investigação, é possível considerar a região como o modelo de recorte geográfico basilar. Independente da clivagem de abordagem, existe a compulsória necessidade da delimitação espacial e temporal do objeto de estudo. Invariavelmente, ao recorte espacial poderá ser dado o nome de região ( $x, y$ ou $z$ ), conforme a característica latente que o identifica, ou seja, que lhe dá forma e função.

É claro que a força de agentes econômicos, tais como: corporações empresariais, meios de comunicação ou o Estado (através da institucionalização de recortes territoriais legais), acaba por sobressair na relevância social das definições das regiões.

A este respeito, Bezzi (2004, p. 22) afirma que

[...] o conceito de região tem um forte caráter político e ideológico" ao verificar que em "diversas abordagens, o papel do Estado como agente de 
regionalização, ou seja, como ele organiza, rearranja ou desorganiza os recortes regionais de acordo com a ótica do capital, do poder e da sociedade.

Haverá tantas regiões para quantos forem aqueles que a identifiquem, que a caracterizem ou que a delimitem. Região é um conceito simbólico, socialmente construído, de livre demarcação; é o modelo geográfico originário. Não há Geografia sem região, bem como, não existe Biologia sem a vida ou a História sem o tempo.

Porém, convém destacar que no âmbito da interface "ciência-planejamento", apesar de se reconhecer a existência de "livres demarcações regionais", a institucionalização das fronteiras das regiões decorrem de minuciosos estudos técnicos de visão prospectiva (estratégica). No planejamento científico regional, a busca por uma equilibrada construção de uma organização espacial deve ser precedida por compromissos técnicos objetivos que almejam a intervenção, onde os valores sociais democráticos do Estado de Direito sejam observados, bem como as restrições do ambiente natural.

Assim, as fronteiras criadas pelas regionalizações são sobremaneira ações antrópicas, ou seja, ações de natureza política, embora se identifiquem os limites fisiográficos inerentes às regiões biogeográficas ou aos chamados “domínios morfoclimáticos” regionais.

Observando o aspecto epistemológico, a perspectiva da fronteira, do limite, do padrão paisagístico, do domínio, isto é, da regere (região) em sua essência etimológica, produz sustentação teórica para a Geografia enquanto ramo científico. Para Allix apud Christofoletti (1982, p. 15), “o estudo regional é a mais completa expressão do método geográfico”.

Sobre este assunto, importante contribuição oferta Paulo C. Gomes (2008, p. 53) ao afirmar que

[...] na linguagem cotidiana do senso comum, a noção de região parece existir relacionada a dois princípios fundamentais: o de localização e o de extensão. Ela pode assim ser empregada como uma referência associada à localização e a extensão de certo fato ou fenômeno, ou ser ainda uma referência a limites mais ou menos atribuídos à diversidade espacial.

Ademais, acerca dos princípios que fundamentam o conceito de região, pode o "domínio" também constituir fundamento basilar aos princípios deste conceito. Para Gomes (2011, p. 54), o domínio definidor de uma região constitui-se "por uma regularidade de propriedades que a definem". Pode-se afirmar que o princípio do domínio, ou mesmo, do predomínio, dá a determinada localidade uma "personalidade, uma forma de ser diferente e particular" (GOMES, 2011, p. 56). 
Os domínios morfoclimáticos elaborados pelo professor Aziz N. Ab’Sáber para a definição das regiões fisiogeográficas do Brasil é um bom exemplo de como as propriedades regulares constroem também uma identidade natural das regiões. Ab’Saber elaborou o conceito de domínio morfoclimático ${ }^{1}$ para esclarecer a interação entre vegetação, clima, solo e formas de relevo.

A região, como conceito e modelo geográfico de análise, contribui inequivocamente para a evolução dos estudos da ciência geográfica. Dentre os conceitos geográficos mais utilizados, o de região possui singular relevância por sua enorme difusão dentre ciências naturais, humanas ou no âmago do ideário popular.

Apesar do enorme uso por outras ciências do conceito "região", certas correntes do pensamento geográfico são ainda resistentes com a utilização deste. Com isso, empregam, para indicar abrangências de distribuição horizontal de fenômenos sociais ou físicos, terminologias, tais como: "delimitação espacial", "abrangência espacial", "território de ação", “domínio”, “zonas”, “áreas” etc.

A magnitude e a força do conceito de região sustentam explicações da espacialização de quaisquer abordagens, às quais dão às territorialidades humanas uma identidade nominável. Os limites parecem se tornar uma necessidade explicativa. A Geografia clássica, por alguns autores também denominada "tradicional", trouxe importantes contribuições à perspectiva dos estudos de unidades de paisagens homogêneas.

Neste sentido, o conceito de região como uma representação advinda da percepção paisagística natural se transformou em modelo analítico de fenômenos sociais e, por conseguinte, em possibilidade de modelo de intervenção.

Porém, as modelagens regionais para intervenção é temática que vem sendo negligenciada pelo pensamento geográfico contemporâneo brasileiro, cujo alinhamento teórico-ideológico inclina-se aos conceitos e instrumentos metodológicos da chamada Geografia Crítica - que possui, sobremaneira, apenas um viés analítico. As "possibilidades de intervenção" poderiam dar outro ânimo à ciência geográfica, mas esbarram em questões doutrinárias e de interpretação paradigmática de correntes majoritárias de pensamento.

Outras ciências sociais, como, por exemplo, a Sociologia e a Economia, adentram com desenvoltura no campo que poderia ser de notória responsabilidade da Geografia. Logo, em se tratando de Brasil, elas inclusive vêm ocupando posições de destaque em autarquias ou órgãos governamentais, como, por exemplo, no Instituto Brasileiro de Geografia e Estatística

\footnotetext{
${ }^{1}$ AB'SÁBER, Aziz N. Os domínios de natureza no Brasil: potencialidades paisagísticas. São Paulo: Ateliê
} Editorial, 2003. 
(IBGE), no Instituto Nacional de Colonização e Reforma Agrária (INCRA), no Departamento Nacional de Obras Contra a Seca (DNOCS), na Fundação Nacional do Índio (FUNAI) e nas Secretarias Estaduais de Planejamento. Nestas frações do Estado, a priori, os geógrafos deveriam assumir uma posição de destaque.

Cabe salientar que a Geografia, por sua natureza racional, histórica e sintetizadora, é uma ferramenta de poder, e a região é um instrumental técnico modelar a esta finalidade. Inexiste Geografia onde está ausente um cenário de forças pela partilha e usufruto da natureza e do que socialmente é produzido a partir dela.

A região, assim, é um conceito central para a ciência geográfica do ponto de vista da perspectiva "representação $\rightarrow$ modelos $\rightarrow$ intervenção" materializado na escolha de um determinado recorte espacial temático selecionado. As ações de intervenções traduzem-se nas ações do planejamento territorial.

Acerca da região, enquanto conceito, e da regionalização, enquanto sistema de ação e de intervenções, Haesbaert (2010, p. 4), afirma que

[...] numa analogia com a História, podemos afirmar que, correspondendo aproximadamente ao que representa a periodização como questão central para os historiadores, a regionalização aparece como uma problemática central para os geógrafos.

Este autor acrescenta ao afirmar que "tanto uma região, enquanto espaço efetivamente construído e diferenciado, como a ideia de região são, sem dúvida, criações históricas" (HAESBAERT, 2010, p. 8). A trajetória da construção da Geografia moderna indica que o conceito de região passou por transformações evolutivas, conforme as contribuições e influências das escolas do pensamento geográfico.

É interessante observar o caráter uniformizador intrínseco e o sentido imaginário que o conceito de região traz em si. O termo "região" é, sobretudo, um discurso, uma intencionalidade na busca por enquadramentos e categorizações de lugares e territorialidades. Neste sentido, Albuquerque Júnior (1999, p. 24) aponta que “a região não é uma unidade que contém uma diversidade, mas é produto de uma operação de homogeneização que se dá na luta com as forças que dominam outros espaços regionais, por isso ela é aberta, móvel e atravessada por diferentes relações de poder". 


\section{A NOVA GEOGRAFIA: GEOGRAFIA APLICADA E O \\ PLANEJAMENTO}

\subsection{A CONJUNTURA DO SURGIMENTO DA NOVA GEOGRAFIA}

A existência de escolas de pensamento ou de linhas teóricas é fato comum em todos os domínios da ciência, em função dos processos próprios da evolução do conhecimento, da especialização do objeto de estudo e da tecnificação metodológica. A grande difusão de conhecimentos no século XX é outro fator que colaborou com o surgimento de novas tendências nas ciências.

A segunda metade do século XX - período conhecido como pós-guerra - caracterizouse pela intensificação dos fluxos de mercadorias e pela sofisticação dos meios de transporte e comunicação. Além disso, trata-se de um período de germinação do que ainda seria denominado de revolução da informática.

As grandes mudanças técnico-científicas do período pós-guerra foram impulsionadas pelo surgimento de novos campos de conhecimento, bem como de novas correntes de pensamentos nas ciências já existentes. Paradoxalmente, os conflitos militares em âmbito mundial, que marcaram negativamente a história do século $\mathrm{XX}$, propiciaram a difusão e a efervescência de saberes.

Em se tratando de ciências sociais, por decorrência das características intrínsecas de objeto de estudo e dos seus aspectos metodológicos, o fenômeno da difusão de escolas de pensamento também foi característica marcante no período. Um bom exemplo deste seccionamento nas ciências sociais ocorreu na Antropologia, com as vertentes de pensamento funcionalista e estruturalista ${ }^{2}$, que vieram em contraposição aos estudos etnográficos de cunho evolucionista. As duas grandes correntes de pensamento da Sociologia também receberam a nomenclatura funcionalista e estruturalista, apesar de serem teoricamente distintas do que representam suas homonônimas na Antropologia.

A situação da ciência geográfica, no âmbito do século XX, seguiu também a tendência da difusão de abordagens, pois existiram valiosas contribuições da Geografia política ou da Geopolítica, da Geografia comportamental, da Nova Geografia (NG) (especialmente aquela de corte "teorético-quantitativo" - aqui denominada de Geografia Modelo-Teórica - GMT) e da Geografia crítica. Todas trouxeram enorme efervescência acadêmica e dinamismo aos

\footnotetext{
${ }^{2}$ LÉVI-STRAUSS, Claude. Antropologia estrutural. Rio de Janeiro: Tempo Brasileiro, 1985.
} 
circuitos de pensamento governamentais e/ou corporativos onde os geógrafos atuavam. As ciências, em geral, refletem o nível de agitação intelectual e cultural do período histórico no qual se encontram.

De todas as escolas de pensamento da Geografia, cabe maior destaque às características e contribuições trazidas pela chamada NG ou Geografia Teorética e Quantitativa (GTQ). Esta escola de pensamento - aqui denominada de GMT - representou um grande salto metodológico à ciência ao aperfeiçoar a tecnificação do conhecimento geográfico inserindo as contribuições da Estatística e da Matemática, a apresentação de modelos explicativos da realidade geográfica para melhor se compreender os fenômenos espacializados, além de expor uma abordagem por meio da teoria de sistemas. A referida escola de pensamento geográfico possui como um dos cernes filosófico-metodológicos a busca por um enquadramento maior da Geografia ao método científico.

A História da GTQ possui alguns marcos de produção teórica que marcam a gênese desta corrente. Para o geógrafo Antônio Christofoletti (1982, p. 73), um dos maiores expoentes brasileiros desta corrente de pensamento, "a contribuição de Fred K. Schaefer, em 1953, sobre Exceptionalism in Geography: a Methodological Examination, marca cronologicamente a tomada de consciência dessas tendências renovadoras".

Acerca do núcleo originário da GTQ em relação às cátedras universitárias, aquele autor afirma que ela surgiu em meados dos anos cinqüenta de "grupos de geógrafos sediados em Washington e Chicago" (CHRISTOFOLETTI, 1982, p. 73).

Em relação à gênese das nomenclaturas recebidas pela GTQ, Christofoletti (1982) afirma ainda que a denominação "Nova Geografia - NG" foi inicialmente proposta pelo geógrafo inglês David Manley, em 1966, que considerou as novas abordagens metodológicas em curso desde os anos 1950 uma inovação. Este autor assevera ainda, que a denominação "Geografia Teorética e Quantitativa" deriva da nomenclatura apresentada pelo geógrafo Ian Burton, em 1963, ao se referir à ocorrência de uma "revolução quantitativa e teorética da Geografia" (CHRISTOFOLETTI, 1982, p. 73).

Embora seja sabido que o cenário de difusão de produção e informações geográficas tenha ocorrido no pós-guerra, dado a conjuntura geral e de ebulição no pensamento geográfico, que culminou na constituição da NG como corrente de pensamento científico, merecem destaques alguns notórios trabalhos desenvolvidos pela Geografia Aplicada nos Estados Unidos da América (EUA) e na Alemanha, ainda na década de 1930. 
Nos EUA, de acordo com o professor Ronald Boyce (2004), da Seattle Pacific University, os geógrafos tiveram, inicialmente, importante papel na concepção e implementação do projeto de desenvolvimento do Vale do Rio Tennessee, levado a cabo a partir de 1933 pela Tennessee Valley Autorithy (TVA) ${ }^{3}$ - autarquia federal criada para gerenciar as políticas públicas de desenvolvimento de uma região à época deprimida. $\mathrm{O}$ projeto de desenvolvimento do Tennessee foi o "maior, mais abrangente e mais controverso projeto de planejamento regional e de desenvolvimento realizado na história norte-americana" (BOYCE, 2004, p. 23).

No entanto, em função das questões ideológicas e culturais que permearam o cenário de conflitos da $2^{\circ}$ Grande Guerra e, apesar da continuidade das ações gerais da TVA, os trabalhos de planejamento regional foram abandonados a partir de 1938, e a palavra "plano" passou a ser evitada naquela autarquia em um contexto em que os geógrafos passaram a ser vistos como profissionais de segunda classe (BOYCE, 2004). Muitos geógrafos saíram do projeto. A atuação dos geógrafos passou, então, a centrar-se na produção de mapas de suscetibilidade de erosão do solo, estudos de áreas para recreação e lazer, levantamento de dados sistemáticos, estudos de economia rural etc.

Por sua vez, a grande contribuição alemã no campo da Geografia pragmática foi a apresentação da Teoria dos Lugares Centrais (TLC) ${ }^{4}$ pelo geógrafo Walter Christaller em 1933. Sua teoria apontou a existência de uma hierarquia na atuação espacial da oferta de bens e serviços disponíveis em relação às redes urbanas, o que implica na constatação de que algumas cidades, mais que outras, constituem-se como localidades centrais, impondo às circunvizinhas de mercado menor uma razão de polaridade.

A TLC foi resgatada a partir dos anos 1950 e 1960 nos EUA por meio das pesquisas de Geografia de mercado, entre as quais se destacam as de Brian Berry (1967), que cunhou o conceito de "sistemas de lugares centrais" no comércio a varejo. A base de dados dos trabalhos de Berry sobre a geometria da distribuição do comércio de varejo foi obtida em pesquisas realizadas no Estado norte-americano de Iowa.

Em âmbito nacional, a produção científica da Geografia Aplicada e da GTQ ficou muito concentrada no Instituto Brasileiro de Geografia e Estatística (IBGE), que realizou

\footnotetext{
${ }^{3}$ A Tennessee Valley Autorithy (TVA) é ainda uma agência de desenvolvimento que faz parte da estrutura governamental do Governo dos Estados Unidos da América (EUA). Esta agência foi uma das referências de modelos de autarquia para a criação da Superintendência de Desenvolvimento do Nordeste (SUDENE) no Brasil.Cf. TENNESSEE VALLEY AUTORITHY - TVA. Disponível em: 〈http://www.tva.gov>. Acesso em: 23 dezembro 2014.

${ }^{4}$ A Teoria dos Lugares Centrais (TLC) será detalhada no Capítulo 3.
} 
várias cooperações técnicas com instituições de ensino e pesquisa dos EUA e do Reino Unido. Assim, a proximidade filosófica da tradição da Geografia francesa foi rompida. A produção do IBGE foi de grande robustez teórica e de alto valor conceitual e sua divulgação foi concentrada, entre outros meios, na Revista Brasileira de Geografia (RBG), que foi editada entre 1938 e 1996. Em 2005, sua produção foi retomada, mas em 2006 foi novamente encerrada.

Em contraponto, as produções científicas dos Departamentos de Geografia das universidades brasileiras apresentaram pouco alinhamento metodológico-filosófico com a GTQ. Nas universidades, por questões de posicionamentos ideológicos, crescia o número de adeptos da chamada Geografia Crítica, cuja produção apontava constatações de problemas sociais do desenvolvimento, mas sem a devida contundência metodológica ${ }^{5}$.

Da produção dos Departamentos de Geografia das universidades alinhadas à GTQ destacou-se a então chamada Faculdade de Filosofia, Ciências e Letras de Rio Claro (atual Universidade Estadual Paulista "Julio de Mesquita Filho" - UNESP, campus Rio Claro), que se tornou uma referência brasileira neste tipo de fazer/saber geográfico. Inclusive, a partir da expertise formada nesta Universidade foi criada a Associação de Geografia Teorética e o Boletim de Geografia Teórica (ambos em 1971), como veículos de divulgação científica.

Adentrando especificamente na abordagem teórica da GTQ, é preciso salientar que ela foi dirigida, sobretudo, aos estudos e diagnósticos de fenômenos sociais e econômicos diversos, uma vez que apresentou um rigor metodológico de pesquisa ausente nos diversos segmentos anteriores da geografia humana. Os vários segmentos da chamada Geografia física já comungavam dos pressupostos metodológicos das ciências da natureza, que são indiscutivelmente pacíficos enquanto método científico. Porém, na Geografia humana, aspectos relacionados ao rigor do método científico foram fortalecidos neste contexto de debates e mudanças.

A priorização da abordagem da GTQ aos temas e fenômenos de natureza econômica e social também ficou conhecida como "escola locacional" (FAISSOL, 1978), pois correlacionou as interações da métrica das distâncias a outros fenômenos, dando-lhes uma racionalidade e até mesmo apresentando perspectivas de comportamentos futuros e/ou apreensão de tendências.

Neste sentido, Capel e Urteaga (1982, p. 28) apontam que esta corrente da Geografia "dirigirá una atención preferente a los problemas de orden socioeconómico", cujos "temas

\footnotetext{
${ }^{5}$ A massificação da Geografia Crítica no meio acadêmico e sua fragilidade teórico-metodológica estão entre as causas de má formação profissional dos geógrafos brasileiros.
} 
locacionales" representaram uma preocupação constante, ofertando a abertura de novas frentes de investigação.

A focalização da GTQ aos temas de natureza socioeconômica acabou por aproximá-la de outros ramos do conhecimento científico, em especial, da Economia, da Sociologia e da Estatística, o que produziu uma abordagem interdisciplinar e, até mesmo, uma sobreposição de campos de atuação profissional. A Filosofia, enquanto fundamento pretérito ao conhecimento de natureza científica, é outra fonte de conhecimento da qual a GTQ também se utilizou como meio de fundamentar seus postulados teóricos. É costume salientar que fundamentos científicos são, antes de tudo, fundamentos de natureza lógico-positivos.

Corroborando com a observação de que a GTQ possuiu uma perspectiva interdisciplinar, Geiger (1970, p. 69) afirma que

[...] o processo de desenvolvimento do emprêgo da linguagem matemática, paralelo ao desenvolvimento de novas sistematizações do conhecimento, vem ocorrendo em outras ciências sociais, seja a psicologia, seja a economia (que, aliás precederam a geografia neste desenvolvimento). Ao mesmo tempo, observa-se a acentuação do contato interdisciplinar e a tendência à uma abordagem interdisciplinar quanto a tudo que diz respeito à atividade humana. A renovação atual no campo da geografia é, pois, extremamente influenciada pelos contatos que se estabeleceram entre ela e outra ciências.

Ao aprofundar as nuances metodológicas da GTQ, é possível observar que apesar da complexa maneira com que são formados e distribuídos os fenômenos espaciais, existem padrões a serem identificados. Acerca da distribuição dos fenômenos espaciais, Capel e Urteaga (1982, p. 28) sentencia que "existe un orden que permite explicarlos".

\subsection{CARACTERÍSTICAS ELEMENTARES DA "NOVA GEOGRAFIA" (GEOGRAFIA TEORÉTICA E QUANTITATIVA OU GEOGRAFIA "MODELO-TEÓRICA")}

Em relação às características da GTQ, Christofoletti (1982) aponta 05 (cinco) metas básicas que delineiam metodologicamente sua abordagem, quais sejam:

1) rigor maior na aplicação da metodologia científica;

2) desenvolvimento de teorias;

3) uso de técnicas estatísticas e matemáticas;

4) abordagem sistêmica; e

5) o uso de modelos. 
O "rigor maior na aplicação da metodologia científica" tem por base 02 (dois) postulados da filosofia do Positivismo lógico, a saber: 1) controle de enunciados; e, 2) verificação de hipóteses. Neste sentido, a metodologia científica passa a ser considerada como um paradigma para a pesquisa geográfica, o que impõe a busca pelo estabelecimento de predições ou tendências.

Acerca das predições e do estudo de tendências, Christofoletti (1982, p. 17, grifo nosso) afirma que "o resultado do trabalho geográfico deve ser capaz de prever o estado $\underline{\text { futuro dos sistemas de organização espacial e contribuir de modo efetivo para alcançar o }}$ estado mais condizente e apto para as necessidades humanas".

Em relação ao "desenvolvimento de teorias", a NG buscou superar a lacuna existente na Geografia tradicional e efetivamente estimulou o desenvolvimento de teorias relacionadas mormente às questões de distribuição, localização e hierarquias de eventos. Os estudos dos padrões de distribuição espacial dos fenômenos fundamentaram a formulação de teorias acerca das organizações espaciais.

O "uso das técnicas estatísticas e matemáticas" pode ser considerado uma das características mais visíveis, e que culminou inclusive na adjetivação "Geografia Quantitativa". As técnicas matemáticas e estatísticas tiveram como base a produção de informações (os dados espaciais da análise), que serviram como ferramentas para análises seriais e multivariadas.

Faz-se importante salientar que o uso de linguagens estatísticas e matemáticas tinha por objetivo enquadrar a Geografia em postulados metodológicos de ordem científica. Neste sentido, torna-se necessário "destacar alguns aspectos que a quantificação levantou na análise geográfica: o da precisão e o da especificação, propriedades necessárias a qualquer ramo científico" (FAISSOL, 1978, p. 32).

Por sua vez, a "abordagem sistêmica" desta corrente geográfica teve como função metodológica e conceitual o tratamento das informações, enquadrando-as como "conjuntos complexos". A teoria dos sistemas auxilia o pesquisador a compreender a interdependência do rol de variáveis intervenientes nos fenômenos. Para Christoffoletti (1982, p. 19), "a aplicação da teoria de sistemas aos estudos geográficos serviu para melhor focalizar as pesquisas e delinear com maior exatidão o setor de estudo desta ciência, além de propiciar oportunidade para considerações críticas de muitos dos seus conceitos".

Já a questão do "uso de modelos" relaciona-se com a construção e uso de esquemas 
interativos conceituais, os quais, além de oportunizarem a verificação de teorias, dão margem à aplicação dos métodos quantitativos e operacionalizam a visualização da abordagem sistêmica em formato simplificado e reduzido.

Independentemente do alinhamento de corrente do fazer geográfico, ficou inequívoco que a New Geography ${ }^{6}$ representou a maior "revolução metodológica" que a ciência geográfica conheceu em sua história. No Brasil, contudo, poucos compreenderam sua contundência teórica e robustez científica.

As 05 (cinco) características apresentadas por Christofoletti em relação à GTQ representam uma definição eminentemente "metodológica", ou seja, do "como fazer" ou "da operacionalidade" do conhecimento geográfico. Sem a menor dúvida, uma forma segura de se conhecer um objeto é ir em busca de suas características; nas ciências, esta forma seria atingida por meio da busca das características do que a mesma produziu, observando-se tanto aspectos metodológicos, quanto aspectos de natureza ontológica.

Às características metodológicas, vale acrescentar um aspecto fundamental desta corrente de pensamento na clarificação do objeto da ciência geográfica. Neste sentido, a GTQ entendeu que a Geografia possui um objeto de estudo definido, que é, ou melhor, que são as “organizações espaciais" (FAISSOL, 1978; CHRISTOFOLETTI, 1982) ou "sistemas espaciais" (BERRY, 1967).

Interessante notar que o termo "espaço" e suas variantes, como, por exemplo, espaço geográfico e organização espacial, foram bastante difundidas com a GTQ no mundo acadêmico e institucional. Atualmente, diversos trabalhos de múltiplas correntes de pensamento (inclusive na Geografia Crítica) apresentam quase que "naturalmente" terminologias derivadas do conceito "espaço" como linguagem analítica, apesar da ocorrência de debates acerca de aspectos epistemológicos que se refletem no uso destes conceitos.

Portanto, ao se transversalizar às múltiplas correntes de pensamento, as novas linguagens e metodologias trazidas pela GTQ passou a ter abrangência mais plural no mundo acadêmico.

\subsection{PERSPECTIVA IDIOGRÁFICA E A PERSPECTIVA NOMOTÉTICA}

Os novos aspectos metodológicos trazidos pela GTQ consolidaram uma clivagem de perspectivas de abordagem teórica que se encontra em debate desde a gênese da Geografia

\footnotetext{
${ }^{6}$ Nome da Geografia Teorética-Quantitativa (GTQ) nos países anglo-saxões.
} 
enquanto conhecimento científico: a perspectiva idiográfica ${ }^{7}$ e a perspectiva nomotética.

Por perspectiva idiográfica entende-se a abordagem de pesquisa que compreende os acontecimentos como únicos, ou seja, a descrição da paisagem, do mundo real, teria um caráter sui generis para cada lugar e não se replicaria. A Geografia regional francesa, com seu descritivismo no estudo de paisagens, é um bom exemplo de como esse gênero de raciocínio também se verificou no pensamento geográfico.

Por sua vez, a perspectiva nomotética compreende a abordagem que salienta a generalização, recorrência e identificação de um ordenamento ou de um tipo de regularidade de fenômenos independentes do tempo e do espaço - o que favoreceria uma espécie de abordagem para identificação de lógicas, ordenações e padrões.

Para esta perspectiva, fato individual constitui-se como um exemplo entre vários outros no "rol de semelhantes" e "o que importa em seu estudo são as condições e aspectos semelhantes com as condições gerais, e não as particularidades únicas" (CHRISTOFOLETTI, 1982, p. 82).

Quadro 2.1 - Perspectiva idiográfica e nomotética da pesquisa geográfica.

\begin{tabular}{|l|l|l|}
\hline \multicolumn{2}{|c|}{ Diferenciação de Perspectivas Metodológicas na Ciência Geográfica } \\
\hline \multicolumn{1}{|c|}{ Aspectos } & \multicolumn{1}{c|}{ Idiográfica } & \multicolumn{1}{c|}{ Nomotética } \\
\hline Abordagem & Singularidades & Aspectos Gerais \\
\hline Conhecimento & Especializados & Generalizados \\
\hline Escala de Estudo & Local & Regional/Global \\
\hline Tipo de Estudo & Estudo de Caso & Teóricos/Modelares \\
\hline Procedimento Argumentativo & Descrição & Modelagens e Quantificação \\
\hline Método Prioritário & Indutivo & Dedutivo \\
\hline Replicação do Conhecimento & Baixa & Alta \\
\hline Intenção Preditiva & Baixa & Alta \\
\hline Temporalidade & Entende o Presente & Visão Prospectiva \\
\hline Foco Interpretativo & Interpretação Histórica & Interpretação Funcional \\
\hline
\end{tabular}

Fonte: Do autor.

Evidentemente, a GTQ adotou um viés de abordagem metodológica muito mais próximo à perspectiva nomotética da ciência geográfica, do que da perspectiva idiográfica.

\footnotetext{
7 Apesar da expressão linguisticamente correta ser "idíografia" (posto que remete a uma análise científica de casos individuais), alguns autores brasileiros (tais como Speridião Faissol, 1978, e Antonio Christofoletti, 1982) se basearam ou realizaram de fato uma tradução equivocada. Em alguns de seus textos consta a expressão "ide ografia”, que na verdade significa representação imagética de uma idéia.
} 
É preciso perceber que a identificação da perspectiva idiográfica e nomotética não implicam na identificação de uma polaridade conceitual ou antagonisno de abordagem de pesquisa. Uma perspectiva não é totalmente excludente à outra, bem como não existe uma clivagem completa entre a Geografia física e Geografia humana. Em verdade, a construção do conhecimento geográfico possui, a depender do objetivo do trabalho, a peculiaridade de se valer, naturalmente, dos raciocínios sintético e analítico. Neste sentido, resta ao pesquisador ser coerente em suas escolhas metodológicas.

No contexto de estudos de abordagens metodológicas, importante contribuição oferta Faissol (1978) ao interpretar as análises locacionais do geógrafo Petter Haggett. Esta interpretação apresentou um modelo-síntese da aplicação de teorias com foco na dimensão escalar, a variância e a replicação de caos à luz dos métodos indutivo e dedutivo, que são intrínsecos às perspectivas idiográficas e nomotéticas.

No modelo-síntese de Haggett, quanto mais aplicados os princípios da teoria dedutiva, maior a abrangência escalar e a replicação de casos, e menor a variância interna dos pressupostos e hipóteses. Contrariamente, quanto mais aplicados os princípios da teoria indutiva, menor a replicação de caos, menor a abrangência escalar e maior a variância interna dos pressupostos e hipóteses.

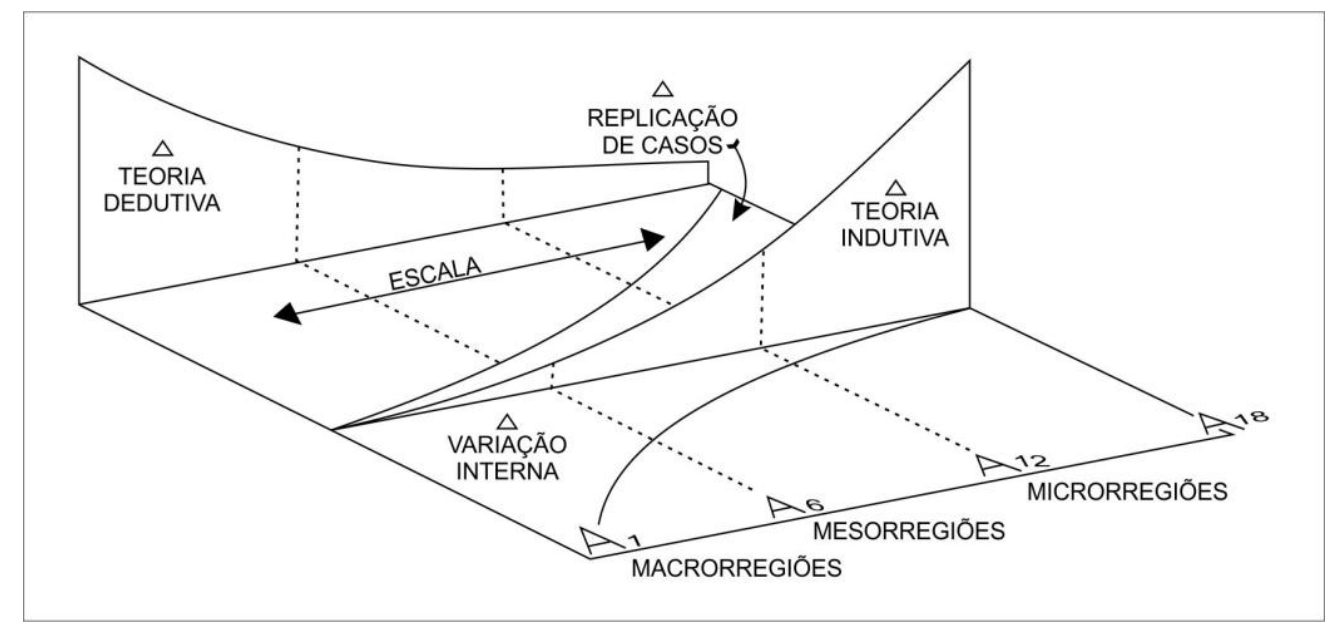

Figura 2.1 - Esquema da inter-relação teoria dedutivo-indutiva, variância, escala e replicação de casos.

Fonte: Faissol (1978, p. 16).

Os trabalhos do tipo "estudos de caso" servem como um bom exemplo de como uma abordagem com um viés inicial "idiográfico" pode, a partir da realização de conexões teóricas, buscar (se detectados padrões a partir da replicação do mesmo método de pesquisa a outras localidades) as ligações com aspectos gerais e comuns.

Entretanto, a GTQ possui a ousadia da busca pela generalidade e aspectos comuns a 
partir da origem. Seu ponto de chegada é a descoberta de estruturas gerais ou de uma ordem comum decorrente de uma base teórica elaborada.

Ademais, as diferenciações entre as perspectivas idiográfica e nomotética elucidam melhor a compreensão do que foi metodologicamente a GTQ, fato este que possibilita externalizar a intenção de se resgatar aspectos desta corrente de pensamento geográfico sob nova abordagem, dada a contundência metodológica da qual utilizara.

Esta nova abordagem, que revigora elementos da GTQ, tem como norte a construção de uma proposta geográfica de cunho "modelo-teórico", pois, se pretende, a partir de "representações abstratas" ou "modelares", analisar a realidade e propor conhecimentos geográficos aplicáveis. Neste aspecto, as bases teóricas elaboradas são insumos estruturantes para esta GMT.

\subsection{ALGUNS EXEMPLOS DE TRABALHOS REALIZADOS SOB A PERSPECTIVA DA NOVA GEOGRAFIA}

A apresentação de exemplos é uma forma elucidativa para a demonstração de trabalhos científicos que foram elaborados no âmbito das concepções da GTQ, uma vez que a complexidade argumentativo-modelar, a fundamentação estatístico-matemática e a busca por uma visão sistêmica não são de compreensão trivial ${ }^{8}$.

Os exemplos, apesar da grandeza conceitual, não serão aprofundados, pois não representam o objeto do presente estudo. Eles servem como referência para fundamentar o papel técnico-científico da GTQ e seus postulados teóricos - os quais voltarão a ser apresentados quando da discussão dos modelos de regiões de ordem interfederativa (de abordagem prevista nos Capítulos 4 e 5 que se seguem).

\subsubsection{O trabalho de William Warntz}

O geógrafo norte-americano William Warntz (1973) aponta que a NG pode ser entendida como uma "teoria geral de sistemas espaciais". Warntz estudou estudou a distribuição espacial da renda dos cidadãos norte-americanos e concluiu que a renda sobe à

\footnotetext{
${ }^{8}$ No Brasil diversos trabalhos fundamentados na Geografia Teorético-Quantitativa foram realizados por entes governamentais como secretarias de planejamento estaduais e por autarquias federais, especialmente nos anos 70; contudo, é provável que muitos dos que os elaboraram não tenham sabido desta filiação epistemológica. Atualmente, os EIAs/RIMAs utilizados no licenciamento ambiental possuem lastro conceitual na Geografia Teorética-Quantitativa.
} 
medida da elevação da concentração espacial de pessoas (densidade demográfica), ou seja, cidades grandes concentram as maiores rendas; por sua vez, as áreas de menor densidade humana, possuem renda menor. Assim como nos aspectos demográficos existe uma densidade que representa um fator de aglomeração; em relação à renda, existe também, uma densidade a qual apresenta uma massa física - "one weights".

Neste trabalho constatou-se a existência de um padrão - uma constante estatística para a explicação da distribuição da renda nos EUA, conforme a densidade de renda por unidades de área, ou seja, tem-se um fator "pressão", similar ao que ocorre na compressão de partículas de gases que são fluidas.

A pesquisa de Warntz chegou a seguinte a equação (2.1):

$$
\mathrm{DA}=\mathrm{PT}
$$

onde:

$\mathrm{D}=$ Densidade de Renda (Income Density);

$\mathrm{A}=$ Área;

$\mathrm{P}=$ População total; e

$\mathrm{T}=$ Renda per capita (per capita income)

A referida equação tomou por base uma analogia com as ciências naturais, precisamente com a equação da Lei dos Gases, de Boyle e Gay-Lussac. É preciso salientar a equação original (2.2), a saber:

$\mathrm{PV}=\mathrm{RT}$

onde:

$\mathrm{P}=$ indica pressão;

$\mathrm{V}=$ indica o volume;

$\mathrm{R}=$ indica a constante de gases; $\mathrm{e}$

$\mathrm{T}=$ temperatura do sistema.

A Figura 2.2, a seguir, sintetiza o resultado da referida pesquisa, que indica a coincidência entre densidade humana e a migração da renda per capita. 


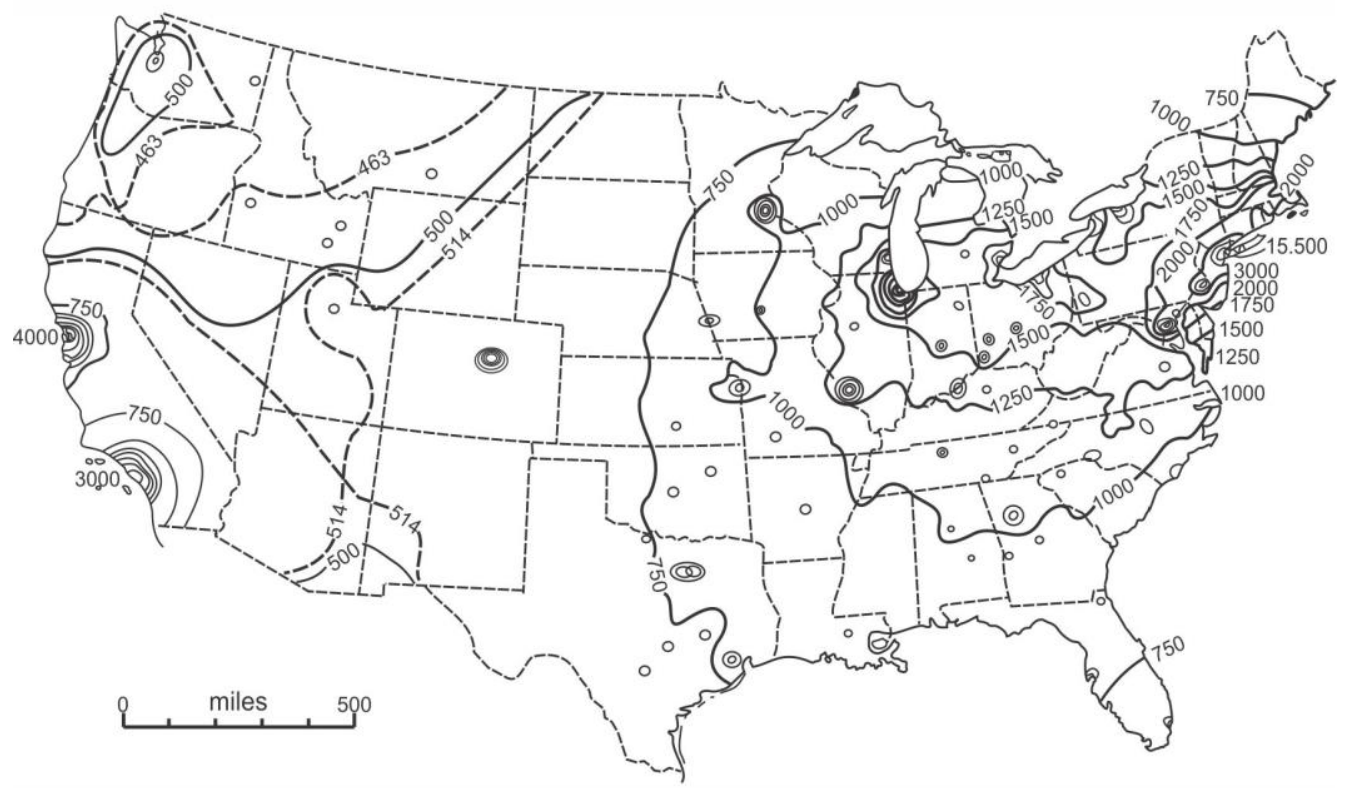

Figura 2.2 - Níveis de renda per capita nos Estados Unidos da América e a densidade populacional. Fonte: Warntz (1973, p. 110).

\subsubsection{O trabalho de Michael F. Dacey}

Outra contribuição importante ao desenvolvimento da GTQ foi dada pelo geógrafo norte-americano Michael F. Dacey - professor da Universidade de Northewestern (Chicago, Illinois, EUA). Ele apresentou estudos sobre padrões de distribuição espacial de fenômenos, por meio do Programa "Mathematical Methods in the Social Sciences" (MMSS).

No trabalho intitulado Some questions about spatial distributions, publicado em 1973, Dacey buscou adaptar modelos estocásticos ${ }^{9}$ aos estudos de distribuição espacial. Mais do que respostas, aquele autor apresentou questionamentos acerca de estudos sobre a morfologia da dispersão espacial de fenômenos, observando, assim, a ocorrência de 03 (três) tipologias de dispersão, quais sejam: 1) diagramas de concentração; 2) diagramas de aleatoriedade; e, 3) diagramas de distribuição regular.

Embora seja sabido que os referidos padrões de distribuição constituem-se como modelos reduzidos da realidade, eles possuem grande significância, pois tratam de uma morfologia espacial de comportamento de variáveis que auxiliam na compreensão de formas, funções e processos espaciais pretéritos, atuais e futuros.

\footnotetext{
${ }^{9}$ Modelos estocásticos são modelos de distribuição aleatória ou casuísticos.
} 

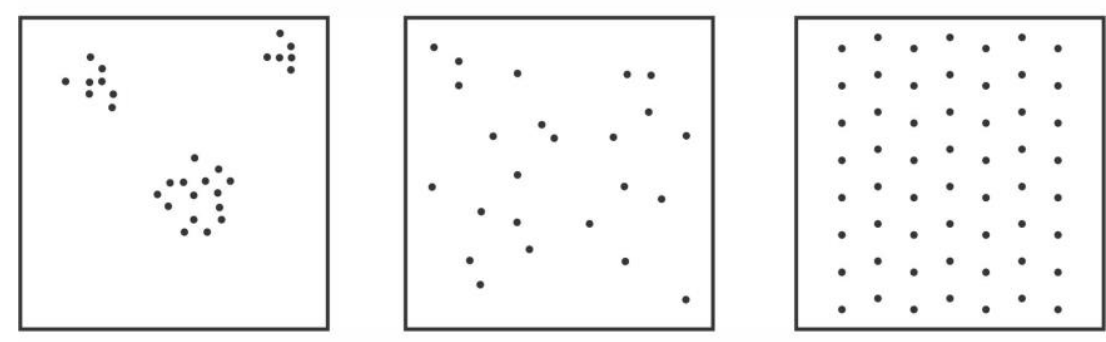

Figura 2.3 - Diagrama de ilustração de Dispersão Espacial (da esquerda para direita): concentração ou clusters, aleatória ou random, e regularidade.

Fonte: Adaptado de Dacey (1973, p. 132).

A respeito da simplificação da realidade por aspectos de distribuição, Dacey (1973, p. 133), afirma categoricamente que "aplications of the continuum hypothesis are highly simplified, but they illustrate the basic steps involved in the classification of spatial distributions".

Este autor, ao questionar o padrão de dispersão como constatação da distribuição espacial, afirma que outros componentes caracterizam a distribuição espacial, como, por exemplo, a densidade e a dispersão. Para Dacey (1973), o padrão de dispersão espacial é a área ou arranjo geométrico de fatos geográficos dentro da área de estudo sem considerar o seu tamanho; e a densidade da distribuição espacial é a frequência global de ocorrência do fenômeno dentro da área de estudo em relação ao tamanho desta área; por sua vez, a dispersão da distribuição espacial caracteriza-se como a extensão da propagação de fatos geográficos dentro da área de estudo.

A contribuição conceitual de Dacey (1973) centra-se exatamente na elucidação esquemática da distribuição espacial (bidimensional) de conceitos estatísticos contidos em histogramas, quais sejam: forma, densidade e dispersão. O conceito "forma" tem uma natureza morfológica e até de estética espacial, enquanto que a densidade possui natureza funcional. A dispersão seria derivada de um processo da resultante de forças. Uma abordagem envolvendo os referidos conceitos constitui uma estrutura de análise.

Tal exemplificação, embora simples, permite uma compreensão de distribuição espacial de fenômenos, a partir de um reduzido elementar modelo. Faz-se importante salientar que a ciência geográfica possui como princípios a localização e a distância (extensão) de objetos de análise - princípios contidos na proposta de Dacey (1973). 


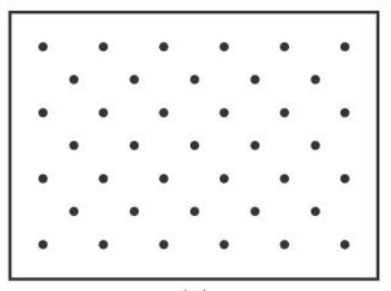

(a)

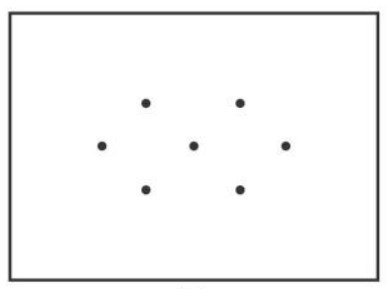

(c)

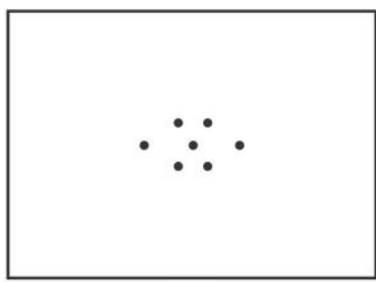

(e)

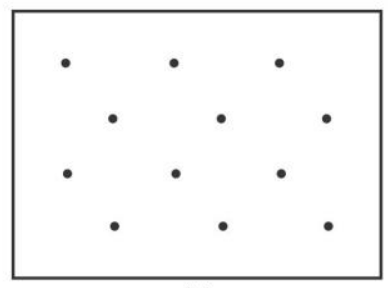

(b)

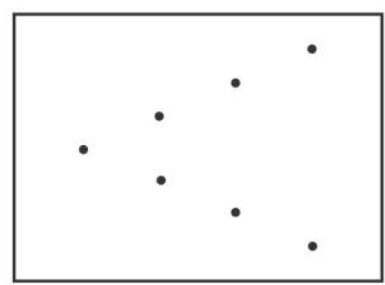

(d)

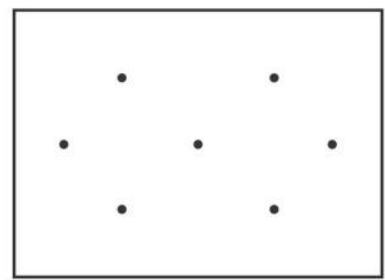

(f)

Figura 2.4 -Padrão, Densidade e Dispersão de Fenômenos.

Obs.: Os diagramas (a) e (b) tem o mesmo padrão e dispersão, porém, diferem em densidade. Os diagramas (c) e (d) têm a mesma densidade e dispersão, porém, diferem em padrão. Os diagramas (e) e (f) têm as mesmas densidades e padrão, porém, diferem em dispersão.

Fonte: Adaptado de Dacey (1973, p. 136).

Ademais, por meio da distribuição espacial dos fenômenos, é possível obter uma apreensão da morfologia das formas que são subjacentes aos processos espaciais e às funções que, socioeconomicamente, lhe são atribuídas. Portanto, a dialética das formas possui sua representatividade na análise geográfica sob o viés teórico-modelar.

\subsection{A GEOGRAFIA APLICADA E O PLANEJAMENTO}

Uma das maiores diferenças trazidas pela NG em relação aos estilos de pensamento geográfico que a antecederam é seu caráter instrumentalista, no que concerne à aplicação de conceitos operacionais e técnicas analíticas ao mundo real.

A dimensão da Geografia Aplicada teve um claro viés técnico e, portanto, consistiria em um instrumento de interesse social, na medida em que, a "spatial organization" (substituindo a baixa operacionalidade das clássicas "paysages") pôde ser vista como 
resultante de variáveis de construção política, cultural e socioeconômica ao longo do tempo.

Entretanto, a gênese do processo de planejamento remonta aos primórdios da humanidade. Muitas ações racionalizadas de proteção e previsão se deram a partir da necessidade de proteção de comunidades em início de sedentarização, frente às agruras das forças da natureza ainda não compreendidas ou controladas. As técnicas de sobrevivência eram pouco desenvolvidas.

Neste sentido, Morris (apud ESCUDERO, 2014, p. 11) aponta que "la actividad de planificación es un fenómeno de antigua data, cuyo origen podría encontrarse en el período en que las primeras comunidades nómades se transformaron en sedentarias (alrededor de 10.000 años A.C.)".

Diante da imperiosa necessidade de sobrevivência e de enfrentamento das adversidades naturais por comunidades primitivas, Escudero (2014, p. 11) afirma que

La ocurrencia periódica de ciertos fenómenos naturales, tales como los períodos de siembra y cosecha asociados a lluvias, migraciones de animales, subidas de cauces de ríos, cosechas y otros factores, requería un esfuerzo de establecer patrones de comportamiento de las variables que afectaban la vida en comunidad, encontrando regularidades que podían configurarse como formas previsibles de entender el futuro y, por tanto, anticiparse a este, en un ámbito de mayor complejidad que la mera recolección de datos.

Para este autor, as formas mais rudimentares de planejamento derivam da construção de conhecimentos elementares das forças da natureza e, por isso,

[...] estaban estrechamente relacionadas con el uso del territorio y buscaban controlar la naturaleza en virtud de la necesidad de supervivencia de la comunidad. En ese marco surgieron expresiones de formas de ordenamiento territorial reflejadas, por ejemplo, en asuntos como la localización de las aldeas, el acceso al agua, el uso alternativo del suelo para vivienda, agricultura, pastoreo y disposición de los residuos, entre otros (ESCUDERO, 2014, p. 11).

Do ponto de vista do planejamento moderno, de cunho técnico-científico, a sua formulação é bastante recente e remonta a postulados criados no século XX (mensuração, previsibilidades, técnicas de organização, instrumentalização etc.) ao incorporar conhecimentos, experiências de múltiplos ramos do conhecimento, tais como: Administração, Economia, Engenharia, Sociologia, Estatística e Geografia. São notórias as contribuições de Frederich Taylor (1856-1915) e J. Henri Fayol (1841-1925) na formulação de conceitos 
administrativos que posteriormente foram absorvidos pelo planejamento.

Em se tratando de planejamento, este é a ação de natureza técnica que consiste no maior campo de atuação de ciências diversas, entre as quais, a Geografia Aplicada ${ }^{10}$. Inexiste planejamento sem uma devida base territorial de estudos, abrangência e prospectiva. $\mathrm{O}$ planejamento se faz com e sobre fatores produtivos (terra, capital e trabalho), sendo o substrato físico de solo natural ou de solo construído uma variável constante, ou seja, um palco de atuação de interesses múltiplos, regulações ou para implantação de políticas públicas pelo Estado.

Merece destaque a atuação do planejamento moderno em um viés de estudos de capacidade de suporte com vistas à disponibilização de serviços públicos por áreas conforme as aglomerações demográficas. Evidentemente, deve ser considerado o número de habitantes da localidade, a dimensão da estrutura de serviços a ser disponibilizada, a localização do prédio público, a taxa de incremento populacional, enfim, a aferição da existência de tendência e de previsibilidade visando à busca do ponto ótimo do investimento governamental.

Um aspecto importante a ser destacado no planejamento da disponibilidade serviços públicos é que as áreas mais pobres das cidades em geral são, dentre outros aspectos, aquelas mais desprovidas de serviços públicos. As desigualdades sociais são também desigualdades espaciais, de escala local, sub-regional ou regional. Neste mesmo sentido, pode ser entendido que as "desigualdades sociais são quase que simétricas com as desigualdades regionais" (FAISSOL, 1978, p. 36).

Sob tal aspecto, a prestação de serviços públicos foi, em grande medida, um dos focos de execução de políticas públicas e do planejamento executado no período do pós-guerra ${ }^{11}$. As concepções de justiça social do Estado de Bem Estar Social (Welfare State) apregoavam e apregoam $^{12}$ a importância estratégica dos serviços públicos ao soerguimento a um padrão socioeconômico superior de uma determinada comunidade, cidade ou região.

O planejamento é, sem dúvida, uma ferramenta para se combater as desigualdades sociais por meio da organização da disponibilidade dos serviços públicos, da execução de

\footnotetext{
${ }^{10}$ Em várias universidades de tradicão anglo-saxônica, os departamentos, programas ou disciplinas da Geografia estão relacionados diretamente ao planejamento ou a algum tipo de intervenção instrumental. Na Universidade de Toronto denomina-se "Geography and Program in Planning"; na Universidade de Oxford, o Departamento de Geografia denomina-se "School of Geography and Environment"; $\mathrm{e}$, entre as disciplinas do Departamento de Geografia da Universidade de Teerã, encontram-se "Geography and Urban Planning" e "Geography and Rural Planning".

${ }^{11} \mathrm{Na}$ Inglaterra, as ações de Estado robustecidas a partir do planejamento territorial ficaram conhecidas como "Town and Country Planning"; na França, como "Aménagement du Territoire".

${ }^{12}$ As concepções do Welfare State continuam vivas como doutrina política.
} 
políticas compensatórias, do incentivo ao empreendedorismo e à economia solidária, da proteção ambiental, da mobilidade intra-urbana, entre outros aspectos qualificados como estratégicos nos processo de tomada de decisão.

O planejamento pode ser entendido, deste modo, como a capacidade do Estado em responder as demandas da sociedade por serviços públicos, pela abertura de novas fronteiras de negócios e de uso de recursos naturais, pela indução aos investimentos públicos e privados, por fomento às ações que tenham por norte a alteração de inércias indesejáveis do passado ou por redução da força monopolística que certos lugares exercem sobre a aglomeração de firmas, pessoas e investimentos.

O planejamento também atua sobre uma concepção modelar, isto é, sobre uma base idealizada de situação a ser buscada ou atingida, a partir do estudo de um cenário préexistente a ser superado. A ação prospectiva, a qual fundamenta a ação da Geografia Aplicada, representa a transposição de cenários na busca por um melhor desempenho espacial coletivo. O diagnóstico da situação presente, devidamente sistematizado por meio de parâmetros estatísticos, é uma etapa mais do que necessária; é decisiva.

Em síntese, o planejamento é uma aplicação sistematizada de teorias, conceitos e técnicas na busca de um tipo de intervenção para ações de Estado que modifiquem o padrão de escolhas dos agentes econômicos e da própria ação governamental, visando aumentar a eficácia do uso dos fatores de produção (terra, capital, trabalho), onde a lógica temporalprospectiva impõe a tentativa de um salto a um nível superior de qualidade em relação ao padrão socioeconômico originário.

A respeito da interação entre a Geografia e o planejamento, importante referência dános a justificativa do Projeto de Lei (PL) n. 1339/1968, que propôs a criação, em âmbito nacional, da profissão do geógrafo, e que culminou na publicação da Lei n. 6.664/1979 ao afirmar que

[...] é, aliás, bastante clara a importância da ciência no planejamento. Quaisquer que sejam os empreendimentos projetados, eles se realizarão em alguma parcela da superfície do planeta, cujas características terão de ser bem conhecidas e interpretadas. Da localização dependerá o sucesso ou o insucesso do que se pretende realizar. Ora, o Geógrafo é, pela sua formação, e, por excelência, o profissional que está constantemente preocupado com as causas e as consequências da localização dos fenômenos sobre a Terra (CÂMARA DOS DEPUTADOS, 1968, p. 8, grifo nosso). 
A mesma justificativa do referido PL aprofunda a fundamentação da proximidade e da interação da ciência geográfica com a produção de meios conceituais e metodológicos de intervenção, ao afirmar que

[...] também na Europa ocidental a importância da Geografia Aplicada vem se impondo aos organismos públicos e privados e com extensão aos territórios dependentes, sobretudo africanos. E o mesmo se observa nos países socialistas, onde ocorreu um verdadeiro "descobrimento" da Geografia como ciência fundamental ao planejamento econômico e social (CÂMARA DOS DEPUTADOS, 1968, p. 8, grifo nosso).

$\mathrm{Na}$ busca contínua da Geografia por uma interpretação teórico-científica da realidade por meio da espacialidade construída constata-se, a partir da cinética das formas, das funções e dos processos espaciais geradores, a sua tentativa de explanar sobre os modos possíveis de levar a sociedade à superação dos desafios contemporâneos. Mas isso seria particularmente oportuno se o fizesse sob o olhar da temporalidade prospectiva. Assim, é possível chegar ao entendimento de que a melhor contribuição da Geografia é a de ser, sem dúvida, uma espécie de "ciência do planejamento".

O planejamento realiza-se, com efeito, a partir de uma base de dados, isto é, não há como realizar planejamento sem o devido manuseio de informações prévias - sejam elas quantitativas ou qualitativas - do cenário presente. E sabe-se que o anseio da GTQ pelas linguagens e métodos estatísticos e matemáticos deriva da necessidade de, a partir deles, disponibilizar informações úteis, práticas e manipuláveis.

Para Capel e Urteaga (1982), a "predicción", isto é, a previsão ou busca da regularidade de fenômenos é a meta científica a ser perseguida pela GTQ e, por conseguinte, pelo planejamento. O juízo preditivo pode ser entendido como a interpretação de uma força de tendência ou como intervenções necessárias à reversão ou ao enfraquecimento de uma situação classificada como indesejada.

A dimensão cartesiana (da busca de entendimentos por uso de ferramentas matemáticas) evidencia a intenção científica de desvendar as "forças espaciais de tendências"; ou seja, existe, ceteris paribus, uma razoável probabilidade de se conhecer fenômenos futuros. Para tanto, a GTQ adota, do ponto de vista estatístico, segundo Faissol (1978, p. 21), o "uso de modelos probabilísticos, em substituição aos modelos determinísticos". Neste sentido, não se tem um fenômeno social propriamente "determinado", mas haveria, sim, a possibilidade de captação de determinada força de tendência, que consistiria em uma probabilidade de manutenção, incremento ou decréscimo da ocorrência de fatos sociais 
específicos.

Acerca da aplicação de ferramentas estatísticas para captação das forças de tendência como instrumento essencial ao processo de planejamento, o geógrafo Pedro Pichas Geiger (1970, p. 67, grifo nosso) afirma que

[...] de acôrdo com o processo geral das ciências sociais, hoje em dia não se trata apenas de estudar os fatos geográficos na sua evolução até o presente, mas de indicar as tendências espontâneas do movimento para o futuro, bem como apontar as possibilidades de intervenção no processo econômico, no sentido de se alcançar situações espaciais mais desejáveis. (sic)

Em relação à essencialidade do conceito "tendência", Geiger et al. (1974, p. 83) assevera

Quando, a partir dos valores observados de uma série, fazemos um gráfico, podemos observar que esse conjunto de pontos irá representar uma tendência do fenômeno em estudo, tendência essa que poderá ser crescente, decrescente ou estacionária. É interessante também observar que o gráfico de uma série temporal se assemelha à trajetória de uma partícula que se desloca sob a influência de forças físicas. Todavia o movimento pode ser provocado, em vez de forças físicas, por uma combinação de forças econômicas, sociais, psicológicas e outras, no decorrer do tempo.

A contribuição da GTQ ao planejamento deu-se, por outro lado, na medida da absorção pelo Estado de quadros técnicos e pelo fomento na criação de autarquias governamentais com a finalidade de produzir conhecimentos sistematizados aplicáveis na busca de soluções aos desafios sociais contemporâneos de cada época. A Emergência da GTQ coincide com o período do pós-guerra, onde a necessidade de reconstruções econômicas e de reavaliação de formas de uso do território tornou-se a temática daquele momento. No Brasil, o IBGE foi um órgão de referência na produção de conhecimento pelo viés conceitual da GTQ.

Tal emergência coincide com o período de gestão de políticas econômicas conhecidas como "nacional-desenvolvimentismo" ou de "industrialização tardia", caracterizado pelo incremento da ação do poder público no provimento de infraestrutura de energia, de transporte e em indústrias de base (siderurgia, metalurgia, petroquímica, eletricidade etc.).

Cabe destacar que diversos foram os economistas que também trabalharam com teorias locacionais, cujos estudos foram conhecidos como "ciência regional" (ISARD, 1971). Entretanto, a contribuição da GTQ foi fundamentar uma estrutura conceitual e metodológica que ajudou a organizar e estruturar descrições, classificações e análises de distribuição 
espacial de fenômenos.

Faissol (1978), ao analisar a relação interdisciplinar da chamada escola locacional que possui grande contribuição tanto da Economia quanto da Geografia -, afirma que a "localização", enquanto princípio fundamental da ciência geográfica acaba sendo uma variável central desta escola de pensamento. É possível afirmar que a chamada "Teoria dos Lugares Centrais" representou, portanto, uma das maiores contribuições científicas da Geografia no século XX.

A respeito dos fundamentos da Teoria dos Lugares Centrais (TLC), da interação Geografia-Economia e a contribuição do geógrafo em relação à produção de conhecimentos locacionais, Faissol (1978, p. 20, grifo nosso) afirma que

\begin{abstract}
A teoria de localidades centrais está, sem dúvida, apoiada em teoria locacional, como concebida na Economia; na realidade ela se apóia, inclusive, em premissas desta teoria locacional, de planície isotrópica, sem limite, para melhor descrever e especificar a função distância. Noções como o alcance de um bem (range) e mercado para que o bem possa ser produzido economicamente (treshold), são parte integrante dos dois campos disciplinares, ou se preferirmos da intersecção das duas. A contribuição do geógrafo para a melhor especificação da teoria foi, sem dúvida, $\underline{\text { a }}$ especificação da função distância, que tem uma conotação espacial indubitável.
\end{abstract}

Assim, a GTQ inseriu a variável locacional e o princípio da distância não apenas como um insumo ou variável na análise ou como um fator de produção, mas sim, territorializou um fundamento basilar do funcionamento dos modelos socioeconômicos de diagnóstico e de intervenção prospectiva. Vale destacar que a localização e a distância são dois princípios geográficos incontestes.

Com efeito, percebeu-se a fácil absorção das políticas de Estado, dos princípios racionais, teóricos e quantitativos desta Geografia, em função do viés instrumental e pragmático que lhe é próprio. O Estado foi e continua sendo o maior empregador de geógrafos no mundo, pois a Geografia é um instrumento de poder.

Um dos problemas gerados com a "estatização" do conhecimento geográfico resultou em divergências conceituais e até de natureza ideológica entre pesquisadores, técnicos e acadêmicos, envolvendo concepções variantes da ação estatal relativamente bem discernidas entre o "planejamento" e a "planificação". A clivagem entre o planejamento e a planificação envolvia a dimensão da ação estatal, sendo a planificação derivada de uma concepção de economia estatizada aos moldes do socialismo real, enquanto que o planejamento buscou 
ajustes nas economias de mercado na busca de uma situação de equilíbrio, de uma melhor distribuição dos bens e de justiça social.

É preciso atentar-se ao fato de que as experiências socialistas de planificação econômica são anteriores àquelas de planejamento ocorridas no mundo capitalista, cujo modelo soviético - de fortíssimas intervenções na economia e nas liberdades liberais clássicas - serviu como parâmetro em estudos acadêmicos e em processos de escolhas governamentais.

Em relação a esta divergência (planejamento-planificação), é possível afirmar que existiu uma polaridade de pensamento com divergências robustas de abordagem em relação ao papel do Estado e à dimensão e liberdade de ação do mercado, entendido como a livre iniciativa dos agentes econômicos.

Tais divergências colocaram de um lado a questão da regulação e do controle (planejamento), em contraposição ou alternativa ao chamado dirigismo estatal (planificação).

Destarte às diferenciações da natureza de modelos e concepções político-ideológicas, uma questão importante a ser ressaltada no planejamento é a interação entre as ações e as concepções de desenvolvimento social e econômico. Sobre tal questão, Ferreira (1999, p. 144) assevera:

Na realidade, o planejamento nada mais é que um instrumento a serviço da expansão de um modelo de desenvolvimento baseado na universalização das formas de produção e de consumo, na hegemonia de um padrão dito moderno a ser seguido, tendo as propostas um caráter uniformizante.

Ainda acerca do planejamento enquanto prospectiva governamental, Ferreira (1999, p. 143) corrobora:

E é na intervenção governamental sobre o uso e a ocupação do território que o poder sobre o espaço se manifesta de forma mais abrangente, quando o poder público se torna o grande promotor da ocupação territorial, o gestor dos usos, o impulsionador das mudanças e da modernização, tendo o território como estratégia de desenvolvimento econômico e social.

No mundo ocidental e na experiência brasileira ${ }^{13}$, o planejamento como articulação de meios de intervenção das ações do Estado sobre o uso potencial do território e dos fatores de produção nele contidos, robusteceu-se, sobretudo, no pós-guerra como um dos principais instrumentos para o desenvolvimento. Alguns organismos internacionais ligados à

13 Vale mencionar que, apesar das agências brasileiras de desenvolvimento regional (SUDENE, SUDAM e SUDECO) terem buscado em sua gênese realizar ações de planejamento territorial, em fase posterior, assumiram papel de órgãos de fomento econômico por meio do uso de incentivos fiscais e creditícios. 
Organização das Nações Unidas (ONU), como, por exemplo, a United Nation Educational, Scientific and Cultural Organization (UNESCO) ${ }^{14}$, a Food and Agriculture Organization $(\mathrm{FAO})^{15}$ e a Organização Mundial da Saúde (OMS), tiveram e ainda têm enorme relevância na construção de referências conceituais, metodológicas e de suporte técnico no processo de planejamento.

\subsection{A GEOGRAFiA APLICADA E A REgULAMENTAÇÃo DA PROFISSÃO DO GEÓGRAFO NO BRASIL}

Adentrando especificamente na importância da aplicabilidade do conhecimento geográfico, vale ressaltar o papel da publicação da Lei n. 6.664, de 26 de junho de 1979, que regulamenta a profissão do geógrafo, na busca por efetivar e robustecer a aplicação tecnocientífica dos conhecimentos geográficos pelo Estado e pela iniciativa privada.

O Estado brasileiro entendeu como de interesse nacional a criação de uma profissão específica para lidar com as questões relacionadas à organização, racionalização e regulação do espaço geográfico, em um contexto em que o regime militar dirigente possuía uma clara política de ocupação territorial de áreas pouco ocupadas, especialmente, aquelas situadas no Planalto Central e na Amazônia. O incentivo à colonização, à demarcação de terras indígenas, os investimentos em infraestrutura e a busca pelo crescimento econômico também estavam entre os objetos e ações propostas.

O desafio da fronteira como limite territorial e, mais especificamente, da fronteira amazônica, foi central neste período. Por isso, Becker e Egler (1998, p. 211) ressaltam que a Amazônia assumiu o papel da "grande fronteira", dado o valor simbólico e até lendário que aquela parte do território representa no imaginário nacional. Neste cenário, fazia-se necessária a formação de profissionais habilitados no exame de questões relacionadas às novas territorialidades e fronteiras.

Deste modo, torna-se importante conhecer as nuances da origem da regulamentação da profissão do geógrafo. A regulamentação desta profissão partiu da iniciativa de um PL de autoria do Deputado Federal pelo MDB (Movimento Democrático Brasileiro) ${ }^{16}$ de São Paulo,

\footnotetext{
${ }^{14}$ Em português: Organização das Nações Unidas para a Educação, Ciência e Cultura.

${ }^{15}$ Em português: Organização das Nações Unidas para a Agricultura e Alimentação.

${ }^{16}$ Foi instituído pelo AI-2, que transformou o sistema partidário brasileiro em bipartidário. O MDB agregou várias siglas partidárias existentes e se constituiu no partido de oposição. A Aliança Renovadora Nacional (ARENA) se constituía no partido de sustentação do regime.
} 
Ewaldo de Almeida Pinto, que era oposicionista ao regime político em vigor. Tal iniciativa legislativa foi apresentada em 29 de maio de $1968^{17}$, sendo denominada de PL n. 1.339/1968.

Paradoxalmente, o mesmo grupo/regime de poder que cassou o mandado do Deputado Ewaldo de Almeida Pinto ${ }^{18}$, faz tramitar o referido PL até sua sanção presidencial em 1979, pelo General João Figueiredo. Se o PL em questão tramitou até virar lei, os formuladores políticos do regime militar - que tinham a hegemonia do parlamento - consideraram-no de conteúdo favorável aos seus interesses à organicidade das ações do Estado.

Em geral, os regimes de natureza militar constituem-se em burocracias orgânicas e profissionais, cuja estrutura estatal atua como centro de ações políticas, sociais e econômicas.

A amplitude conceitual, a robustez técnica e a visão prospectiva presentes na definição de atribuições funcionais para uma categoria profissional (o geógrafo) originária de um campo científico que possui um forte viés analítico e uma sólida base humanista, chama a atenção neste PL. O texto final da Lei sancionada possui a seguinte redação em seu art. $3^{\circ}$, in verbis:

Art. $3^{\circ}$ É da competência do Geógrafo o exercício das seguintes atividades e funções a cargo da União, dos Estados, dos Territórios e dos Municípios, das entidades autárquicas ou de economia mista e particulares:

I - reconhecimentos, levantamentos, estudos e pesquisas de caráter físicogeográfico, biogeográfico, antropogeográfico e geoeconômico e as realizadas nos campos gerais e especiais da Geografia, que se fizerem necessárias:

a) na delimitação e caracterização de regiões e sub-regiões geográficas naturais e zonas geoeconômicas, para fins de planejamento e organização físico-espacial;

[...];

d) no zoneamento geo-humano, com vistas aos planejamentos geral e regional;

[...]

g) na política de povoamento, migração interna, imigração e colonização de regiões novas ou de revalorização de regiões de velho povoamento;

h) no estudo físico-cultural dos setores geoeconômicos destinados ao planejamento da produção;

$[\ldots]$;

j) no estudo e planejamento das bases físicas e geoeconômicas dos núcleos urbanos e rurais;

$[\ldots]$;

m) no levantamento e mapeamento destinados à solução dos problemas regionais;

n) na divisão administrativa da União, dos Estados, dos Territórios e dos Municípios (grifos nossos).

\footnotetext{
${ }^{17}$ O dia 29 de maio é considerado o "Dia do Geógrafo" em função de ter sido nesta data a criação do Instituto Brasileiro de Geografia e Estatística (IBGE). Na mesma data comemora-se o "Dia do Estatístico".

${ }^{18}$ O Deputado teve o mandado cassado por força de Ato Institucional (AI) publicado em 17 de janeiro de 1969.
} 
Outro aspecto salutar que pode ser destacado encontra-se na justificativa do PL $\mathrm{n}$. 1.339/1968, e centra-se na constatação da relação direta entre o incremento da importância da Geografia como campo de conhecimento técnico-científico e a efervescência socioeconômica do Estado-Nação na qual se situa. A este respeito, a justificativa do referido PL afirma:

O papel desempenhado por essa disciplina é tanto mais notável quanto mais dinâmicas são as atividades de uma nação, quanto mais intenso for o seu surto econômico e demográfico. Mas é preciso que essa nação conte com um número suficiente de geógrafos de formação moderna (CÂMARA DOS DEPUTADOS, 1968, p. 8, grifo nosso).

Nos dias atuais, a Lei n. 6.664/1979 continua em vigência apesar do desconhecimento de vários núcleos de formação de geógrafos quanto à regulamentação da profissão e seus dispositivos. Tem-se ainda em algumas universidades certo conflito de identidade sobre o tipo de conhecimento geográfico a ser ensinado, o que resulta em formação profissional com objetivos pouco definidos. Por conseguinte, as resistências ao registro profissional no Sistema Conselho Federal de Engenharia e Agronomia (CONFEA)/Conselho Regional de Engenharia e Agronomia (CREA) são claramente identificadas, o que coloca o geógrafo em posição secundária junto àquelas instituições e ao mercado de trabalho. 


\section{TEORIAS CLÁSSICAS DA LOCALIZAÇÃO E DAS CENTRALIDADES: PREMISSAS TEÓRICO-FILOSÓFICAS DO PLANEJAMENTO TERRITORIAL}

\subsection{A EVOLUÇÃO DO PENSAMENTO ECONÔMICO-ESPACIAL}

O estabelecimento de referenciais teóricos para se estudar novas espacialidades dirigidas ao planejamento governamental territorializado deve considerar, preliminarmente, os estudos existentes acerca das teorias clássicas da localização e das centralidades.

Por teorias clássicas da localização e das centralidades entendem-se aquelas cujos núcleos propositivos centram-se na compreensão da lógica do funcionamento da distribuição espacial de mercados e populações, permitindo um entendimento modelar ou padrão das centralidades e abrangências geográficas das dispersões e/ou concentrações de bens e serviços.

Estas teorias indicam também as tendências e os comportamentos dos fluxos dos consumidores e vendedores realizados a partir de localidades em direção às áreas de mercado que são escolhidas mediante a relação custo-distância de onde se encontram.

Vale ressaltar a pouca disponibilidade de bibliografias primárias em língua portuguesa referentes às teorias da localização e das centralidades. Por outro lado, é importante esclarecer que "não existe uma abordagem teórica única em economia regional" (MONASTÉRIO; CAVALCANTE, 2011, p. 44). Assim, a existência de abordagens teóricas diversas dá a dimensão da riqueza que os temas de economia regional e de geografia econômica possibilitam.

Neste sentido, os economistas Leonardo Monastério e Luis Ricardo Cavalcante (2011) apresentam um infograma demonstrando a evolução do pensamento das teorias locacionais enfatizando seus autores e os respectivos países de origem, conforme demonstrado na Figura 3.1, a seguir. Os países de origem foram representados pelas bandeiras nacionais onde foi inserida uma menção à principal obra do autor em referência.

A importância de autores alemães na construção de teorias locacionais permitiu denominar suas produções teóricas como "teorias clássicas da localização", como "escola alemã”, ou ainda, como "geometria germânica” (MONASTÉRIO; CAVALCANTE, 2011).

Faz-se importante salientar que a distribuição espacial das atividades econômicas, do ponto de vista clássico, é explicada a partir da aplicação dos postulados das teorias da 
localização cujos fundamentos econômicos elucidam o desejo pela chamada "localização ótima" (MONASTÉRIO; CAVALCANTE, 2011).

A "localização ótima", do ponto de vista da firma, seria a alteração da estrutura de custos de produção e de transporte visando minimizá-los a partir de escolhas e/ou mudanças de natureza locacional. Com efeito, a métrica da distância constitui a variável chave nas teorias da localização e das centralidades.

Entre os estudos realizados acerca da distribuição espacial de mercados e populações nas teorias da localização e das centralidades, duas grandes linhas merecem destaque: 1) a "Teoria dos Lugares Centrais - TLC"; e, 2) Os "Modelos de Interação Gravitacional, Potencial ou Espacial - MIGPEs".

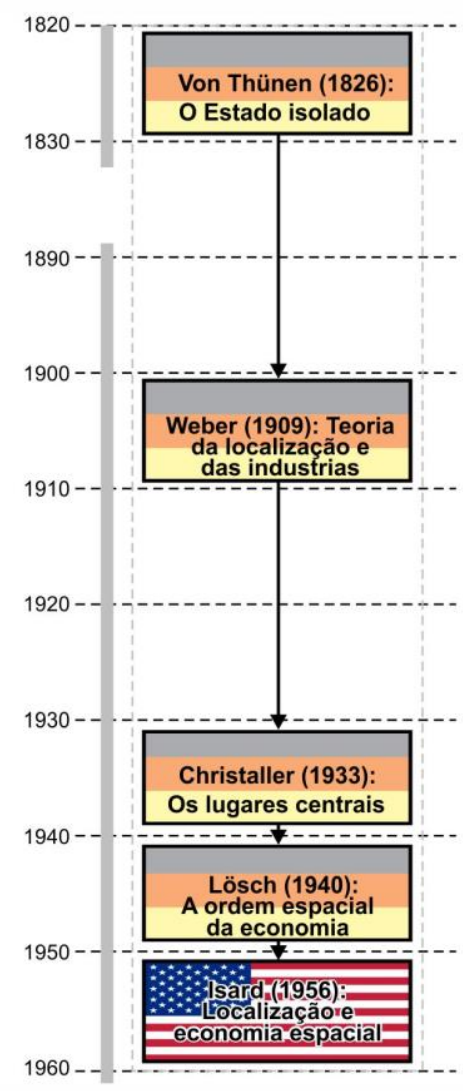

Figura 3.1 - Teorias clássicas da localização e das centralidades.

Fonte: Monastério e Cavalcante (2011, p. 47). 
Ressalta-se que, embora existam sólidos trabalhos no âmbito das "teorias do desenvolvimento regional ${ }^{19}$ " que possuem, inclusive, conectividade direta com as aplicações de políticas públicas com base nas "teorias clássicas da localização e das centralidades", o presente Capítulo abordará somente este último grupo conceitual como objeto teórico.

No âmbito das teorias clássicas da localização e das centralidades, a abordagem será subdividida em "Teoria dos Lugares Centrais" e em "Modelos de Interação Gravitacional, Potencial ou Espacial". A Figura 3.2, a seguir, apresenta os principais teóricos ligados às duas correntes das teorias clássicas da localização e das centralidades.

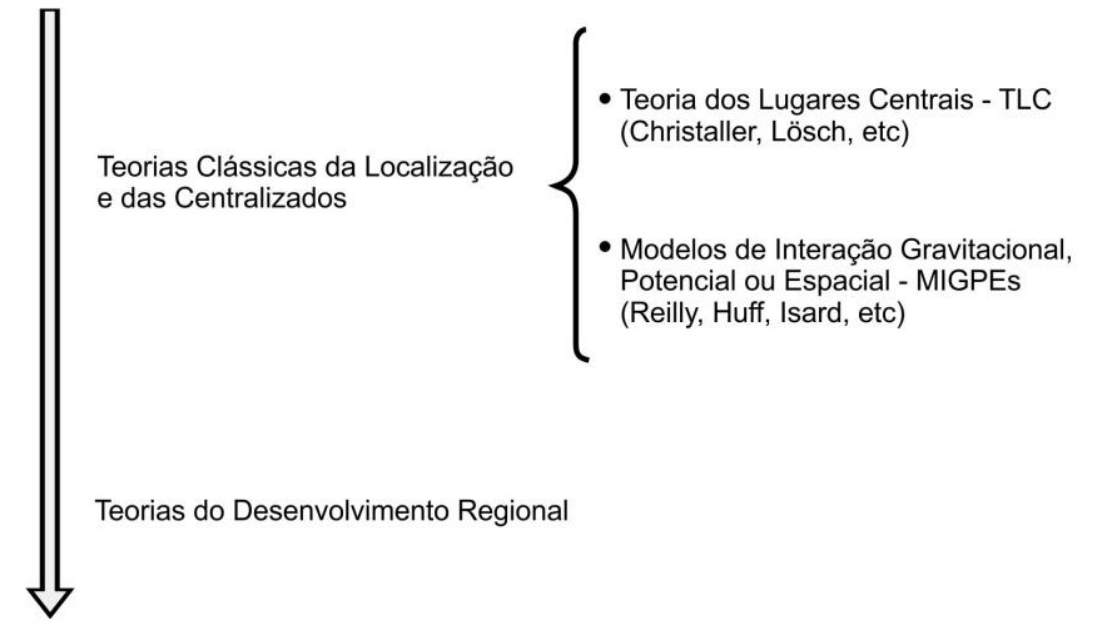

Figura 3.2 - Estrutura conceitual de abordagem das teorias clássicas da localização e das centralidades e das teorias do desenvolvimento regional.

Fonte: Do autor.

Um aspecto interessante referente ao campo de estudo das teorias clássicas da localização e das centralidades dá-se pela interface entre as disciplinas da Geografia Econômica e da Economia Regional, uma vez que tanto economistas quanto geógrafos produziram pesquisas e conhecimentos acerca da temática.

Tal interface de modelos clássicos de oferta e de demanda - de viés eminentemente econômico, com a interação da métrica da distância nas escolhas dos assentamentos humanos (fator preponderantemente centrado na geografia humana) - produz uma área de conhecimento interdisciplinar.

\footnotetext{
${ }^{19}$ Monastério e Cavalcante (2011) apontam a existência de dois grandes blocos teóricos do pensamento regional, a saber: 1) Teorias Clássicas da Localização; e, 2) Teorias do Desenvolvimento Regional.
} 


\subsubsection{Outros estudos locacionais: os trabalhos de Von Thunen e Weber}

Embora não enquadrados na $\mathrm{TLC}^{20}$, merecem menção os trabalhos dos economistas Johann Heinrich Von Thünen (1783-1850) e Alfred Weber (1868-1958) pela discussão locacional de atividades econômicas. Faz-se necessário salientar que a TLC é um estudo de natureza locacional, mas vários estudos locacionais não se enquadram nos limites desta Teoria.

O trabalho de Von Thünen é pioneiro ao apresentar um modelo com base no incremento da renda conforme a proximidade do centro consumidor, em função do custo de transporte. O modelo proposto por Thünen trabalha a "locação de equilíbrio do ponto de vista da firma" (CAPELLO, 2008, n. p.) e foi elaborado observando-se o comportamento de produtos agrícolas. Ou seja, o fator distância representa uma diferença de rentabilidade em um "modelo concêntrico" (BERRY, 1967, p. 339).

Assim, a porção terra, que geraria maior rentabilidade e, portanto, situada mais próxima do centro de consumo, passaria a ter um valor econômico maior, atraindo a produção de bens ou atividades econômicas de maior valor agregado.

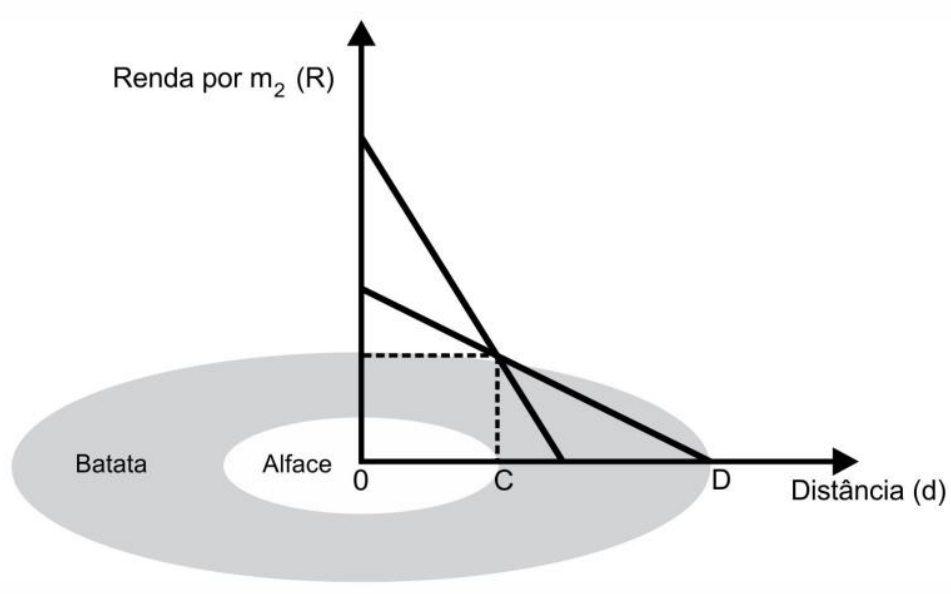

Figura 3.3 - Relação entre a renda e a distância para produtos agrícolas: Modelo dos Anéis de Von Thünen. Fonte: Monastério e Cavalcante (2011, p. 52).

O princípio da estrutura concêntrica (anelar) da relação renda-distância para produção agrícola de Thünen foi aperfeiçoado para o estudo de fatores locacionais também para

\footnotetext{
${ }^{20}$ Conforme preconizam Berry (1967) e Capello (2008).
} 
ambientes urbanos, segundo Garner (1975), a partir dos trabalhos de Garrison et al. ${ }^{21}$. A Figura 3.4 apresenta o comportamento descrito por Garner.

A descrição de Garner demonstra que a disposição de atividades econômicas em ambientes urbanos obedeceria à lógica da disposição anelar conforme a renda auferida pela atividade econômica comparada à distância de um ponto a um núcleo central. Para o seguimento $\mathrm{P}$, de maior renda, tem-se uma área comercial. Para o seguimento PQ, de renda intermediária, tem-se a propensão às atividades industriais. E para o segmento mais periférico (QD), prevaleceriam os usos residenciais.

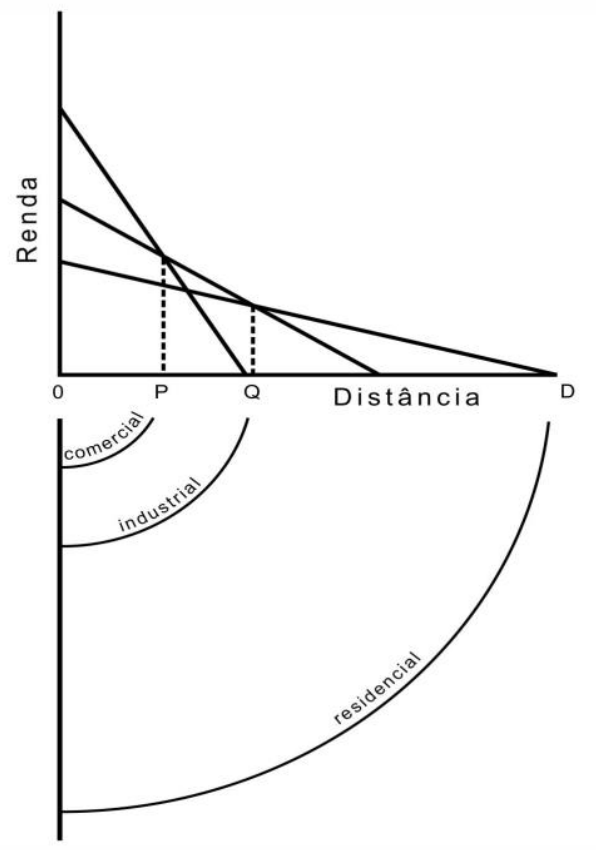

Figura 3.4 - Comportamento anelar da relação renda-distância de atividades econômicas em ambiente urbano. Fonte: Adaptado de Garner (1975).

O próprio Garner (1975) relativiza o modelo afirmando que este representa uma simplificação da disposição de atividades econômicas em algumas cidades, uma vez que existem situações onde há uma concentração de residências de populações de baixa renda no centro da cidade. A setorização derivada do planejamento urbano é outra situação que fragiliza o referido Modelo. Ademais, as distorções promovidas por barreiras naturais e por padrões de deslocamento gerados por rotas de transporte também são mencionadas pelo autor como ressalvas à rígida estrutura anelar.

${ }^{21}$ Cf. GARRISON, W.; BERRY, B. J. L.; MARBLE, D. F.; NYSTUEN, J. D.; MORRILL, R. L. Studies of higway developmentand geography change. Seatle, 1959. 
Entretanto, o padrão anelar serve para demonstrar que determinados usos do solo podem gerar renda e, assim, produzirem forças de tendências alocativas.

Por sua vez, segundo Capello (2008), o Modelo de Weber foi construído para se aplicar aos estudos de disposição da localização industrial. Neste modelo, a interação entre a distância dos insumos no processo produtivo e a localização do centro consumidor mediado pelo peso (participação) relativo destes componentes nos custos do processo produtivo constituem as variáveis de análise.

Na Figura 3.5, a seguir, os pontos M1 e M2 seriam representações onde se localizam as matérias primas, enquanto o ponto $\mathrm{C}$ seria o ponto de representação do mercado consumidor. Por sua vez, o ponto P seria o ponto de escolha da "localização de equilíbrio" (CAPELLO, 2008) para planta industrial, conforme a ponderação dos custos "a", "b" e "c" referentes aos deslocamentos de insumos do produto final para o mercado consumidor $\mathrm{C}$.

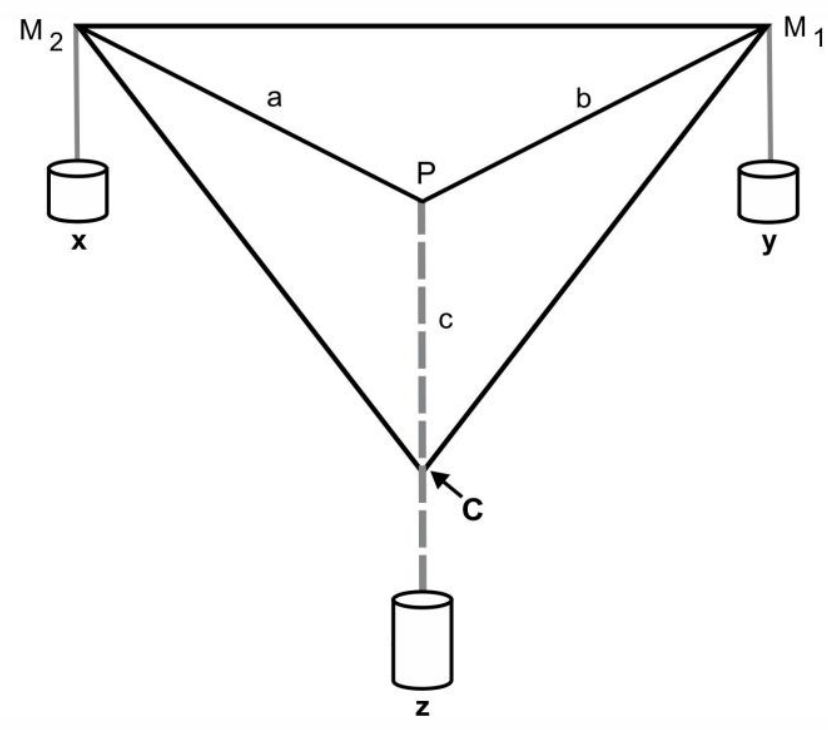

Figura 3.5 - Triângulo locacional de Weber: escolhas a partir do mínimo custo de transporte. Fonte: Adaptado de Capello (2008).

O Modelo de Weber é, portanto, uma comparação direta entre as economias de aglomeração com os custos de transporte.

\subsection{A TEORIA DOS LUGARES CENTRAIS}

De acordo com Berry (1967), as bases da TLC foram desenvolvidas por dois estudiosos alemães, a saber: o geógrafo Walter Christaller (1893-1969) e o economista 
August Lösch (1906-1945), sem que houvesse a simultaneidade e a parceria entre os estudos. Em relação à autoria da TLC, a economista italiana Roberta Capello (2008), em sua obra Regional Economics, aponta, do mesmo modo, Christaller e Lösch como os primeiros estudiosos a desenvolverem os modelos que fundamentaram esta teoria.

O Trabalho de Walter Christaller na formulação da TLC deu-se por meio da obra Die Zentralen Örte in Süddeutschland, publicada originalmente em alemão, em 1933, e em inglês, em 1966, com o título Central Places of Southern Germany. Por sua vez, o principal trabalho de August Lösch materializou-se na obra Die Räumliche Ordnung der Wirtschaft, publicada originalmente em alemão, em 1940, e em inglês, em 1954, com o título The Economics of Location. A edição em espanhol do trabalho de Lösch recebeu título de Teoría Económica Espacial.

Apesar de reconhecer a importância dos dois teóricos alemães na autoria e no desenvolvimento sistematizado da TLC, Berry (1967) afirma que conclusões semelhantes prévias à teoria foram alcançadas pelo sociólogo rural americano C. J. Galpin, e pelo estudioso Leon Lalane.

Um aspecto fundamental da TLC aponta que "the theory is developed essentially detached from considerations of the behavior of retailers and consumers over time and space" (BERRY, 1967, p. 59, grifo nosso). Em outras palavras, a TLC tornou a "funçãodistância" (FAISSOL, 1978, p. 20) o eixo central na análise de localização de povoações e de investimentos econômicos por sua geometria descritiva, sejam eles demandantes ou ofertantes.

Assim, a TLC enuncia a existência de um arranjo espacial desejado pelos ofertantes e demandantes na busca da "distribuição ótima" ou pela "área ótima de oferta" de um bem simples tendo em vista a dispersão populacional. De igual modo, tem-se um "deslocamento ótimo" entre os consumidores na busca da redução dos custos de deslocamento.

Neste sentido, Berry (1967, p. 3) afirma ainda que a "Central-places theory is the theory of the location, size, nature, and spacing of these clusters of activity, and is therefore the theoretical base of much of urban geography and of the geography of retail and service business".

Interessante notar que enquanto para Lösch o desenvolvimento teórico centra-se em uma abordagem do comportamento econômico da dinâmica espacial dos ofertantes, Christaller enfatiza o comportamento da demanda e a consequente resposta dos agentes de mercado, conforme os 03 (três) princípios geoeconômicos que desenvolveu. 
Acerca das semelhanças e diferenças entre Christaller e Lösch, Berry (1967, p. 59, grifo nosso) sentencia:

Both theorists agree on the spatial arrangement of stores required for optimal distribution of a single goods to a dispersed population. However, their arguments diverge significantly when they seek to obtain locations for many kinds of goods considered simultaneously, with results that make Lösch's economic landscapes more relevant to secondary production at its later market-oriented stages, and Christaller's hierarchies most appropriate in analysis of retail and service business in the tertiary sector.

Apesar das abordagens distintas entre Christaller e Lösch, tem-se uma convergência em relação às localidades centrais, à geometria hexagonal das regiões geoeconômicas e à busca pela redução do custo distância que fundamentam a TLC.

Em suma, é possível concluir que "a distribuição espacial da atividade humana reflete um ajustamento ordenado do fator distância” (GARNER, 1975, p. 125), pois, racionalmente, há uma busca constante pela minimização dos seus efeitos.

\subsubsection{Os lugares centrais de Christaller}

De acordo com Capello (2008, n. p.), o "Modelo de Christaller" tem por base a constatação de que os centros urbanos se localizam onde se encontram bens e serviços para serem comercializados e, portanto, torna-se possível o estabelecimento de uma hierarquia acerca da organização territorial, conforme a complexidade mercantil do que está sendo ofertado e demandado.

Assim, conforme dispõe a Figura 3.6, a seguir, em seu item (A), a quantidade demandada de um bem é maior quanto menor for seu preço; e o preço pela TLC é um ajuste do fator distância, o que implica na existência de centralidades (lugares centrais). Tem-se ainda uma interação entre a hierarquia dos lugares e o tipo de bens disponibilizados em cada mercado, conforme evidencia o item (B) da referida Figura.

Neste sentido, os bens superiores tenderão a se localizar em núcleos urbanos de mais alta hierarquia, ao passo que os bens de menor complexidade tenderão a se concentrar em assentamentos de hierarquia imediatamente inferior. Por decorrência da especialização hierárquica, os assentamentos urbanos tenderão a se localizar "no ponto médio da linha que 
une os centros de ordem superior" (MONASTÉRIO; CAVALCANTE, 2011, p. 58) (vide Figura 3.9, a seguir).

Por outro lado, Garner (1975, p. 127) interpreta o Modelo de Christaller pela geometria das formas hexagonais, afirmando que a base do modelo da localidade central é o da "treliça regular". Para este autor, os elementos básicos do modelo tem seu desenvolvimento sob uma superfície isotrópica ${ }^{22}$ - isto é "sob condições de uma distribuição uniforme da população e do poder aquisitivo, terreno uniforme e localização de recursos e facilidades de transporte iguais em todas as direções" (GARNER, 1975, p. 127).

Para o Modelo de Christaller em si, os núcleos urbanos que concentram bens e serviços são denominados de "lugares centrais" cuja nomenclatura serviu de termo conceitual para a TLC.
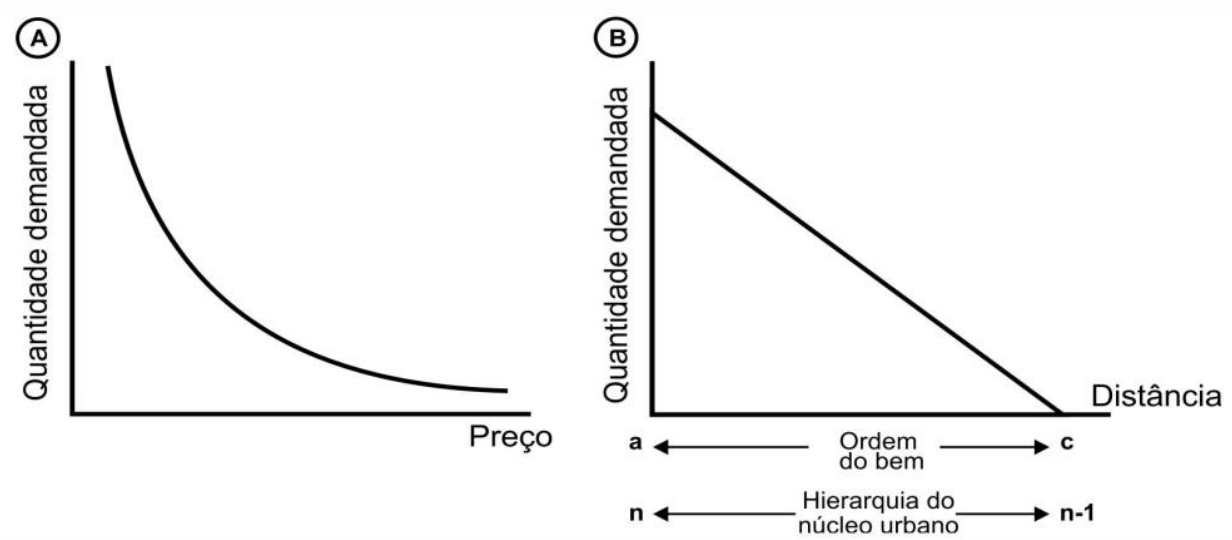

Figura 3.6 - Variações de comportamento de demandas de um bem. (A) Relação demanda e preço de um bem; (B) Relação demanda e distância com ênfase na ordem de importância dos bens e na hierarquia dos núcleos urbanos.

Fonte: Adaptado de Bradford e Kent (1987).

Capello (2008) acrescenta que a estrutura teórica de Christaller se dá mediante a idealização dos conceitos espaciais de threshold ${ }^{23}$ (núcleo) e range (alcance/borda), que fundamentam tecnicamente os 03 (três) princípios basilares do modelo, a saber: 1) mercado; 2) transporte; e, 3) administrativo. O conceito de range pode ser entendido como uma esfera de influência ou uma área de abrangência, ou uma região (regere) stricto sensu.

\footnotetext{
${ }^{22}$ Uma das maiores críticas ao Modelo de Christaller centra-se exatamente na situação demasiadamente ideal da chamada "superfície isotrópica".

23 Os conceitos de "threshold" e de "range" assemelham-se ao conceito de hinterland que se refere, dentre outros aspectos, à região de alcance de uma área portuária. O conceito de hinterland foi utilizado por George G. Chisholm na obra Handbook of Commercial Geography, de 1888.
} 


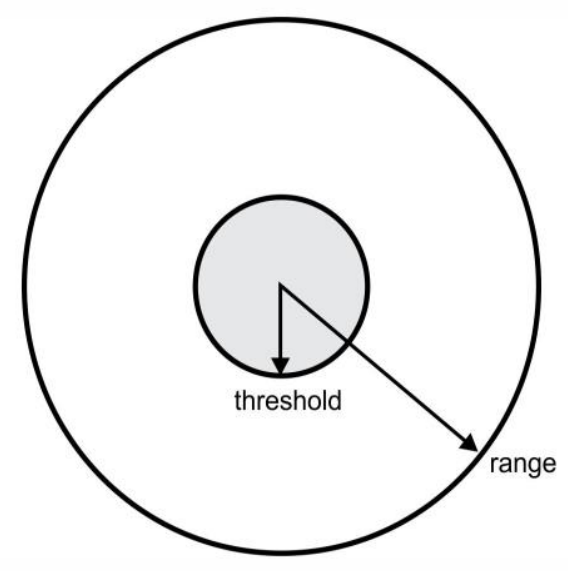

Figura 3.7 - Relação entre o núcleo e o alcance dos lugares centrais, segundo o Modelo de Christaller. Fonte: Adaptado de Capello (2008).

Acerca dos conceitos descritos na Figura 3.7, Capello (2008, n. p. grifo nosso) afirma que

[...] Christaller introduces the concepts of threshold and range. These express in geographical terms the economic forces that organize activities in space: transportation costs and aglomeration economies, or economies of scale. The range of a service is the maximum distance that consumers are willing to travel to purchase it (wich includes the maximum transportation costs that they are willing to pay in doing so).

Em relação aos princípios da Teoria de Christaller, faz-se necessário observá-los em detalhes, conforme se segue:

- Princípio de Mercado: este aponta a existência de uma hierarquia entre os lugares centrais de tal modo que os centros de bens e serviços de primeira ordem proveem bens e serviços superiores, bem como os centros de bens e serviços de segunda ordem disponibilizam bens e serviços mais inferiores em relação aos de primeira ordem. Em outras palavras, existem áreas de influência e de subordinação de áreas de mercado.

O hexágono é a figura geométrica que, para a TLC, permite a inter-relação entre as áreas de mercado de bens de grandezas diferentes. A Figura 3.8, a seguir, evidencia esquematicamente a dinâmica espacial do princípio de mercado. 


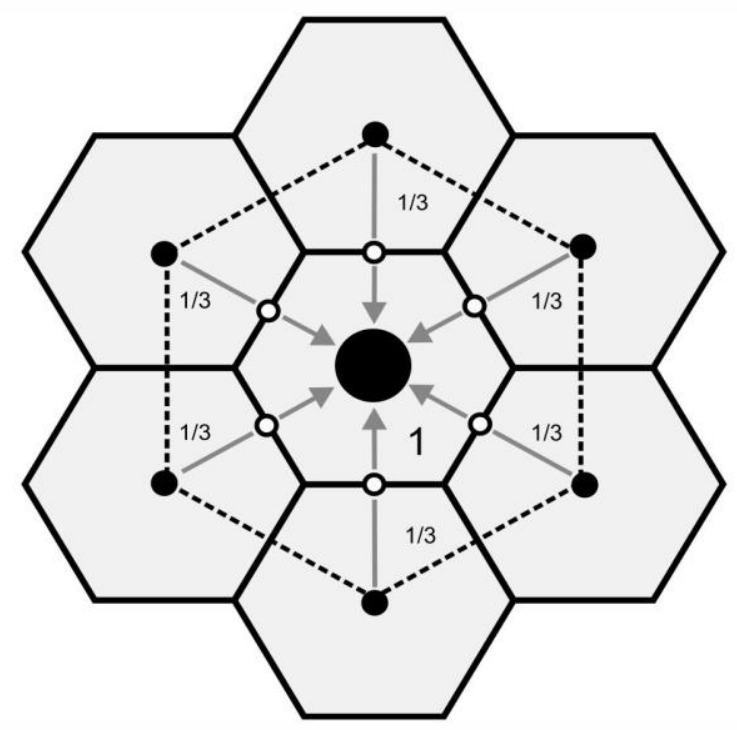

Figura 3.8 - Esquema hexagonal do Princípio de Mercado.

Fonte: Adaptado de Capello (2008).

Interessante notar que no Modelo de Christaller, associado à métrica da distância, é apresentado um coeficiente de área abrangida e de lugares centrais de menor hierarquia associados ao de hierarquia maior que os polariza. Para o Modelo, o lugar central de hierarquia superior recebe a nomenclatura (n), enquanto o de hierarquia imediatamente inferior recebe a nomenclatura (n-1), (n-2) etc.

Para o Princípio de Mercado, para cada assentamento/núcleo urbano de nível superior (n) tem-se uma área polarizada (n-1) igual a 03 (três) vezes a área central (a área do polígono superior + frações que somadas equivalem a 02 (dois) polígonos). A esta unidade de medida do Modelo de Christaller denominou-se "K3".

Princípio de Transporte: este pressupõe que as rotas de deslocamento entre duas cidades são estabelecidas mediante o critério do menor custo tanto quanto possível, ou seja, aproxima-se do deslocamento linear. De acordo com este princípio um lugar central é o ponto médio de uma rota de tráfego originária de localidades pré-existentes.

Na distribuição de lugares centrais, conforme a lógica do princípio do transporte, os centros de menor ordem estão localizados no ponto médio de cada lado do hexágono e não nas extremidades como poderia se imaginar. A Figura 3.9 demonstra esquematicamente este princípio. 


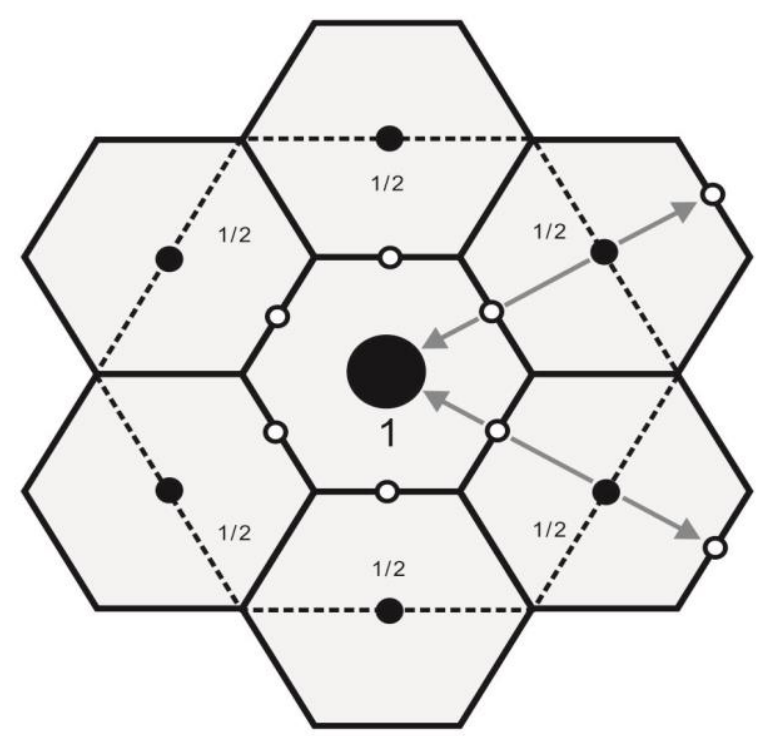

Figura 3.9 - Esquema hexagonal do Princípio de Transporte.

Fonte: Adaptado de Capello (2008).

Para o Princípio de Transporte, para cada assentamento/núcleo urbano de nível superior tem-se uma área polarizada igual a 04 (quatro) vezes a área central (a área do polígono superior + frações que somadas equivalem a 03 (três) polígonos). A esta unidade de medida do Modelo de Christaller denominou-se "K4".

- Princípio Administrativo: este aponta que os centros de ordem superior são reduzidos em relação aos centros de inferior, que são integralmente subordinados em proporção de 6 para 1. O centro de ordem superior possui, além de sua área de mercado, a de 06 (seis) centros de ordem inferior circunvizinhos. Novamente, o diagrama hexagonal é o que permite a observação da interação das forças de polaridade e de conexão existentes, conforme dispõe a Figura 3.10.

Por sua vez, para o Princípio Administrativo, para cada assentamento/núcleo urbano de nível superior (n) tem-se uma área polarizada (n-1) equivalente a 07 (sete) vezes a área central. A esta unidade de medida, o Modelo denomina "K7". 


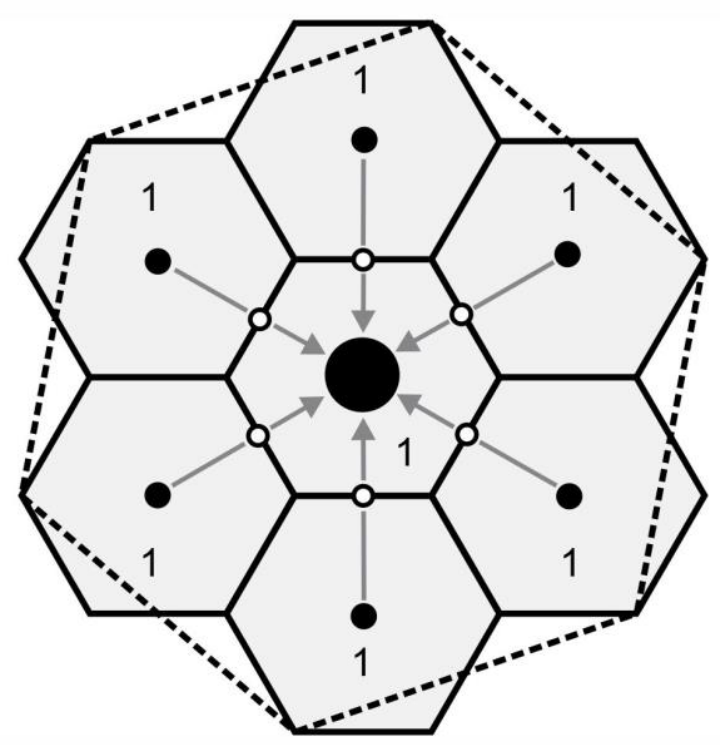

Figura 3.10 - Esquema hexagonal do Princípio Administrativo.

Fonte: Adaptado de Capello (2008).

\section{A Importância do Modelo de Christaller}

É de grande importância a produção teórica de Walter Christaller, sobretudo, para a Geografia humana e econômica, podendo ser considerada um dos mais bem sistematizados postulados teóricos deste ramo do conhecimento técnico-científico.

Interessante salientar que no Modelo de Christaller os Princípios de Mercado, de Transporte e Administrativo possuem, respectivamente, os coeficientes de áreas de influência K3, K4 e K7, que correspondem, além da proporção de área/território sob influência, ao multiplicador referente ao número de assentamentos urbanos existentes no Modelo.

Assim, para o Princípio de Mercado, para cada cidade de hierarquia superior (n), existem 03 (três) cidade de hierarquia imediatamente inferior (n-1). De igual modo, para o Princípio de Transporte, para cada cidade de hierarquia superior (n), existem 04 (quatro) cidades de hierarquia imediatamente inferior (n-1). O Princípio Administrativo obedece a mesma lógica aglutinativa com o coeficiente 07 (sete).

Acerca da relevância do Modelo de Christaller, Bradford e Kent (1987, p. 18) afirmam que "a abordagem teorética de Christaller foi para a geografia do povoamento semelhante à de Von Thüner para o uso agrícola do solo e à de Weber para a localização industrial". Ou seja, não há como não se estudar a distribuição espacial de populações sem se conhecer o que foi produzido pelo geógrafo por Christaller. 
Por outro lado, a TLC tem sido pouco estudada, o que para Garner (1975, p. 127, grifo nosso)

[...] é surpreendente não ter havido uma tradução satisfatória do original alemão até a de Baskin, em 1966. Talvez mais surpreendente ainda é não haver uma crítica completa das idéias contidas no Modelo, embora o estudo de seus aspectos espaciais possa ser encontrado em Berry e Pred (1961, págs.3-18), Ullman (1941), Barry e Garrison (1958 A, B, e C) e Bunge (1962), e uma crítica de suas posições econômicas é dada por Baskin (1966).

Para o geógrafo Roberto Lobato Corrêa (2005, p. 41), o trabalho de Christaller tem relação com a definição de regiões homogêneas e com as forças de polaridade locacional, cuja teoria refere a "um quadro teórico sobre a diferenciação dos núcleos de povoamento, no que se refere à importância que apresentam enquanto lugares de distribuição de produtos industrializados e serviços, ou seja, enquanto localidades centrais".

Assim, a TLC, de acordo com Corrêa (2005), aponta que a diferença das diversas localidades centrais, é uma nítida hierarquia da atuação espacial da oferta de bens e serviços oferecidos. A estratificação de localidades centrais é uma função da dimensão territorial e do volume de população potencialmente usufrutuária do que é disponibilizado pelo núcleo polarizador.

A existência de um conhecimento sistematizado, de uma teoria geral definidora da centralidade espacial/territorial enquanto fenômeno dá importância à teoria de Christaller. Sob este aspecto, Correa (2005, p. 17) acrescenta que

[...] a recuperação da teoria das localidades centrais é importante porque ela trata de um tema relevante que é o da organização espacial da distribuição de bens e serviços, portanto, de um aspecto da produção e de sua projeção espacial, sendo assim uma faceta da realidade social. Recuperá-la porque se torna necessário enriquecer nossa compreensão sobre as diferentes formas de espacialização da sociedade.

\subsubsection{Regiões econômicas: os cones espaciais de Losch}

A teoria de August Lösch, que ficou conhecida no conceito síntese por "Cone de Lösch”, foi construída a partir de estudos dos problemas da localização em economias de mercado. 
Para aquele teórico é possível construir um determinado "equilíbrio possível entre as localizações" por meio das "regiões econômicas" (LÖSCH, 1957, p. 100). As regiões econômicas - um conceito eminentemente econômico e geográfico (geoeconômico) - seriam a resultante de forças das condições de equilíbrio geral de mercado, detectáveis a partir das teorias do preço $^{24}$.

Para que ocorra o equilíbrio das localizações, Lösch (1957 p. 94-98) aponta a ocorrência de 05 (cinco) condições essenciais, quais sejam:

- Condição 1 - A localização do indivíduo deve ser, para ele, o mais vantajoso quanto possível;

- Condição 2 - A existência de localizações numerosas e espaços totalmente aproveitados;

- Condição 3 - Devem desaparecer as ganâncias extraordinárias (cada ofertante deve estar circunscrito a sua área de mercado);

- Condição 4 - As regiões de produção, compra e venda devem ter extensão mínima possível; e

- Condição 5 - Nas bordas das regiões econômicas é nula a força de ligação de localidades com relação ao núcleo pertencente (existem linhas de indiferença em relação a regiões vizinhas).

Esquematicamente, a Figura 3.11 permite uma compreensão melhor da interação econômica que se constrói a partir do efeito distância, conforme a observância das condições do Modelo de Lösch. Conforme dispõe esta figura, ao preço (p) tem-se a demanda (q1); com a majoração do preço pela distância $(\mathrm{m})$, tem-se o preço (p+mt) (distância do ponto $(\mathrm{m})$ ao ponto (p) multiplicado pelo custo unitário do deslocamento) o que implica na redução da quantidade demandada até o ponto (q2). De igual modo, para o consumidor, situado no ponto $(\mathrm{r})$, o preço do bem lhe custará (p+rt) (distância do ponto (r) ao ponto (p) multiplicado pelo custo unitário do deslocamento), o que reduzirá a demanda para a origem da curva, ou seja, para 0.

Considerando a liberdade dos deslocamentos dos agentes de mercado em todas as direções e, conforme a queda da quantidade consumida com o incremento da distância para o

\footnotetext{
${ }^{24}$ A teoria do preço envolve as relações intrínsecas à economia clássica. O aumento dos preços implica em redução do consumo. Os bens, para Lösch (1957), deveriam possuir elasticidade-preço.
} 
consumidor devido aos custos de transporte, o comportamento da redução do consumo medida pela relação preço-distância obedece ao descrito na Figura 3.11- item (B).
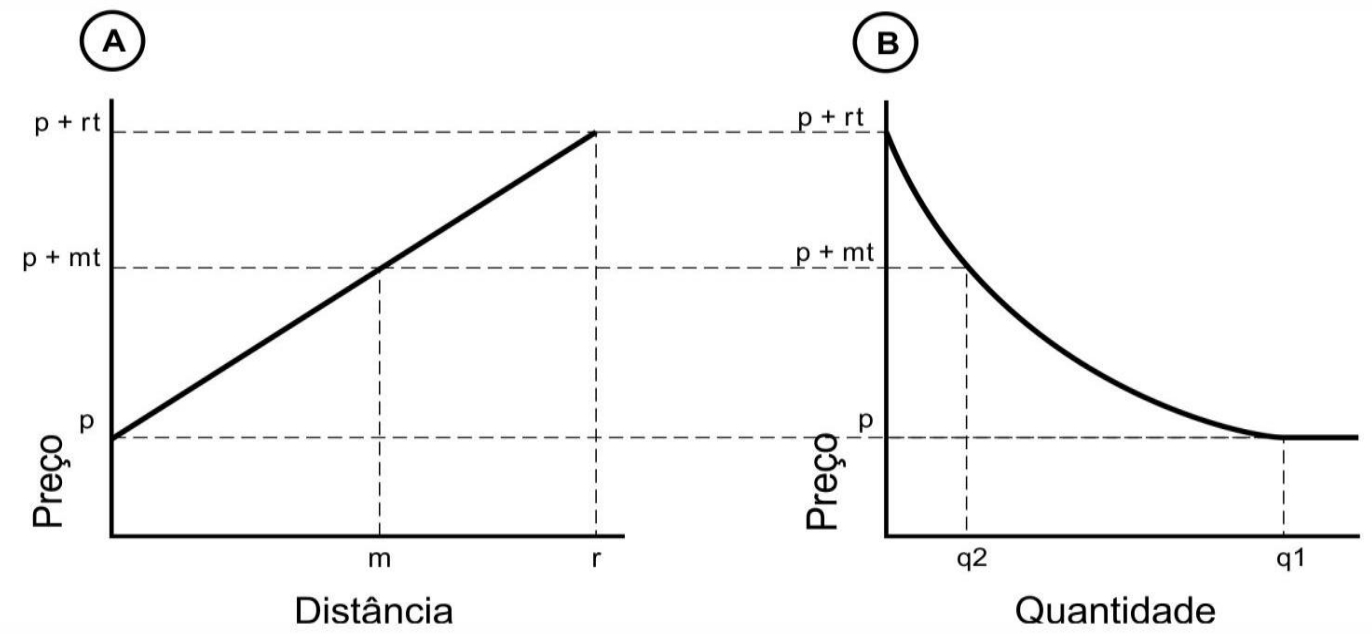

Figura 3.11 - Variações preço-distância e preço-quantidade de um bem ou serviço. (A) Interação preço-distância; (B) Interação preço-quantidade. O preço aumenta com a distância, enquanto a quantidade consumida declina com o aumento do preço.

Fonte: Adaptado de Berry (1967).

A Figura 3.12, por sua vez, evidencia o comportamento da quantidade demandada em relação à distância sob uma perspectiva tridimensional. A quantidade (q1) seria aquela cujos demandantes estaria a uma distância 0 , enquanto que na distância (m), a quantidade demandada cai para a quantidade (q2). Na distância (r), a quantidade demandada zera.

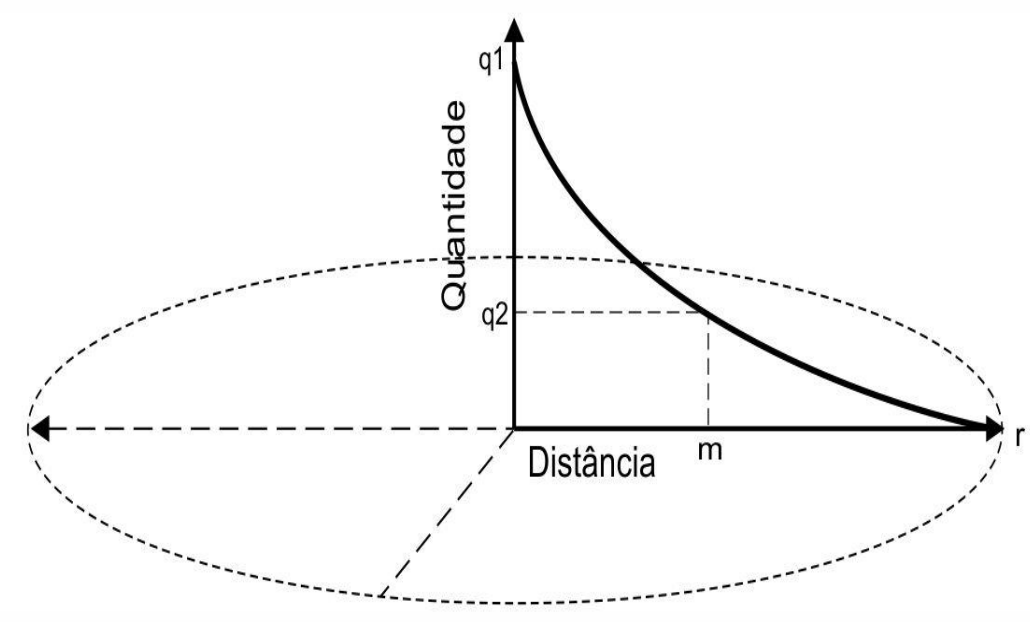

Figura 3.12 - Cone de demanda espacial de Lösch.

Fonte: Adaptado de Lösch (1957) e Berry (1967). 
Lösch (1957), ciente da inexistência da forma circular pura, propõe que a interação entre as regiões de mercado vizinhas seja convertida em um hexágono regular, aproveitando a dimensão do círculo. O hexágono seria o polígono geométrico que menos se afastaria da geometria circular e permitiria uma cobertura maior por unidade de área

Para Lösch (1957), a racionalidade hexagonal na distribuição de mercados constitui uma verdadeira "rede", conforme evidencia a Figura 3.13.

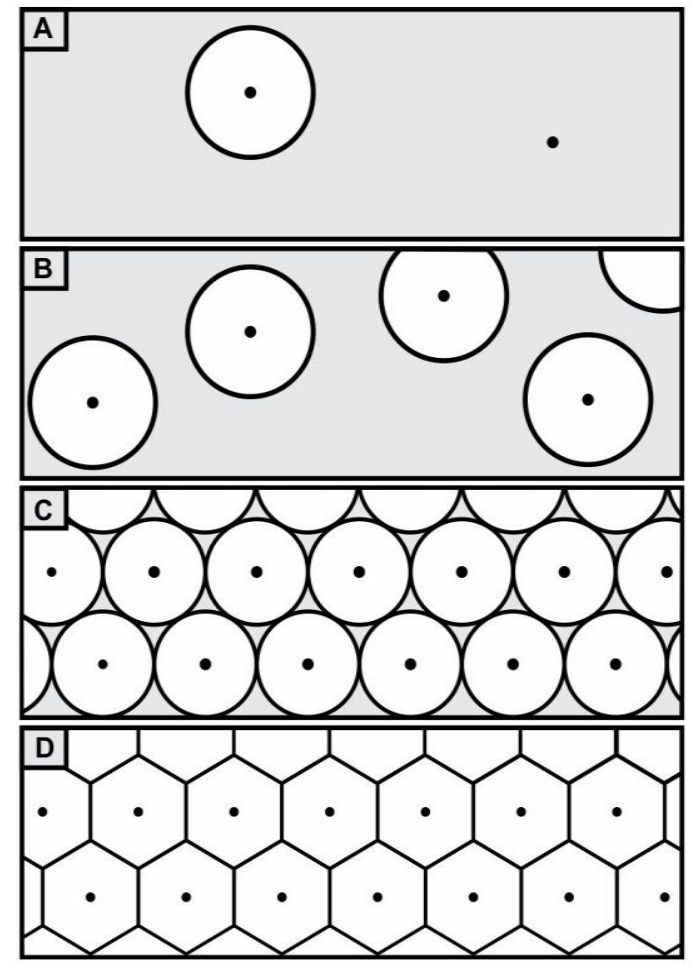

Figura 3.13 - Desenvolvimento de redes de mercado: da circunferência ao hexágono (situação (A) para a situação (D)).

Fonte: Adaptado de Losch (1957).

Lösch (1957, p. 114), em relação à forma geométrica ideal das regiões econômicas, afirma:

Resumindo, podemos comprobar que el hexágono simétrico será la forma más ventajosa para la región, tanto más cuanto más grande y redondeada se a la región total, cuanto más elástica sea la demanda em el limite regional y cuanto más la distancia de envio necesaria se acerque a la distancia posible. 
É interessante salientar que a elaboração da teoria econômica de Lösch foi posterior a de Christaller, tendo inclusive a obra Teoría Económica Espacial (editada em espanhol) realizado 11 citações do livro Central Places of Southern Germany de Christaller. As citações são sempre convergentes, entre outros aspectos, à opção pela geometria do hexágono regular como polígono de distribuição ideal de mercados e de população.

O trabalho de Lösch considera um mercado sob condições de monopólio (MONASTÉRIO; CAVALCANTE, 2011), sem, portanto, o controle das forças livres de mercado. Suas contribuições teóricas colaboraram, inclusive, na fundamentação dos princípios específicos de orientação de investimentos em economias planificadas.

Sobre a orientação e o dirigismo de investimentos por regiões de mercado do modelo loschiano e a situação de monopólio, é pertinente afirmar que "[...] os planejadores de localização nos países socialistas inspiram-se nos trabalhos de Weber e Lösch" (IAN HAMILTON, 1975, p. 197).

Assim, faz-se necessário observar que, não obtido a formação hexagonal ideal, é possível constatar a hipótese da existência de áreas neutras cujas abrangências das "regiões econômicas" são nulas, o que implica na indiferença de preferência do consumidor na escolha de um ofertante (A) ou (B). A Figura 3.14 evidencia esquematicamente tal situação, que também pode ser denominada de duopólio.

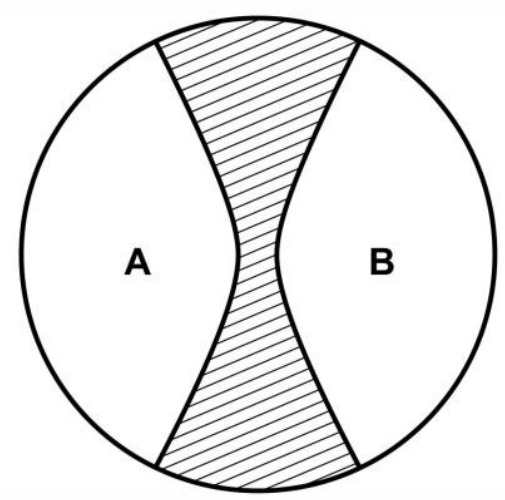

Figura 3.14 - Zona onde a escolha dos consumidores é indiferente entre (A) e (B).

Fonte: Berry (1967, p. 113).

O próprio Lösch (1957) defende a regulamentação da economia ${ }^{25}$ para que se obtenha “condições de equilíbrio". Para aquele autor, as condições de equilíbrio "constituyen los principios fundamenales de todas las intervenciones estatales" (LÖSCH, 1957, p. 100).

\footnotetext{
${ }^{25}$ Lösch (1957, p. 100) denomina tal intervenção como "regulación moderada".
} 
O viés metodológico da teoria de Lösch apresenta-se como de caráter dedutivo geral, com princípios e condições comuns a todos os lugares. A teoria de Christaller, de igual modo, possui a mesma filiação metodológica.

\subsubsection{A Geometria Hexagonal}

Esquematicamente, tanto Christaller quanto Lösch apontaram o hexágono como a forma geométrica ideal para representar a distribuição espacial de seus modelos teóricos.

A forma utilizada para se subtrair os vazios existentes entre áreas de mercados dos centros de mercados justapostos delimitados por circunferências foi a adoção do hexágono como forma geométrica modelar básica para o planejamento e a adequação de núcleos de povoamento. A Figura 3.13 demonstra tal objetivo.

O geógrafo Petter Haggett (1976) afirma que a escolha do hexágono como forma geométrica deriva da observância da Teoria Elementar do Mosaico ${ }^{26}$, que trata do problema da repartição eficaz de superfícies por centros concorrentes.

A Figura 3.15, em seu item (A), evidencia as distâncias radiais máximas de 04 (quatro) polígonos com área de 1,0 $\mathrm{km}^{2}$. A mesma Figura, por sua vez, em seu item (B), demonstra a relação entre a distância radial máxima e o perímetro de polígonos com área de $1,0 \mathrm{~km}^{2}$. Na Figura estão dispostos os polígonos cujos vértices variam entre 03 (três) e 10 (dez), acrescido das medidas da circunferência. Neste sentido, é possível notar que o aumento do número de vértices implica na redução do perímetro; o círculo representa o polígono de menor perímetro e de menor distância radial máxima.

A distância radial máxima serve para demonstrar o quanto de eficiência se tem nas formas geométricas diversas, observadas a partir do Princípio do Transporte de Christaller, que implica na busca pela menor distância; ou analisadas a partir da $2^{\circ}$ Condição e da $3^{\circ}$ Condição das regiões de mercado de Lösch, que implicam, respectivamente, na existência de localizações numerosas e espaços totalmente aproveitados e em áreas de produção, compra, venda com extensões mínimas possíveis.

\footnotetext{
${ }^{26}$ Conforme o chamado "Plano Euclidiano", são mosaicos regulares apenas o triângulo equilátero, o quadrado e o hexágono.
} 
(A)
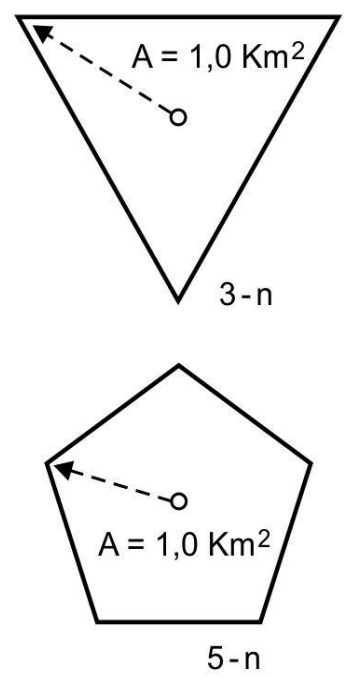
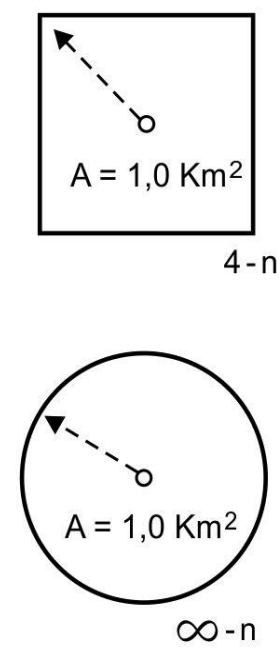

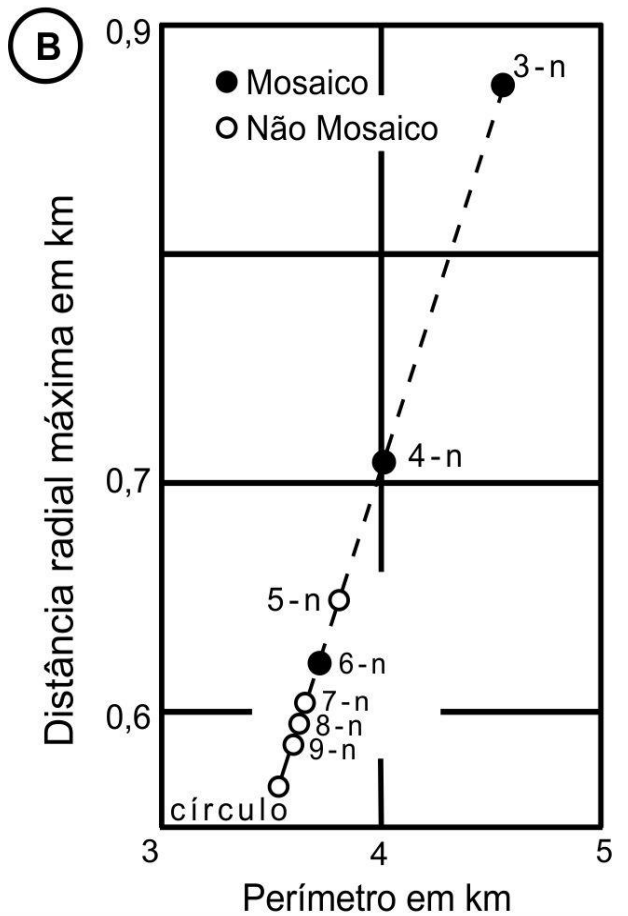

Figura 3.15 - Eficácia de distintos tipos de polígonos regulares em relação à distância do centro e ao cumprimento do perímetro.

Fonte: Haggett (1976, p. 66).

A Figura 3.15, item (B), demonstra que entre os polígonos que são mosaicos, o hexágono conserva a melhor vantagem em relação ao círculo. Uma vez estando descartado a circunferência em função da existência dos vazios, o hexágono cumpre geometricamente as funções de partilha "ideal" de territórios.

Para Haggett (1976, p. 65) a eficácia de repartição tem por finalidade atingir a "eficácia do movimento" e a "eficácia dos limites". Por eficácia do movimento entende-se a medida de distância entre o centro e os setores periféricos de um território. E por eficácia dos limites, entende-se a medida do perímetro do território.

O primeiro parâmetro busca reduzir os custos de transporte (financeiros e de tempo) e, o segundo, é “importante en la práctica puesto que representa, por ejemplo, los gastos de cercado de uma explotación agrícola, o los gastos de defensa de um Estado [...]" (HAGGETT, 1976, p. 65).

Uma ótima aferição da regularidade e verossimilhança empírica do hexágono enquanto polígono modelar da TLC foi realizada e descrita também por Haggett (1976). Este trabalho empírico foi realizado no Brasil, no Estado de Santa Catarina, na década de 1960, e excluiu os municípios costeiros e os de fronteira da amostra. Os 84 municípios restantes 
foram estudados para verificação do número de contatos de suas linhas divisoras. A variação de contatos das fronteiras municipais variou de 2 a 14 .

Como fecho da pesquisa, este eminente geógrafo inglês conclui que

El número de contactos medio de la muestra es 5,71. Se trata de una aproximación sorprendente al número hexagonal propuesto por Christaller y

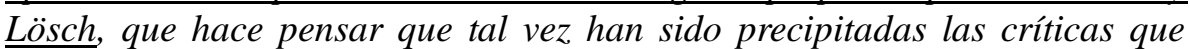
consideraban demasiado teórico el sistema hexagonal. Unos recuentos preliminares de áreas administrativas, en Francia y en China, confirman que la cifra obtenida em el Brasil no es excepcional, pero habrá que investigar más hasta poder estar seguros de haber aislado una constante de la organización territorial (HAGGETT, 1976, p. 69, grifo nosso).

Para Garner (1975, p. 127), o hexágono adotado na TLC, ao constituir-se em um "modelo de treliça regular", permite que as conexões dos núcleos periféricos em relação aos centrais dão-se por meio de triângulos equiláteros. A Figura 3.9 evidencia tal demonstração.

\subsection{MODELOS DE INTERAÇÃO GRAVITACIONAL, POTENCIAL OU ESPACIAL}

Os MIGPEs, ou simplesmente "Modelos Gravitacionais", constituem outro ramo de abordagem teórica dos métodos de análise locacional. Os Modelos Gravitacionais utilizados na descrição de fatores locacionais fazem uso de postulados teórico-modelares das ciências da natureza, em especial, aqueles contidos na Lei dos Gases ${ }^{27}$ de Boyle (ISARD, 1971), onde prevalece o comportamento das massas moleculares e não o das moléculas em separado.

Em relação à interação do Modelo Gravitacional com as ciências da natureza, Haggett (1976) aponta que este tem como um dos precursores a produção acadêmica de William J. Reilly, cujos postulados das chamadas "forças de atração de áreas comerciais" tinham por base uma analogia direta com a "teoria newtoniana" 28 .

Para a teoria newtoniana, o princípio da dinâmica estabelece que os corpos sejam atraídos entre si na proporção direta de suas massas e na proporção inversa do quadrado da distância entre eles. Ou seja, tem-se uma interação entre a massa de corpos, entre o movimento e os efeitos das forças de inércia.

\footnotetext{
27 A Lei dos Gases se refere ao comportamento mecânico de partículas gasosas, sendo considerada uma aplicação do princípio da dinâmica da Lei de Newton.

${ }^{28}$ A Teoria Newtoniana ou Leis de Newton é um dos fundamentos da Física Clássica e aborda o comportamento de massas/partículas diante de forças de interação.
} 
A produção acadêmica de Reilly ficou conhecida como "Lei da Gravitação de Reilly" ou "Lei de Reilly", cujo cerne teórico afirma que "two centers attract trade from intermediate place approximately in direct proportion to the sizes of the centers and in inverse proportion to the square of the distance from these two centers to the intermediate place" (BERRY, 1967, p. 41). Na linguagem matemática, esta Lei obedece a equação (3.1), que se segue:

$\frac{\mathrm{T}_{\mathrm{A}}}{\mathrm{T}_{\mathrm{B}}}=\frac{\mathrm{P}_{\mathrm{A}}}{\mathrm{P}_{\mathrm{B}}}\left[\frac{\mathrm{D}_{\mathrm{B}}}{\mathrm{D}_{\mathrm{A}}}\right)^{2}$

Onde:

$\mathrm{T}_{\mathrm{A}}, \mathrm{T}_{\mathrm{B}}=$ proporção de mercado de um lugar intermediário atraído pelo centro $(\mathrm{A})$ e $(\mathrm{B})$;

$\mathrm{P}_{\mathrm{A}}, \mathrm{P}_{\mathrm{B}}=$ tamanhos de $(\mathrm{A})$ e $(\mathrm{B}) ; \mathrm{e}$

$\mathrm{D}_{\mathrm{A}}, \mathrm{D}_{\mathrm{B}}=$ distâncias de $(\mathrm{A})$ e $(\mathrm{B})$ de um ponto intermediário.

Como o modelo de Reilly possui um viés determinístico e nenhum modelo determinístico descreve, de modo verossímil, os 'variáveis' comportamentos humanos, o mesmo, embora seja uma referência, não pode ser aplicado indiscriminadamente.

Porém, este modelo traz consigo o aspecto da tese geral da força de atração, conforme o custo distância. A partir dos conhecimentos de Reilly, o professor David L. Huff ${ }^{29}$ (19312014) desenvolveu uma teoria locacional com base na probabilidade de deslocamento de consumidores aos centros de comerciais, conforme a distância a percorrer. A chamada "Lei de Huff” é um aperfeiçoamento da "Lei de Reilly” e é dada pela seguinte expressão matemática:

$$
\mathrm{P}_{\mathrm{A} 1}=\frac{\underline{\mathrm{S}}_{1}}{\sum_{\mathrm{i}=1}^{\mathrm{r}}\left(\begin{array}{l}
\mathrm{T}_{\mathrm{A} 1}^{\alpha} \\
\underline{\mathrm{S}}_{\mathrm{i}}{ }^{\alpha}
\end{array}\right)}
$$

Onde:

\footnotetext{
${ }^{29}$ Foi professor emérito do Departamento de Geografia e Meio Ambiente da Universidade do Texas, em Austin, e Professor da Escola de Negócio McComb’s da mesma Universidade.
} 
$\mathrm{P}_{\mathrm{A} 1}=$ é a probabilidade que o consumidor localizado no ponto (A) visitar o centro comercial 1

$\mathrm{S}_{1}=$ é a dimensão do tamanho do mercado/centro comercial 1;

$\mathrm{T}_{\mathrm{A} 1}=$ é o tempo de viagem gasto da origem ao centro comercial 1;

$\mathrm{S}_{\mathrm{i}}=$ representa as diferentes tamanhos de áreas comerciais;

$\Sigma \mathrm{P}_{\mathrm{A} 1}=$ possui valor máximo igual a $1 ; \mathrm{e}$

$\mathrm{A}=$ parâmetro que varia com diferentes níveis de hierarquia.

No referido Modelo Gravitacional, por corolário, o comportamento das massas moleculares é entendido como o comportamento coletivo, enquanto que o das moléculas representaria o comportamento dos indivíduos ou de famílias específicas.

Tal Modelo representa uma abordagem operacional para mensurar os padrões dinâmicos de forças de atração de áreas de comércio. Os métodos quantitativos que fundamentam a linguagem matemática do modelo são formulações probabilísticas do comportamento dos agentes de mercado diante da consideração da distância enquanto custo e, portanto, fator locacional de escolha comportamental.

Acerca do modelo de Huff ${ }^{30}$, Berry (1967) apresenta as aplicações deste para as vilas situadas no Estado norte-americano de Iowa, conforme expresso na Figura 3.16 onde os anéis externos têm valores regressivos com base no distanciamento do núcleo central, que possui valor 1,0. Existe uma área (hachurada, índice 0,33) que será neutra ou indiferente à força polarizadora dos centros comerciais adjacentes.

A utilização de Modelos Gravitacionais para a localização de pontos comerciais e previsão de vendas estima como o potencial de gastos dos consumidores será atraído para cada ponto da rede varejista.

Em relação ao Modelo Gravitacional, Isard (1971, p. 530), assevera que

[...] la justificación del modelo gravital es simplesmente que la interacción entre dos poblaciones cualesquiera puede suponerse que está en relación direta con su tamaño, permaneciendo todo lo demás igual, y puesto que la distancia implica fricción, incovenientes y coste, tal interacción puede suponerse inversamente relacionada con la distancia.

\footnotetext{
${ }^{30}$ A Advanced Huff Model é uma das ferramentas do Programa ArcGIS Marketplace, utilizado no planejamento da expansão comercial de grandes redes de varejo multinacionais.
} 


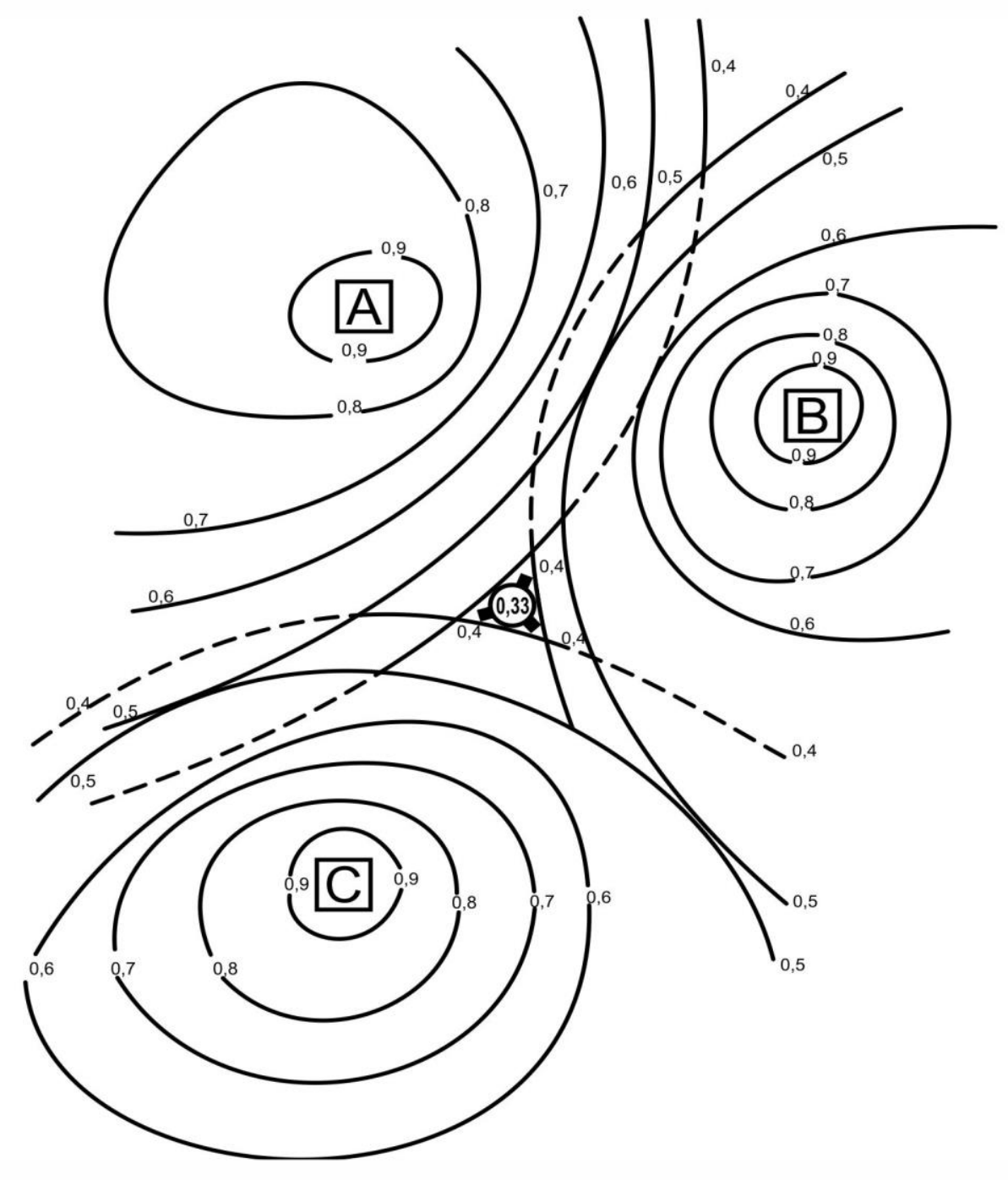

Figura 3.16 - Probabilidade para consumo em 03 (três) centros comerciais distintos (A, B e C). Fonte: Berry (1967, p. 55).

Isard (1971, p. 530), no tocante à interação entre as partes individuais e os comportamentos coletivos no âmbito de unidades regionais, afirma que

[...] la región se considera como un todo. Este conglomerado se estructura de acuerdo com ciertos principios. Estos gobiernan de forma total el nivel de comportamiento de las partes individuales, deteniendo y iniciando su acción. Las relaciones interregionales pueden concebirse como interacciones entres masas. Por outra parte puede decirse que los principios generales gobiernan la frecuencia e intensidad de tales interacciones y, por ello, modulan el comportamiento de las unidades (partes) individuales dentro de cada masa. 


\subsection{TEORIAS CLÁSSICAS DA LOCALIZAÇÃO E DAS CENTRALIDADES APLICADAS AO PLANEJAMENTO DE UNIDADES ADMINISTRATIVAS}

Do ponto de vista social, uma contribuição importante das análises das teorias clássicas da localização e das centralidades centra-se na delimitação de áreas administrativas e em seu comportamento de eficiência em termos de custos para o Estado e de acessibilidade para a população. Neste sentido, 02 (dois) conceitos instrumentais se destacam: 1) lugares centrais; e, 2) polos de serviços.

Uma boa forma de se compreender a eficiência econômico-espacial dos custos da disponibilização de serviços públicos, mediante a observância dos princípios dos lugares centrais ou dos polos de serviços, dá-se a partir da compreensão da dinâmica da produção de bens na economia industrial, cujo sistemático trabalho de monitoramento de custos e o esforço de produtividade representam os parâmetros a serem considerados.

Para a Economia Industrial, os custos de um bem produzido são demonstrados na Figura 3.17, a seguir, e apresentam comportamento de acordo com a curva de Custo Médio de Longo Prazo (CMeLP), que possui formato em (L) descendente, para um bem ou serviço, quando do aumento da quantidade produzida até o limite da estabilização. Esta curva demonstra um nível de produtividade conforme a quantidade produzida para um mesmo número de unidades produtoras, o que corresponde a uma "Economia de Escala".

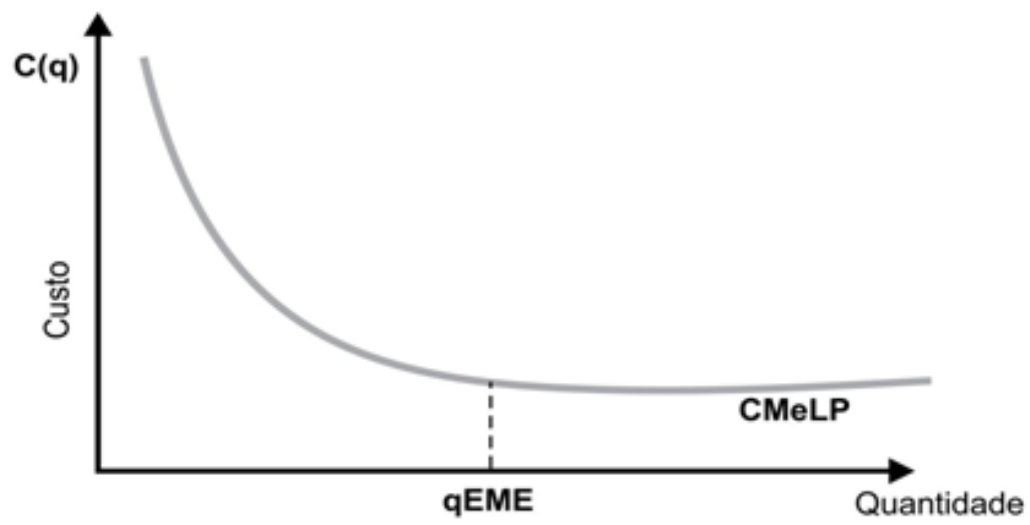

Figura 3.17 - Curva de Custo Médio de Longo Prazo em processos industriais. Onde: $\mathrm{C}(\mathrm{q})=$ Custos; $\mathrm{qEME}=$ Quantidade na Escala Mínima Eficiente; CMeLP = Custo Médio de Longo Prazo.

Fonte: Looty e Szapiro (2002, p. 53).

Assim, quanto maior a quantidade produzida, menores serão os custos unitários de produção até o ponto de estabilização da curva. As quantidades produzidas em nível menor do 
ponto Quantidade na Escala Mínima Eficiente (qEME) indicam a ineficiência produtiva e o custo unitário maior do que o ponto "ótimo".

Para Lootty e Szapiro (2002, p. 49), a curva do custo de longo prazo "pode ser considerada como uma curva de planejamento". Para estas autoras, os custos de longo prazo refletem

[...] as escolhas da empresa quando as quantidades de todos os fatores podem variar. Neste sentido no longo prazo, o que importa é o exame do comportamento global do custo frente à possibilidade da variação dos fatores de produção e, portanto, em relação ao nível de produto. Logo, é importante analisar o comportamento do custo médio de longo prazo (CMeLP). À medida que o nível de produção aumenta, os CMeLP de uma empresa podem permanecer constantes, aumentar ou diminuir. Se o CMeLP é reduzido quando a produção é elevada, a empresa possui economia de escala (LOOTTY; SZAPIRO, 2002, p. 49).

Semelhantemente, aos modelos da economia industrial, onde o custo de produção é decrescente quando do aumento da quantidade produzida, nas análises locacionais da economia regional, o custo do serviço prestado cai na proporção do aumento da dimensão da área administrada (custo inversamente proporcional à área de abrangência atendida).

Assim, a Economia de Escala aplicável ao planejamento governamental territorializado pode ser entendida como o rateio de custos frente à distribuição de benefícios, em proporção tal que o valor global de cada serviço prestado decresça à medida do aumento da área administrada/ofertada. A redução de ociosidades e os ganhos de eficiência são ingredientes contidos na relação C(q)/qEME da Figura 3.17.

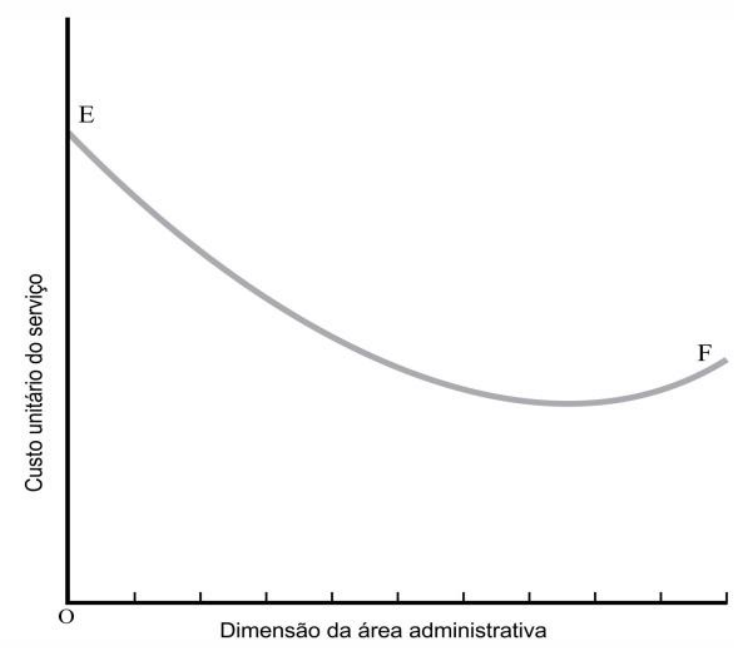

Figura 3.18 - Relação entre o custo e a dimensão da área administrativa.

Fonte: Adaptado de Isard (1971). 
$\mathrm{Na}$ prestação de serviços públicos, a dimensão de áreas administrativas representa o denominador e se dá pela área/dimensão de abrangência administrada até o ponto máximo da eficiência, conforme dispõe a curva (EF) da Figura 3.18, a seguir. Assim, é possível obter um ganho de escala mediante o adequado planejamento territorial da disponibilização de serviços públicos.

Entretanto, seria muito simples aos planejadores pensar somente do ponto de vista do custo do Estado na prestação de serviço, a partir da teoria da firma (redução dos custos, maximização da eficiência). Ocorre que o fator "distância" age nos modelos, de modo a dificultar o acesso aos serviços disponibilizados. Ou seja, a eficiência na redução do custo implica a perda de participação social. Cabe mensurar, assim, as "economías y deseconomías de yuxtaposición (o aglomeración)" (ISARD, 1971, p. 507). O raciocínio de Isard (1971) é representado por meio da linha $(\mathrm{AB})$ da Figura 3.19.

A interseção entre as Figura 3.18 e 3.19 se concretiza na Figura 3.20 que permite visualizar as implicações das dimensões de áreas administrativas quando dos custos e da participação comunitária nos serviços públicos disponibilizados.

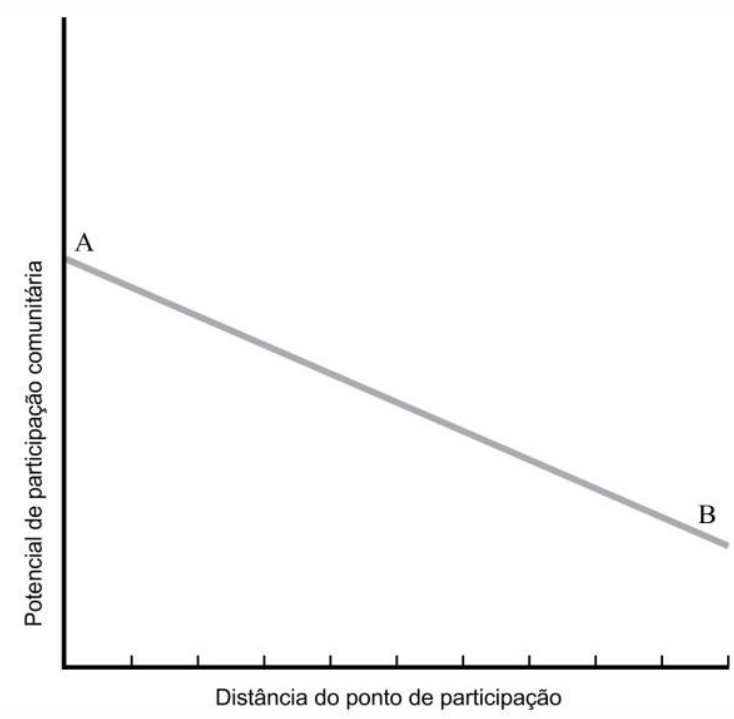

Figura 3.19 - Relação entre participação comunitária e distância.

Fonte: Adaptado de Isard (1971). 


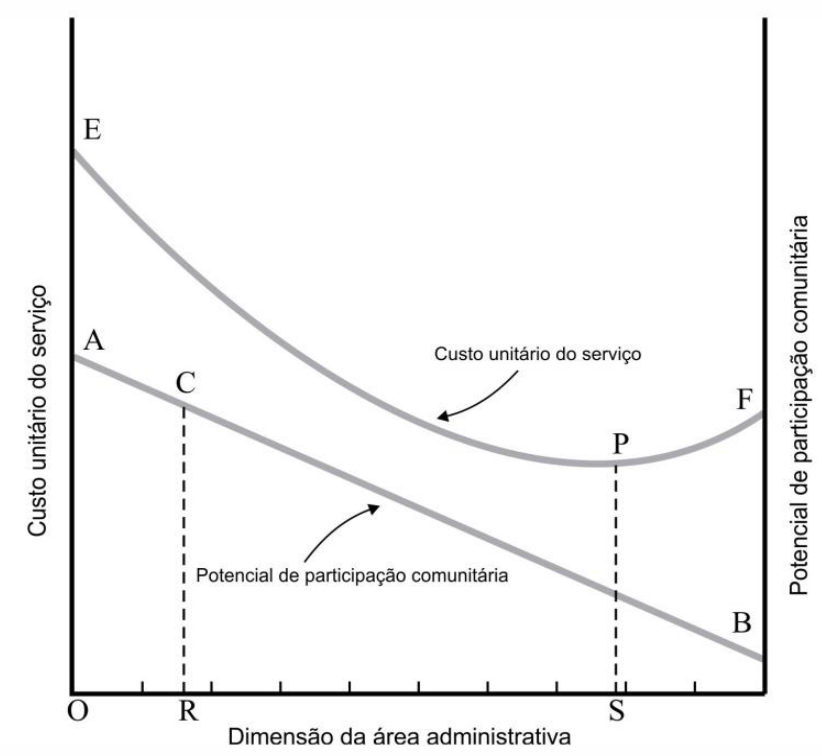

Figura 3.20 - Relação entre custo do serviço, participação comunitária e dimensão da área administrativa.

Fonte: Adaptado de Isard (1971).

O comportamento do custo unitário do serviço, representado pela curva (EF), face à linha de decréscimo do potencial de participação comunitária, representada pela reta $(\mathrm{AB})$, implica na obtenção do ponto (PS), que representa o menor custo unitário para a área administrativa mais apropriada, ao menos do ponto de vista da eficiência. Logo, o ponto (P) é considerado o ponto de dimensão administrativa mais eficiente e que corresponde à área administrativa (OS) e ao custo unitário (PS).

Apesar da eventual opção pelo ponto (P) e observando-se o custo (PS) (de maior eficiência de custo), faz-se importante observar que tal ponto representa a participação social diminuta. Ao administrador, é desejável que o tamanho da área administrativa seja uma escolha até o limite ao ponto mais eficiente do ponto de vista do custo, de forma a aumentar a participação comunitária nos serviços disponibilizados.

A este respeito, Isard (1971, p. 546) afirma que "es pequeño el incremento en el coste unitario; en cambio, es sensible el incremento en el potencial de participación comunitaria". Haveria, assim, certo ponto de equilíbrio ou ponto de escolha "ótima" entre a eficiência econômica e a participação social.

Este "ponto ótimo" serve de base para fundamentar a implementação de "polos" ou a escolha de "lugares centrais" para disponibilizar serviços e bens públicos. Para Isard (1971), o comportamento descendente de custos e de participação de social em serviços aplica-se bem 
nos necessários dimensionamentos de áreas de abrangência de escolas de Ensino Fundamental, de Ensino Médio e para aquelas voltadas ao Ensino Superior.

A escolha de pólos ou a definição dos "lugares centrais" para disponibilizar serviços e bens públicos representa mais do que um aspecto técnico, constitui-se num desafio de natureza técnico-político, especialmente, se for considerada a complexidade da estrutura federalista do Estado brasileiro.

A escolha de polos ou a definiç̧ão dos "lugares centrais" para disponibilizar serviços e bens públicos representa mais do que um aspecto técnico: constitui-se em um desafio de natureza técnico-político, especialmente quando se considera a complexidade da estrutura federalista do Estado brasileiro.

Do ponto de vista de uma estrutura político-administrativa federalista, torna-se ainda mais necessário compreender o efeito dos "dimensionamentos", tendo vista a partilha de obrigações entre a União, os Estados, os Municípios e o Distrito Federal.

Sobre a interação da partilha de obrigações intra-federativas, da interface com as dimensões das áreas administrativas e a questão da participação comunitária, Isard (1971, p. 548) assevera que

[...] se tenderá a asignar al gobierno federal las funciones administrativas para las cuales el potencial de participación comunitaria es de nivel bajo em todos los tamaños de las áreas administrativas, para las cuales se obtienen mayores economías de escala cuando se considera la nación entera como el área administrativa y para las cuales otros elementos importantes necesitan un control federal más que un control estatal o metropolitano.

As implicações econômicas e sociais das escolhas das dimensões das áreas administrativas são um pré-requisito para a definição das regiões como unidade de planejamento. Tais implicações ganham mais robustez em um cenário onde a unidade regional de planejamento envolveria uma cooperação federativa horizontal e vertical, sob o arranjo inter-federativo. 


\subsection{A NATUREZA DEDUTIVO-PROBABILÍSTICA DOS MODELOS E AS TEORIAS LOCACIONAIS: A ANALOGIA COMO PROCEDIMENTO TÉCNICO- CIENTÍFICO}

A interpretação dos padrões locacionais mediante mecanismos comportamentais e de instrumentos de modelos de forças de mercado passou a ser objeto de questionamentos na medida da evolução das teorias originárias da Física.

Para os modelos e para as teorias locacionais clássicas, os postulados de causa e efeito fundamentaram a interação entre populações, mercados, áreas de polaridades e forças de fluxos.

Por certo período, os modelos locacionais de natureza clássica foram interpretados sob um viés determinístico e normativo. As concepções de natureza normativa fundamentaram, inclusive, as correntes geográficas que apregoavam o determinismo ambiental.

Vale destacar que a interação entre os modelos das ciências da natureza e os modelos das ciências sociais se dá mediante analogias, isto é, pela busca de similaridades e não por efeito da aplicação direta. As ciências sociais, embora também comunguem dos rigores do método científico, possuem suas especificidades metodológicas.

Sobre o aspecto "similaridade" entre os "modelos das ciências sociais" versus "modelos das ciências da natureza", Reis Júnior (2007, p. 42) afirma que

A analogia tende a desempenhar um papel previsível nas explicações científicas, dado que é natural - pelo menos no nível preliminar - procurar compreender o desconhecido em termos do que já o é. O encontro de semelhanças entre fatos distintos denota, no mínimo, um talento do intelecto; só que não escapa de riscos.

Embora de grande utilidade explicativa, Reis Júnior (2007) aponta as ressalvas em relação à aplicação das "analogias" entre os modelos das ciências da natureza e os das ciências sociais, uma vez que a perspectiva extremada da "causalidade" e do "determinismo" "simplificou demasiadamente" as abordagens teóricas.

Ressalta-se que o comportamento humano e os fenômenos sociais são movidos por causas múltiplas, cujo livre arbítrio e as escolhas não racionais sustentam ações fora do feixe "normal" de distribuição de um dado fenômeno.

Outro aspecto muito importante que colaborou com a melhor interpretação dos modelos se deu, segundo Haggett (1976), com a publicação, em 1927, do Princípio da 
Indeterminação $^{31}$ pelo físico alemão Werner Heisenberg (1901-1976). Com efeito, este princípio gerou dúvidas nos que entendiam o comportamento locacional humano a partir de interpretações exclusivas por relações de "causa e efeito" de campos de força. O Princípio da Indeterminação de Heisenberg foi formulado a partir das descobertas da descontinuidade da matéria e da energia realizadas pelo físico alemão Max Planck ${ }^{32}$ (1858-1947).

Como os estudos de Planck tiveram como objeto o comportamento espectral de matérias radiantes, o princípio da indeterminação conclui que algumas partículas têm posição variável devido ao seu movimento, e por isso, tem localização não precisamente conhecida.

O Princípio da Indeterminação tornou possível, deste modo, o entendimento de que as "leyes físicas no eran determinísticas, sino solo aproximaciones estadísticas de una muy alta probabilidad, basadas en poblaciones inmensas pero finitas impregnó con cierta lentitud las ciencias sociales" (HAGGETT, 1976, p. 37).

Deste modo, embora se reconheça a contundência e verossimilhança dos modelos e das teorias locacionais, estes não possuem um viés normativo; representam um esquema conceitual descritivo, e com isso, constituem uma "representação aproximada" (HACKING, 1996, p. 246) de fenômenos de origem abstrata emanados do pensamento dedutivo.

Assim, a Geografia, como as demais ciências, busca na Filosofia da Ciência (FC)33 fundamentos lógicos que auxiliam na construção de procedimentos representacionais e de modelos que possuem utilidades em técnicas de intervenção no mundo concreto.

Em relação ao entendimento probabilístico do comportamento locacional humano, Haggett (1976, p. 37) afirma ainda que "la sustitución de leyes normativas por la idea de las tendencias probabilísticas dio lugar a una visión enteramente nueva del comportamien en la cual era posible acomodar tanto el libre arbitrio como la determinación".

Os Modelos Gravitacionais e as teorias locacionais têm enorme valor teóricoconceitual, a partir do reconhecimento da natureza dedutivo-probabilística dos postulados que apresentam, pois, tem por fundamentos os princípios de economia clássica.

Neste sentido, existe uma interação direta entre a distância e os movimentos/fluxos, uma vez que os deslocamentos implicam em custos adicionais para o acesso a serviços públicos ou privados ou para aquisição de bens econômicos. A distância é uma variável-custo facilitadora ou inibidora das atividades econômicas, dependendo do ponto em que o eventual

\footnotetext{
31 Também denominado "Princípio da Incerteza".

32 Max Planck postulou que a matéria só poderia emitir ou absorver energia em pequenas quantidades, ou subpartículas denominadas de "quanta". Sua produção acadêmica tornou possível a produção da teoria quântica. Planck ganhou o Prêmio Nobel de Física em 1918.

${ }^{33}$ A abordagem da Filosofia da Ciência está disposta no Capítulo 1 desta Dissertação.
} 
agente se encontre do centro de mercado e serviço. Assim, a qualidade central de um núcleo de mercado ou polo de serviço é sua "centrality" (BERRY, 1967, p. 3).

É interessante notar que entre alguns aspectos comportamentais humanos que incidem diretamente nas relações de movimento-distância e de morfologia-distância de núcleos de povoamento, a questão do exercício do "mínimo esforço" parece se destacar.

Sobre tal questão, Berry (1967, p. 3, grifo nosso) assevera que

Consumers who must visit the market place on a regular basis want a location that permits them to conduct their business with minimum of effort, and if a choice of location is available will always prefer the one which involves least effort.

Neste mesmo sentido, o economista alemão August Lösch (1957), ao desenvolver sua teoria econômica espacial, abordou, dentre outros aspectos, a abrangência de regiões econômicas diante da transposição de barreiras naturais pelos fluxos mercantis.

Para este economista, embora inexista uma "superfície de tráfego ideal" (que liga linearmente dois pontos quaisquer), há sempre um princípio econômico na redução de custos dos transportes a partir da rota mais eficiente, uma espécie de "lex parsimoniae, como principio del medio menor o de la resistencia mínima" (LÖSCH, 1957, p. 186, grifo nosso).

O caso prático da construção de pontes ferroviárias sobre rios de larga extensão é mencionado por Lösch (1957) como um exemplo de escolhas locacionais mediante critérios de economicidade, ou seja, quanto mais elevado o custo de construção, tanto mais provável que a ponte se desvie da direção original da ferrovia para cruzar o rio pelo caminho mais curto.

Com a mesma racionalidade, a Figura 3.21 evidencia a situação do envio de mercadorias entre o Havaí e Nova Orleans. Quanto maior o obstáculo a transpor, maior seria o desvio a percorrer (caminho I ou caminho II). O raciocínio de Lösch (1957) deriva de uma analogia da Lei da Refração ${ }^{34}$ da Luz, cuja transposição de meios se dá pela interface de menor resistência e refratância.

Na Figura 3.21, o caminho I refere-se ao Canal do Panamá, enquanto o caminho II refere-se ao Canal da Nicarágua ${ }^{35}$. Assim, “cuanto más elevados son los costos del canal, tanto más angosto debe ser, ceteris paribus, el lugar donde se haga el corte, quiere decir,

\footnotetext{
${ }^{34}$ Lei que descreve a relação entre os ângulos de incidência e refração quando a luz ou outras ondas atravessa uma fronteira (interface) entre dois meios isotrópicos diferentes.

${ }^{35}$ Situação de comparações em 1943, ano da conclusão da obra Teoria Econômica Espacial. Em junho de 2013, a Assembleia Nacional da Nicarágua aprovou uma concessão pelo prazo de 50 anos do futuro Canal da Nicarágua à Hong Kong Nicaragua Canal Development Investment Company (HKND Group).
} 
tanto mayor será la ventaja del Canal de Panamá sobre el de Nicarágua” (LÖSCH, 1957, p. 188).

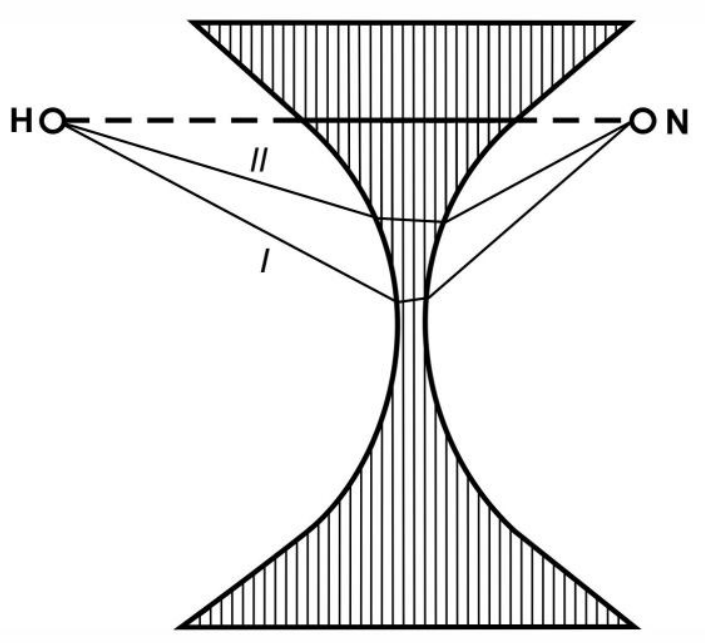

Figura 3.21 - Representação esquemática de menor custo de transporte.

Fonte: Adaptado de Losch (1957).

Sobre a questão da morfologia do movimento a partir da perspectiva locacional clássica do custo, a Figura 3.22 - item (A), apresenta, do ponto de vista probabilístico, os deslocamentos entre o ponto $(\alpha)$ e $(\beta)$. A Figura, elaborada por Haggett (1976), considerou o território como um plano uniforme, sendo que a linha tracejada a partir da medianiz seria o caminho de menor distância e, consequentemente, do menor esforço entre os pontos.
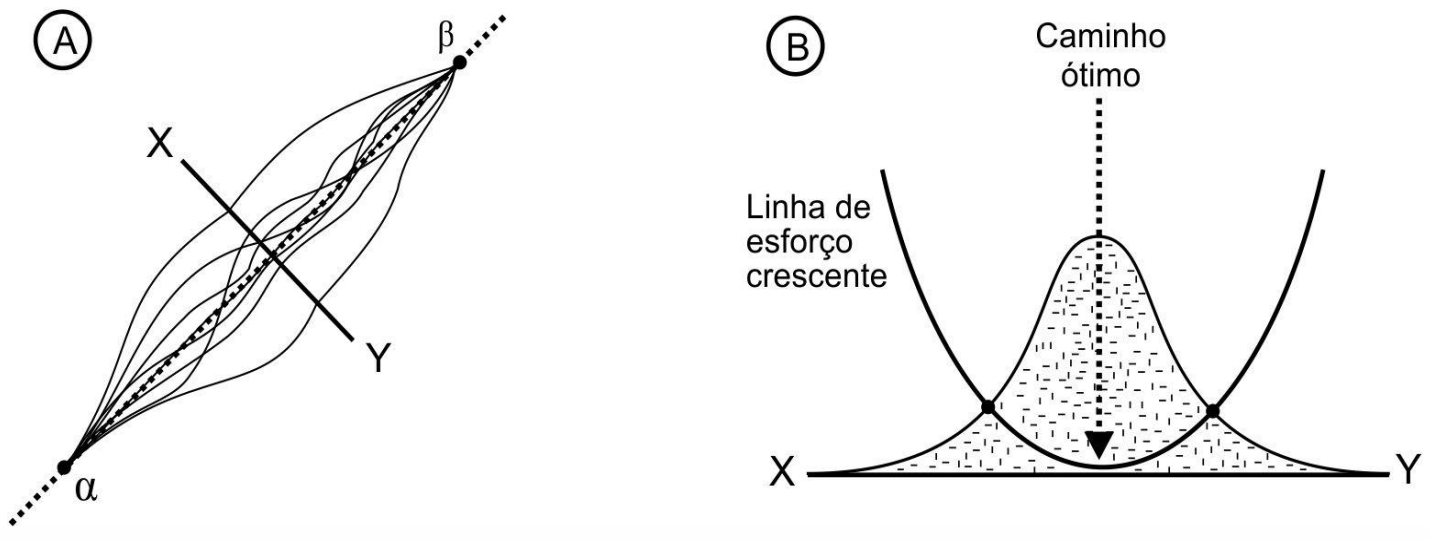

Figura 3.22 - Rotas hipotéticas de deslocamentos e análises da curva de esforço. (A) Corte perpendicular em rotas de deslocamento; (B) Linha de esforço crescente a partir do chamado caminho ótimo entre dois centros sob o ponto de vista da teoria probabilística.

Fonte: Adaptado de Haggett (1976). 
Já o item (B) da Figura 3.22 representa o corte perpendicular nos traçados de interconexão entre os pontos $(\alpha)$ e $(\beta)$ sobreposto à linha de esforço crescente e à distribuição da frequência dos deslocamentos a partir da Curva de Gauss.

Em relação à distribuição dos deslocamentos por meio da menor distância, Haggett (1976, p. 46) afirma que

[...] a medida que los caminos divergen del óptimo, aumenta la cantidad de trabajo que deben efectuar (en términos de distancia a recorrer). Podemos inferir que caminos reales tenderán a fluctuar alrededor del óptimo de un modo aleatório, dado una distribuición de Gauss alreador del camino de mínimo esfuerzo.

A construção teórica desenvolvida por Haggett (1976) menciona o padrão das rotas das ferrovias no noroeste dos Estados Unidos da América (EUA) como um exemplo da variância de distribuição real frente ao chamado caminho do mínimo esforço. Logo, o fator distância pela ótica do "mínimo esforço" configura, à luz dos padrões locacionais clássicos, mais um aspecto da natureza probabilística das escolhas da satisfação das necessidades humanas sobre o território.

A força do livre arbítrio e a diversidade dos fatores no mundo concreto geram múltiplas forças de dispersão, apesar de confirmarem a força de tendência dos movimentos da maioria. Daí tem-se a atualidade dos Modelos Gravitacionais e das teorias locacionais.

Afora as concepções determinístico-normativas e as de natureza probabilísticas, os modelos estocásticos (aleatórios) tiveram seu papel na explicação de fenômenos de distribuição espacial cujos fundamentos deram-se a partir da teoria dos jogos nos comportamentos econômicos.

Esta concepção de pensamento, apesar de ainda presente, fragilizou-se devido à contundência dos fatores locacionais de mercado determinados, inclusive, pela posição geográfica de infraestruturas, como, por exemplo, as de transporte, que sedimentam caminhos pré-existentes e se caracterizam como "fixos" territoriais (SANTOS, 1985). 


\section{O FEDERALISMO COMO PREMISSA INSTITUCIONAL PARA REGIONALIZAÇÕES NO PLANEJAMENTO}

\subsection{ASPECTOS TEÓRICOS DO FEDERALISMO}

Um aspecto importante no entendimento das relações de governabilidade de um Estado-Nação e em ações de definição de limites e de regionalizações como premissa ao processo de planejamento centra-se no formato institucional da estrutura políticoadministrativa do Estado.

Neste sentido, 02 (dois) formatos institucionais distintos se destacam: o Estado unitário; e o Estado federal. Estes dois modelos de Estado possuem antagonismos, pois, o primeiro apresenta uniformidade das instâncias decisórias e das representações estatais em todo o território governado; e o segundo, possui diversidade institucional das instâncias decisórias e das representações do Estado a partir de suas unidades regionais constitutivas (entes federativos) em um processo nítido de divisão espacial do poder.

O formato da configuração do Estado indica como os processos de planejamento atingem e/ou envolvem porções territoriais que necessitam de ações estatais em função de processos de escolhas técnicas e políticas.

Por sua vez, as ações estatais terão conduções distintas a depender de como as forças governamentais se organizam. A dualidade entre Estado centralizado e Estado federativo permeia um debate filosófico de modelos de gestão política, de gestão pública, de participação popular em decisões de interesse comum e de identidade social e regional coletiva que abrange todo o processo de legitimação do poder.

É comum buscar explicações de sucessos socioeconômicos de alguns Estados-Nações a partir do dualismo do formato estatal. Os modelos de estado alemão e norte-americano, em contraposição ao modelo francês, servem de base de análise.

A ciência política entende o federalismo como a teoria do Estado federal, cujo cerne tem por base a agregação de centros de poder de relativa autonomia como partícipes de uma entidade estatal maior.

Parte significativa de experiências federalistas internacionais indica uma contraposição aos movimentos nacionalistas como forma legítima exclusiva de organização políticoterritorial. 
Para o cientista político Norberto Bobio (1995, p. 481),

[...] o princípio constitucional no qual se baseia o Estado federal é a pluralidade dos centros de poder soberanos coordenados entre eles, de modo tal que ao governo federal, que tem competência sobre o inteiro território da federação, seja conferida uma quantidade mínima de poderes, indispensável para garantir a unidade política e econômica, e aos Estados federais, que têm competência cada um sobre o próprio território, sejam assimilados os demais poderes.

Este autor afirma que o federalismo tem por base a teoria do "governo supranacional, instrumento político que permite instaurar relações pacíficas entre as nações e garantir ao mesmo tempo sua autonomia, através da sua subordinação a um poder superior, mas limitado [...]” (BOBBIO, 1995, p. 477).

O arranjo político federalista transcende a concepção do convívio pacífico entre nacionalidades, pois adentra na perspectiva da integração e homogeneização regional. Pode-se afirmar que o mecanismo federalista mantém forças políticas mais ativas, pois existe uma espécie de "moto contínuo" de interesses, ora conflitantes e, ora convergentes, entre o governo central e os governos regionais.

O arranjo federalista também pressupõe a integração regional como um instrumento de política de gestão territorial para combater a baixa inserção nas atividades econômicas e de infraestrutura que estão sujeitas as porções do território cuja história econômica traz, por motivações diversas, uma força de inércia de um processo isolacionista.

Entende-se que o federalismo traz consigo um viés mais integracionista exatamente pela sobreposição de escala intergovernamental, abrangendo uma forma de alinhamento entre os interesses locais, regionais e nacionais.

Para o Professor Rainer-Olaf Schultze (1995, p. 15, grifo do autor),

[...] numa formulação mais moderna: em sistemas políticos constituídos de modo federativo, trata-se da conciliação de concepções opostas de sociedade, que podem ser esquematicamente representadas ao longo de um continuum bipolar, definido por uma concepção centrípeta de sociedade, que visa a integração e a igualdade das condições de vida, e por uma concepção centrífuga, voltada para a autonomia e independência e para a multiplicidade das condições de vida.

A Figura 4.1 baseada nos postulados teóricos de Schultze (1995), apresenta esquematicamente a sintetize da correlação entre forças de centralização e forças de 
descentralização. O formato do Estado entre unitário ou do tipo aliança corresponde à resultante da força predominante.

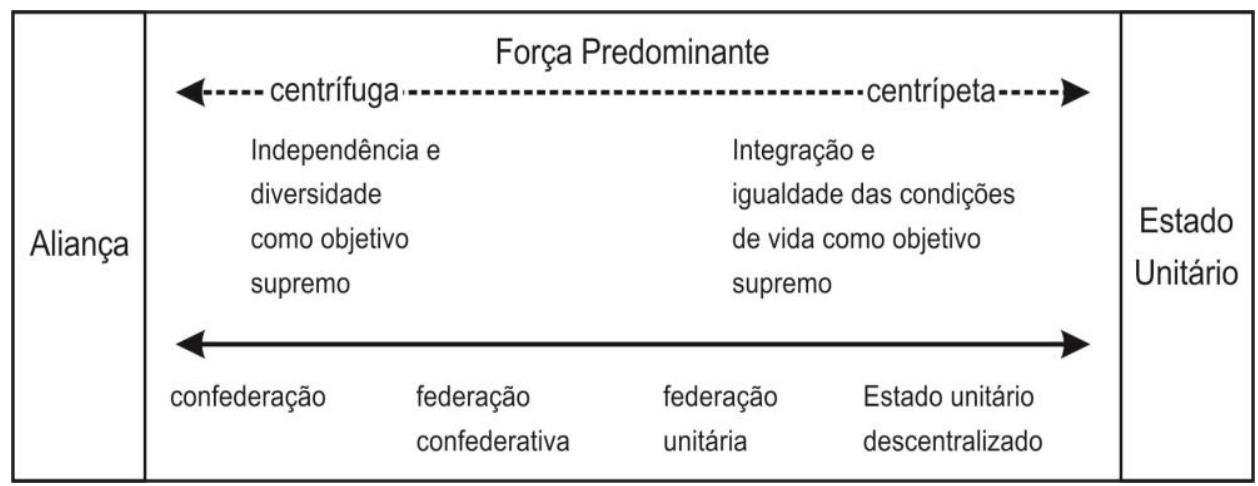

Figura 4.1 - Relação entre a força centrífuga e a força centrípeta e o formato do Estado.

Fonte: Adaptado de Schultze (1995).

Por sua vez, o professor Michael Bothe (1995, p. 5, grifo do autor) afirma, em relação ao federalismo, que

[...] do ponto de vista histórico, um ordenamento estatal federalista sempre significa um equilíbrio num campo de tensão entre forças centrífugas e centrípetas ou integrativas e desintegrativas. Sua finalidade é simultaneously to generate and maintain both unity and diversity. O peso político dos Estados membros é uma função da relativa força ou fraqueza dos respectivos fatores desintegrativos.

A relação de descentralização com centralidade do federalismo pode ser entendida como um teorema do modelo federalista. Embora o federalismo possua princípios gerais que o caracteriza, ele foi implantado e aperfeiçoado de forma distinta, conforme os arranjos políticos, históricos ou mesmo culturais de cada país.

Neste sentido, a socióloga Aspásia Camargo (2001) apresenta distinções entre o federalismo norte-americano e o federalismo alemão ao afirmar que o sistema estadunidense tem por base a autonomia dos poderes, na competição e autonomia dos Estados membros. Em oposição, o federalismo cooperativo alemão tem por base os "mecanismos de integração e de interpenetração" e o "princípio da subsidiariedade" (CAMARGO, 2001, p. 81).

Para Camargo (2001, p. 85), um dos pilares do princípio da subsidiariedade deriva do fato de que as políticas públicas devem ser "diretamente conduzidas pela autoridade ou instituição mais próxima o quanto possível do cidadão". Tal ação implicaria na primazia do município sobre a instância estadual, e esta, sobre o ente federal. 
Em relação ao chamado federalismo cooperativo, este pode ser entendido como os arranjos políticos de entidades federativas em prol do alinhamento de interesses e de execução de ações comuns, de modo vertical (níveis federativos distintos) ou horizontal (mesmo nível federativo).

\subsection{O FEDERALISMO BRASILEIRO: ASPECTOS HISTÓRICOS E JURÍDICOS}

No caso do federalismo brasileiro, os estados-membros não representam nações, embora exista a constituição de identidades regionais bem consolidadas.

O federalismo à "moda brasileira" é um federalismo de estados membros ${ }^{36}$; não é o federalismo de nações aglutinadas. Isto se explica pelas relações de identidade que foram criadas durante a história do Brasil. Deve ser reconhecido na história brasileira que a unidade linguística, as fronteiras externas pacificadas e um Estado central - embora frágil, mas existente - foi deixado como herança pela colonização portuguesa.

Neste sentido, o sistema federativo brasileiro se constituiu na expressão jurídicopolítica da partilha espacial de poder por meio da institucionalização de unidades políticas relativamente autônomas (as províncias). A manutenção da unidade territorial brasileira certamente foi obtida a partir de complexas alianças entre lideranças regionais (elites regionais) e a manutenção de interesses econômicos existentes.

A estrutura provincial do Brasil Império derivada do sistema sesmarial, baseado na propriedade da terra e em domínios regionais, dá o caminho histórico dos arranjos geográficos de poder que foram secularmente construídos.

É válido mencionar a ocorrência dos chamados movimentos nativistas no segundo quarto do século XIX, que foram impulsionados por conflitos de interesses entre os poderes "provinciais" e o “central". Dentre os movimentos nativistas destacaram-se a Balaiada (Província do Maranhão, 1838-1841), a Sabinada (Província da Bahia, 1837-1838), a Cabanagem (Província do Pará, 1835-1840) e a Farroupilha (Província do Rio Grande do Sul, 1835-1945). A Farroupilha culminou inclusive, em um movimento separatista que não obteve êxito.

O federalismo na história geopolítica brasileira contemporânea representa um arranjo clássico da teoria do "Path Dependence",37, onde o processo de tomada de decisão do presente

\footnotetext{
${ }^{36}$ Os entes federativos, a depender do país, podem ser chamados de estado, província, cantão ou länder (Farias, 2000).

${ }^{37}$ A teoria do "Path Dependence" ficou conhecida como a Teoria do Qwerty ou da dependência do caminho.
} 
possui uma enorme força residual das tendências, das instituições e dos grupos de interesses do passado. Milton Santos (1996) chama isso de "rugosidades espaciais", onde, apesar da mudança da função, as formas ${ }^{38}$ permanecem constituídas.

O federalismo tem sido percebido como uma condicionante institucional do padrão do Estado brasileiro, que representa um desafio de interpretação conceitual e metodológica aos processos de delimitação das regiões enquanto recortes espaciais para a elaboração do planejamento de políticas públicas.

Parte dos problemas gerenciais brasileiros tem origem na enorme centralização de recursos no ente federal, além das dificuldades interpretativas dos arranjos institucionais federativos. Poucas políticas públicas possuem organicidade federativa. O caso da Lei do Sistema Único de Saúde (SUS) (Lei n. 8.080, de 19 de setembro de 1990), que disciplina as funções para todos os entes federativos, destoa da regra geral.

Com efeito, é necessário compreender o formato do Estado nacional, em especial, as repartições de competências constitucionalmente determinadas a partir da distribuição vertical do poder e das obrigações consequentes. A distribuição vertical de poder compreende os Municípios, os Estados, o Distrito Federal e a União.

Inclusive, em relação às questões de abordagem teórica, da produção acadêmica e de fundamentação filosófica da questão federativa, Santiago (2013, p. 2) afirma que

Em tempos recentes, o debate conceitual acerca do federalismo tem perdido fôlego, não se encontrando obras de peso que sobre o tema se debrucem. Este silêncio teórico, contudo, não reflete a realidade de transformações e dificuldades que este modelo de organização política estatal vem enfrentando.

A importância e relevância do tema "federalismo" para o ordenamento jurídico brasileiro podem ser demonstradas na abordagem que a Constituição Federal (CF) de 1988 trata a temática. Para a Carta Magna, o federalismo é abordado no artigo $1^{\circ}$, do Título I - Dos Princípios Fundamentais, que afirma
A República Federativa do Brasil, formada pela união indissolúvel dos Estados e Municípios e do Distrito Federal, constitui-se em Estado Democrático de Direito e tem como fundamentos:
I - a soberania;
II - a cidadania;
III - a dignidade da pessoa humana;
IV - os valores sociais do trabalho e da livre iniciativa;
$\mathrm{V}-\mathrm{o}$ pluralismo político (grifo nosso).

\footnotetext{
${ }^{38}$ A forma aqui é entendida como a unidade federativa que se originou de uma província.
} 
Ao tratar a temática federalista exatamente no art. $1^{\circ}$, a CF de 1988 define o federalismo como princípio fundamental, ou seja, o formato do Estado é um ponto de partida do regramento constitucional do Estado-Nação brasileiro. O caráter indissolúvel da União, dos Estados, dos Municípios e do Distrito Federal reforça a perspectiva de unidade e de aliança nos fundamentos jurídicos da carta constitucional.

Este formato do Estado-Nação na introdução da carta constitucional serve para designar o padrão de identidade, de reconhecimento e de autorreconhecimento institucional. A complexidade administrativa, de relações identitárias, de obrigações tributárias, de garantias de direitos, dão-se em nível trino (União, Estados e Municípios). A compreensão teórica e jurídica do amálgama institucional torna-se um imperativo ao exercício da cidadania, aos tomadores de decisão, ao planejamento governamental e às escolhas para alocação de investimentos pelo capital privado.

Em um cenário onde as economias de mercado tendem a aumentar o nível de globalização dos intercâmbios comerciais, os impactos, os impedimentos ou as potencialidades dão-se em diferentes escalas. Assim, a forma federalista ${ }^{39}$ de Estado precisa ser mais bem compreendida, especialmente, quando se trata de planejamento governamental.

Inclusive, em sistemas federativos cresce a relação dos entes-federados na execução de defesa de interesses externos por meio de sistemas de representação e de interlocução, sem a participação do Governo Central. Os Estados membros de federações que, em âmbito internacional, buscam a representação de interesses, passaram a ser denominados pela pesquisadora Déborah B. L. Farias (2000) de "Governos Não Centrais - GNCs". Para esta autora, tem-se o aumento do processo de representatividade de interesses internacionais por "GNCs".

Farias (2000) atenta que a diplomacia do "Governo Central" tem sempre mais interesse pelas políticas de cunho estratégico (high politics), enquanto que os "GNCs" possuem, em matéria de assuntos internacionais, maior interesse em relação às políticas de negócios (low politics).

No que tange às relações entre o poder centralizado e poder descentralizado, o geógrafo português Gonçalo Santinha (2014, p. 89), ao estudar as múltiplas relações institucionais existentes no âmbito da União Europeia (UE), aponta que a gestão de interesses

${ }^{39}$ Dos quase 200 países do mundo, apenas 22 constitucionalmente se intitulam federações. Apesar disto, o federalismo abrange mais de $40 \%$ do território mundial e mais de $1 / 3$ da população total da Terra (FARIAS, 2000). 
tende a se dar por meio de "governança multinível", pois, existe sobreposição em uma mesma localidade, de interesses locais, regionais, nacionais e do próprio bloco europeu.

O conceito de "governança multinível" é de muita utilidade também ao sistema federativo brasileiro, pois, sobreposições de competência e/ou de conflitos de interesses e/ou vácuos de ação do poder público são comuns e possuem dimensões multiescalares.

Adentrando especificamente nas relações internas do Brasil, a força da convicção federativa nacional pode ser demonstrada quando da observação das limitações aos atos normativos pelo Congresso Nacional (CN). A este respeito, a Carta Magna de 1988 traz em seu art. 60 uma salvaguarda aos temas que estão explicitamente protegidos de quaisquer mudanças em função de serem considerados perpétuos. Esta se refere às limitações à apresentação de Emendas Constitucionais (ECs) pelos congressistas.

O $\S 4^{\circ}$ do art. 60 da CF de 1988, assim dispõe

A Constituição poderá ser emendada mediante proposta:

[...].

$\S 4^{\circ}$ Não será objeto de deliberação a proposta de emenda tendente a abolir:

I - a forma federativa de Estado;

II - o voto direto, secreto, universal e periódico;

III - a separação dos Poderes;

IV - os direitos e garantias individuais (grifo nosso).

Neste $\S 4^{\circ}$ do artigo 60 as matérias que são imunes à mudança por ações legislativas estão textualmente descritas. Nota-se que dentre as matérias com restrições de propostas, se apresenta, em primeiro lugar, a forma federalista de Estado, seguido pelo voto direto, secreto universal e periódico; pela separação dos poderes; e pelos direitos e garantias individuais.

Ao se referir à proteção de forma rigorosa de partes específicas da Constituição, aquelas cujas alterações não são permitidas por Lei ou mesmo Emenda Constitucional (EC), Oliveira (1996, p. 21), afirma que estas “[...] constituem o núcleo intocável da Constituição. São doutrinariamente denominados de cláusulas pétreas".

É interessante notar que o texto constitucional aponta para o fato de que o Congresso Nacional não pode deliberar sobre qualquer Proposta de Emenda Constitucional (PEC) que tende a abolir os conteúdos descritos no $\S 4^{\circ}$ do art. 60. Ou seja, a simples "tendência" à abolição de matérias ligadas ao federalismo possuem vedação de apreciação.

No Brasil, na relação entre os entes federativos ${ }^{40}$, observa-se que os limites de competências e atribuições são definidos pelos arts. 21, 22, 23 e 24 da Constituição Federal.

\footnotetext{
${ }^{40}$ No Brasil, diferentemente de outros países federativos, o Município constitui-se como um ente federado.
} 
$\mathrm{O}$ art. 21 trata exclusivamente das competências da União; o art. 22 dispõe sobre as competências legislativas privativas da União; o art. 23 refere-se às competências comuns da União, dos Estados, dos Municípios e do Distrito Federal; e, o art. 24 aborda os aspectos em que a União, os Estados e o Distrito Federal podem legislar concorrentemente.

A divisão de competência entre os entes federativos apresenta numerosas sobreposições, sendo necessária maior clareza nos limites de competência dos entes federativos. As judicializações por invasão de competência são algo comum. As fronteiras da soberania administrativa não são claras para os gestores.

O federalismo brasileiro é um desafio a mais ao exercício pleno da cidadania e ao bom desempenho da gestão pública. Os protagonismos políticos que culminem em ações do tipo "governança multinível” (SANTINHA, 2014), sob o viés do chamado federalismo cooperativo, ou subsidiário, têm se tornado urgentes e necessários.

É interessante notar ainda, os apontamentos do art. 43 da CF de 1988 cujo título é "Das regiões". Este artigo afirma que "Para efeitos administrativos, a União poderá articular sua ação em um mesmo complexo geoeconômico e social, visando o seu desenvolvimento e à redução das desigualdades regionais".

Embora exista avançada disposição constitucional, o instrumento jurídico “Das Regiões" não está claramente tipificado e/ou regulamentado infraconstitucionalmente.

O aprofundamento teórico do sistema federativo e as inequívocas contribuições advindas dos exemplos do federalismo alemão e do norte-americano induzem à necessidade de uma melhor compreensão teórica deste tipo de formato de Estado, pois dele derivam divisões territoriais e respectivas repartições de competências dos organismos de Estado que devem ser consideradas no processo de planejamento.

A clareza em relação às competências das estruturas estatais também contribuiria para a redução da insegurança jurídica para os investimentos privados.

\subsection{NOVAS TERRITORIALIDADES EM ARANJOS INTERFEDERATIVOS: CONSORCIAMENTOS E ECONOMIA DE ESCALA}

O federalismo, enquanto premissa institucional para o estudo de novas espacialidades e para o planejamento governamental territorializado, deve considerar os estudos contidos nas teorias clássicas da localização e das centralidades como base teórico-filosófica ao planejamento territorial. 
Entre as teorias clássicas da localização e das centralidades, a perspectiva trazida pela Teoria dos Lugares Centrais (TLC) e os postulados dos Modelos Gravitacionais, com a definição de uma hierarquia da atuação espacial da oferta de bens e serviços e a definição de polos de serviços, podem ser instrumentais técnicos utilizáveis ao possibilitar a aglutinação de mais de um ente federativo para atuação do Estado.

Adicionalmente às contribuições da releitura contemporânea da TLC, o geógrafo Milton Santos (1996) apresentou 02 (dois) conceitos significativos que permitem um melhor entendimento das relações envolvendo os elos de centralidades, de integrações e de cooperações entre territórios e cidades contíguas; ou mesmo, do isolamento relacional destes entes.

Tais conceitos foram por ele denominados "horizontalidades e verticalidades", sendo que as "horizontalidades serão os domínios da contiguidade, daqueles lugares vizinhos reunidos por uma continuidade territorial" (SANTOS, 1996, p. 16).

Por sua vez, as verticalidades são definidas como relações formadas por "pontos distantes, ligados por todas as formas e processos sociais" (SANTOS, 1996, p. 16). Em geral, as verticalidades podem ser entendidas como integrações de localidades que se conectam a partir dos arranjos produtivos e/ou políticos construídos ou por conexões econômicas ou por interligações político-administrativas.

Os arranjos de polaridades contidos na TLC, bem como as constatações de formações de configurações territoriais a partir de relações de coexistências superpostas de horizontalidades e verticalidades de lugares e de agentes econômicos são pontos teóricos relativamente pacíficos.

Há de se distinguir que a cooperação federativa pode se dar basicamente via cooperação vertical (realizada entre entes federativos de níveis distintos), e via cooperação horizontal (realizada entre entes federativos de mesmo nível administrativo). Por sua vez, a cooperação interfederativa envolveria uma transversalidade entre entes administrativos de mesmo nível administrativo, e a participação de ente(s) administrativo(s) de nível(is) distinto(s).

Em âmbito nacional, a perspectiva de proposição de ações de cooperação interfederativa ou consorciativas não é tema novo e já foi objeto de proposição por técnicos e gestores públicos. Porém, constata-se a inexistência de uma tradição administrativa pública na 
realização de ações cooperativas, apesar da amplitude contemporânea dos estudos de planejamento em âmbito nacional com viés consorciativo ${ }^{41}$.

Para Linhares, Cunha e Ferreira (2012), as ações pioneiras na gestão pública no que tange às políticas de aglutinação se deram com o Consórcio Intermunicipal de Saúde de Penápolis, criado em 1986, e com o Consórcio Intermunicipal Grande ABC, criado em 1990. Ambos situados no Estado de São Paulo. Com efeito, as ações consorciativas apresentam "destaque para a área de saúde, cujas iniciativas de consorciamento são, até hoje, as mais expressivas em quantidade" (LINHARES; CUNHA; FERREIRA, 2012, p. 41).

Os novos arranjos de políticas públicas de natureza decorrem da constatação das dificuldades gerenciais da repartição de obrigações e direitos inseridos na CF de 1988. O Brasil é um país de notória dificuldade administrativa por decorrência de sua extensão territorial superdimensionada e uma forte cultura patrimonialista, entre outros aspectos.

Em relação aos novos arranjos de políticas públicas de cooperação interfederativa, Andrade (1994, p. 220, grifo nosso) afirma que

[...] a divisão territorial do Brasil necessitaria ser retificada, com a criação de uma unidade intermediária entre o estado e o município, que poderia ser denominada de região administrativa ou de departamento, que aglutinaria uma série de municípios e procuraria dar maior racionalidade à distribuição geográfica dos serviços e das iniciativas dos estados.

Por outro lado, embora existam poucos instrumentos "reais" de gestão territorial por meio da definição de áreas geográficas multientes federativos, 03 (três) legislações no Brasil se destacam, quais sejam: a Lei n. 9.433/1997, que institui a Política Nacional dos Recursos Hídricos (PNRH); a Lei n. 11.107/2005, que dispõe sobre a contratação de consórcios públicos (execução cooperativa de serviços públicos ou obras); e, a Lei n. 12.305/2010, que cria a Política Nacional dos Resíduos Sólidos (PNRS).

A primeira Lei, baseada na legislação francesa e teoricamente lastreado na chamada região lablacheana, institui no inc. $\mathrm{V}$ de seu art. $1^{\circ}$ a bacia hidrográfica como "a unidade territorial para implementação da Política Nacional de Recursos Hídricos e atuação do Sistema Nacional de Gerenciamento de Recursos Hídricos”. Ou seja, a região natural de planejamento para o caso dos recursos hídricos deverá ser adotada como unidade de base, o

\footnotetext{
${ }^{41}$ Alguns estudos do Instituto de Pesquisa Econômica Aplicada (IPEA) têm trazido recentemente os desafios da discussão federativa. Cf. LINHARES, Paulo de Tarso; MENDES, Constantino Cronemberger; LASSANCE, Antonio (Orgs.). Federalismo à brasileira - Questões para discussão. Brasília: IPEA, 2012.
} 
que implica em um planejamento que aglutine entes federativos de todas as esferas de governo.

Ao seu tempo, a Lei n. 11.107/2005, que dispõe sobre a contratação de consórcios públicos (execução cooperativa de serviços públicos ou obras), representa um marco legal ao ofertar personalidade jurídica aos consórcios públicos de prestação de serviços e definir diretrizes e regras para constituição dos atos consorciativos entre todos os entes federativos.

É interessante observar que na área de atuação dos consórcios providos por entes municipais, a União (Governo Federal) somente participará, caso o(s) governo(s) estadual(is) esteja(m) inserido(s). Este modelo da Lei tem a finalidade de, quando da cooperação vertical, todos os entes federados estejam inclusos como partícipes na assunção de obrigações.

Por sua vez, a Lei n. 12.305/2010 cria um moderno dispositivo de transposição do Município enquanto unidade de planejamento/ação governamental por meio do "Plano Intermunicipal dos Resíduos Sólidos".

Presume-se, assim, que os legisladores observaram a pouca capacidade unitária de alguns Municípios na execução da disposição final de resíduos, podendo então, um determinado agregado de Municípios agir solidariamente com seus vizinhos. O rateio de obrigações, de custos, inexoravelmente, geraria uma chamada "economia de escala" ou um "ganho de escala".

Deste modo, a economia de escala aplicável ao planejamento governamental territorializado multifederativo pode ser entendida como o rateio de custos frente à distribuição crescente dos benefícios, em proporção tal que o valor global de cada serviço prestado é menor se realizado por meio consorciado em relação à prestação individualizada Município a Município, pois, a quantidade unitária de cada serviço ofertado cresce impondo ganhos econômicos implícitos. Têm-se ainda situações onde os elevados custos de serviços impõem a ação consorciada, como é o caso de serviços de saúde do tipo Unidade de Terapia Intensiva (UTI) ou de cirurgia de alta complexidade.

A redução de ociosidades e os ganhos de eficiência são variáveis contidas na relação Custo/Quantidade na Escala Mínima Eficiente (C(q)/qEME) da Figura 3.17 do Capítulo 3 da presente Dissertação.

O modelo de prestação de serviços públicos por meio de consorciamento pode gerar ganhos de eficiência na aplicação de recursos públicos e, por conseguinte, a região objeto dessas políticas públicas pode atingir melhores níveis de desenvolvimento social e de bem estar econômico e ambiental. 
Este novo cenário impõe um repensar federativo e a aplicação do conceito de região como insumo produtivo e variável de processo nos planejamentos governamentais em todos os níveis estatais.

A articulação federativa pode possibilitar a execução consorciada de serviços públicos. Neste cenário, o conceito de região ganha organicidade na medida em que uma rede de informações e posteriores ações produzem efeitos concretos na prestação mais eficiente de serviços públicos.

Do ponto de vista da teoria geográfica, o consorciamento da execução de políticas públicas adentra no princípio da multi-escalaridade, uma vez que o Município, o Estado e Governo Federal representam, respectivamente, as dimensões do local, do regional e do nacional.

A PNRH, a Lei dos Consórcios Públicos e a PNRS são instrumentos de gestão administrativa que possuem um caráter modernizante, pois tem por base as unidades territoriais de planejamento, gestão e ações que transcendem, isoladamente, a rígida divisão dos 4 (quatro) entes federativos.

Estas Leis trazem o território circunscrito e delimitado como um insumo obrigatório para o planejamento e execução de políticas públicas. É o que Steinberger (2013, p. 54) denomina de "reconhecimento contemporâneo sobre a inseparabilidade entre Estado, políticas-públicas e território".

Os exemplos das duas legislações ambientais e da Lei dos Consórcios Públicos permitem inferir a possibilidade de extensão de soluções consorciadas para múltiplas áreas. Tal ação demanda um esforço político e gerencial inicialmente de grande vulto, uma vez que se enquadra na concepção do planejamento governamental territorializado.

Os esforços de definição conceitual, os arranjos políticos institucionais e os necessários fluxos de informação para a constituição das regiões/polos, quando da execução das políticas públicas escolhidas, seriam compensados do ponto de vista econômico pelos ganhos advindos da "economia de escala".

\subsubsection{As políticas públicas e o federalismo fiscal}

Além da abordagem jurídica, histórica e cultural da questão federalista, existe uma abordagem de natureza econômica que é bastante esclarecedora em termos de compreensão da eficiência e dos custos das políticas públicas. 
Segundo Rogério Boueri (2012), a abordagem econômica do federalismo surgiu no âmbito da economia do setor público tradicional e desde os trabalhos pioneiros de Musgrave (1959) e Oates (1972) os cientistas sociais a têm denominado de "federalismo fiscal".

A abordagem econômica do federalismo fiscal pressupõe a existência de mais de um nível de governo e o estudo de qual nível torna mais efetiva e eficiente a tomada de decisões e a execução de políticas públicas.

Em relação ao objeto da teoria do federalismo fiscal, Boueri (2012, p. 235, grifo nosso) afirma que esta

[...] é primariamente preocupada com a forma ótima de atribuição de funções às diversas esferas de governo e, também, com as implicações destas escolhas sobre o bem-estar econômico. O objetivo seria a prescrição de como o governo deveria intervir na atividade econômica em virtude da existência de externalidades ou do problema de provisão de bens públicos e da definição de qual esfera de governo interviria de forma mais eficiente em termos de bem-estar.

Para a teoria do federalismo fiscal, a "forma ótima" de atribuição de funções nas diversas esferas de governo é compreendida a partir do conceito de "Ótimo de Pareto". Por sua vez, o "Ótimo de Pareto" pressupõe um equilíbrio de mercado em economia concorrencial.

Uma das grandes contribuições em relação à construção teórica relacionada ao federalismo fiscal centra-se no chamado Teorema da Descentralização, elaborado em 1972 pelo professor Wallace Oates (1999, p. 1122, grifo nosso), que assim se expressa:

In the absence of cost-savings from the centralized provision of a (local public) good and of interjurisdictional externalities, the level of welfare will always be at least as high (and typically higher) if Pareto-efficient levels of consumption are provided in each jurisdiction than if any single, uniform level of consumption is maintained across all jurisdictions [...]. 


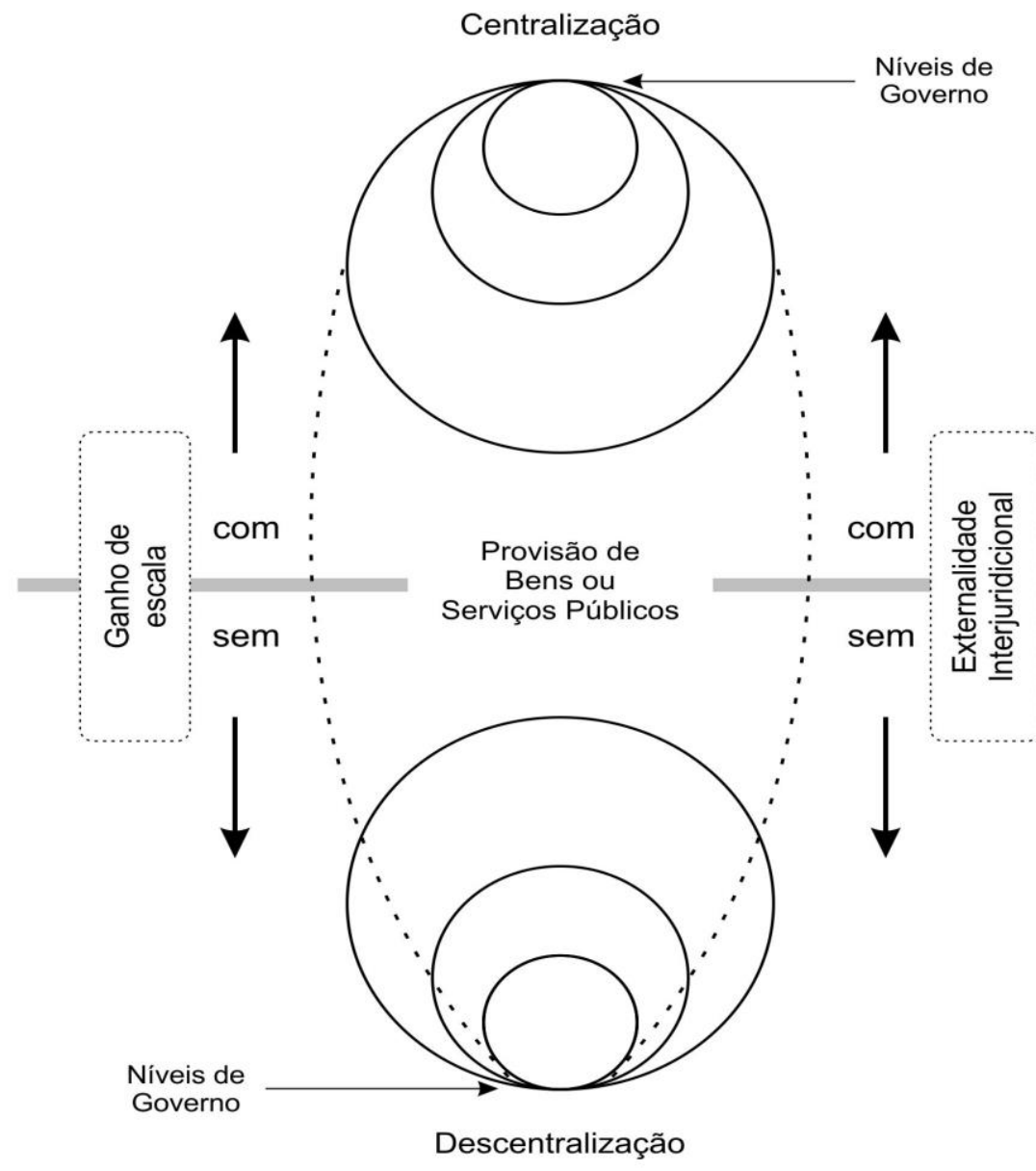

Figura 4.2 - Esquema gráfico do Teorema da Descentralização de Wallace Oates.

Fonte: Do autor.

Deste modo, para o Teorema da Descentralização de Oates, os elementos que definiriam se um serviço ou bem público seria ofertado de modo centralizado dão-se pela existência de ganhos de escala e de externalidades interjurisdicionais. Na inexistência de ganhos de escala e de externalidades interjurisdicionais, haveria, para o Teorema da Descentralização, vantagem na descentralização de bens e serviços públicos. A Figura 4.2 demonstra esquematicamente o Teorema da Descentralização de Oates.

Em relação às escolhas por centralização ou descentralização de bens e serviços públicos, Vargas (2011, p. 54, grifo do autor) afirma que "em outros termos, haveria um trade off entre a eficiência de proverem-se bens públicos uniformes de formas centralizada vis a vis à eficiência de proverem-se os bens públicos localmente [...]".

As externalidades interjurisdicionais entendidas como fronteiras e limites administrativos são um conceito de apreensão um pouco mais complexo em relação à 
objetividade do conceito de ganho de escala. A respeito da abordagem das externalidades interjurisdicionais pelo Teorema da Descentralização, Oates (1999, p.1130, grifo nosso), afirma que

The existence and magnitude of spillover effects from localized public policies clearly depend the geographical extent of the relevant jurisdiction. One way to deal with such spillovers is to increase the size of the jurisdiction, thereby internalizing all the benefits and costs.

Ou seja, Oates propõe o aumento do tamanho da jurisdição e a internalização dos custos e benefícios para a busca da eliminação dos efeitos das externalidades (spillover effects) das políticas públicas a partir de uma tácita perspectiva de que a extensão geográfica é um fator a ser considerado, em virtude da localização marginal dos transbordamentos característicos da flexibilização dos limites jurisdicionais de unidades administrativas por fenômenos econômicos reais.

Deste modo, pode ser entendido que para se atingir o "Ótimo de Pareto", o tamanho da unidade (administrativa) corresponderá ao tamanho da externalidade.

Um bom exemplo de institucionalização de unidades administrativas derivadas da incorporação dos spillover effects (externalidades) são as Regiões Integradas de Desenvolvimento (RIDEs) ${ }^{42}$, instituídas no Brasil pelo Governo Federal a partir de 1998, que incorpora Municípios e Estados na busca de solução de problemas transfronteiriços em aglomerações urbanas que permeiam mais de uma unidade federativa cuja gestão metropolitana fica também sob incumbência do Governo Federal.

Entretanto, a teoria do federalismo fiscal foi atualizada, sendo contemporaneamente denominada "Teoria do Federalismo Fiscal de Primeira Geração" e "Teoria do Federalismo Fiscal de Segunda Geração" (VARGAS, 2011).

A este respeito, Boueri (2012, p. 237, grifo nosso) esclarece que

A principal diferença entre as duas abordagens reside em que, enquanto a teoria de primeira geração se utiliza de métodos e instrumentos ligados à microeconomia tradicional, tais como economias de escala e externalidades, a teoria de segunda geração busca incorporar os avanços recentes da teoria microeconômica, como a teoria dos contratos, o problema do agente e do principal etc.

\footnotetext{
${ }^{42}$ A primeira Região Integrada de Desenvolvimento (RIDE) foi criada em 1998 por meio da Lei Complementar n. 94, de 19 de fevereiro de 1998, e abrange o Distrito Federal e 22 municípios de seu entorno, situados nos Estado de Goiás e Minas Gerais.
} 
Na presente Dissertação, o desafio de delimitação de regiões multi-entes federativos se elucida com os postulados das Teorias do Federalismo Fiscal de Primeira Geração.

\subsubsection{As relações intergovernamentais consorciativas e o Teorema da Descentralização}

A construção de um modelo de prestação de serviços públicos de forma consorciativa se robustece com a incorporação das contribuições do Teorema da Descentralização de Oates, entre as quais se destacam: a questão da abordagem da dimensão da área administrativa (para a eliminação das externalidades) e a questão dos eventuais ganhos de escala.

A forma consorciativa de prestação de serviços públicos transcende a dicotomia entre as concepções centralistas e descentralistas trazidas pelas Teorias do Federalismo Fiscal e envolve um arranjo cooperativo, isto é, a construção de arranjos gerenciais. Vargas (2001) aponta a necessidade de formalização de "institucionalidades" para a descentralização de serviços. De igual modo, a constituição de institucionalidades é necessária para aglutinação consorciativa.

Por conseguinte, as institucionalidades político-administrativas como instância gerencial delineiam linhas mestras que "deveriam orientar as relações intergovernamentais" (VARGAS, 2011, p. 67). Portanto, a abordagem econômica possui reflexos diretos nos arranjos políticos e no arcabouço jurídico.

Ao se transpor à dicotomia centralização-descentralização contida nas Teorias do Federalismo Fiscal, ressalta-se que a grande contribuição do Teorema da Descentralização de Oates é apresentar um paradigma para solução da dimensão da área administrativa cuja solução centra-se na internalização de todos os benefícios e custos, eliminando, assim, as externalidades.

Com efeito, as relações governamentais para consorciamento de serviços e bens públicos de modo interfederativo podem considerar dimensões de unidades de administrativas com externalidade minimizadas. 


\subsection{A POLÍTICA NACIONAL DE DESENVOLVIMENTO REGIONAL: ENTENDIMENTOS PARA TEMÁTICA FEDERATIVA}

A doutrina do Governo Federal acerca do conceito de região como instrumento de gestão territorial se dá a partir de uma análise da Política Nacional de Desenvolvimento Regional (PNDR), instituída pelo Decreto n. 6.047, de 22 de fevereiro de 2007.

O referido Decreto possui 03 (três) objetivos básicos: reduzir as desigualdades de nível de vida entre as regiões brasileiras; promover a equidade no acesso a oportunidades de desenvolvimento; e orientar os programas e ações federais no território nacional.

Do ponto de vista da tese central e dos objetivos, a PNDR, em seu sentido amplo busca basicamente a redução das chamadas desigualdades regionais (também denominadas de disparidades regionais). Ou seja, o foco da ação está na redução das diferenças socioeconômicas entre as diversas regiões do território brasileiro e na construção de um padrão de desenvolvimento com nível mais uniforme e de melhor paridade comparativa entre os lugares.

Assim, a concepção filosófica do PNDR pode ser entendida como uma busca por uma "homogeneização", isto é, por uma menor discrepância dos lugares em relação aos indicadores socioeconômicos.

A redução das desigualdades regionais é demasiadamente importante, pois é causa geradora de concentrações econômicas, de cidades macrocéfalas, de fluxos migratórios, de estigmatização cultural, de sobrecarga da infraestrutura de alguns lugares e diversos outros custos socioeconômicos indesejáveis.

As propostas no âmbito da PNDR, definidas a partir dos objetivos supramencionados, buscam, então, corrigir as distorções produzidas no território pelas forças monopolistas do sistema capitalista. Assim, o Estado, atua corretivamente após a produção dos efeitos indesejados gerados pelo sistema econômico.

A abordagem da PNDR como reparadora de disparidades pode ser aferida por meio de intervenções e aportes de recursos do Estado nas áreas deprimidas, na criação de áreas especiais de planejamento e intervenção como se observa no Programa Faixa de Fronteira, no Programa do Semiárido e no Programa BR-163 Sustentável.

A respeito da origem das desigualdades regionais, um outro documento publicado pelo Ministério da Integração Nacional (MI) intitulado "Política Nacional de Desenvolvimento Regional- Sumário Executivo” (Sem data) em sua página 12, afirma que esta é o 
[...] resultado da dinâmica assimétrica do crescimento capitalista, que se concentra em alguns espaços, enquanto condenam outros à estagnação e ao desperdício de fatores produtivos. A PNDR atua no sentido de contrabalançar a lógica centrípeta das forças de mercado, por meio da promoção e valorização da diversidade regional, conciliando, assim, competitividade e expressão produtiva de valores socioculturais diversos.

O papel do Estado como compensador das distorções do sistema capitalista acaba colocando-o como o ator que assume o ônus, os custos das externalidades econômicas produzidas. Assim, o ente estatal envereda-se em uma busca constante pelos meios para mitigar as distorções que o modelo econômico hegemônico manifesta sobre o território.

Sob outro ponto de vista, mostrou-se ausente a construção de eixos conceituais de dimensionamento espaciais por meio de regionalizações para prestação de serviços simples e especializados. O incentivo à percepção da concepção e construção de "redes regionais" cuja implicação elementar é a agregação consorciativa de uma malha de lugares a um polo concêntrico (a uma região strito sensu) também não foi abordado.

Percebe-se que faltou um foco para atuação do planejamento das ações de Estado como um prestador de serviços a partir das obrigações de seus multi-entes federados. O Estado, em uma concepção de eficiência gerencial, pode coordenar suas forças e agir de forma interfederativa visando a redução das externalidades e a obtenção dos ganhos de escala.

Um raríssimo esforço consorciativo na PNDR é averiguado na incorporação das Regiões Integradas de Desenvolvimento - RIDE do Distrito Federal e Entorno ${ }^{43}$, na RIDE do Pólo das Cidades de Petrolina e Juazeiro ${ }^{44}$, e na da Grande Teresina e Timon ${ }^{45}$ que já existiam anteriormente ao Decreto de instituição da referida política.

Por uma questão de temporalidade pretérita e, principalmente, pela importância do marco legal para as políticas transversais interfederativas, é preciso registrar o lapso à referência aos instrumentos da Lei dos Consórcios Públicos na PNDR.

Sancionada 22 meses antes do Decreto que instituiu a PNDR, a Lei dos Consórcios Públicos e o seu instrumento legal central - o consórcio federativo - não recebeu a devida

43 A Região Integrada de Desenvolvimento do Distrito Federal e Entorno (RIDE/DF) foi criada pela Lei Complementar $n^{\circ} .94$, de 19 de fevereiro de 1998 e regulamentada pelo Decreto ${ }^{\circ} .2 .710$, de 04 de agosto de 1998, alterado pelo Decreto $\mathrm{n}^{\circ}$. 3.445, de 04 de maio de 2000.

${ }^{44}$ A Região Administrativa Integrada de Desenvolvimento do Pólo Petrolina/PE e Juazeiro/BA foi criada pela Lei Complementar $\mathrm{n}^{\circ}$. 113, de 19 de setembro de 2001, e regulamentada pelo Decreto $\mathrm{n}^{\circ}$. 4.366, de 9 de setembro de 2002.

45 A Região Administrativa Integrada de Desenvolvimento do Pólo Grande Teresina foi criada pela Lei Complementar $\mathrm{n}^{\circ} .112$, de 19 de setembro de 2001, e regulamentada pelo Decreto $\mathrm{n}^{\circ} .4 .367$, de 9 de setembro de 2002 . 
abordagem nesta política. O foco na redução das desigualdades e, notadamente, a gestão dos instrumentos de financiamento do desenvolvimento regional prevaleceram.

Vale destacar o papel do Estado no processo de desenvolvimento regional, que ainda constitui-se como um forte agente de poder sobre o território devido a sua alta capilaridade, apesar da tácita percepção da ocorrência de um cisalhamento de esforços, de recursos e de capital humano entre os entes federativos diversos. 


\section{REGIÃO, UNIDADE INTERFEDERATIVA APLICADA À GESTÃo AMBIENTAL DE PROJETOS DE INFRAESTRUTURA E AO PLANEJAMENTO DE SERVIÇOS PÚBLICOS CONSORCIADOS}

\subsection{UMA ABORDAGEM CONCEITUAL DOS IMPACTOS DE PROJETOS DE INFRAESTRUTURA: REPARAÇÕES E AS INSTITUIÇÕES FEDERATIVAS}

Os grandes projetos de infraestrutura produzem profundas modificações nas relações de obrigações entre os entes federativos em função dos aspectos locacionais envolvidos na interação impactos/externalidades em relação aos benefícios que são produzidos.

Os projetos de infraestrutura produzem diversos benefícios socioeconômicos de abrangência difusa, em âmbito nacional, regional e em escala local. Assim, os benefícios possuem uma transversalidade em relação à escala territorial de abrangência.

Porém, os impactos negativos, ou seja, as externalidades ou mesmo os danos ao patrimônio socioambiental, possuem uma abrangência mais concentrada em nível local ou, em menor ocorrência, em nível local-regional.

Entre os tipos de impactos negativos, a base local dos impactos de natureza socioeconômica refere-se, notadamente, ao incremento de demanda por serviços públicos de competência municipal e de competência estadual devido ao aumento populacional por consequência das obras.

Anteriormente à análise da perspectiva da escala de abrangência dos projetos de infraestrutura e os conflitos interfederativos envolvendo compensações e/ou reparações, há de se observar a existência de abordagens múltiplas em termos do conceito "impacto ambiental" e de terminologias conexas.

Quadro 5.1 - Abordagens múltiplas do dano, da externalidade e do impacto ambiental.

\begin{tabular}{|l|l|l|l|l|}
\hline $\begin{array}{c}\text { Campo do } \\
\text { Conhecimento }\end{array}$ & \multicolumn{1}{|c|}{$\begin{array}{c}\text { Foco da } \\
\text { Abordagem }\end{array}$} & $\begin{array}{c}\text { Método de } \\
\text { Avaliação }\end{array}$ & $\begin{array}{c}\text { Instrumento } \\
\text { Técnico/Processual }\end{array}$ & $\begin{array}{c}\text { Medida } \\
\text { Reparatórias }\end{array}$ \\
\hline $\begin{array}{l}\text { Direito } \\
\text { Ambiental }\end{array}$ & Dano & Tipificação & Responsabilização & $\begin{array}{l}\text { Punição/Reparação } \\
\text { do Dano }\end{array}$ \\
\hline $\begin{array}{l}\text { Economia } \\
\text { Ambiental }\end{array}$ & Externalidade & Valoração & Quantificação & $\begin{array}{l}\text { Compensação } \\
\text { Financeira }\end{array}$ \\
\hline $\begin{array}{l}\text { Ciências do } \\
\text { Ambiente }\end{array}$ & Interferência/Impacto & Caracterização & $\begin{array}{l}\text { Avaliação de } \\
\text { Impacto }\end{array}$ & $\begin{array}{l}\text { Compensação } \\
\text { Ambiental }\end{array}$ \\
\hline
\end{tabular}

Fonte: Do autor. 
Quanto às linhas teóricas dos efeitos negativos ao meio natural e/ou ao meio antropizado, o Quadro 5.1 apresenta 03 (três) abordagens: a do direito ambiental; a da economia ambiental; e a das ciências do ambiente.

O direito ambiental, enquanto campo de conhecimento, foca no fenômeno do "dano", buscando tipificá-lo (materialidade) para fundamentar a responsabilização (autoria) e a aplicação de medida punitiva ou reparatória.

A economia ambiental tem como foco de abordagem o fenômeno da "externalidade", visando valorá-la e quantificá-la para calcular as compensações financeiras.

Por sua vez, as ciências do ambiente, lideradas pela Biologia e ciências correlatas, têm como foco de abordagem o impacto ambiental caracterizando-o para avaliá-lo por meio de metodologias específicas a fim de se medir a "alteração natural" visando avaliar a intervenção, a busca de alternativas ou mesmo, a substituição de área por meio da compensação ambiental.

Inexiste em nenhuma das abordagens a perspectiva de considerar os efeitos negativos como obrigatórios, determinantes e consumados. No entanto, há situações múltiplas que a sociedade, pelas limitações tecnológicas ou por processos frágeis de escolhas, acaba por absorver uma a carga negativa dos efeitos de intervenção no meio natural. Por isso, a perspectiva de objeção a um empreendimento, ou de minimização e de mitigação dos efeitos serem adotados previamente às medidas reparatórias.

As medidas de reparação e compensação e outras conexas que são utilizadas no processo administrativo de licenciamento ambiental ou em instâncias judiciais dependem do campo de conhecimento originário adotado. A abordagem do "dano" diferencia-se da abordagem da "externalidade", que por sua vez diferencia-se da do "impacto". Isto não impede a ocorrência de mescla de abordagens e conceitos. Deste modo, é imperativa a compreensão conceitual do entendimento de impacto ambiental, de externalidade e de dano.

Entende-se como impacto ambiental a "alteração da qualidade ambiental que resulta da modificação de processos naturais ou sociais provocada pela ação humana" (SÁNCHEZ, 2008, p. 32). O impacto nesta concepção é visto como uma força de transformação que resulta em alterações qualitativas, ou seja, em transformações nas características naturais e sociais que possui como origem uma ação antrópica.

Entende-se por externalidade a situação na qual "os agentes econômicos que a emitem impõe, geralmente de forma involuntária, custos a outros agentes econômicos - consumidores e outras empresas" (MUELLER, 2007, p. 232). 
Para o professor Charlles Mueller (2007), a poluição é um ótimo exemplo de uma externalidade ambiental produzida. Ele exemplifica o caso de uma empresa que lança dejetos em um rio e pode estar provocando doenças e perdas de dias de trabalho a indivíduos além de fazer outras empresas, também usuárias das águas do rio, a incorrerem em custos adicionais de purificação.

Existem diversos tipos de externalidades conforme a tipologia da intervenção sobre o meio natural, ou sobre o meio natural antropizado utilizado como meio de vida de populações. Porém, as externalidades guardam consigo a característica da invonluntariedade do fenômeno, que a um só tempo, produz uma subtração no nível de bem estar físico e social do ponto de vista paretiano ${ }^{46}$.

A externalidade seria o entendimento e/ou a abordagem econômica do impacto ambiental originário das ciências naturais; ou o dano físico, econômico ou social tipificado na ciência jurídica.

Em relação ao conceito de dano ambiental, o jurista Edis Milaré (2014, p. 320, grifo nosso) afirma que

[...] é dano ambiental toda interferência antrópica infligida ao patrimônio ambiental (natural, cultural, artificial), capaz de desencadear, imediata ou potencialmente, perturbações desfavoráveis (in pejus) ao equilíbrio ecológico, à sadia qualidade de vida, ou a quaisquer outros valores coletivos ou de pessoas.

Na concepção do jurista Milaré, o dano ao meio ambiente abrange além do patrimônio natural, os patrimônios construídos pelas sociedades humanas. Esta moderna concepção jurídica considera o ambiente antrópico como parte do "meio ambiente" e, por conseguinte, deve haver tutela jurisdicional do poder público diante de intervenções e riscos potencialmente geradores de danos.

Há de se ressaltar que o princípio poluidor-pagador, o mais difundido princípio ambiental, materializou-se em compensações financeiras diversas como certificados remunerados de emissões, compensações ambientais etc.

A utilização e/ou beneficiamento de recursos naturais no setor de mineração, a extração de petróleo e o uso de recursos hídricos para geração de energia elétrica implicam em outras compensações financeiras que são distintas da compensação ambiental. É necessário se distinguir compensação ambiental, relacionada aos impactos ambientais

\footnotetext{
${ }^{46}$ Ótimo de Pareto.
} 
(FARIA, 2008), das compensações financeiras, relacionadas à partilha de benefícios pelo usufruto de bens naturais de titularidade estatal.

Em relação às compensações financeiras, sobre a atividade de geração elétrica usuária de recursos hídricos incide a Compensação Financeira pela Utilização de Recursos Hídricos para Fins de Geração de Energia Elétrica (CFURH). No setor de mineração, incide a Compensação Financeira pela Exploração de Recursos Minerais (CFEM). Por sua vez, ao setor de petróleo, recaem obrigações derivadas dos "royalties". Todas essas compensações financeiras possuem um rateio entre os entes federativos diretamente afetados pelas nuances da produção.

Acerca da definição da compensação ambiental enquanto instituto do direito ambiental, Faria (2008, p. 10, grifo nosso) afirma:

\begin{abstract}
Atualmente, a Compensação Ambiental, strictu sensu, é entendida como um mecanismo financeiro que visa a contrabalançar os impactos ambientais ocorridos ou previstos no processo de licenciamento ambiental. Trata-se, portanto de um instrumento relacionado com a impossibilidade de mitigação, imposto pelo ordenamento jurídico aos empreendedores, sob a forma preventiva implícita nos fundamentos do Princípio do Poluidor- Pagador. Nesse contexto, a licença ambiental elimina o caráter de ilicitude do dano causado ao ambiente [...].
\end{abstract}

No Brasil, modernamente, a compensação ambiental foi estabelecida pelo art. 36 da Lei n. 9.985/2010, que instituiu o Sistema Nacional de Unidades de Conservação (SNUC). Assim, não se pode confundir compensação ambiental com compensação financeira e royalties, pois estes não possuem uma natureza reparatória em relação aos impactos ambientais e caracterizam-se pela natureza distributiva de recursos financeiros em uma espécie de repartição dos benefícios.

Tanto a compensação ambiental como as compensações financeiras existentes no setor de mineração, de geração hidrelétrica e de petróleo, são formas de aplicações dos princípios de economia ambiental neoclássica que foram absorvidos pelas políticas públicas do setor de minas e de energia, bem como pela política ambiental. As reparações pecuniárias aliviariam a subtração de bem estar que determinado tipo de intervenção produz ou gera.

No entanto, as atividades econômicas às quais incidem compensações financeiras não estão isentas do pagamento da compensação ambiental. Ou seja, não se pode confundir compensações financeiras com o instituto da compensação ambiental. 


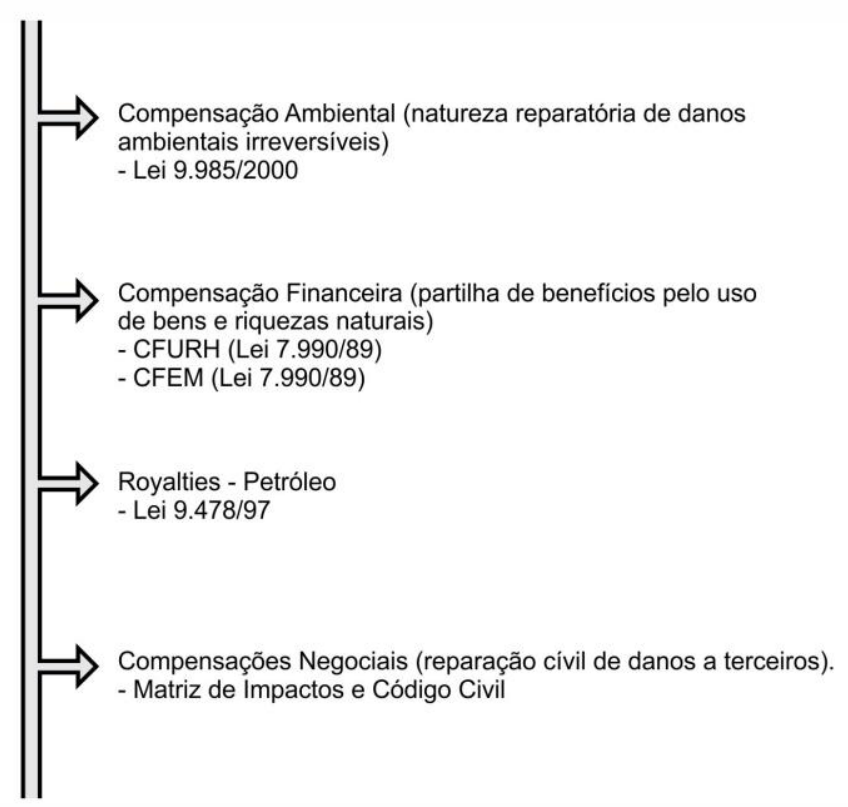

Figura 5.1 - Compensações ambientais e financeiras pelo uso de recursos naturais.

Fonte: Do autor.

Ademais, existem ainda as compensações financeiras de impactos, danos ou externalidades produzidas a terceiros no âmbito do processo de execução de obras ou atividades de engenharia que são detectáveis nos estudos ambientais quando da elaboração da chamada Matriz de Impactos Ambientais. Para cada impacto, externalidade ou dano deve haver algum tipo de medida contrária que o minimize, o mitigue ou o compense.

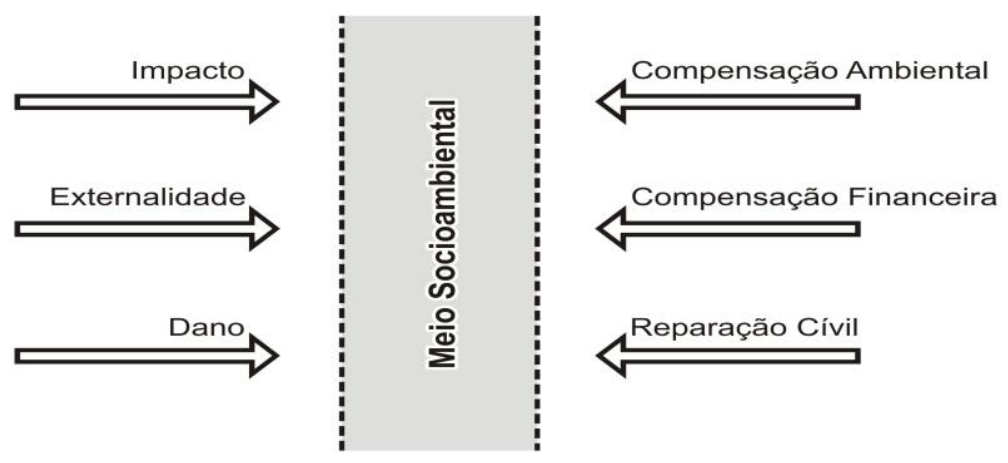

Figura 5.2 - Esquema das forças contrárias na análise de intervenções ambientais.

Fonte: Do autor. 
A origem lógico-jurídica das reparações em matéria ambiental surge, de acordo com Milaré (2014), de postulados do Direito Civil que possui base axiomática na Teoria da Responsabilidade Civil Objetiva

Para a Teoria da Responsabilidade Civil Objetiva e seu princípio fundamental, a responsabilidade civil objetiva, os danos provocados aos bens naturais como patrimônio coletivo e pluri-individuais estão sujeitos às obrigações de reparações. Com efeito, aos agentes geradores de danos, impactos, e externalidade deve recair o "ônus dos custos sociais de suas atividades" (MILARÉ, 2014, p. 430).

Assim, o Direito Ambiental pode ser entendido como um ramo do conhecimento jurídico que sintetiza, a partir dos paradigmas constitucionais, postulados do Direito Civil (patrimônio material coletivo), do Direito Administrativo (tutela do Estado) e do Direito Penal (punição a atos antijurídicos e lesivos).

Neste sentido, torna-se importante uma abordagem da temática ambiental de caráter interdisciplinar com múltiplas abordagens teóricas, de modo a melhor qualificar o ato danoso à coletividade, seja ele denominado impacto ambiental, externalidade ou dano.

A aplicação do princípio da responsabilidade civil objetiva dá-se pelo mero estabelecimento da vinculação entre o dano e a fonte de geração (apenas o nexo de causa e efeito). A relação de culpa ou intencionalidade não tem importância para a Teoria da Responsabilidade Civil Objetiva.

Sobre a questão da intencionalidade e culpa do agente gerador do dano ambiental, Milaré (2014, p. 429) afirma que a ação de reparação tem fundamento no "risco da atividade". A multiplicidade dos riscos como externalidades aponta para uma dimensão maior dos efeitos de várias atividades econômicas, o que é modernamente denominada de "sociedade de risco" (BECK, 2001, p. 61). Com efeito, é possível, então se falar em convergência entre a abordagem da economia ambiental neoclássica e a Teoria da Responsabilidade Civil Objetiva do Direito.

Cabe ressaltar que este trabalho não tem como objeto o aprofundamento das discussões acerca da natureza dos impactos ambientais ou socioambientais de obras de infraestrutura, nem no processo de licenciamento ambiental. A abordagem dos impactos socioambientais busca tão somente uma discussão teórica elementar dos arranjos institucionais interfederativos, dentre os quais, aqueles relacionados à reparação, mitigação e/ou compensação de impactos, de danos, ou de externalidades detectáveis. 
A metodologia do estudo de caso, não será abordada. Porém, alguns exemplos de empreendimentos serão mencionados como forma de tornar mais factível e crível o entendimento das relações interfederativas no âmbito do licenciamento ambiental. Os estudos de caso envolvendo reparação de danos e/ou compensação de impactos a partir de arranjos interfederativos são complexos e exigiriam estudos específicos.

A constatação de que problemas ambientais transbordam competências e limites de entes federativos e, acima de tudo, o fato de que as reparações cíveis e/ou as compensações (em muitos casos), necessitam de ações interfederativas delimitadas por um limite geográfico instrumental, a região, são explicações teóricas pertinentes.

\subsection{FEDERALISMO COOPERATIVO, ATUAÇÕES SUPLETIVAS OU SUBSIDIÁRIAS DE ENTES FEDERATIVOS NA POLÍTICA AMBIENTAL}

Interessante mencionar que o tema das interações dos entes federativos foi incorporado à legislação como forma de se criar mecanismos de institucionalização da transposição dos limites originais de competência, no caso de falhas ou situações adversas, e para evitar conflitos de sobreposição de competências nas ações estatais dos entes federativos.

Este mecanismo de interações dos entes federativos em matéria ambiental pode se caracterizar como um instrumento de "cooperação institucional” (MILARÉ, 2014, p. 649), dado a perspectiva do ente federativo de nível administrativo superior poder arguir, excepcionalmente, competências originárias de ente administrativo de nível imediatamente inferior, para sanar falhas gerenciais, técnicas ou omissões.

Um importante instrumento jurídico de delimitação de competências dos entes federativos e de cooperação institucional deu-se com a publicação da Lei Complementar (LC) n. 140, de 08 de dezembro de 2011, que regulamentou o parágrafo único e os incs. III, VI e VII do art. 23 da Constituição Federal, que definem as competências comuns da União, dos Estados, dos Municípios e do Distrito Federal em matéria de proteção ao meio ambiente, o combate à poluição e a preservação de florestas, da fauna e da flora.

A LC n. 140/2011 surge no complexo cenário das relações federativas do setor ambiental brasileiro, onde as competências comuns precisavam ser delimitadas a fim de evitar conflitos de competência, bi-jurisdições sobre atividades, ou mesmo, hiatos institucionais. Esta legislação tentou definir as ações de caráter supletivo e as de caráter subsidiário entre os entes federativos. 
A LC n. 140/2011, em seu art. $2^{\circ}$, inc. II, define a ação supletiva como a "ação do ente da Federação que se substitui ao ente federativo originariamente detentor das atribuições, nas hipóteses definidas nesta Lei Complementar”. Para o referido ditame, as hipóteses da ação supletiva concentram-se nas situações onde inexista órgão ambiental capacitado ou conselho de meio ambiente no ente federativo imediatamente inferior. Porém a própria Lei não esclareceu o que se entende por "órgão ambiental capacitado".

Por sua vez, o art. $2^{\circ}$, item III da mesma Lei, define a ação subsidiária como a "ação do ente da Federação que visa a auxiliar no desempenho das atribuições decorrentes das competências comuns, quando solicitado pelo ente federativo originariamente detentor definidas nesta Lei Complementar".

Em relação à cooperação institucional de âmbito interfederativo, a LC n. 140/2011, define em seu art. $4^{\circ}$ os seguintes instrumentos de colaboração recíproca: consórcios públicos; convênios, acordos de cooperação técnica e instrumentos similares; comissões tripartites e bipartites; fundos públicos e privados e outros instrumentos econômicos; e, delegação de atribuições de um ente federativo a outro.

Nota-se, que a referida Lei cita o consórcio como o primeiro instrumento de cooperação a ser observado, seguida pelas comissões tripartites e bipartites e demais instrumentos. A inobservância das fronteiras geopolíticas pelos fenômenos ambientais impõe um pensar e um agir pelo Estado de modo consorciado, dado a abrangência dos problemas em relação entes federativos envolvidos e a própria repartição de competências contidas nos ordenamentos jurídicos.

A cooperação institucional pode ocorrer em nível horizontal, envolvendo Municípios ou Estados; ou vertical, envolvendo Municípios, Estados ou Estados e a União; ou Municípios, Estados e a União, dependendo do arranjo acordado. Pode haver ainda uma cooperação institucional oblíqua envolvendo arranjos entre entes federativos de mesmo nível juntamente com a participação de ente(s) federativo(s) de nível administrativo superior, conforme demonstra a Figura 5.3. Este do tipo de relação é denominada neste trabalho de cooperação institucional interfederativa.

Dentre os instrumentos de cooperação federativa, três legislações no Brasil se destacam: a Lei Federal n. 9.433/1997, que institui a Política Nacional dos Recursos Hídricos (PNRH); a Lei Federal n. 11.107/2005 que dispõe sobre a contratação de Consórcios Públicos (execução cooperativa de serviços públicos ou obras); e a Lei Federal n. 12.305/2010, que cria a Política Nacional dos Resíduos Sólidos (PNRS). 
A Lei n. 9.433/1997, que instituiu a PNRH e criou o Sistema Nacional de Gerenciamento de Recursos Hídricos (SINGREH), estabeleceu a bacia hidrográfica como a unidade territorial para implantação da referida Política e atuação do Sistema em questão ${ }^{47}$.

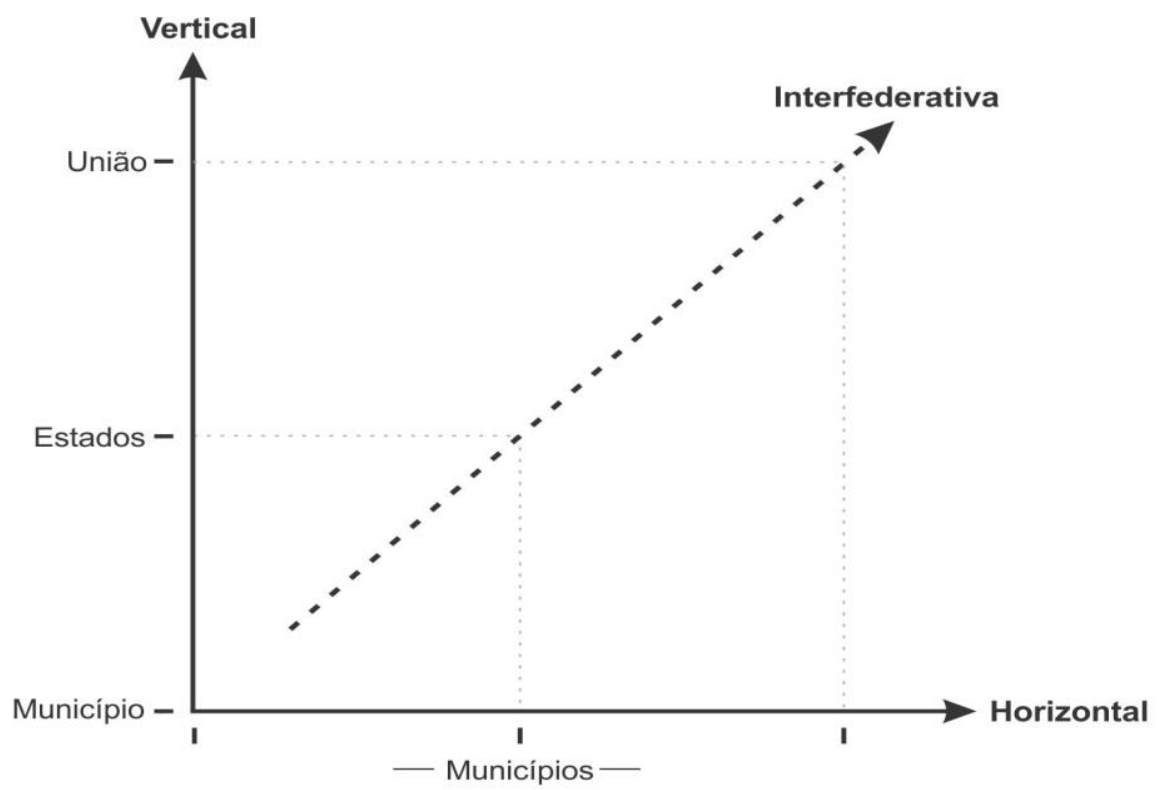

Figura 5.3 - Cooperação federativa vertical, horizontal e interfederativa.

Fonte: Do autor.

Considerar a bacia hidrográfica como unidade de implementação de políticas públicas é considerar a Geografia Física como arranjo político obrigatório. Ou seja, a região natural, física, passa a ser uma unidade de gestão político-administrativa, dado a importância, escassez e valor econômico atual e futuro dos recursos hídricos.

Para gestão da bacia hidrográfica, a Lei n. 9433/1997 criou ainda os Comitês de Bacia Hidrográfica, que se constitui em uma instância político-administrativa que possui, entre outras atribuições, a aprovação do Plano de Recursos Hídricos da bacia. O Plano de Recursos Hídricos é o documento técnico-político que prevê a partilha do uso da água entre os diversos usuários.

Os membros do Comitê de Bacia Hidrográfica, no caso, de rio de domínio federal, são constituídos de representantes de todos os entes federativos situados, em todo ou em parte, na

\footnotetext{
${ }^{47}$ Item V, do art. $1^{\text {o }}$ da Lei n. 9.433/1997. Cf. BRASIL. Lei n. 9.433, de 8 de janeiro de 1997. Institui a Política Nacional de Recursos Hídricos, cria o Sistema Nacional de Gerenciamento de Recursos Hídricos, regulamenta o inciso XIX do art. 21 da Constituição Federal, e altera o art. $1^{\circ}$ da Lei n. 8.001, de 13 de março de 1990, que modificou a Lei n. 7.990, de 28 de dezembro de 1989. Brasília, 1997. Disponível em: <http://www.planalto.gov.br/ccivil_03/LEIS/19433.htm>. Acesso em: 30 outubro 2013.
} 
bacia hidrográfica. Os representantes dos usuários de recursos hídricos e entidades civis de recursos hídricos da região de atuação também possuem assento no Comitê.

A concepção filosófica da Lei n. 9433/1997 traz, além de um viés democrático, a inovação do Comitê de Bacia Hidrográfica como instância decisória e de diálogo entre usuários, num modelo de cooperação de vetor horizontal e vertical, ou seja, de forma interfederativa.

Já a Lei n. 12.305/2010, que cria a PNRS, apresenta os seguintes dispositivos de cooperação federativa: planos intermunicipais de resíduos sólidos; planos microrregionais de resíduos sólidos; e os planos de resíduos sólidos de regiões metropolitanas ou aglomerações urbanas. Embora seja uma cooperação federativa horizontal (entes de mesmo nível administrativo) o estímulo associativo representa um avanço institucional.

Outro aspecto importante na legislação de resíduos sólidos é a prioridade de acesso aos recursos da União para o agregado de municípios com planos intermunicipais de resíduos sólidos. Ou seja, os instrumentos de incentivos econômicos da Lei estão convergindo para uma abordagem de cooperação consorciativa.

Outro instrumento consorciativo muito importante que possui natureza interfederativa foi trazido pela Lei n. 11.107/2005, que dispõe sobre a contratação de consórcios públicos e execução cooperativa de serviços públicos ou obras públicas. Esta Lei traz a perspectiva da aglutinação de esforços como forma de gestão administrativa e não restringe quaisquer serviços ou obras públicas onde o consorciamento seja vedado, o que garante um grande rol de possibilidades. Ações e execuções de políticas públicas ambientais podem, também, ser executadas por meio consorciativo.

Diferentemente dos convênios entre os entes federativos, a Lei do Consórcio estabeleceu personalidade jurídica aos atos associativos, podendo ser classificados como de direito público ou de direito privado, conforme a finalidade a que se destinam. Ao conceder personalidade jurídica aos consórcios públicos esta Lei dá poderes cíveis amplos para realizar contratações, convênios, receber auxílios, subvenções e vários outros negócios jurídicos.

Interessante observar que na área de atuação dos consórcios providos por entes municipais, a União (governo federal) somente participará caso o(s) governo(s) estadual(is) esteja(m) inserido(s). Esta situação enquadra-se na cooperação interfederativa plena.

Em relação à importância da Lei dos Consórcios Públicos, Linhares, Cunha e Ferreira (2012, p. 43, grifo nosso), afirmam que 
A principal inovação da Lei dos Consórcios Públicos é a adoção de mecanismos que emprestam maior confiança ao compromisso firmado pelos entes federados quando do estabelecimento de consórcio público. Dois elementos da nova legislação expressam este objetivo. Em primeiro lugar, a obrigatoriedade de que o protocolo de intenções firmado entre estes entes receba a aprovação dos respectivos poderes legislativos, o que empresta maior publicidade e comprometimento político. Em segundo lugar, a substituição do convênio por nova modalidade de contrato administrativo, denominada de contrato de consórcio público, cercada de maiores garantias legais quanto à possibilidade de denúncia unilateral ou incumprimento pelos contratantes.

Quanto à capacidade de articulação interfederativa e a ação mais coordenada das forças do Estado, os consórcios públicos constituem uma "instância de articulação federativa capaz de contrapor se à excessiva fragmentação da administração pública brasileira no exercício de suas competências constitucionais" (LINHARES; CUNHA; FERREIRA, 2012, p. 54).

\subsection{EMPREENDIMENTOS LINEARES: O IMPACTO TRANSVERSAL DA FAIXA DE SERVIDÃO E A POSSIBILIDADE DE AÇÕES INTERFEDERATIVAS}

Os empreendimentos lineares de engenharia são considerados aqueles cujas partes constitutivas de suas estruturas físicas estão dispostas em uma determinada faixa territorial situada entre pontos específicos de interconexões destinados à integração de logísticas de transporte e distribuição.

Os empreendimentos lineares são, sobretudo, empreendimentos que lidam com fluxos, seja de materiais combustíveis, minérios, energia, sinais elétricos, água, ou mesmo os que possibilitam o deslocamento de pessoas e cargas por meios de veículos e composições como no caso das rodovias e ferrovias.

Tais empreendimentos não são uma linha no sentido restrito, pois em função de obstáculos físicos, restrições derivadas de vulnerabilidade ambientais, e a existência de assentamentos humanos apresentam-se como um conjunto de semirretas (no caso de linhas de transmissão), e ou até de linhas e curvas (no caso de rodovias e ferrovias). Os segmentos de empreendimentos de engenharia conectados uns aos outros interligam pontos onde a busca pela menor distância torna-se uma constante dos projetos. Cabe ressaltar que a distância é sempre uma variável custo .

Entre os empreendimentos de infraestrutura entendidos como lineares destacam-se as linhas de transmissão de energia elétrica de alta tensão (eletrodutos), os polidutos (oleodutos, 
gasodutos, alcooldutos etc.), aquedutos (adutoras, canais de irrigação, sistemas de transposição de bacias hidrográficas ${ }^{48}$ ), as rodovias, as ferrovias, infovias (vias de cabos de fibra ótica).

Estes empreendimentos lineares guardam consigo o importante aspecto que marca perpetuamente a faixa territorial por onde passam cujo cerne denomina-se de faixa de servidão ou de faixa de domínio. O caráter ad aeternum é o componente de restrição ao uso do solo que representa uma condição explícita e determinante às metamorfoses transformativas da dinâmica ação humana ao longo do tempo.

As faixas de servidão são instituídas pelos empreendimentos de linhas de transmissão e gasodutos, enquanto as faixas de domínios são constituídas no caso de implantação de rodovias e ferrovias. As infovias se utilizam ou de faixas de domínio existentes ou de estruturas da rede das linhas de transmissão. As faixas de servidão e de domínio constituem verdadeiros fixos territoriais, que possuem inclusive as salvaguardas da chamada "desapropriação por utilidade pública ${ }^{49}$ por meio da servidão administrativa".

A servidão administrativa como a manifestação contratual civil intrínseca à faixa de servidão pode ser entendida como o ato no qual a propriedade privada, embora mantida com o seu titular, sofre limitações ao direito de propriedade (notadamente na implantação de culturas arbóreas, no uso do fogo, na utilização de pivôs centrais, construção de edificações, dentre outros usos). Ou seja, embora a propriedade esteja formalmente mantida com o titular original, o uso do imóvel fica condicionado às rígidas regras estabelecidas no Contrato de Servidão $^{50}$. A Norma Brasileira (NBR) n. 5.422/1985 (Projetos de Linhas Aéreas de Transmissão de Energia Elétrica) da Associação Brasileira de Normas Técnicas (ABNT) é o referencial técnico que determina restrições ao uso e ocupação do solo em faixas de servidão de linhas de transmissão que são inclusas no Contrato de Servidão.

Faz-se necessário explicar que a implantação de empreendimentos lineares não implica somente na mudança do aspecto visível dos lugares, ou mesmo na manutenção posterior da imutabilidade perpétua da paisagem; com a faixa de servidão e/ou de domínio ocorrem "uma mudança substancial de valoração do território em função de sua resignificação por meio da constituição de uma nova configuração espacial” (PORTELA, 2013, p. 80).

\footnotetext{
${ }^{48}$ Como os utilizados no Projeto de Integração da Bacia do Rio São Francisco - PISF.

${ }^{49}$ Utilidade pública é o status obtido por um empreendimento de engenharia cujo funcionamento, em tese, aumenta o nível de bem estar coletivo. A desapropriação por utilidade pública é definida pelo Decreto Lei $\mathrm{n}^{\circ}$. 3.365, de 21 de junho de 1941.

${ }^{50}$ Contrato de Servidão é o contrato no qual são estabelecidas as normas de uso do solo da faixa territorial objeto da servidão administrativa, que por sua vez, ocorre somente em caso de empreendimentos de utilidade pública. Ver Lei Federal nº 10.406, de 10 de janeiro de 2002 (Novo Código de Civil)
} 
A limitação do uso do solo nas faixas de servidão e de domínio dá-se, sobretudo, pelo status non aedificanti da área onde o direito de construir está suprimido do rol de direitos de um determinado proprietário de imóvel.

No caso do setor elétrico, aos empreendedores é exigida a compensação ao proprietário de imóvel impactado pela faixa de servidão. O procedimento indenizatório é realizado por meio do Programa de Implantação da Faixa de Servidão e Indenizações (PIFSI), que consiste basicamente na reparação pecuniária pela desvalorização imobiliária ocorrida a partir das restrições de pleno uso e gozo do direito de propriedade. A metodologia de cálculo das indenizações está disposta na NBR n. 14.653/2001 (Avaliação de Bens), também da ABNT.

Além do PIFSI, instituído como medida de controle/mitigação dos impactos, danos ou externalidades criados a partir da implantação da faixa de servidão, os órgãos ambientais podem solicitar, no âmbito dos procedimentos administrativos de licenciamento ambiental, a exigência da elaboração do Plano Diretor para as cidades abrangidas pela área de influência do empreendimento.

A ação dos órgãos ambientais surge da observância do que determina o art. 41 do Estatuto das Cidades, Lei n. 10.257/2001, que assim dispõe:

Art. 41. O plano diretor é obrigatório para cidades:

$[\ldots]$

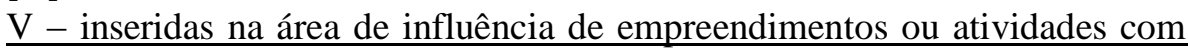
significativo impacto ambiental de âmbito regional ou nacional.

[...] (grifo nosso).

O entendimento da exigência de Plano Diretor nasce da responsabilidade compartilhada entre o empreendedor, então concessionário de serviço público, e o poder público municipal em relação à jurisdição e ao controle da faixa de servidão. A situação de faixa de servidão em perímetros urbanos ou em áreas de expansão urbana torna a situação mais especial pelo aumento do potencial restritivo imposto.

Embora o empreendedor seja obrigado a apoiar a elaboração de Plano Diretor, este instrumento de política urbana é de competência privativa dos poderes públicos municipais, pois tem de ser aprovado como Lei a partir da avaliação da iniciativa de Projeto de Lei (PL) originário do executivo municipal. Como uma Lei Municipal, o Plano Diretor é mais do que um instrumento técnico; é um instrumento de natureza técnico-político. 
As restrições do uso ou adequações urbanísticas da faixa de servidão em perímetros urbanos, ou em áreas de expansão urbanas ou de interesses econômico do município devem constar como o foco dos Planos Diretores quando da busca da mitigação dos efeitos restritivos impostos pela faixa de servidão.

Há uma incompreensão no meio técnico de diversos órgãos ambientais quanto ao fechamento do ciclo, o que torna a medida mitigadora, na maioria das vezes, inócua, pois o foco deveria ser disciplinar os usos compatíveis e restringir outros classificados como não permitidos. A Figura 5.4, a seguir, evidencia esquematicamente o ciclo de atividades a partir do impacto da restrição ao uso e ocupação do solo.

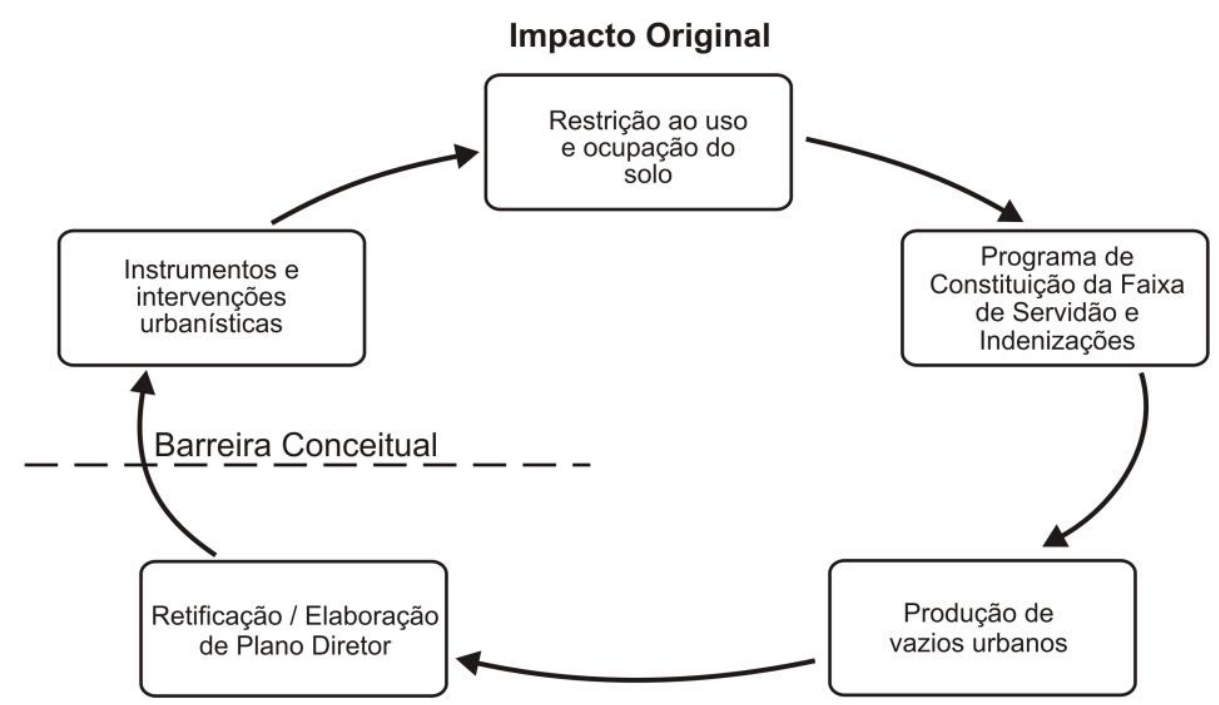

Figura 5.4 - Impacto da restrição ao uso e ocupação do solo e as implicações urbanísticas e as barreiras conceituais no processo de licenciamento ambiental.

Fonte: Do autor.

É interessante observar que o Município como ente governamental competente para aprovação do Plano Diretor e responsável pela gestão do território municipal deve observar as limitações do uso do solo de que dispõe a Lei Municipal, recepcionando, inclusive, os dispositivos restritivos das faixas de servidão. E ainda, há de se considerar a existência de uma barreira conceitual entre a elaboração/retificação de Plano Diretor e os instrumentos e intervenções urbanísticas, conforme demonstrado na Figura 5.4.

Por outro lado, a jurisdição, a fiscalização de conformidade técnica, as restrições de uso do solo da faixa de servidão, no caso do setor de energia elétrica, ficam a cargo da Agência Nacional de Energia Elétrica (ANEEL) - uma autarquia federal em regime especial, 
então classificada como poder concedente. Ao Instituto Brasileiro do Meio Ambiente e dos Recursos Naturais Renováveis (IBAMA) recaem as competências, no âmbito da faixa de servidão, da fiscalização de impactos ambientais ou socioambientais.

A experiência prática mostra a ocorrência de vácuo de ação de Estado que, por vezes, torna a gestão das áreas de servidão conflitantes pelo desconhecimento entre as competências e obrigações que cabem ao ente federal e ao ente municipal.

É muito comum uma omissão de ambos os entes federativos, tornando as faixas de servidão objeto de ações vedadas pelas normas técnicas. Problemas como falta de iluminação, acúmulo de lixo e formação de favelas são típicos de várias faixas de servidão situadas em perímetros urbanos.

O fenômeno da não utilidade social da faixa de servidão em perímetros urbanos, ou do uso conflitivo com normas técnicas, pode ser chamado de "vazios urbanos", por sintetizar o emaranhado de nuances sociais e técnicas que a faixa de servidão produz. Com a faixa de servidão há uma imposição pelo não uso do solo, conforme evidenciam as Figuras 5.5, 5.6 e 5.7, a seguir.

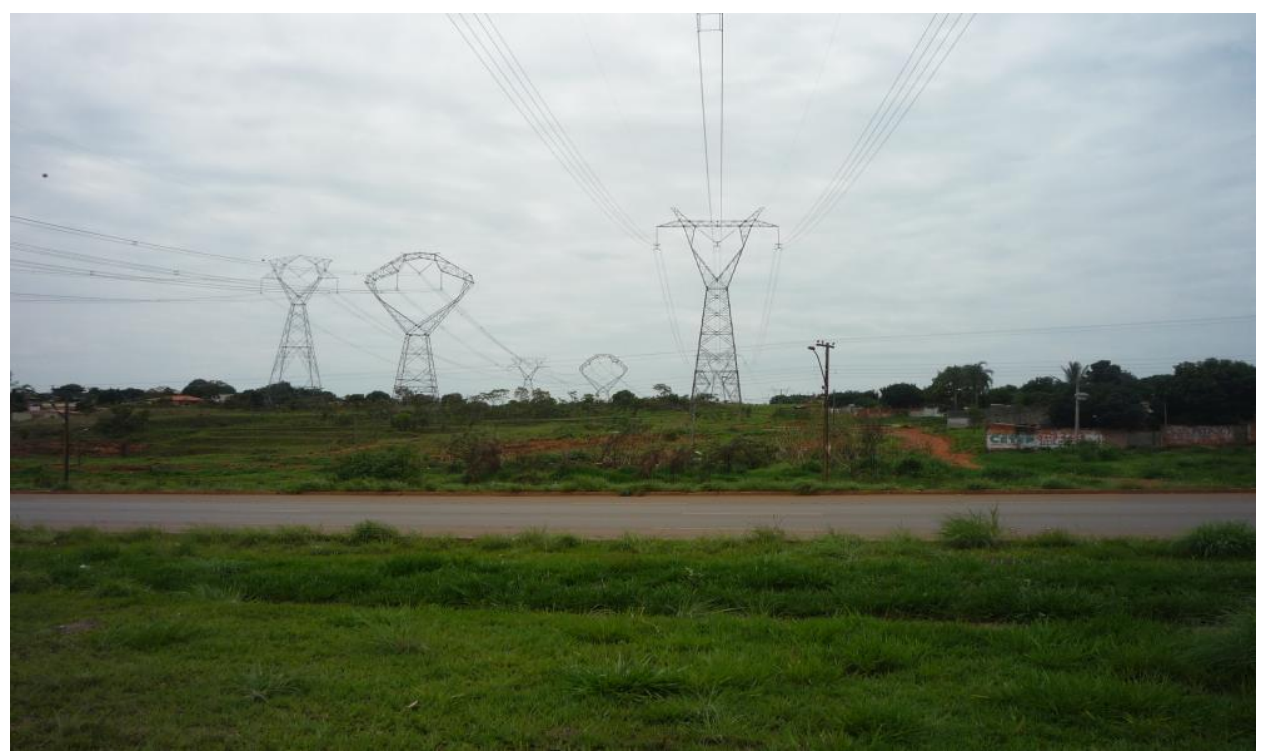

Figura 5.5 - Visada frontal do perímetro urbano do município de Águas Lindas de Goiás (Entorno do Distrito Federal) com situações de vazio urbano criado pelas faixas de servidão das Linhas de Transmissão $500 \mathrm{kV}$ Norte-Sul, Circuitos 1, 2 e 3. Data: Novembro/2015.

Fonte: Do autor.

São raros os casos de processos de licenciamento ambiental em que os técnicos que produzem os estudos ambientais percebem o impacto dos vazios urbanos envolvidos. $\mathrm{O}$ licenciamento ambiental tem no componente biótico o mais forte vetor de atuação teórico. $\mathrm{O}$ 
componente socioeconômico ainda está em fase de consolidação nos processos de licenciamento.

Assim, o maior problema das faixas de servidão em ambientes urbanos centra-se na perda da função "utilidade" dessas áreas para os munícipes, o que as torna verdadeiros "vazios urbanos", dado a impossibilidade e ou limitações de execução de benfeitorias pelo poder público ou mesmo por proprietários particulares.

Mais do que um "vazio urbano" é possível se falar em "vazio institucional", caracterizado pela obscura determinação de obrigações entre o poder publico municipal, responsável pela execução do Plano Diretor e o poder público federal representado pela concessionária de serviço público. Ou seja, tem-se um conflito federativo envolvendo faixas de servidão em perímetros urbanos.

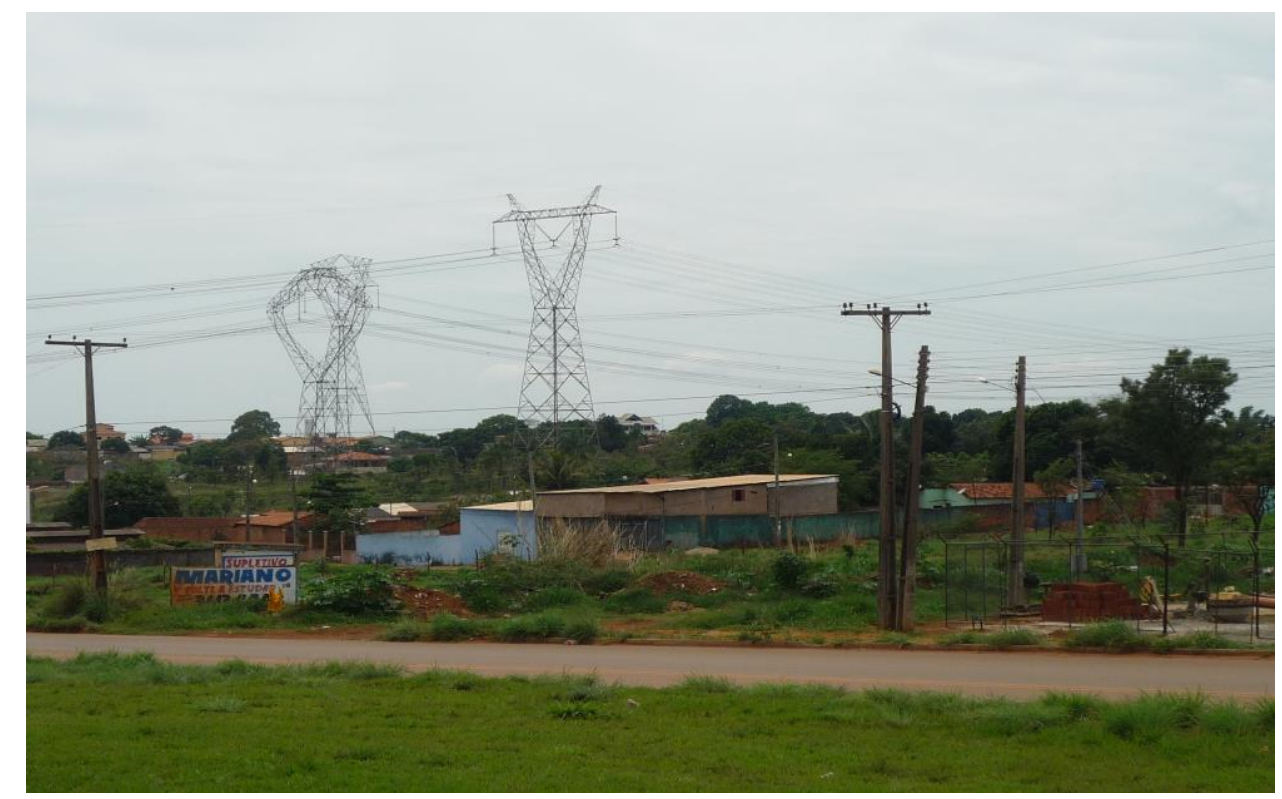

Figura 5.6 - Visada diagonal do perímetro urbano do município de Águas Lindas de Goiás (Entorno do Distrito Federal) com situações de vazio urbano criado pelas faixas de servidão das Linhas de Transmissão $500 \mathrm{kV}$ Norte-Sul, Circuitos 1, 2 e 3. Data: Novembro/2015.

Fonte: Do autor.

Interessante observar quando se consegue obter sinergias entre faixas de servidão típicas de linhas de transmissão com as faixas de domínio típicas de rodovias, a exemplo do que demonstra a Figura 5.8. Tal situação forma um corredor de jurisdição dupla para a gestão pública (entes reguladores distintos para Linhas de Transmissão e Rodovia) e dupla operação de empreendimento, por serem distintos os agentes econômicos gestores das benfeitorias de engenharia. 


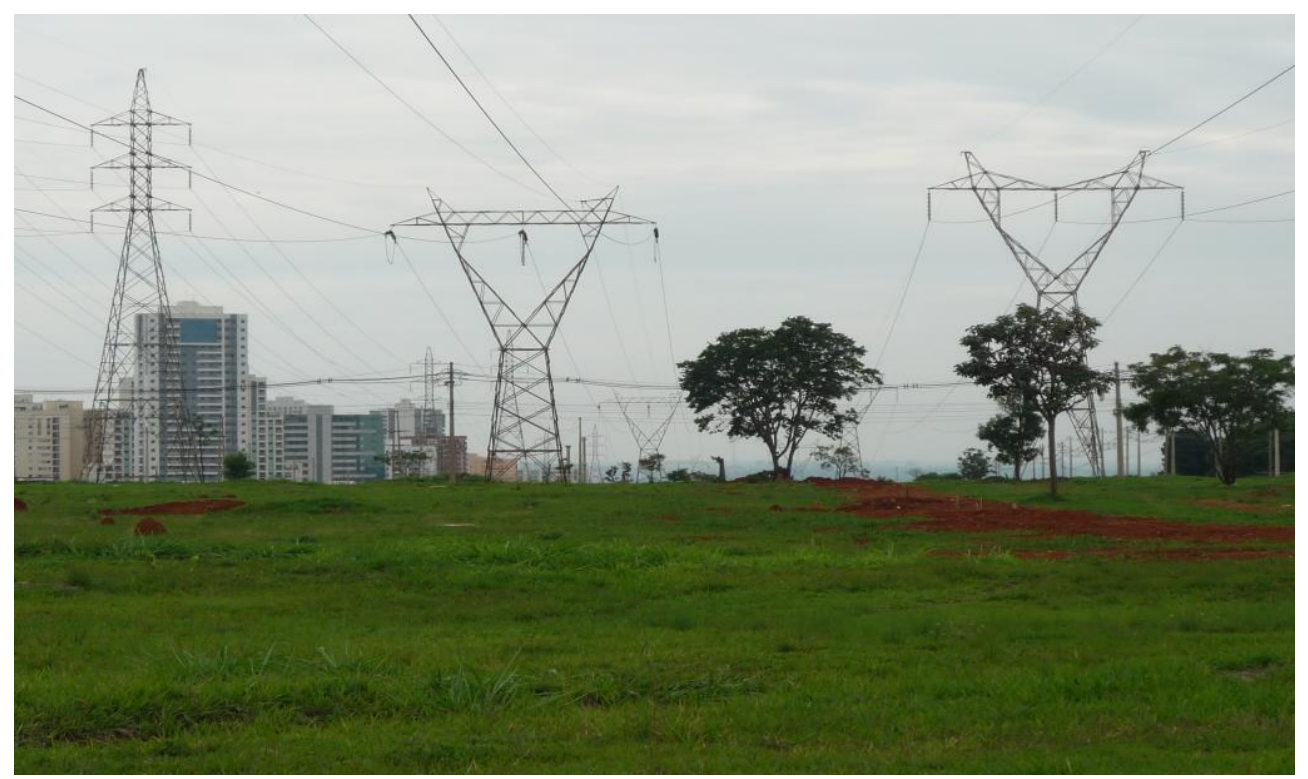

Figura 5.7 - Vazio urbano em Taguatinga Sul (Distrito Federal) - Vista da direita para esquerda: faixas de servidão das Linhas de Transmissão 230 kV Brasília Sul-Brasília Geral, circuitos 1 e 2, e da faixa de servidão da Linha de Transmissão 138 kV Brasília Sul-Brasília Norte ${ }^{51}$. Data: Novembro/2015.

Fonte: Do autor.

Passa existir, assim, uma corresponsabilidade sobre faixas territoriais restritivas e, por conseguinte, os impactos socioambientais são reduzidos. Existem ainda situações onde ocorre o aproveitamento da faixa de servidão para usos permitidos, como construção de parques lineares ou ciclovias. As Figuras 5.9 e 5.10 evidenciam uma situação de conversão de um antigo vazio urbano em um parque linear. Esta situação localiza-se na cidade de Taguatinga, Distrito Federal.

O viés utilitarista na abordagem das faixas de servidão ou de domínio em perímetros urbanos possibilita pensar, à luz das ações cooperativas em matéria ambiental contidas na LC n. 140/2011, a implantação do consórcio para gestão da faixa de servidão/domínio urbana, no intuito de se conceber e consolidar uma região linear de gestão interfederativa multinível Município-União.

${ }^{51}$ Como as Linhas de Transmissão de $138 \mathrm{kV}$ da Companhia Energética de Brasília (CEB) estão associadas ao sistema de distribuição de cargas no âmbito do Distrito Federal, esta empresa classifica seu sistema de transporte de energia como de "Linhas de Distribuição". 


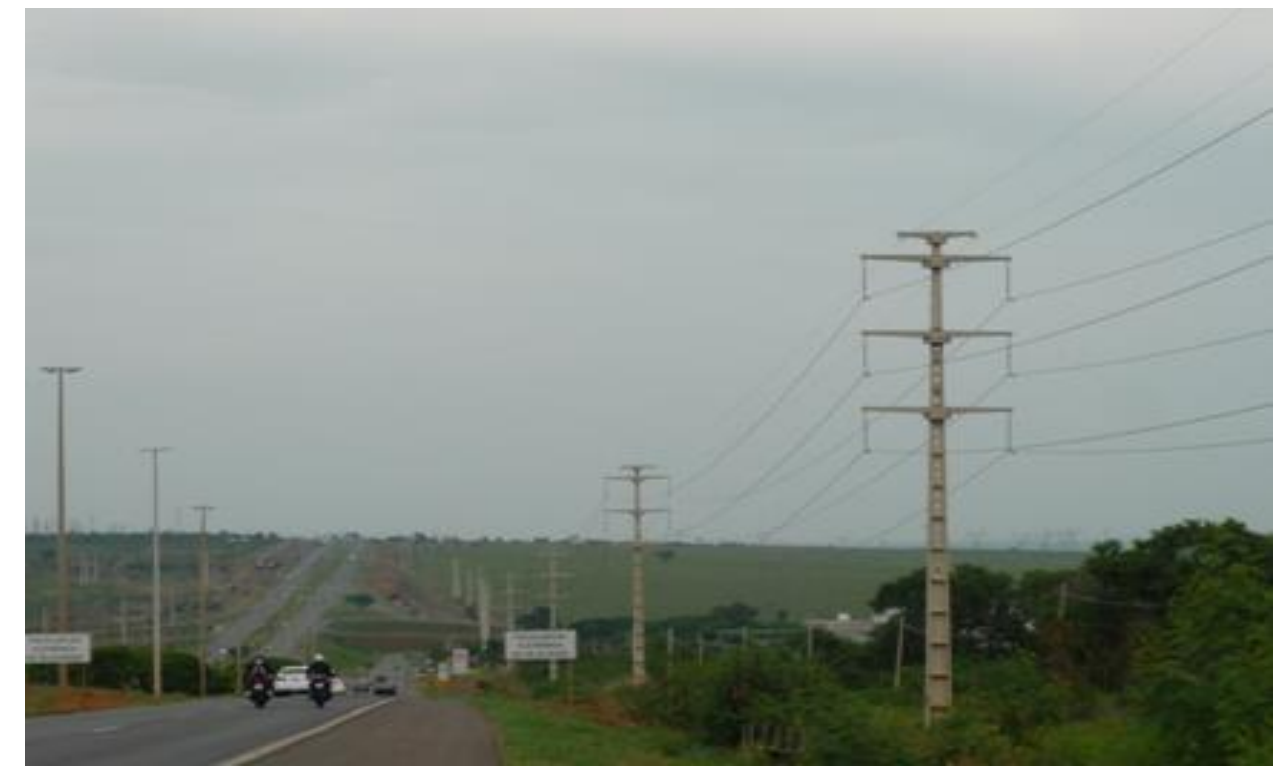

Figura 5.8 - Situação de sinergia entre faixa de domínio da Rodovia BR - 060 e a faixa de servidão da Linha de Transmissão 138 kV Samambaia-Monjolo (sentido Brasília-Goiânia). Data: Novembro/2015.

Fonte: Do autor.

A perspectiva consorciativa para repartição de obrigações, a construção de uma gestão compartilhada e de uma ação institucional comum envolveria a concessionária de serviços públicos como representante do ente federal para que assuma as externalidades econômicas e os impactos socioambientais que uma faixa de servidão/de domínio produz.

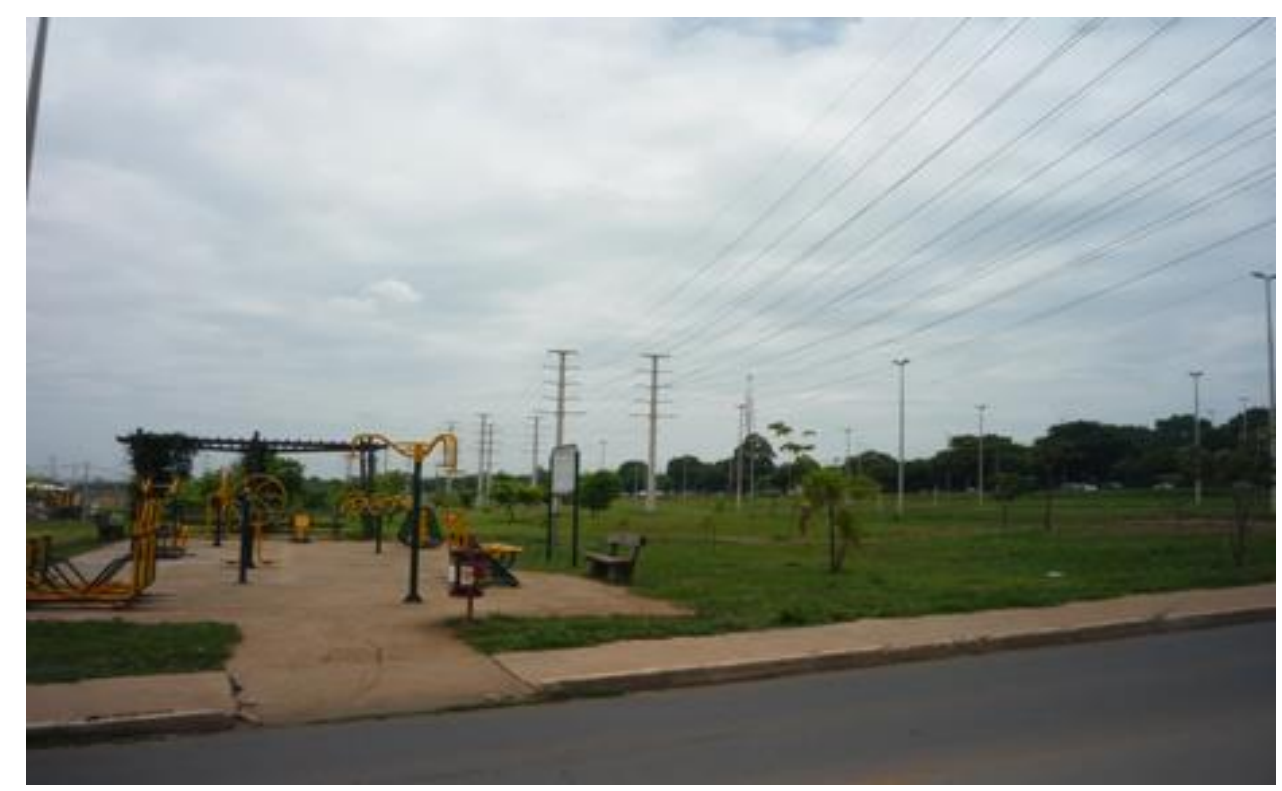

Figura 5.9 - Extinção de um vazio urbano com a construção de um parque urbano e vivencial - Vista da Linha de Transmissão 138 kV Taguatinga-Ceilândia e da Linha de Transmissão 138 kV Taguatinga-Taguatinga Norte, parque urbano Taguaparque, Taguatinga, Distrito Federal. Data: Novembro/2015.

Fonte: Do autor. 


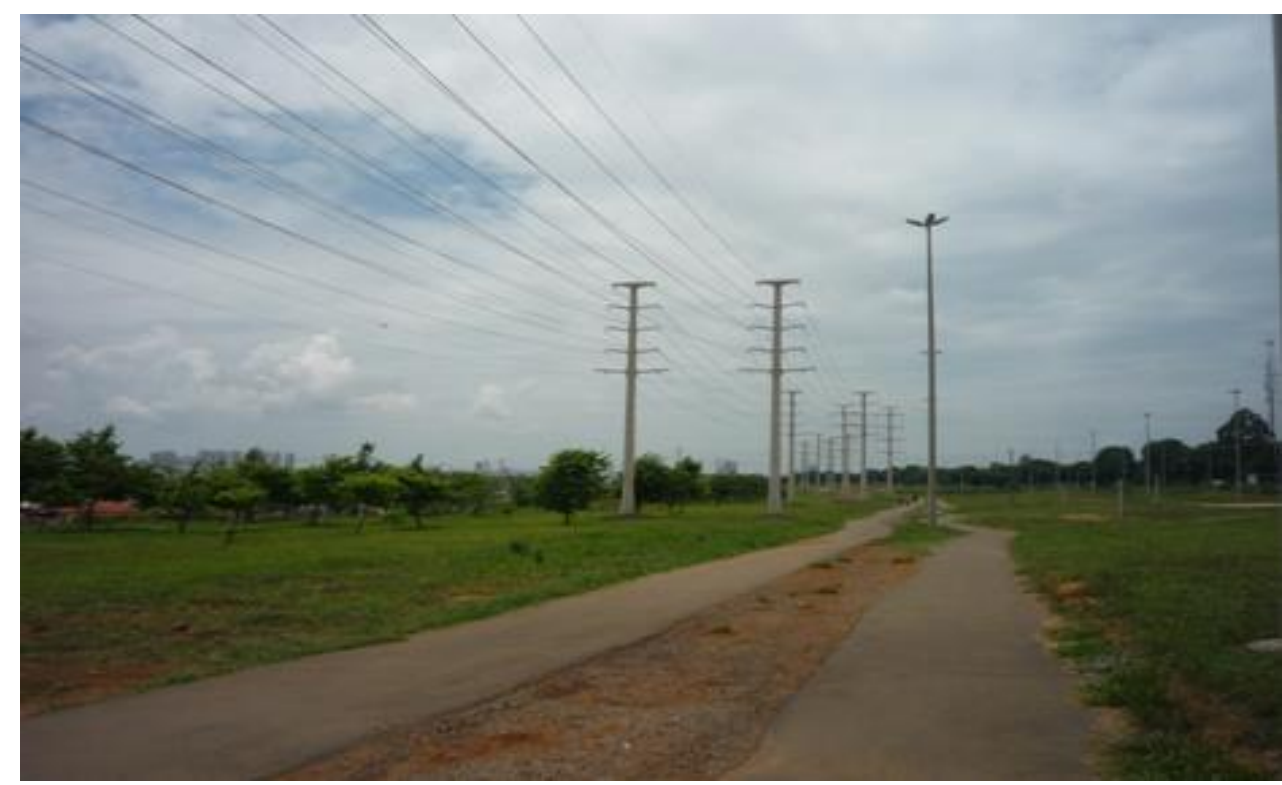

Figura 5.10 - Extinção de um vazio urbano com a construção de um parque urbano com ciclovia - Vista da Linha de Transmissão 138 kV Taguatinga-Taguatinga Norte e da Linha de Transmissão 138 kV TaguatingaCeilândia, parque urbano Taguaparque, Taguatinga, Distrito Federal. Data: Novembro/2015.

Fonte: Do autor.

Para linhas de transmissão, a ação da União caberia à concessionária de serviço de transporte ou distribuição de energia. No caso de faixas de domínio, caberia ao ente gestor do empreendimento ou concessionária de serviço. Há a necessidade, com efeito, de formalizar uma configuração de uma região linear, onde a jurisdição seja consorciada entre partícipes da intervenção.

Por outro lado, há uma carência de estudos para saber se a opção do traçado na implantação da Linha de Transmissão se aproximou do perímetro urbano da cidade ou a malha urbana se aproximou da faixa de servidão. De forma elementar parece existir concomitantemente os 02 (dois) fenômenos.

\subsubsection{O vazio institucional interfederativo em empreendimentos pontuais e os impactos socioambientais}

A situação dos impactos socioambientais de empreendimentos pontuais de infraestrutura indica a existência dos mesmos vazios institucionais em matéria de interação da União-Municípios, dos empreendimentos lineares. Entretanto, para empreendimentos pontuais, os impactos, as externalidades ou os danos são fortemente concentrados, não sendo possível ignorá-los. 
Empreendimentos de infraestrutura de grande porte que tem natureza pontual, como as usinas hidrelétricas, as usinas termoelétricas, os portos e os aeroportos, trazem consigo diversos impactos, dentre os quais, o impacto do aumento populacional que, por si só, possui um efeito multiplicador sobre diversas demandas de serviços públicos.

O incremento de demanda por serviços públicos é um impacto que pressiona sobremaneira as estruturas governamentais de serviços municipais e estaduais. $\mathrm{O}$ acréscimo de demanda é visto como um impacto ou dano a ser reparado civilmente. O licenciamento ambiental federal, em muitos casos, tem exigido melhorias em serviços públicos como forma de compensar ou reparar as sobrecargas que o novo cenário produz.

Neste sentido, muitos municípios que sediam grandes investimentos pontuais de infraestrutura acabam por constituir considerável força de polaridade sobre populações vizinhas por apresentarem a perspectiva da disponibilidade de oportunidade de negócios e de serviços.

Em razão dos aspectos derivados do efeito polaridade e dos subsequentes problemas advindos, alguns empreendimentos de infraestrutura licenciados pelo IBAMA na Amazônia Legal considerou no Termo de Referência ${ }^{52}$ emitido para confecção do Estudo de Impacto Ambiental (EIA) e Relatório de Impacto Ambiental (RIMA) uma nova escala dos efeitos dos impactos: a Área de Abrangência Regional (AAR).

Este fato se deu pelo entendimento de que os impactos possuem disseminação ampla e abrangência regional. Comumente nos procedimentos de licenciamento ambiental são exigidas as seguintes escalas de dimensões dos impactos ambientais, a saber: Área Diretamente Afetada (ADA) (exigido para aproveitamento hidrelétricos), Área de Influência Direta (AID) e Área de Influencia Indireta (AII).

Dentre os empreendimentos cuja solicitação de EIA/RIMA tiveram a inclusão da AAR, destacam-se: Usina Hidrelétrica de Belo Monte ${ }^{53}$; Linha de Transmissão $500 \mathrm{kV}$ Tucuruí-Xingu-Jurupari ${ }^{54}$; e, Linha de Transmissão 500 kV Jurupari-Oriximiná e $230 \mathrm{kV}$

${ }^{52}$ Entende-se por Termo de Referência o documento que traz as exigências iniciais das informações, dados e metodologias necessárias à elaboração do Estudo de Impacto Ambiental/Relatório de Impacto Ambiental (EIA/RIMA).

53 Conforme Termo de Referência contido no Processo Administrativo n. 02001.001848/2006-75 - IBAMA. Cf. BRASIL. Instituto Brasileiro do Meio Ambiente e dos Recursos Naturais Renováveis - IBAMA. Termo de referência para elaboração do Estudo de Impacto Ambiental e respectivo Relatório de Impacto Ambiental EIA/RIMA do Aproveitamento Hidrelétrico de Belo Monte. Processo Administrativo n. 02001.001848/200675. Brasília, v. IV, f. 618-677, dez. 2007.

${ }^{54}$ Conforme Termo de Referência contido no Processo Administrativo n. 02001.005015/2008-45 - IBAMA. Cf. BRASIL. Instituto Brasileiro do Meio Ambiente e dos Recursos Naturais Renováveis - IBAMA. Termo de referência para o Estudo de Impacto Ambiental e respectivo Relatório de Impacto Ambiental (EIA/RIMA) da 
Jurupari-Laranjal do Jarí-Macapá ${ }^{55}$. Em tempo posterior, outros empreendimentos também inseriram a AAR como escala para elaboração dos estudos ambientais.

Como o efeito de polaridade de demandas e sobrecargas de serviços tem uma abrangência regional (range), é possível aplicar os postulados da Teoria dos Lugares Centrais (TLC) ao planejamento do combate aos efeitos indesejados de projetos de infraestruturas, adotando com isso, o conceito de polos de serviços.

Este tipo de planejamento para ser efetivo envolveria instituições de Estado de âmbito interfederativo, pois existem serviços públicos de competência de municípios, dos Estados, e ainda, alguns que são de competência do ente federal.

A visão de longo prazo de viés interinstitucional é necessária, na medida em que a ação do empreendedor como agente econômico limita-se ao horizonte temporal de perturbação de uma condição pré-existente.

\subsection{OS SERVIÇOS PÚBLICOS DE SAÚDE: POSSIBILIDADES DE CONSORCIAMENTO INTERFEDERATIVO}

Os serviços públicos de saúde podem ser entendidos como um dos mais complexos serviços disponibilizados pelo Estado, pela enorme tecnicidade dos serviços em si, o que exige grande qualificação de pessoal, bem como, pela distribuição de competências entre os entes federativos.

Os problemas de gestão da saúde são, antes de tudo, problemas de gestão pública e têm origem, dentre outros fatores, na carência de planejamento sistêmico. A organizacidade do Sistema Único de Saúde (SUS) possui uma estrutura federativa com definiçõos específicas para a União, para os Estados e para os municípios, conforme disciplina a Lei n. 8.080/1990 (Lei do SUS). Pode-se afirmar que, apesar de variados problemas e deficiências, as políticas públicas executadas pelo SUS aglutinam um arranjo federativo bem definido em termos de divisão de competências.

Há, porém, um viés descentralizador explícito na Lei do SUS, que busca atribuir ao município a execução dos serviços básicos e de média complexidade de saúde. Inclusive, a

Linha de Transmissão 500 kV Tucuruí-Xingu-Jurupari. Processo Administrativo n. 02001.005015/2008-45. Brasília, v. I, f. 170-197, out. 2008.

${ }^{55}$ Conforme Termo de Referência contido no Processo Administrativo n. 02001.004314/2008-62 - IBAMA. Cf. BRASIL. Instituto Brasileiro do Meio Ambiente e dos Recursos Naturais Renováveis - IBAMA. Termo de referência para o Estudo de Impacto Ambiental e respectivo Relatório de Impacto Ambiental (EIA/RIMA) da Linha de Transmissão 500 kV Jurupari - Oriximiná e 230 kV Jurupari-Laranjal do Jarí - Macapá. Processo Administrativo no ${ }^{\circ}$ 02001.004314/2008-62. Brasília, v. I, f. 138-165, out. 2008. 
primeira competência que cabe à Coordenação Estadual do SUS (exercida pelos entes federativos estaduais) definida pela Lei n. 8.080/1990, refere-se à promoção da descentralização $^{56}$ para os municípios dos serviços e ações de saúde. Outro elemento que demonstra o caráter descentralizador é a definição da ação direta em serviços de saúde dos entes estaduais restrita às ações de caráter supletivo ${ }^{57}$. Somente as ações e a gestão de sistemas públicos de alta complexidade, de referência estadual e regional ficam sob incumbência dos entes federativos estaduais.

À Direção Nacional do SUS (exercida pelo Governo Federal) compete, entre várias outras ações, a organização de protocolos técnicos, a organização de estatísticas, a definição de ações de vigilância em saúde, a definição de critérios de controle e aplicação de recursos públicos, a cooperação técnica e financeira. A promoção da descentralização para as unidades federativas e para os municípios dos serviços e ações de saúde, respectivamente, de abrangência estadual e municipal, também se enquadram como competências do ente federal.

Por sua vez, a gestão e a cooperação financeira do SUS, materializada na descentralização de recursos do ente federal para Estados, Distrito Federal e municípios fica sob gestão do Fundo Nacional de Saúde (FNS).

Um aspecto interessante na Lei do SUS é a expressa possibilidade dos municípios desenvolverem ações conjuntas por meio dos consórcios públicos, garantindo uma cooperação federativa horizontal. Mas a cooperação de entes de diferentes níveis federativos não está expressa na Lei do SUS, apesar de não haver nenhum dispositivo que contrarie ou vede a cooperação vertical.

A Figura 5.11, elaborada por Linhares, Cunha e Ferreira (2012, p. 44), demonstra que no ano de 2009, 2.323 municípios apresentavam algum tipo de consorciamento em matéria de saúde, número bem superior aos dos consorciamentos no setor de educação que atingiram 398 municípios e o de habitação que possuíam 170 municípios consorciados. Outra característica demonstrada na Figura 5.11 é o número ascendente de consórcios públicos no Brasil, o que representa uma mudança de cultura gerencial do setor público.

A pesquisa de Linhares, Cunha e Ferreira inserida no artigo Cooperação Federativa: a Formação de Consórcios entre Entes Públicos no Brasil, publicada em 2012 pelo Instituto de

\footnotetext{
${ }^{56}$ Conforme preconiza o Item I do art. 17 da Lei no $.8 .080 / 1991$ (Lei do SUS). Cf. BRASIL. Lei n. 8.080, de 19 de setembro de 1990. Dispõe sobre as condições para a promoção, proteção e recuperação da saúde, a organização e o funcionamento dos serviços correspondestes e dá outras providências (Lei Orgânica da Saúde). Brasília, 1990. Disponível em: <http://www.planalto.gov.br/ccivil_03/Leis/L8080.htm〉. Acesso em: 03 outubro 2015.

${ }^{57}$ Conforme preconiza o Item III do art. 17 da Lei no ${ }^{\circ}$. 8.080/1991 (Lei do SUS). Cf. Ibidem.
} 
Pesquisa Econômica Aplicada (IPEA), demonstra apenas os consórcios intermunicipais. Não abrangeu os tipos e os números de consorciamento de entes federativos distintos.

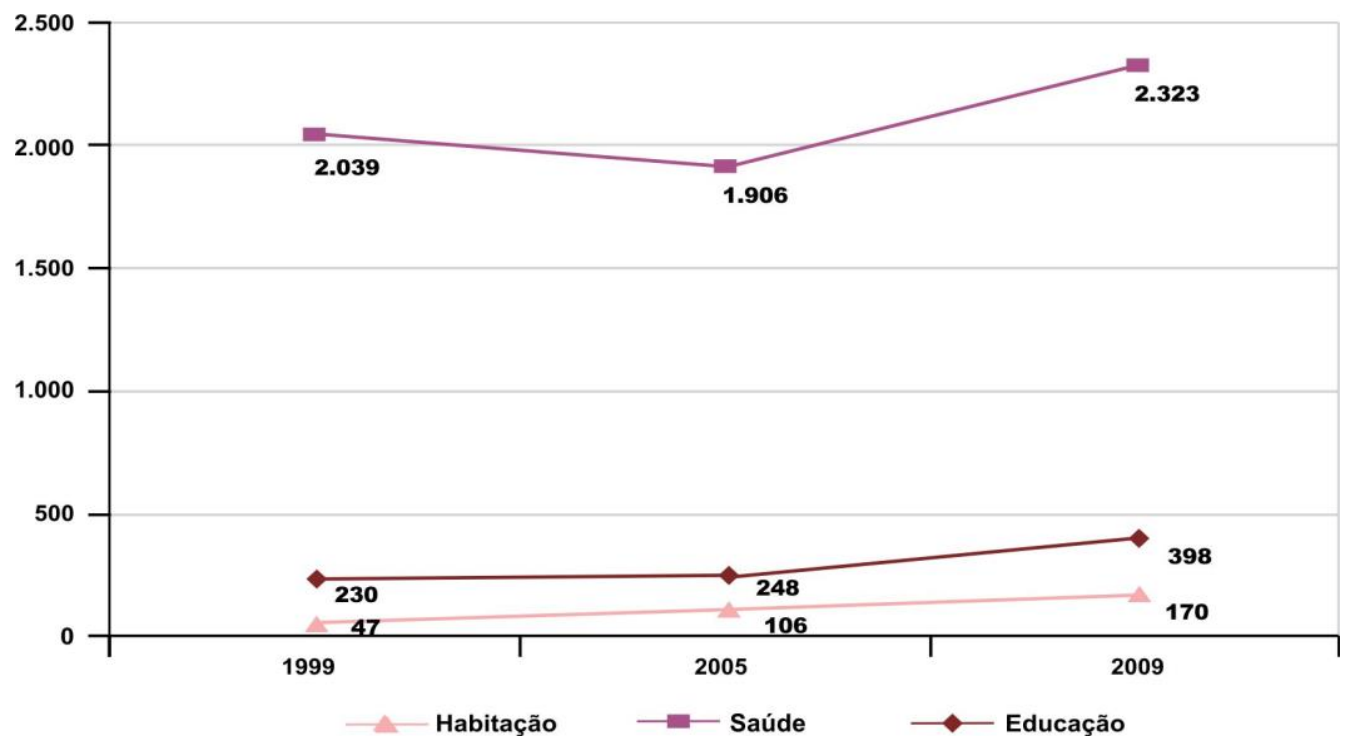

Figura 5.11 - Trajetória do número de municípios com consórcios intermunicipais - anos 1999, 2005 e 2009. Fonte: Linhares, Cunha e Ferreira (2012, p. 44).

Neste sentido, uma análise do exemplo dos serviços públicos de saúde disponível nos municípios do Entorno Sul do Distrito Federal frente aos recursos descentralizados pelo FNS, gerido pelo Ministério da Saúde (MS), possibilita mensurar relações de cooperação institucional de entes federativos colaterais e de níveis administrativos distintos.

O Entorno Sul do Distrito Federal é o nome dado ao conjunto formado pelos quatro municípios goianos situados junto à saída rodoviária sul (Rodovias BR-040 e BR-050) do Distrito Federal, composto por Luziânia - mais antigo e cessionário territorial dos demais; Cidade Ocidental, Novo Gama e Valparaíso de Goiás (PORTELA, 1999). O exemplo do Entorno Sul é emblemático, pois, é uma região que, embora se situe no Estado de Goiás, possui enorme dependência dos serviços públicos do Distrito Federal em função da baixa disponibilidade e qualidade dos serviços na região. Os municípios do Entorno Sul estão entre os 21 municípios que compõem a Região Integrada de Desenvolvimento do Distrito Federal e Entorno - RIDE. O Distrito Federal também integra a RIDE.

O fato dos municípios do Entorno Sul estarem inseridos em uma RIDE os coloca em situação de especial interesse, pois existe a possibilidade legal pela ação "integrada de desenvolvimento" que foi tipificada pela LC n. 94, de 19 de fevereiro de 1998, que criou o instrumento legal de desenvolvimento regional da RIDE. A região do Distrito Federal e 
Entorno, pelas particularidades diversas que possui, pode servir como um laboratório de políticas públicas interfederativas.

Neste sentido, o desenvolvimento integrado proposto pela Lei da RIDE aborda uma perspectiva de unificação de esforços na prestação de serviços públicos, dentre os quais estão inseridos os de saúde por meio do Programa Especial de Desenvolvimento do Entorno do Distrito Federal ${ }^{58}$.

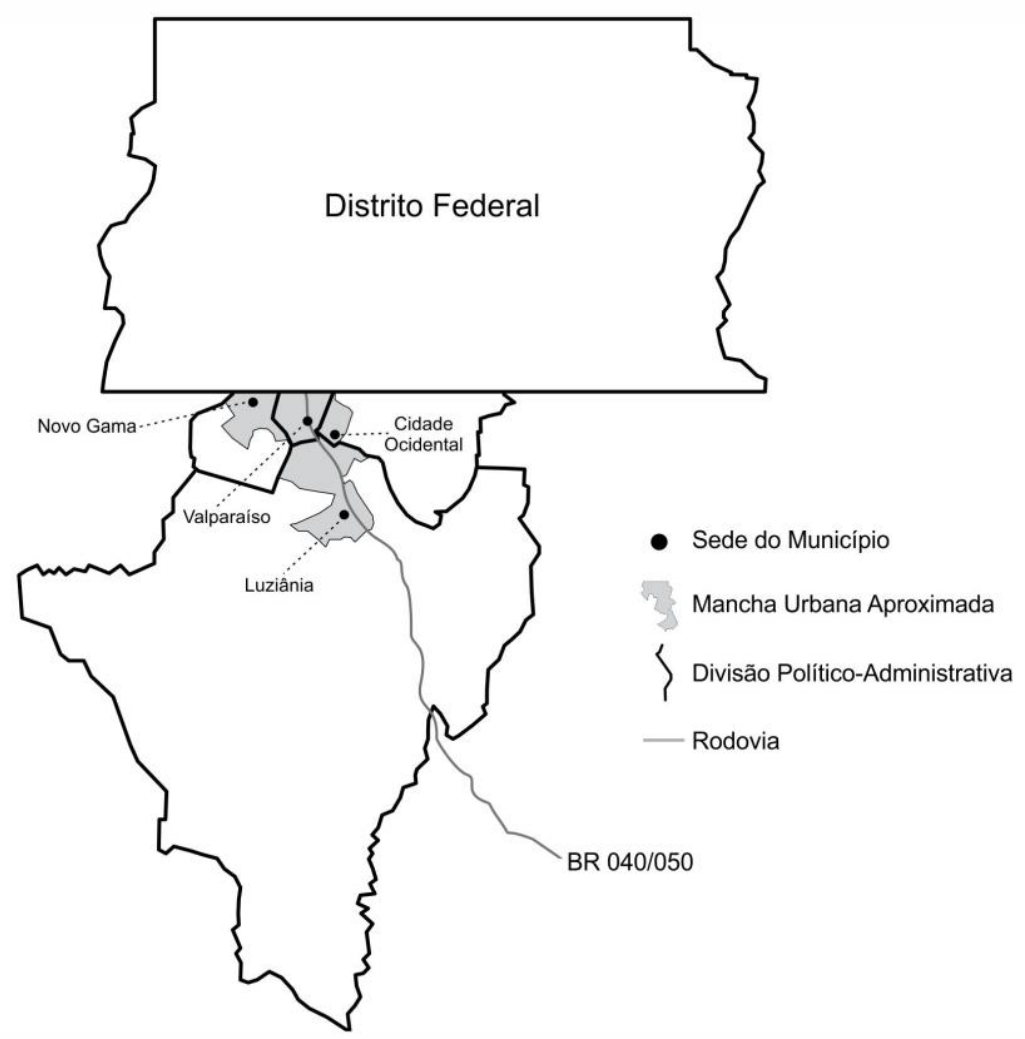

Figura 5.12 - Disposição geográfica dos municípios do Entorno Sul do Distrito Federal.

Fonte: Adaptado de Guia e Cidade (2010).

Uma análise da Tabela 5.1 que demonstra a distribuição do FNS por rubrica e Municípios do Entorno Sul do Distrito Federal - ano de 2014, permite observar a forma de distribuição dos repasses federais aos 04 (quatro) municípios que constitui o referido agregado urbano. Os dados foram obtidos a partir de pesquisa no sítio eletrônico do FNS -

${ }^{58}$ Art. $4^{\text {o }}$ da Lei Complementar n. 98, de 18 de fevereiro de 1998. Cf. BRASIL. Lei Complementar n. 94 , de 19 de fevereiro de 1998. Autoriza o Poder Executivo a criar a Região Integrada de Desenvolvimento do Distrito Federal e Entorno - RIDE e instituir o Programa Especial de Desenvolvimento do Entorno do Distrito Federal, e dá outras providências. Brasília, 1998. Disponível em: <http://www.planalto.gov.br/ccivil_03/leis/lcp/lcp94.htm>. Acesso em: 16 outubro 2015. 
ano de 2014. Vale salientar que o repasse do FNS prevê a aplicação de recursos nas seguintes áreas específicas, conforme a natureza do dispêndio em saúde: assistência farmacêutica; atenção básica; gestão do SUS; média e alta complexidade ambulatorial e hospitalar; e vigilância em saúde.

Merece atenção os quantitativos de repasses financeiros classificados como "média e alta complexidade ambulatorial e hospitalar”. Nesta rubrica, no ano de 2014, o Município de Cidade Ocidental recebeu o equivalente a $44 \%(\mathrm{R} \$ 3.985 .137,52)$ do total de recursos repassados pelo FNS. O cômputo do Município de Luziânia em "média e alta complexidade ambulatorial e hospitalar" atingiu 49\% (R\$16.999.690,40); o do Município do Novo Gama atingiu $24 \%(\mathrm{R} \$ 2.224 .434,29)$ do total de repasses; enquanto que os repasses a Valparaíso de Goiás atingiram 39\% ( $\mathrm{R} \$ 10.296 .279,74)$ do total. No cômputo do total do Entorno Sul, a rubrica "média e alta complexidade ambulatorial e hospitalar" foram recebidos $\mathrm{R} \$$ 33.505.541,95, o que equivale a $42 \%$ do total de recursos repassados pelo FNS. 
Tabela 5.1 - Distribuição de recursos do Fundo Nacional de Saúde por rubrica e Municípios do Entorno Sul do Distrito Federal - 2014.

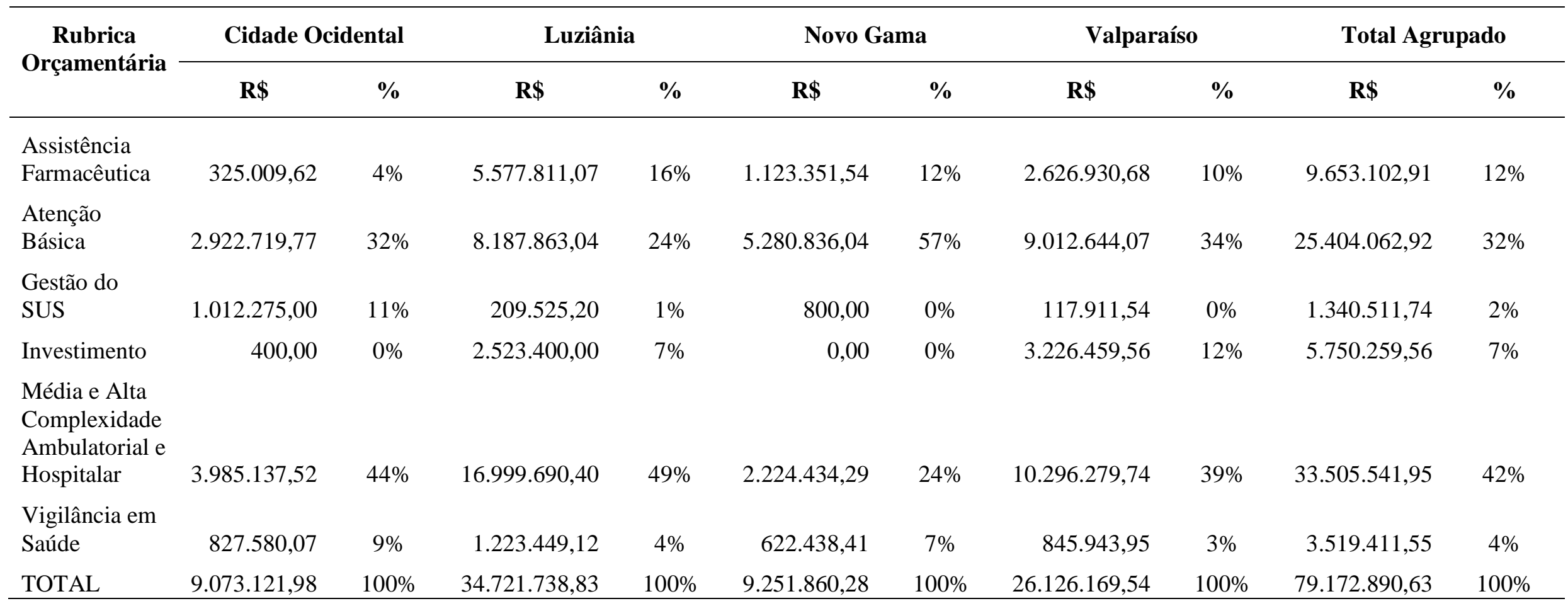

Fonte: FNS (2014). 
É interessante observar o que pode ser entendido como atividades e/ou serviços de "média e alta complexidade ambulatorial e hospitalar". De acordo com a publicação do MS, intitulada O SUS de A a Z: garantindo saúde nos Municípios (BRASIL, 2009, p. 207), os procedimentos de média complexidade

[...] compõe-se por ações e serviços que visam a atender aos principais problemas de saúde e agravos da população, cuja prática clínica demande disponibilidade de profissionais especializados e o uso de recursos tecnológicos de apoio diagnóstico e terapêutico.

De acordo com a referida publicação, os grupos de procedimentos de média complexidade são:

- procedimentos especializados realizados por profissionais médicos, outros profissionais de nível superior e nível médio;

- cirurgias ambulatoriais especializadas;

- procedimentos tráumato-ortopédico;

- ações especializadas em odontologia;

- patologia clínica;

- anatomopatologia e citopatologia;

- radiodiagnóstico;

- exames ultra-sonográficos;

- diagnose;

- fisioterapia;

- terapias especializadas;

- próteses e órteses; e

- $\quad$ anestesia (BRASIL, 2009).

Por sua vez, o mesmo documento ( $O$ SUS de A a Z: garantindo saúde nos Municípios) (BRASIL, 2009, p. 32), define os procedimentos que são qualificados como de alta complexidade, entendendo-os como o

[...] conjunto de procedimentos que, no contexto do SUS, envolve alta tecnologia e alto custo, objetivando propiciar à população acesso a serviços qualificados, integrando-os aos demais níveis de atenção à saúde (atenção básica e de média complexidade). 
Para este documento de referência, as principais áreas que compõem a alta complexidade do SUS estão organizadas em "rede" e incluem:

- assistência ao paciente portador de doença renal crônica (por meio dos procedimentos de diálise);

- assistência ao paciente oncológico;

- cirurgia cardiovascular; cirurgia vascular; cirurgia cardiovascular pediátrica;

- procedimentos da cardiologia intervencionista;

- procedimentos endovasculares extracardíacos;

- laboratório de eletrofisiologia;

- assistência em tráumato-ortopedia;

- procedimentos de neurocirurgia;

- assistência em otologia;

- cirurgia de implante coclear;

- cirurgia das vias aéreas superiores e da região cervical;

- cirurgia da calota craniana, da face e do sistema estomatognático;

- procedimentos em fissuras lábio-palatais;

- reabilitação protética e funcional das doenças da calota craniana, da face e do sistema estomatognático;

- procedimentos para a avaliação e o tratamento dos transtornos respiratórios do sono;

- assistência aos pacientes portadores de queimaduras;

- assistência aos pacientes portadores de obesidade (cirurgia bariátrica);

- cirurgia reprodutiva;

- genética clínica;

- terapia nutricional;

- distrofia muscular progressiva;

- osteogênese imperfeita; e

- fibrose cística e reprodução assistida (BRASIL, 2009).

Presume-se que para procedimentos de "média e alta complexidade ambulatorial e hospitalar" deve haver estabelecimentos em saúde com tipos de leitos compatíveis com a complexidade que estes serviços requerem e uma organização gerencial por meio de "rede", ou seja, a prestação de serviços de forma associada. 
A Tabela 5.2, a seguir, apresenta para os 04 (quatro) municípios do Entorno Sul o número de leitos de Unidade de Terapia Intensiva (UTI) e intermediário, o de leito de internação simples e o de hospitais municipais. Nota-se que para todo o conjunto do Entorno Sul existem somente dois leitos de UTIs que se localizam no Município de Luziânia. Existem 03 (três) hospitais municipais, sendo que o Município do Novo Gama não possui hospital local. Em relação aos leitos de internação existem 139 unidades. Conforme dados da Tabela 5.2, nem o Governo Federal, nem o governo do Estado de Goiás possuem nos Municípios relacionados qualquer tipo de unidade de saúde em funcionamento.

Entretanto, para os complexos serviços dispostos pelo MS como de Médio e alta complexidade, bem como, pelo montante de recursos destinados a tal finalidade, poderia haver uma quantidade maior de leitos de UTIs e Intermediários.

Esta avaliação estatística da distribuição de recursos federais aos Municípios para que disponibilizem serviços de saúde à população, e a inexistência de ação direta do ente federal e do ente estadual na prestação de serviços de saúde, impõe aos Municípios a tarefa de executar sozinhos os serviços de saúde.

O caso desses Municípios é emblemático, pois seus perímetros urbanos são contíguos ao Distrito Federal e entre si, enquanto os recursos, os esforços estão dissipados. Há de se ressaltar que no Entorno Sul já residem mais de meio milhão de habitantes. 
Tabela 5.2 - Leitos de internação do Sistema Único de Saúde no Entorno Sul e os repasses para custeio de média e alta complexidade.

\begin{tabular}{|c|c|c|c|c|c|c|c|}
\hline Município & $\begin{array}{l}\text { Leito de UTI e Leito } \\
\text { Intermediário }\end{array}$ & $\begin{array}{c}\text { Leito de } \\
\text { Internação Simples }\end{array}$ & $\begin{array}{l}\text { Hospital } \\
\text { Municipal }\end{array}$ & $\begin{array}{c}\text { Hospital } \\
\text { Federal/Estadual }\end{array}$ & $\begin{array}{l}\text { População } \\
\text { Ano 2015 }\end{array}$ & $\begin{array}{c}\text { Média e Alta } \\
\text { Complexidade (R\$) }\end{array}$ & $\begin{array}{c}\text { Percentual do } \\
\text { Repasse Federal }\end{array}$ \\
\hline Cidade Ocidental & 0 & 24 & 1 & 0 & 64.229 & $3.985 .137,52$ & $44 \%$ \\
\hline Luziânia & 2 & 85 & 1 & 0 & 194.039 & $16.999 .690,40$ & $49 \%$ \\
\hline Novo Gama & 0 & 0 & 0 & 0 & 106.677 & $2.224 .434,29$ & $24 \%$ \\
\hline Valparaíso & 0 & 30 & 1 & 0 & 153.255 & $10.296 .279,74$ & $39 \%$ \\
\hline Total Agrupado & 2 & 139 & 3 & 0 & 518.200 & $33.505 .541,95$ & $42 \%$ \\
\hline
\end{tabular}

Fonte: Brasil (2015). 
Ademais, em um contexto de deterioração continuada dos serviços públicos de saúde cujas causas são diversas, a dispersão de recursos e esforços dos entes federativos está entre as forças motivadoras de tal situação. Deste modo, tem-se a necessidade de se combater a “excessiva fragmentação da administração pública” (LINHARES; CUNHA; FERREIRA, 2012, p. 54), pois, a simples descentralização de recursos financeiros via municipalização, em vários casos, pode gerar efeito dispersivo, eficiência questionável na aplicação de recursos e no aproveitamento de pessoal.

Como os serviços de saúde pública, apesar das particularidades inequívocas, possuem as características gerais da distribuição espacial dos demais serviços públicos, é possível realizar uma análise das bases físico-regionais de suas localizações, observando-se os municípios e os recursos de que dispõem como unidades que podem ser agregadas a partir dos limites e das possibilidades da forma federalista do Estado brasileiro.

Neste sentido, os modelos de região interfederativa aplicam-se também aos serviços de saúde, a partir de uma concepção e estrutura regional a ser compartilhada com os entes partícipes cujos fundamentos teóricos originam-se nos pressupostos da TLC e nos arranjos de polaridade dos Modelos Gravitacionais de distribuição de serviços e mercados. Os conceitos econômicos do ganho de escala e os estudos estatísticos de demanda atual e projetada de serviços de saúde por tipologias, mediante a taxa de incremento populacional, obrigatoriamente somam-se à íntegra da análise.

Conforme disposto no Capítulo 3 da presente Dissertação, a TLC possui os seguintes princípios: Princípio do Mercado, Princípio do Transporte e Princípio Administrativo. O Princípio de Mercado prevê uma hierarquia de bens (bens se exclui da aplicação neste caso) e serviços disponibilizados, havendo uma evolução do gradiente da disponibilidade (do serviço menos complexo ao mais complexo). Ou seja, os serviços especializados podem ser concentrados.

O Princípio do Transporte busca reduzir os efeitos dos custos de deslocamento, devendo a escolha do local para disponibilização dos serviços serem, o quanto possível, o mais próxima da relação de equidistância entre as populações e localidades às quais se destinam. Este princípio se atinge por uma eficiência econômica nos deslocamentos e a busca por uma centralidade física. As escolhas dos locais que serão disponibilizados serviços devem ter centralidade geográfica, isto é, devem ser um "lugar central".

Já o Princípio Administrativo aponta para uma hierarquia de serviços disponibilizados e com isso, deve haver uma relação de subordinação e cooperação entre unidades gerenciais. 
Isto representa a perspectiva clara da cooperação, inclusive a de caráter interfederativa de amplitude horizontal e vertical.

Os Modelos Gravitacionais de distribuição de serviços e mercados, também detalhados no Capítulo 3 desta Dissertação, tem no fenômeno da polaridade um núcleo de análise. Existem critérios técnicos para escolha da localização dos polos de serviços, pois temse aí uma relação direta entre a proximidade e o acesso a serviços públicos ou, em outras palavras, uma relação direta entre distância e restrição aos serviços públicos. A natureza e o tipo de serviço é que determinará a métrica ideal de distância.

Com efeito, esta discussão teorética transcende a análise da abordagem por melhoria da gestão administrativa, onde prevalece o foco da eficiência dos recursos e do controle orçamentário e financeiro. Transcende também a abordagem correcional onde prevalece a verificação da regularidade do gasto financeiro.

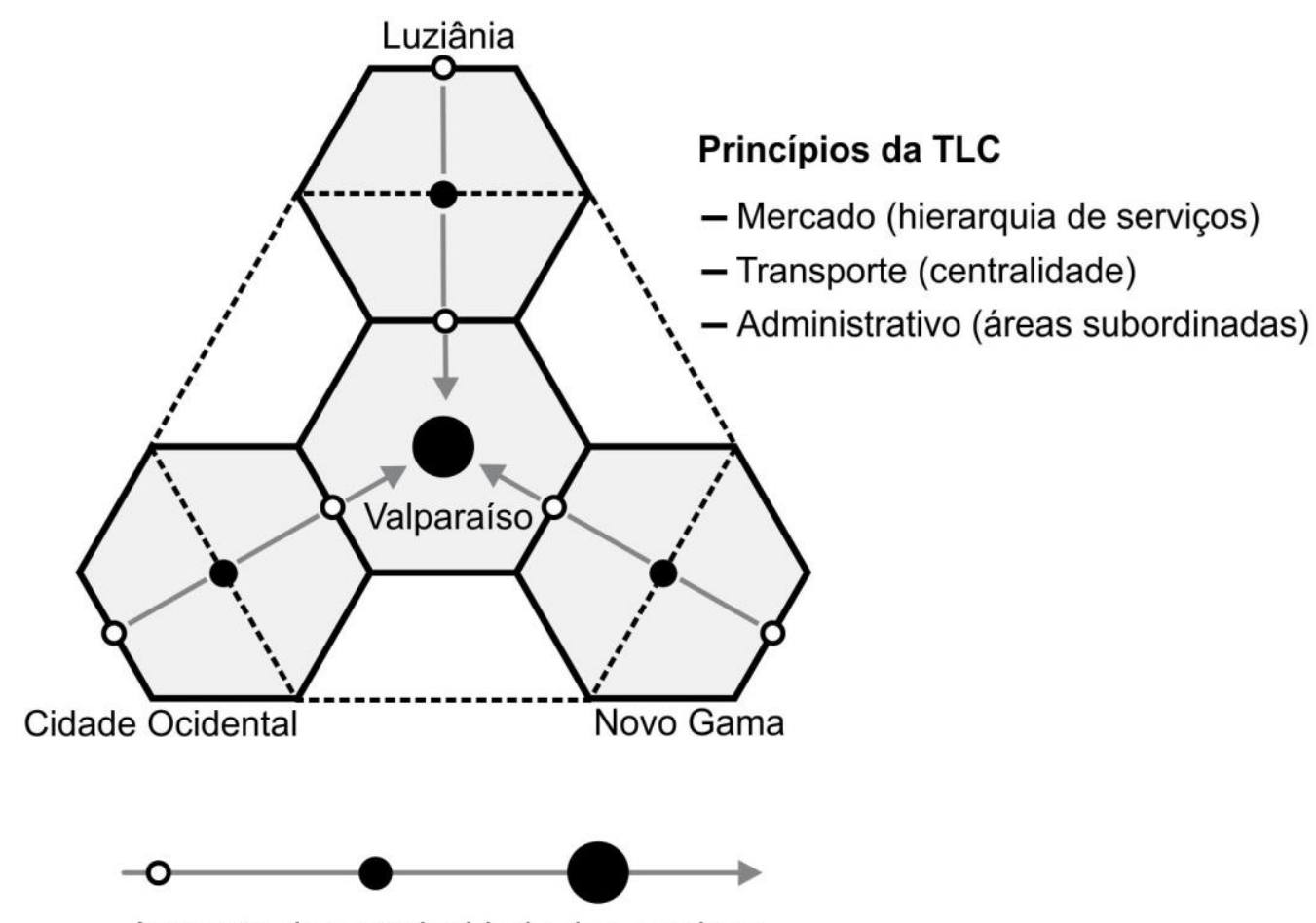

Aumento da complexidade dos serviços

Figura 5.13 - Esquema teórico clássico da Teoria dos Lugares Centrais aplicados ao setor de saúde no Entorno Sul do Distrito Federal.

Fonte: Do autor. 
A abordagem da Geografia Modelo-Teórica (GMT) adentra na questão do planejamento prévio numa visão prospectiva de longo prazo do uso do território e dos serviços que nele estarão dispostos. Assim, a distribuição espacial dos serviços públicos pode buscar um padrão a ser construído com possíveis ganhos de escala para recursos públicos escassos, conforme demonstra a Figura 5.14.

A engenharia contábil-financeira dos rateios de custos, e as nuances jurídicas seriam consequências de um planejamento baseado num projeto de solidariedade federativa tanto horizontal quanto vertical. Uma base comum para abordagem dos problemas de saúde pública, por meio das ações consorciadas interfederativas, constitui uma forma nova de pensar a prestação de serviços pelo Estado.

Neste contexto, a figura do Hospital Regional e o exercício de medir sua região de abrangência para disponibilidade de serviços de saúde de média e alta complexidade, surgem como uma alternativa em políticas públicas regionais de saúde para o Entorno Sul. Isto evitaria os deslocamentos em busca de serviços no âmbito do Distrito Federal, os consequentes e desumanos embaraços burocráticos, e as discriminações de origem geográfica quanto à moradia dos pacientes. Os embaraços burocráticos, de modo geral, criam barreiras de entradas no acesso aos serviços públicos.

A experiência de Hospitais Regionais no Brasil é bastante antiga e se encontra entre os fundamentos do modelo de gestão da saúde pública no Distrito Federal que fora implantado gradativamente como parte das ações do planejamento dos serviços públicos ainda à época da transferência e consolidação da capital federal.

Em linhas gerais, do ponto de vista da relação tipo de serviço-distância, parâmetro geográfico conexo ao do ganho de escala, o sistema de saúde pública do Distrito Federal foi concebido de modo que o atendimento de saúde preventiva básica seria disponibilizado por setores/bairros de cada cidade em centros de saúde; o atendimento de média complexidade e emergência situar-se-ia nos hospitais regionais de cada cidade; e o atendimento de especialidades e altas complexidades foi concebido para funcionar no chamado Hospital de Base de Brasília (HBB).

Deste modo, a saúde básica de cunho preventivo, de mais alta frequência de demanda, deveria ser disponibilizada com grande proximidade geográfica (nível de bairro/setor); os serviços de média complexidade e de urgências, de mediana frequência de demanda, deveriam ser disponibilizados com média proximidade geográfica (por meio dos Hospitais Regionais de cada cidade); e os atendimentos de alta complexidade, de baixa frequência de 
demanda, deveriam ser disponibilizados, por uma questão de eficiência dos recursos, com menor proximidade geográfica em relação à distribuição espacial total do conjunto dos cidadãos e de suas localidades. Interessante notar que a frequência dos serviços demandados pela população relaciona-se diretamente com a proximidade geográfica da disponibilidade do serviço.

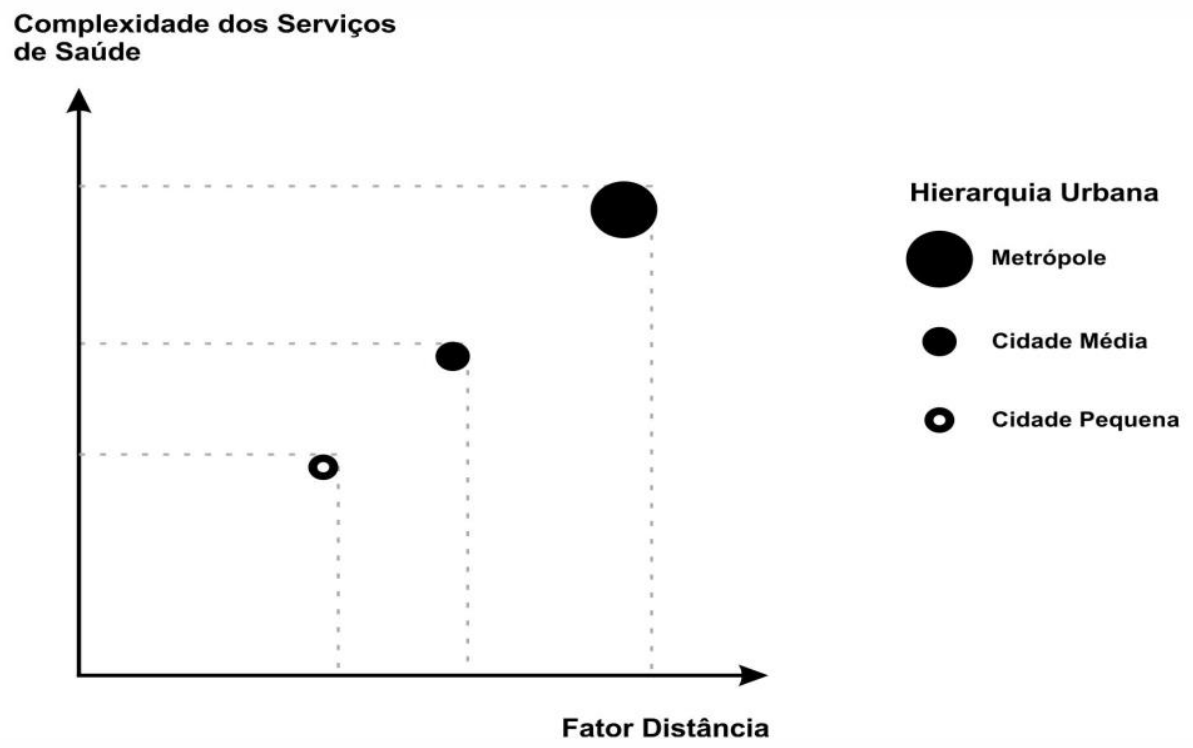

Figura 5.14 - Relação entre a complexidade dos serviços de saúde, fator distância e hierarquia urbana. Fonte: Do autor.

As informações esquematicamente trazidas pela Figura 5.14 demonstram uma gradação da complexidade dos serviços de saúde e uma hierarquia urbana elementar exatamente como preconiza o conceito dos "lugares centrais" (CHRISTALLER, 1966) contido na TLC.

Ao seu tempo, a Figura 5.15 que também encontra-se inserida no Capítulo 3 desta Dissertação como Figura 3.20, contribui adicionalmente na compreensão da relação distânciacusto de serviços, bem como, na relação participação comunitária-distância. $\mathrm{O}$ custo dos serviços é representado pela curva (EF), enquanto a participação comunitária é representada pela reta $(\mathrm{AB})$.

O custo é decrescente conforme se aumenta a área administrativa, enquanto a participação comunitária diminui. O ponto (PS) seria o ponto ótimo da eficiência, porém apresenta baixa participação comunitária, o que impõe ao administrador escolher dimensões 
de áreas administrativas menores para possibilitar incremento na participação comunitária ${ }^{59}$. A frequência na demanda do serviço é que define a diminuição da participação comunitária.

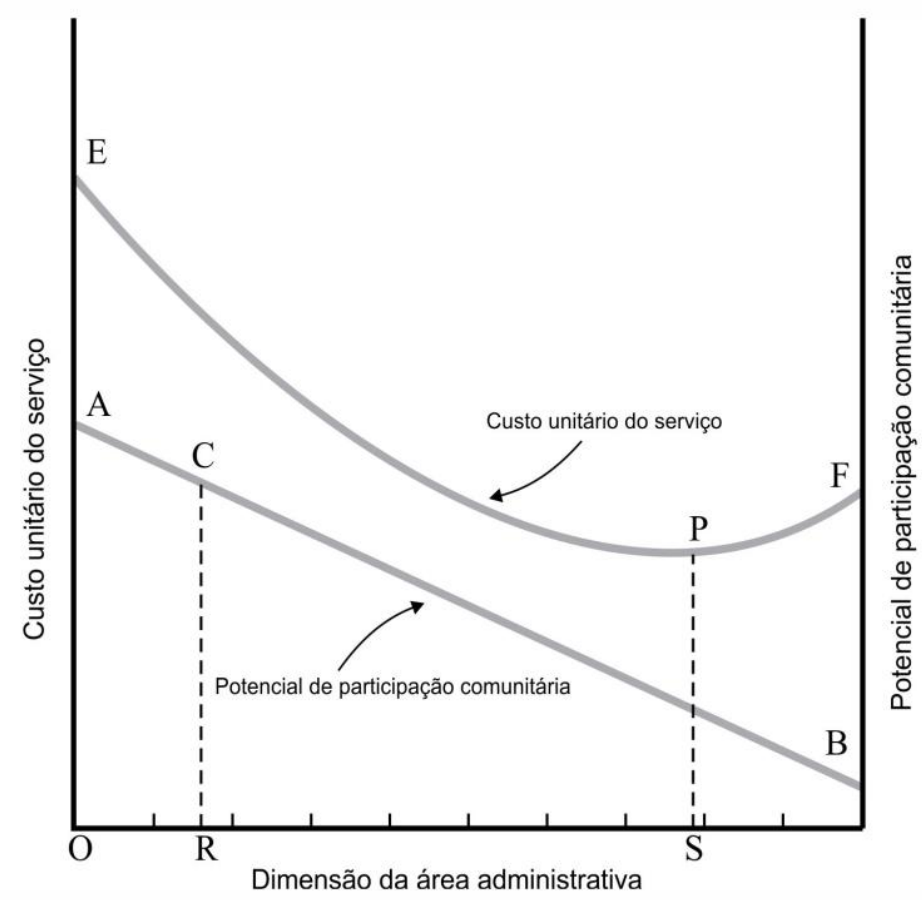

Figura 5.15 - Relação entre custo de serviço, participação comunitária e dimensão da área administrativa. Fonte: Adaptado de Isard (1971).

Assim, o planejamento da disponibilidade dos serviços públicos de saúde envolve uma nítida hierarquia entre a complexidade dos serviços de saúde e o tamanho da região/área administrativa definida. Para serviços de alta complexidade, de baixa frequência de demanda, a região/área administrativa deve ser maior. Isto poderá implicar em aumento da distância a depender da localização dos indivíduos no território.

É importante salientar que a delimitação da dimensão das regiões administrativas (áreas administrativas) é uma das maiores aplicações da TLC e dos Modelos de Interação Gravitacional, Potenciais ou Espaciais (MIGPEs) ${ }^{60}$ para quaisquer tipos de serviços públicos, incluindo-se os de saúde.

A observância do paradigma espacial dos "lugares centrais" originário da TLC e os estudos de aplicação da força de atração dos "polos de serviços" ou "polos de mercado"

\footnotetext{
${ }^{59}$ O setor de educação (Ensino Fundamental, Ensino Médio e Ensino Superior) foi selecionado por Walter Isard (Seções 3.3 e 3.4 do Capítulo 3 da presente Dissertação) como exemplo de hierarquia de serviço e tamanho da área administrativa.

${ }^{60}$ Ver Seções 3.2, 3.3 e 3.4 do Capítulo 3 da presente Dissertação.
} 
oriundos dos MIGPE inter-relacionam-se diretamente com o planejamento governamental de viés interventivo e prospectivo de longo prazo.

Intervir na realidade, mais do que um pressuposto da moderna epistemologia, é uma necessidade para as práticas realísticas - por exemplo, a melhoria do padrão de qualidade e de disponibilidade dos serviços públicos em um cenário de constantes recursos escassos. Daí a importância da construção de modelos de planejamento e de gestão de serviços públicos que considere postulados teóricos reconhecidamente sólidos da TLC e dos MIGPE.

A contribuição da GMT, enquanto corrente de pensamento, é a de construir conceitualmente modelos de planejamento em que as variáveis territoriais múltiplas sintetizadas em arranjos jurídico-institucionais e em divisões de competências políticoadministrativas sejam instrumentalizadas. Isso para possibilitar políticas públicas que visem uma cooperação institucional de natureza interfederativa, ou seja, ter-se-ia com isto, ganhos de escala na aplicação de recursos.

Neste sentido, um eventual Hospital Regional do Entorno Sul, nascido de um modelo de região como unidade basilar de planejamento com o viés do consorciamento interfederativo de serviço público possibilitaria uma soerguimento no padrão socioeconômico da população residente. Os instrumentos jurídicos existentes dispostos na Lei dos Consórcios Públicos e na Lei da RIDE possibilitam e incentivam a prática da cooperação interfederativa. Por fim, os elementos conceituais que fundamentam a teoria regional foram apresentados neste trabalho como subsídios de análise e aos conhecimentos aplicados no planejamento e na gestão de políticas públicas. 


\section{CONSIDERAÇÕES FINAIS}

Como o espectro de abordagem do presente estudo envolveu conceitos e postulados de grande complexidade, teve êxito a busca de fundamentos da Filosofia da Ciência (FC) para robustecer conceitos geográficos, econômicos e de gestão pública, de modo a torná-los mais compreensíveis.

Dentre os fundamentos da FC, a perspectiva dos modelos contribuiu enormemente, pois os conceitos-chave desta Dissertação (intervenção, Geografia Modelo-Teórica - GMT, região, planejamento, federalismo) são construções abstratas e representacionais, úteis à epistemologia da ciência geográfica.

Em particular, para a ciência geográfica a região pode ser considerada o suporte modelar básico. A partir dele, a princípio viabiliza-se toda sorte de análise distributiva, na qual a dimensão espacial seja necessária para demonstrar e/ou captar fenômenos pertinentes à investigação científica. Viabiliza-se também abordagens sobre intervenções técnicas estatais e não estatais.

Nesta Dissertação, o estudo das teorias clássicas da localização e das centralidades, como premissas teórico-filosóficas do planejamento territorial, serviu para fundamentar o significado da região enquanto conceito basilar para análises e proposições de intervenções. Por isso, foram apresentados de forma elucidativa os postulados da Teoria dos Lugares Centrais (TLC), e dos Modelos de Interação Gravitacional, Potencial e Espacial (MIGPEs), a fim de abordar as dimensões espaciais da lógica da distribuição de núcleos populacionais, centros de mercados e abrangências de eventuais políticas públicas.

De fato, inclina-se aqui a concluir que não é possível construir modelos geográficos de análise e intervenção regionais efetivos sem uma abordagem e fundamentação na TLC e nos MIGPEs, pois representam uma contribuição tecno-científica salutar do século XX, da qual a Geografia participou ativamente.

A contribuição da Geografia aos modelos teóricos e de intervenção sintetizados no período do pós-guerra consolidou-se no que atualmente nós chamaríamos de Geografia Modelo Teórica (GMT). Tal corrente de pensamento geográfico renasce como um dos fundamentos do processo de planejamento territorial diante dos desafios locais, regionais, nacionais e globais do século XXI.

A questão da complexidade do formato de Estado de padrão federativo foi outro aspecto abordado como uma premissa obrigatória no arranjo institucional do processo de 
planejamento governamental. No sistema federativo brasileiro, de forte descentralização de serviços públicos, até o Município se constitui como ente federativo e deve, assim, ser incluso no processo de planejamento de longo prazo.

Os exemplos da constatação da existência dos vazios urbanos pela implantação de faixas de servidão de linhas de transmissão, que implicam em conflitos de gestão de uso e ocupação de solo entre entes federativos distintos (federal e municipal), foram utilizados para demonstrar a existência de conflitos institucionais. O uso dos vazios urbanos de faixa de servidão de linhas de transmissão, por sua vez, demonstrou o reconhecimento da existência de região linear e a possibilidade de gestão compartilhada do uso do solo por meio de sistema de cooperação federativa.

Em relação à aplicação concreta da TLC e dos MIPGEs, a exemplificação da situação do setor de saúde do Entorno Sul do Distrito federal foi salutar para a demonstração da possibilidade de execução de políticas públicas por meio de cooperação institucional interfederativa. Embora a solução consorciativa de políticas públicas na área de saúde tenha fundamento legal na Lei dos Consórcios Públicos - Lei n. 11.107/2005, a eficiência deste modelo necessita de estudos mais aprofundados, até mesmo por decorrência da escassa experiência consorciativa interfederativa no Brasil.

Ademais, faz-se necessário apontar a necessidade de aprofundamento de estudos teóricos e empíricos acerca:

i. da definição de uma métrica de distância para "disponibilidade ótima" de serviços públicos por tipologias e entes responsáveis, a partir de pólos de serviços públicos ou lugares centrais baseando-se nas divisões micro, meso e macrorregional do Instituto Brasileiro de Geografia e Estatística (IBGE);

ii. do levantamento de tipos e qualidades de ações de cooperação interfederativa em relação ao uso de faixas de servidão de linhas de transmissão e de gasodutos em ambientes urbanos e semi-urbanos; e

iii. das formas comparadas de experiências internacionais de execução de serviços públicos por meio de cooperação interfederativa nos países que se constituem como federação. 


\section{REFERÊNCIAS}

AB'SÁBER, Aziz N. Os domínios de natureza no Brasil: potencialidades paisagísticas. 2. ed. São Paulo: Ateliê Editorial, 2003. 159 p.

ALBUQUERQUE JUNIOR, Durval Muniz de. A invenção do Nordeste e outras artes. Recife: Fundação Joaquim Nabuco/Ed. Massangana; São Paulo: Cortez, 1999. 338 p.

ANDRADE, Manuel C. de. Territorialidades, desterritorialidades, novas territorialidades: os limites do poder nacional e do poder local. In: SANTOS, Milton et al. (Org.). Território, globalização e fragmentação. São Paulo: HUCITEC, 1994. p. 213-222.

ANDRADE, Manuel Correia de Oliveira. As raízes do separatismo no Brasil. São Paulo: Ed. UNESP, 1999. 198 p.

ANUCHIN, V. A. Theory of Geography. In: CHORLEY, Richard J. Directions in Geography. Londres: Methuen \& Co Ltda., 1973. p. 43-63.

ARRIGHI, Giovanni. O Longo Século XX. 1. ed. São Paulo: Ed. UNESP/Contraponto, 1994. $393 \mathrm{p}$.

ASSOCIAÇÃO BRASILEIRA DE NORMAS TÉCNICAS - ABNT. NBR 5.422 - Projeto de Linhas Aéreas de Transmissão de Energia Elétrica. Rio de Janeiro: ABNT, 1995. 58 p.

NBR 14.653-1 - Avaliação de Bens - Parte 1: procedimentos gerais. 1. ed. Rio de Janeiro: ABNT, 2001. 10 p.

NBR 14.653-2 - Avaliação de Bens - Parte 2: imóveis urbanos. 1. ed. Rio de Janeiro: ABNT, 2004. 34 p.

NBR 14.653-3 - Avaliação de Bens - Parte 3: imóveis rurais. 1. ed. Rio de Janeiro: ABNT, 2004. 27 p.

BASTIÉ, Jean. Algumas reflexões sobre a pesquisa em geografia humana. Boletim Geográfico, v. 32, n. 234, p. 47-79, 1973. 
BECK, Ulrich. Sociedade de risco - Rumo a uma outra modernidade. 2. ed. São Paulo: Editora 34, 2011. 484 p.

BECKER, Bertha K.; EGLER, Claudio A. G.. Brasil - Uma potência regional na economia mundo. 3. ed. Rio de Janeiro: Bertrand Brasil, 1998. 268 p.

BERRY, Brian J. L. Geography of market centers and retail distribution. Englewood Cliffs: Prentice-Hall, 1967. 146 p.

BEZZI, MERI Lourdes. Uma (Re) visão historiográfica - Da gênese aos novos paradigmas. Santa Maria, RS: Ed. UFSM, 2004. 292 p.

BOBBIO, Norberto; MATTEUCCI, Nicola; PASQUINO, Gianfranco. Dicionário de política. 7. ed. Brasília: Ed. UnB, 1995. 1.318 p.

BOTHE, Michael. Federalismo - um conceito em transformação histórica. In: O Federalismo na Alemanha. Fundação Konrad Adenauer Stiftung, n. 7, p. 3-14, 1995.

BOUERI, Rogério. A restrição orçamentária maleável na abordagem da segunda geração da teoria do federalismo fiscal. In: LINHARES, Paulo de Tarso; MENDES, Constantino Cronemberger; LASSANCE, Antonio (Orgs.). Federalismo à brasileira - Questões para discussão. Brasília: IPEA, 2012.

BOYCE, Ronaldo Reed. Geographers and the Tennessee Valley Authority. Geographical Review, v. 94, n. 1, p. 23-42, jan. 2004. Disponível em: <http://www.jstor.org/stable/30033951>. Acesso em: 22 junho 2015.

BRADFORD, M. G.; KENT W. A. Geografia humana: teorias e suas aplicações. Lisboa: Gradiva, 1987. 284 p.

BRASIL. Constituição da República Federativa do Brasil de 1988. Brasília, 1988. Disponível em: <http://www.planalto.gov.br/ccivil_03/Constituicao/Constituicao.htm>. Acesso em: 10 junho 2015.

Decreto n. 6047, de 22 de fevereiro de 2007. Institui a Política Nacional de Desenvolvimento Regional - PNDR e dá outras providências. Brasília, 2007. Disponível em: <http://www.planalto.gov.br/ccivil_03/_ato2007-2010/2007/decreto/D6047.htm>. Acesso em: 18 setembro 2014. 
Decreto-Lei n. 3.365, de 21 de junho de 1941. Dispõe sobre desapropriações por utilidade pública. Rio de Janeiro, 1941. Disponível em: <http://www.planalto.gov.br/ccivil_03/decreto-lei/Del3365.htm>. Acesso em: 10 novembro 2015 .

Instituto Brasileiro do Meio Ambiente e dos Recursos Naturais Renováveis - IBAMA. Termo de referência para o Estudo de Impacto Ambiental e respectivo Relatório de Impacto Ambiental (EIA/RIMA) da Linha de Transmissão 500 kV Jurupari Oriximiná e 230 kV Jurupari-Laranjal do Jarí - Macapá. Processo Administrativo no 02001.004314/2008-62. Brasília, v. I, f. 138-165, out. 2008.

Instituto Brasileiro do Meio Ambiente e dos Recursos Naturais Renováveis - IBAMA. Termo de referência para o Estudo de Impacto Ambiental e respectivo Relatório de Impacto Ambiental (EIA/RIMA) da Linha de Transmissão 500 kV Oriximiná/PA Itacoatiara/PA - Cariri/AM. Processo Administrativo n. 02001.003938/2008-62. Brasília, v. I, f. 105-133, out. 2008.

Instituto Brasileiro do Meio Ambiente e dos Recursos Naturais Renováveis - IBAMA. Termo de referência para o Estudo de Impacto Ambiental e respectivo Relatório de Impacto Ambiental (EIA/RIMA) da Linha de Transmissão 500 kV Tucuruí-XinguJurupari. Processo Administrativo n. 02001.005015/2008-45. Brasília, v. I, f. 170-197, out. 2008.

Instituto Brasileiro do Meio Ambiente e dos Recursos Naturais Renováveis - IBAMA. Termo de referência para elaboração do Estudo de Impacto Ambiental e respectivo Relatório de Impacto Ambiental - EIA/RIMA do Aproveitamento Hidrelétrico de Belo Monte. Processo Administrativo n. 02001.001848/2006-75. Brasília, v. IV, f. 618-677, dez. 2007.

Lei Complementar n. 94, de 19 de fevereiro de 1998. Autoriza o Poder Executivo a criar a Região Integrada de Desenvolvimento do Distrito Federal e Entorno - RIDE e instituir o Programa Especial de Desenvolvimento do Entorno do Distrito Federal, e dá outras providências. Brasília, 1998. Disponível em: <http://www.planalto.gov.br/ccivil_03/leis/lcp/lcp94.htm>. Acesso em: 16 outubro 2015.

Lei Complementar n. 140, de 08 de dezembro de 2011. Fixa normas, nos termos dos incisos III, VI e VII do caput e do parágrafo único do art. 23 da Constituição Federal, para a cooperação entre a União, os Estados, o Distrito Federal e os Municípios nas ações administrativas decorrentes do exercício da competência comum relativas à proteção das paisagens naturais notáveis, à proteção do meio ambiente, ao combate à poluição em qualquer de suas formas e à preservação das florestas, da fauna e da flora; e altera a Lei n. 6.938, de 31 de agosto de 1981. Brasília, 2011. Disponível em: <http://www.planalto.gov.br/ccivil_03/leis/LCP/Lcp140.htm>. Acesso em: 29 outubro 2015. 
Lei n. 6.664, de 26 de junho de 1979. Disciplina a profissão de Geógrafo e dá outras providências. Brasília, 1979. Disponível em: <http://www.planalto.gov.br/CCiViL_03/LEIS/1970-1979/L6664.htm>. Acesso em: 20 junho 2015 .

Lei n. 8.080, de 19 de setembro de 1990. Dispõe sobre as condições para a promoção, proteção e recuperação da saúde, a organização e o funcionamento dos serviços correspondestes e dá outras providências (Lei Orgânica da Saúde). Brasília, 1990. Disponível em: <http://www.planalto.gov.br/ccivil_03/Leis/L8080.htm>. Acesso em: 03 outubro 2015.

Lei n. 9.433, de 8 de janeiro de 1997. Institui a Política Nacional de Recursos Hídricos, cria o Sistema Nacional de Gerenciamento de Recursos Hídricos, regulamenta o inciso XIX do art. 21 da Constituição Federal, e altera o art. $1^{\circ}$ da Lei n. 8.001, de 13 de março de 1990, que modificou a Lei n. 7.990, de 28 de dezembro de 1989. Brasília, 1997. Disponível em: <http://www.planalto.gov.br/ccivil_03/LEIS/19433.htm>. Acesso em: 30 outubro 2013.

Lei n. 10.257, de 10 de julho de 2001. Regulamenta os arts. 182 e 183 da Constituição Federal, estabelece diretrizes gerais da política urbana e dá outras providências. $\quad$ Brasília, 2001. Disponível em: <http://www.planalto.gov.br/ccivil_03/leis/LEIS_2001/L10257.htm>. Acesso em: $1^{\circ}$ novembro 2015.

Lei n. 11.107, de 06 de abril de 2005. Dispõe sobre normas gerais de contratação de consórcios públicos e dá outras providências. Brasília, 2005. Disponível em: <http://www.planalto.gov.br/ccivil_03/_ato2004-2006/2005/lei/111107.htm>. Acesso em: 18 setembro 2014.

Lei n. 12.305, de 2 de agosto de 2010. Institui a Política Nacional de Resíduos Sólidos; altera a Lei n. 9.605, de 12 de fevereiro de 1998; e dá outras providências. Disponível em: <http://www.planalto.gov.br/ccivil_03/_ato2007-2010/2010/lei/112305.htm>. Acesso em: 30 outubro 2013.

. Ministério da Integração Nacional. Política Nacional de Desenvolvimento Regional: Sumário Executivo. S. $\quad$ d. <http://www.mi.gov.br/c/document_library/get_file?uuid=240b7eb3-af5d-458a-ad651e9f4d5e9095\&groupId=24915>. Acesso em: 12 setembro 2014.

Ministério da Integração Nacional. Secretaria de Desenvolvimento Regional. I Conferência de Desenvolvimento Regional: Documento de Referência. Brasília, julho de 2012. Disponível em: <http://www.integracao.gov.br/c/document_library/get_file?uuid=54bce099-503a-4076-8613d90dd6107c79>. Acesso em: 12 setembro 2014. 
Ministério da Saúde. Conselho Nacional de Secretarias Municipais de Saúde. O SUS de A a Z: garantindo saúde nos Municípios. 3. ed. 2. reimp. Brasília: Ed. do Ministério da Saúde, 2009. (Série F. Comunicação e Educação em Saúde) Disponível em: <http://bvsms.saude.gov.br/bvs/publicacoes/sus_az_garantindo_saude_municipios_3ed_p1.pd f>. Acesso em: 20 junho 2015.

2015a. Ministério da Saúde. Fundo Nacional da Saúde. Consulta de Pagamentos. Brasília,
em: <http://www.fns.saude.gov.br/visao/consultarPagamento/pesquisaSiplificadaEntidade.jsf>. Acesso em: 05 novembro 2015.

Ministério da Saúde. Informações de Saúde (TABNET). Brasília, 2015b. Disponível em: <http://www2.datasus.gov.br/DATASUS/index.php?area=02>. Acesso em: 20 junho 2015 .

CÂMARA DOS DEPUTADOS. Dossiê do Projeto de Lei n. 1.339/1968: que disciplina a profissão do geógrafo, cria o Conselho Nacional e os Conselhos Regionais de Geógrafos Profissionais e dá outras providências. Disponível em: $<$ http://camara.gov.br/proposicoesWeb/fichadetramitacao?Proposicao=190830>. Acesso em: 20 junho 2015.

CAMARGO, Aspásia. Federalismo cooperativo e o princípio da subsidiariedade: notas sobre a experiência recente do Brasil e da Alemanha. In: HOFMEISTER, Wilhelm; CARNEIRO, José. M. B. Federalismo na Alemanha e no Brasil. São Paulo: Fundação Konrad Adenauer Stiftung, 2001. p.69-94.

CAMPOS, Rui Ribeiro de. Breve histórico do pensamento geográfico brasileiro nos séculos XIX e XX. Jundiaí, SP: Paco Editorial, 2011. 608 p.

CAPEL, Horacio; URTEAGA, Luis. Las nuevas geografías. 1. ed. Barcelona: Salvat Editores S.A, 1982. 64 p.

CAPELLO, R. Regional economics. London: Routledge, 2008.

CLARK, David. Introdução à geografia urbana. São Paulo: DIFEL, 1985. 281 p.

CHORLEY, Richard J. Geography as human ecology. In: CHORLEY, Richard J. Directions in Geography. Londres: Methuen \& Co Ltda., 1973. p. 155-169. 
CHISHOLM, M. Geography and economics. New York: Frederick A. Praeger, 1966. 230 p.

CHORLEY, Richard J.; HAGGETT, Peter. Modelos, paradigmas e a nova geografia. In: ; ___ (Orgs.). Modelos físicos e de informação em Geografia. São Paulo: EdUSP, 1975. p. 01-22.

CHRISTALLER, Walter. Central places in southern Germany. Englewood Cliffs: PrenticeHall, 1966. 230 p.

CHRISTOFOLETTI, Antonio. As características da Nova Geografia. In: (Org.). Perspectivas da Geografia. São Paulo: Difel, 1982. p.71-101.

As perspectivas dos estudos geográficos. In: (Org.). Perspectivas da Geografia. São Paulo: Difel, 1982. p.11- 36.

CORRÊA, Roberto Lobato. Trajetórias geográficas. $3^{\circ}$ ed. Rio de Janeiro: Bertrand Brasil, 2005. 302 p.

CORRÊA, Roberto Lobato. Região e organização espacial. $8^{\circ}$ ed. Rio de Janeiro: Ática, 2007. 93 p.

DACEY, Michael F. Some questions about spatial distributions. In CHORLEY, Richard J. Directions in Geography. Londres: Methuen \&Co Ltd, 1973. p. 127-151.

EGLER, Cláudio A. G. Questão regional e a gestão do território no Brasil. In: CASTRO, Iná Elias de; GOMES, Paulo Cesar da Costa; CORRÊA, Roberto Lobato. Geografia: conceitos e temas. Rio de Janeiro: Ed. Bertrand Brasil, 2008.

EGLER, Cláudio A. G.; BESSA, W. C.; GONÇALVES, A. F. Pensar o território e a região: por uma agenda de desenvolvimento regional. Revista Mercator, Fortaleza, v. 12, n. 28, p.717, mai./ago. 2013. Disponível em: <http://www.mercator.ufc.br/index.php/mercator/article/viewFile/965/482>. Acesso em: 22 novembro 2014.

ESCUDERO, Carlos Sandoval. Métodos y aplicaciones de la planificación regional y local en América Latina. Santiago: Publicação das Nações Unidas, 2014. 
EVANGELISTA, Helio de Araujo. Geografia teorética, um registro. Revista Geo-Paisagem (on line), a. 6, n. 12, jul./dez. 2007. Disponível em: <http://www.feth.ggf.br/Revista12.htm>. Acesso em: 20 junho 2015.

FAISSOL, Speridião. Teorização e quantificação em geografia. Revista Brasileira de Geografia, v. 40, n.1, p. 03-50, 1978.

FARIA, I. D. Compensação ambiental: os fundamentos e as normas; a gestão e os conflitos. Brasília: Ed. Consultoria Legislativa do Senado Federal, 2008. 115 p. (Textos para Discussão n. 43)

FARIAS, Déborah Barros Leal. Federalismo e Relações Internacionais. 2000. $108 \mathrm{f}$. Dissertação (Mestrado em Relações Internacionais) - Instituto de Ciência Política e Relações Internacionais, Universidade de Brasília, Brasília, 2000.

FERREIRA, Ignez Costa Barboza. Espaço, poder e cultura na gestão do território. In: VASCONCELOS, Pedro de Almeida; MELO E SILVA, Sylvio Bandeira de (Orgs.). Novos estudos de Geografia urbana brasileira. Salvador: Editora UFBA, 1999. p. 143-158.

FURTADO, Celso. A fantasia organizada. Rio de Janeiro: Paz e Terra, 1985. 232 p.

O longo amanhecer: reflexões sobre a formação do Brasil. Rio de Janeiro: Paz e Terra, 1999. 116p.

FREITAS, André Vieira. Uma política de ordenamento territorial para o Brasil?. In STEINBERGER, Marília. Território, Estado e políticas públicas espaciais. Brasília: Editora Ler, 2013. p. 141-161.

GALVÃO, Marília Velloso; FAISSOL, Speridião. A revolução quantitativa na Geografia e seus reflexos no Brasil. Revista Brasileira de Geografia, v. 32, n. 4, p. 5-22, 1970.

GARNER, B. J. Modelos de Geografia urbana e localização de povoações. In: CHORLEY, Richard J.; HAGGETT, Peter. Modelos socioeconômicos em Geografia. Rio de Janeiro: EdUSP, 1975. p.124-177.

GARRISON, W.; BERRY, B. J. L.; MARBLE, D. F.; NYSTUEN, J. D.; MORRILL, R. L. Studies of higway developmentand geography change. Seatle, 1959. 
GEIGER, Pedro Pinchas. Renovação na Geografia. Revista Brasileira de Geografia, v. 32, n. 1, p. 67-71, 1970.

et. al. Introdução à análise de séries temporais. Revista Brasileira de Geografia, v. 36, n. 4, p. 81-108, 1974.

GEORGE, F. H. O uso de modelos na ciência. In: CHORLEY, Richard J.; HAGGETT, Peter (Org.). Modelos socioeconômicos em Geografia. Rio de Janeiro: EdUSP, 1975. p. 20-31.

GIERE, Ronald N. How models are used to represent reality. Philosophy of Science Review, n. 71, p. 742-752, dez. 2004.

GIERE, Ronald N. An agent-based conception of models and scientific representation. Synthese. Synthese Review, v. 172, i. 2, p. 269-281, jan. 2010.

GOMES, Paulo Cesar da Costa. O conceito de região e sua discussão. In: CASTRO, Iná Elias de; GOMES, Paulo Cesar da Costa; CORRÊA, Roberto Lobato. Geografia: conceitos e temas. Rio de Janeiro: Ed. Bertrand Brasil, 2008. p. 49-76.

GRIGG, David. Regiões, modelos e classes. Boletim Geográfico, a. 32, n. 234, p. 3-46, 1973.

GUIA, George Alex da; CIDADE, Lúcia Cony Faria. Segregação residencial e reprodução das desigualdades socioespaciais no aglomerado urbano de Brasília. Cadernos Metrópole, São Paulo, v. 12, n. 23, p. 145-168, jan/jun 2010.

HACKING, Ian. Representar e intervir. 1. ed. Ciudad del México: Ed. Paidós Ibérica, 1996. $321 \mathrm{p}$.

HAESBAERT, Rogério. Região, regionalização e regionalidade: questões contemporâneas. Revista Antares on line (on line), Caxias do Sul, n. 3, jan./jun. 2010. Disponível em: <http://www.ucs.br/etc/revistas/index.php/antares/article/view/416/360>. Acesso em: 20 outubro 2014.

HAGGETT, P. Analisis locacional en la Geografia humana. Barcelona: Editorial Gustavo Gili, 1976. 434 p. 
IAN HAMILTON, F. E. Modelos de localização industrial. In: CHORLEY, Richard J.; HAGGETT, Peter. Modelos sócio-econômicos em geografia. Rio de Janeiro: Edusp, 1975. p.178-236.

ISARD, Walter. Metodos de analisis regional: una introduccion a la ciencia regional. Barcelona: Editorial Ariel, 1971.

KEEBLE, D. E. Modelos de desenvolvimento econômico. In: CHORLEY, Richard J.; HAGGETT, Peter. Modelos socioeconômicos em Geografia. Rio de Janeiro: EdUSP, 1975. p.72-123.

LEMOS, Borges Maurício. O problema da regionalização: dificuldades teóricas e uma metodologia alternativa. In: LAVINAS, Lena; CARLEIAL, Liana M. da Frota; NABUCO, Maria Regina. Reestruturação do espaço urbano e regional no Brasil. São Paulo, HUCITEC, 1993.

LÉVI-STRAUSS, Claude. Antropologia estrutural. 2. ed. Rio de Janeiro: Tempo Brasileiro, 1985. $456 \mathrm{p}$.

LINHARES, Paulo de Tarso; CUNHA, Alexandre dos Santos; FERREIRA, Ana Paula Lima. Cooperação federativa: a formação de consórcios entre entes públicos no Brasil. In: LINHARES, Paulo de Tarso; MENDES, Constantino Cronemberger; LASSANCE, Antonio (Orgs.). Federalismo à brasileira - Questões para discussão. Brasília: IPEA, 2012.

LOOTTY, Mariana; SZAPIRO, Marina. Economias de escala e escopo. In: KUPFER, David; HASENCLEVER, Lia (Orgs.). Economia industrial: fundamentos teóricos e práticos no Brasil. Rio de Janeiro: Editora Campus, 2002.

LORENZANO, Pablo. La teorización filósica sobre la ciência em el siglo XX (Y lo que va del XXI). Discusiones Filosóficas, a. 12, n. 19, p. 131-154, 2011.

LÖSCH, August. Teoria economica espacial. Buenos Aires: Libreria El Ateno Editorial, $1957.535 \mathrm{p}$.

MENDES, C.C.; MATTEO, M. Formação e evolução do planejamento regional no Brasil. In:

CRUZ et al. Economia Regional e Urbana - Teorias e Métodos com Ênfase no Brasil.

Brasília: IPEA, 2011. p. 261-282. 
MILARÉ, E. Direito ambiental. 9. ed. São Paulo: Ed. Revista dos Tribunais, 2014. 1.680 p.

MONASTERIO, L.; CAVALCANTE, L. R. Fundamentos do pensamento econômico regional. In CRUZ et al. Economia Regional e Urbana - Teorias e Métodos com Ênfase no Brasil. Brasília: IPEA, 2011. p. 43-78.

MORAES, Antonio Carlos Robert de. Ordenamento territorial: uma conceituação para o planejamento estratégico. In: MELLO, Neli Aparecida de.; JÚNIOR, Rosalvo de Oliveira (Orgs.). Para pensar uma Política Nacional de Ordenamento Territorial. Brasília: Ministério da Integração Nacional, 2005. p. 43-48.

MUELLER, C. C. Os economistas e as relações entre o sistema econômico e o meio ambiente. 1. Ed. Brasília: EdUnB/FINATEC, 2007. 562 p.

OATES, Wallace E. An essay on federalism fiscal. Journal of Economic Literature, v. 37, n. 3, p. 1120-1149, set. 1999. Disponível em: <http://www.jstor.org/stable/2564874?seq=1\#page_scan_tab_contents $>$. Acesso em: 02 outubro 2014.

OLIVEIRA, Regis de. Processo Legislativo - Contribuição ao Debate. Brasília: Câmara dos Deputados, 1996. 133 p.

PORTELA, F. C. Brasília além do DF: o Entorno Sul, dependências e potencialidades. 1999. 48 f. Monografia de Prática de Pesquisa de Campo II (Bacharelado e Licenciatura em Geografia) - Instituto de Ciências Humanas, Universidade de Brasília, Brasília, 1999.

Faixas de servidão de linhas de transmissão de energia elétrica e os lucros cessantes na cajucultura: métodos e valoração da limitação do uso do solo em territórios produtivos. Revista Espaço \& Geografia, Brasília, v. 16, n. 1, p. 67-95, 2013.

REIS JÚNIOR, Dante Flávio da Costa. Cinquienta chaves.O físico pelo viés sistêmico, o humano nas mesmas vestes... e uma ilustração doméstica: o molde (neo)positivista examinado em textos de Antonio Christofoletti. 2007. $481 \mathrm{f}$. Tese (Doutorado em Geografia) - Instituto de Geociências, Universidade Estadual de Campinas, Campinas, SP, 2007.

SÁNCHEZ, L. E. Avaliação de impacto ambiental: conceitos e métodos. 1. ed. São Paulo: Oficina de Textos, 2008. 495 p. 
SANTIAGO, Marcos Firmino. Breves estudos sobre federalismo brasileiro. Revista do Instituto do Direito Brasileiro, a. 2, n. 4, p. 3111-3145, 2013.

SANTINHA, Gonçalo. O princípio de coesão territorial enquanto novo paradigma de desenvolvimento na formulação de políticas públicas: (re)construindo idéias dominantes. Revista EURE, v. 40, n. 119, p. 75-95, 2014. Disponível em: <http://www.scielo.cl/scielo.php?pid=S0250-71612014000100004\&script=sci_abstract $>$. Acesso em: 02 julho 2015.

SANTOS, M. A natureza do espaço: técnica e tempo, razão e emoção. São Paulo: HUCITEC, 1996. 308 p.

Por uma Geografia nova: da crítica da Geografia a uma Geografia Crítica. 2. ed. São Paulo: HUCITEC, 1980. 236 p.

Espaço do cidadão. 7. ed. São Paulo: EdUSP, 2007. 176 p.

SAUSSURE, Ferdinand. Curso de Linguística General. 6. ed. Buenos Aires: Editorial Losada, S.A.,1967. 368 p.

SCHULTZE, Rainer-Olaf. Federalismo. In O Federalismo na Alemanha - Traduções. Sankt Augustin: Fundação Konrad Adenauer Stiftung, 1995. p.15-32.

SOUZA, Marcelo José Lopes de. O território: sobre espaço e poder, autonomia e desenvolvimento. In: CASTRO, Iná Elias de; GOMES, Paulo Cesar da Costa; CORRÊA, Roberto Lobato (Orgs.). Geografia: conceitos e temas. Rio de Janeiro: Bertrand Brasil, 1995. p. $77-116$.

STEINBERGER, Marília. A Inseparabilidade entre Estado, políticas públicas e território. In: (Org.). Território, Estado e políticas públicas espaciais. Brasília: Ler Editora, 2013. p. 31-64.

SUPPE, Frederick. Understanding scientific theories: an assessment of developments, 19691998. Philosophy of Science, v. 67, supplement, part II: symposia papers, p. 102-115, (sep., 2000). Disponível em: <http://www.jstor.org/stable/188661>. Acesso em: 30 novembro 2014. 
TENNESSEE VALLEY AUTORITHY - TVA. Disponível em: 〈http://www.tva.gov>. Acesso em: 23 dezembro 2014.

VARGAS, Neide César. A descentralização e as teorias do federalismo fiscal. Revista Ensaios - Fundação de Economia Estatístca - FEE, Porto Alegre, v. 32, n. 1, p. 51-76, jun. 2011. Disponível em: <http://revistas.fee.tche.br/index.php/ensaios/article/view/2394/2887>. Acesso em: 22 setembro 2015.

WARNTZ, William. New Geography as general spatial systems theory - old social physics writ large? In: CHORLEY, Richard J. Directions in Geography. Londres: Methuen \&Co Ltd, 1973. p. 89-126. 